\author{
UNIVERSIDADE DE SÃO PAULO \\ FACULDADE DE MEDICINA DE RIBEIRÃO PRETO \\ DEPARTAMENTO DE CIRURGIA E ANATOMIA
}

\title{
EFEITOS DA APROTININA EM CRIANÇAS COM CARDIOPATIA CONGÊNITA ACIANOGÊNICA OPERADAS COM CIRCULAÇÃO EXTRACORPÓREA
}


UNIVERSIDADE DE SÃO PAULO

FACULDADE DE MEDICINA DE RIBEIRÃO PRETO

DEPARTAMENTO DE CIRURGIA E ANATOMIA

\section{EFEITOS DA APROTININA EM CRIANÇAS COM CARDIOPATIA CONGÊNITA ACIANOGÊNICA OPERADAS COM CIRCULAÇÃO EXTRACORPÓREA}

Cesar Augusto Ferreira

Trabalho apresentado à Área de Clínica Cirúrgica do Departamento de Cirurgia e Anatomia da Faculdade de Medicina de Ribeirão Preto da Universidade de São Paulo, para a obtenção do Título de Doutor.

Orientador: Prof. Dr. Walter Villela de Andrade Vicente

Ribeirão Preto

$-2006-$ 


\section{FICHA CATALOGRÁFICA}

\section{Ferreira, Cesar Augusto}

EFEITOS DA APROTININA EM CRIANÇAS COM CARDIOPATIA CONGÊNITA ACIANOGÊNICA OPERADAS COM CIRCULAÇÃO EXTRACORPÓREA.

169 p:il; 29,7 cm

Tese de Doutorado, apresentada a Faculdade de Medicina de Ribeirão Preto/USP, Departamento de Cirurgia e Anatomia. Área de concentração: Clínca Cirúrgica.

Orientador: Prof. Dr. Walter Villela de Andrade Vicente

1. Cirurgia cardíaca pediátrica. 2. Circulação extracorpórea (CEC). 3. Aprotinina. 4. Síndrome da Resposta Inflamatória Sitêmica (SRIS). 5. Síndrome do Extravasamento Capilar Sistêmico (SECS). 6. Proteção miocárdica. 
A DEUS, princípio e fim de tudo ...

Aos meus pais ANTONIO FERREIRA SOBRINHO ("in memoriam") e ELY MARQUES FERREIRA, pelas orações, pelo exemplo de vida, pelo trabalho e incentivo à minha formação médica e humana.

\section{A minha querida esposa e companheira,}

MÔNICA CONSUELO ARANTES ROSA, pela paciência, compreensão, críticas e sugestões, nas diversas fases da elaboração deste trabalho, muito amor e carinho.

\section{À minha querida filha,}

LARA MARIA ARANTES MARQUES FERREIRA, incentivo da nossa vida e fé, que não esconde a esperada finalização deste trabalho, que lhe furtou muitas horas de nossa convivência, muito amor e carinho.

\section{Ao meu irmão,}

LUIZ FERNANDO FERREIRA, apesar da distância, não deixou de transmitir confiança no sucesso desse trabalho. 


\section{AGRADECIMENTOS}

Ao Prof. Dr. Walter Villela de Andrade Vicente, pela orientação persistente e questionadora, buscando sempre a síntese nas exaustivas leituras de inúmeras páginas que foram manuscritas, colaborando com a sua experiência na realização deste trabalho.

A Prof. Dr. Alfredo José Rodrigues, pela oportuna sugestão que levou a concretização deste estudo e ao aperfeiçoamento do trabalho da equipe.

Ao Prof. Dr. Paulo Roberto Barbosa Évora, pelo exemplo que representa em nossa formação científica.

Ao Prof. Dr. Jyrson Guilherme Klamt, pela dedicação e cuidado com as crianças operadas e pela pronta disponibilidade para 0 desenvolvimento da anestesia e da cirurgia cardíaca pediátrica.

À Prof. Dra. Ana Paula C. P. Carlotti, pela dedicação incansável e perseverança à beira do leito na orientação e no tratamento das crianças operadas.

Ao Prof. Dr. Edson Zangiacomi Martinez e ao estagiário Roberto Molina de Souza do Centro de Métodos Quantitativas (CEMEQ), pela excelência e disponibilidade na análise estatística realizada.

Ao Dr. Paulo Henrique Manso e Dr. Fábio Carmona, pela indispensável colaboração na execução deste trabalho.

Aos médicos assistentes da Divisão de Cirurgia Torácica e Cardiovascular e do Centro de Terapia Intensiva Pediátrica do Hospital das Clínicas de Ribeirão Preto, pela colaboração, apoio e incentivo. 
Aos médicos residentes, que atenderam e cuidaram das crianças operadas.

Às perfusionistas, instrumentadoras e funcionários do Centro Cirúrgico e do Centro de Terapia Intensiva Pediátrica, que colaboraram para a realização deste estudo.

À Marlene Lúcio, pela correção ortográfica e exaustiva revisão e formatação.

Ao Alex Adriano da Silva, pelo trabalho de digitação e formatação. 


\section{SUMÁRIO}

LISTA DE FIGURAS $x$

LISTA DE TABELAS Xii

ABREVIATURAS E SIGLAS xiii

RESUMO Xvi

ABSTRACT Xviii

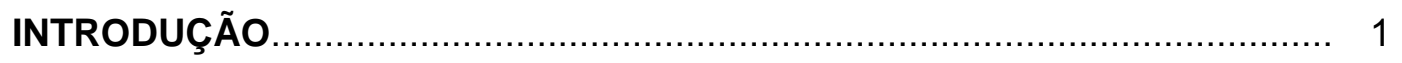

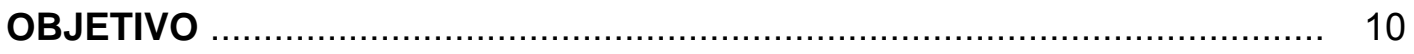

CASUÍSTICA E MÉTODOS............................................................... 12

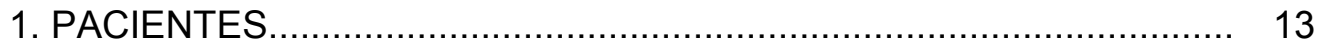

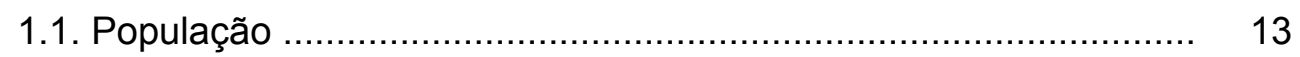

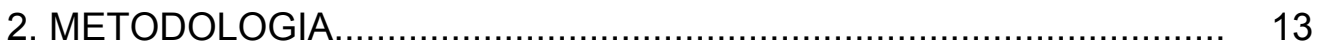

2.1. Sorteio............................................................ 13

2.2. Técnicas anestésica e cirúrgica ............................................. 13

2.3.Características clínicas pré-operatórias................................... 18

2.4. Dados cirúrgicos.................................................................. 18

2.5.Condições clínicas pós-operatórias............................................ 19

2.6. Avaliação bioquímica e hematológica....................................... 19

2.7. Análise estatística............................................................... 21

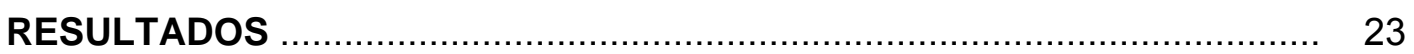

1. CARACTERÍSTICAS DEMOGRÁFICAS ....................................... 24

2. ESCORES DE RICOS CIRÚRGICO ............................................... 25

3. VARIÁVEIS PERI-OPERATÓRIAS ........................................... 25

3.1. Achado cirúrgico, vias de acesso intracardíaco, operações realizadas................................................................... 25

3.2. Duração da operação, anestesia, CEC e pinçamento aórtico, e temperatura esofágica mínima em CEC ..................... 25

3.3. Oxigenadores e hemofiltros empregados................................. 27

3.4. Volume total de perfusato e volemia estimada.......................... 27

3.5. Dose total de aprotinina........................................................ 28

3.6. Dose total de Heparina........................................................... 28

3.7. Utilização de concentrado de hemácias utilizado na CEC e volume de hemofiltrado........................................... 28

3.8. Albuminemia ............................................................ 28

3.9. Pressão arterial média (PAM) durante a CEC ......................... 29

3.10. Temperatura orofaríngea média durante a CEC ................... 30

3.11. Diurese peri-operatória....................................................... 31

3.12. Tempo de fechamento do tórax......................................... 32 
3.13. Balanço de sangue intra-operatório......................................... 32

4. VARIÁVEIS PÓS-OPERATÓRIAS............................................. 33

4.1. Balanço hídrico na admissão na CTIP....................................... 33

4.2. Escore PRISM, na admissão na UTIP................................... 33

4.3. Índice clínico-cirúrgico, segundo Mattos et al. (2006).................. 33

4.4. Tempos de utilização de óxido nítrico, ventilação mecânica, permanência no CTIP e estadia hospitalar.................................. 34

4.5. Variáveis hemodinâmicas...................................................... 36

4.5.1. Freqüência cardíaca média (FC...................................... 36

4.5.2. Pressão arterial média (PAM) ....................................... 36

4.5.3. Pressão venosa central (PVC) ....................................... 36

4.6. Tempo de uso de inotrópicos.................................................. 36

4.7. Escores inotrópicos I e II.................................................... 36

4.8. Incidência de choque, anasarca, derrame pleural e congestão pulmonar, no pós-operatório...................................................... 37

4.9. Temperatura esofágica pós-operatório.................................... 37

4.10. Relação $\mathrm{PaO}_{2} / \mathrm{FiO}_{2}$ no pós-operatório..................................... 38

4.11. Perdas sangüíneas nas primeiras $48 \mathrm{~h}$ de $\mathrm{PO}$........................... 39

4.12. Utilização de hemoderivados nas 48 horas PO......................... 40

4.13. Exposição a doadores de hemoderivados................................ 40

4.14. Diurese e provas de função renal............................................ 41

4.14.1. Diurese................................................................... 41

4.14.2. Uremia e concentração plasmática de creatinina................ 42

4.14.3. Depuração de creatinina (SCHWARTZ)........................... 42

4.15. Hemograma e estudo básico da hemostasia.............................. 43

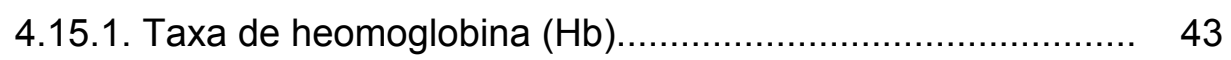

4.15.2. Hematócrito (Hto)..................................................... 44

4.15.3. Contagem de plaquetas............................................. 45

4.15.4. Tempo de tromboplastina parcial ativada (TTPA).............. 46

4.15.5. Tempo de Protrombina (TP)....................................... 46

4.15.6. Contagem de leucócitos................................................. 46

5. MARCADORES INFLAMATÓRIOS DA RESPOSTA INFLAMATÓRIA SISTÊMICA .......................................................................... 47

5.1. Concentração sérica do fator de necrose tumoral - $\alpha$ (TNF- $\alpha) \ldots . \quad 47$

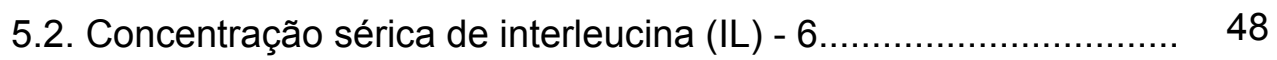

5.3. Concentração sérica de interleucina (IL) - 8............................ 50

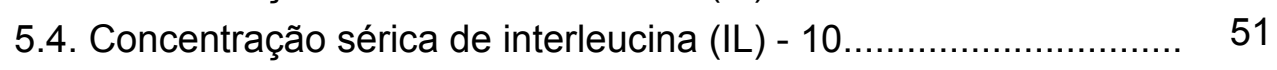

5.5. Proporção IL - 6 / IL - 10 ..................................................... 52

6. MARCADORES DE LESÃO E FUNÇÃO MIOCÁRDICA..................... 53

6.1. Concentração sérica de troponina-I cardíaca (cTnl).................... 53

6.2. Concentração sérica de CKMB............................................. 54

6.3. Nt-proBNP ........................................................... 54 
7. FUNÇÃO HEPÁTICA - TGO …………………………................ 56

8. LACTATO SÉRICO E EQUILÍBRIO ÁCIDO BÁSICO.......................... 56

8.1. Lactato sérico arterial............................................................. 56

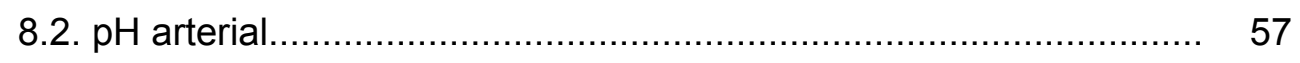

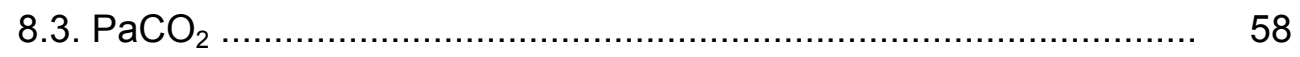

8.4. Concentração arterial de Bicarbonato......................................... 59

9. INCIDÊNCIA DE SÍNDROME DA RESPOSTA INFLAMATÓRIA SISTÊMICA (SRIS), DE SÍNDROME DO EXTRAVA-SAMENTO CAPILAR SISTÊMICO (SECS) E DE DISFUNÇÕES ORGÂNICAS

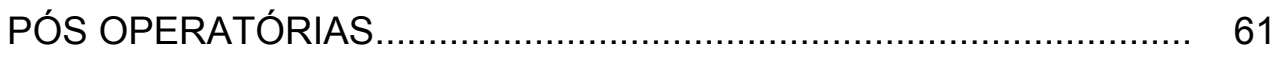

10. INFLUÊNCIA DA PRESENÇA DE SRIS E/OU SECS NAS

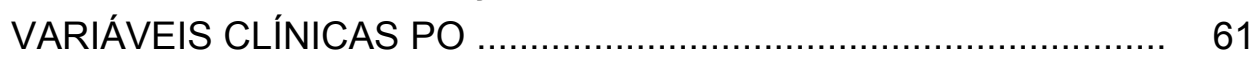

11. PERFIL DOS MARCADORES PARA SRIS E MIOCÁR-DICAS NOS PACIENTES COM SRIS............................................................. 62

12. AVALIAÇÃO ECODOPLLERCARDIOGRÁFICA PO ......................... 63

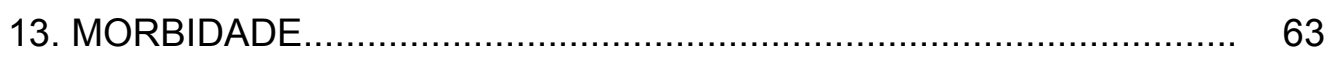

13.1. Complicações respiratórias..................................................... 63

13.2. Complicações neurológicas................................................... 63

13.3. Complicações cardíacas:..................................................... 63

13.4. Complicações hemorrágicas.................................................. 64

13.5. Complicações renais............................................................ 64

13.6. Complicações da ferida cirúrgica (esternotomia)...................... 64

13.7. Outras complicações.......................................................... 64

13.8. Complicações relacionadas à Aprotinina................................... 64

DISCUSSÃO

CONCLUSÕES

REFERÊNCIAS BIBLIOGRÁFICAS ................................................ 85

ANEXOS 


\section{LISTA DE FIGURAS}

FIGURA 1. Albuminemia $(\mathrm{g} / \mathrm{dl})$ dos grupos Aprotinina e Controle, nos tempos $\mathrm{T} 1$ a $\mathrm{T} 4$

FIGURA 2. Pressão arterial média (PAM) $(\mathrm{mmHg})$ durante a CEC nos Grupos Aprotinina (tratamento) e Controle. À esquerda, PAM antes e até 60 minutos de CEC. À direita, PAM nos tempos T1 (antes da CEC), T2 (15 min) e T3 (antes da saída de CEC).

FIGURA 3. Temperatura orofaríngea média $\left({ }^{\circ} \mathrm{C}\right)$ durante a CEC nos Grupos Aprotinina (tratamento) e Controle. À esquerda, temperatura antes e até 60 minutos de CEC. À direita, temperatura nos tempos T1 (antes da CEC), T2 (15 min) e T3 (antes da saída de CEC).

FIGURA 4. Diurese $(\mathrm{ml} / \mathrm{Kg})$, nos grupos Aprotinina e Controle, antes, durante e depois da CEC. As diferenças intergrupos não são estatisticamente significantes.

FIGURA 5. Balanço de sangue intra-operatório $(\mathrm{ml})$, nos pacientes dos grupos Aprotinina e Controle.

FIGURA 6. Temperatura esofágica $\left({ }^{\circ} \mathrm{C}\right)$ horária dos grupos Aprotinina $(\mathrm{T}) \mathrm{e}$ Controle $(\mathrm{C})$, desde a admissão na CTIP até $76 \mathrm{~h}$ mais tarde.

FIGURA 7. Relação PaO2/FiO2 dos grupos Aprotinina (T) vs Controle (C), nos tempos de T5 a T8. Não houve diferença significativa intergrupos.

FIGURA 8. Drenagem mediastinal $(\mathrm{ml} / \mathrm{Kg})$ no $\mathrm{PO}$ dos grupos Aprotinina e Controle nos tempos de T5 a T8....

FIGURA 9. Diurese $(\mathrm{ml} / \mathrm{kg})$ dos grupos Aprotinina e Controle nos tempos de T5 a T8. As diferenças intergrupos estatisticamente significativas estão assinaladas.

FIGURA 10. Depuração de creatinina dos grupos Aprotinina e Controle, no pré-operatório, no PO imediato (Pol) e no $1^{\circ}$ dia PO $\left(1^{\circ} \mathrm{PO}\right)$. Não houve diferenças estatisticamente significantes intergrupos.

FIGURA 11. Taxa de hemoglobina ( $\mathrm{g} / \mathrm{dl})$ nos grupos Aprotinina e Controle, nos tempos T1 a T8. As diferenças significativas estão assinaladas.

FIGURA 12. Taxa de hematócrito (\%) nos grupos Aprotinina e Controle, nos tempos T1 a T8. As diferenças estatisticamente significantes estão identificadas.

FIGURA 13. Contagem de plaquetas $\left(n^{\circ} \times 10^{3} / \mathrm{mm}^{3}\right)$ nos grupos Aprotinina e Controle. As diferenças intragrupos e intergrupos estatisticamente significativas estão assinaladas.

FIGURA 14. Contagem de leucócitos $\left(\mathrm{n}^{\circ} / \mathrm{mm}^{3}\right)$ nos grupos Aprotinina e Controle, nos tempos T1 a T8. As diferenças intragrupos e intergrupos estatisticamente significativas estão assinaladas. 
FIGURA 15. Perfil sérico bifásico da concentração sérica do Fator de Necrose Tumoral alfa (TNF- $\alpha$ ) em pg/ml nos grupos Aprotinina e Controle, nos tempos de T1 a T8. As diferenças estatisticamente significativas intragrupo estão apontadas.

FIGURA 16. Níveis séricos de IL-6 (pg/ml) nos grupos Aprotinina e Controle, nos tempos T1 a T8. As diferenças intragrupos, estatisticamente significativas, estão expostas.

FIGURA 17. Níveis séricos de IL-8 (pg/ml) nos grupos Aprotinina e Controle, nos tempos T1 a T8. As diferenças estatisticamente significativas intragrupo estão indicadas.

FIGURA 18. Níveis séricos de $\mathrm{IL}-10(\mathrm{pg} / \mathrm{ml})$ nos grupos Aprotinina e Controle, nos tempos T1 a T8. As diferenças estatisticamente significativas, intra e intergrupos estão indicadas.

FIGURA 19. Proporção IL-6/IL10 nos grupos Aprotinina e Controle, nos tempos T1 a T8. As diferenças estatisticamente significativas intra-grupo estão assinaladas.

FIGURA 20. Troponina I cardíaca (cTnl) (ng/ml), nos grupos Aprotinina e Controle. As diferenças intragrupo estatisticamente significativas estão assinaladas

FIGURA 21. Níveis de NT-proBNP (fmol/ml) nos grupos Aprotinina e Controle, nos tempos T1 a T8. As diferenças intra-grupo estatisticamente significativas estão assinaladas.

FIGURA 22. Níveis séricos médios de NT-proBNP ( $\mathrm{fmol} / \mathrm{ml}$ ) nos grupos Aprotinina ( $T$ ) vs grupo Controle (C), excluindo o caso 45. Houve diferença estatisticamente significativa intergrupos no tempo T2

FIGURA 23. Lactatemia ( $\mathrm{mmol} / \mathrm{l}$ ) nos grupos Aprotinina e Controle, nos tempos T1 a T8. As diferenças significativas intra e intergrupos estão assinaladas.

FIGURA 24. Medidas do pH nos grupos Aprotinina e Controle, nos tempos T1 a T8. As diferenças significativas intra e intergrupos estão assinaladas..

FIGURA 25. PaCO2 (mmHg) nos grupos Aprotinina e Controle, nos tempos T1 a T8. As diferenças significativas intra e intergrupos estão assinaladas.

FIGURA 26. Concentração arterial de bicarbonato ( $\mathrm{mmol} / \mathrm{l})$ nos grupos Aprotinina e Controle, nos tempos T1 a T8. As diferenças estatisticamente significativas intragrupo estão representadas.

FIGURA 27. Níveis de IL-6 (pg/ml), IL-10 (pg/ml) e proporção IL-6/IL-10 no grupo Aprotinina, nos pacientes com critérios para SRIS (linha cheia contínua) comparado com aos demais (linha descontínua), 


\section{LISTA DE TABELAS}

TABELA 1. Idade (d), peso $(\mathrm{g})$, altura $(\mathrm{cm})$ e superfície corpórea $\left(\mathrm{m}^{2}\right)$ (média \pm desvio padrão), dos grupos Aprotinina e Controle. A mediana aparece entre parênteses.

TABELA 2. Duração (min) da operação, anestesia, circulação extracorpórea (CEC) e do pinçamento aórtico, e temperatura orofaríngea mínima em CEC $\left({ }^{\circ} \mathrm{C}\right)$, nas crianças do grupo Aprotinina.

TABELA 3. Duração (min) da operação, anestesia, circulação extracorpórea (CEC) e do pinçamento aórtico, e temperatura orofaríngea mínima em CEC $\left({ }^{\circ} \mathrm{C}\right)$, nas crianças do grupo Controle.

TABELA 4. Tempos de utilização de óxido nítrico $(\mathrm{h})$, ventilação mecânica (h), permanência no CTIP (dias), de estadia hospitalar (dias) e de uso de drogas inotrópicas, dos grupos Aprotinina e Controle...... 


\section{ABREVIATURAS E SIGLAS}

\begin{tabular}{|c|c|}
\hline Abreviatura & Significado \\
\hline BNP & Peptídeo natriurético tipo B \\
\hline bpm & Batimentos por minuto \\
\hline $\mathbf{C} 3 \mathbf{a}$ & Anafilatoxina C3a, fragmento proteolítico de C3 do complemento \\
\hline C5a & Anafilatoxina $\mathrm{C} 5 \mathrm{a}$, fragmento proteolítico de $\mathrm{C} 5$ do complemento \\
\hline CD & Cluster of diferenciatio (grupo de diferenciação) \\
\hline CD11b & Cadeia integrina $\alpha \mathrm{M}$, ligada não-covalentemente a CD18 \\
\hline CD18 & Subunidade $\beta 2$ da integrina, ligada não-covalentemente a CD11b \\
\hline CEC & Circulação extracorpórea \\
\hline CIA & Comunicação interatrial \\
\hline CIV & Comunicação interventricular \\
\hline CK-MB & Fração MB da creatinofosfoquinase \\
\hline CoAo & Coarctação da aorta \\
\hline cTnl & Troponina cardíaca I \\
\hline CTPI & Centro de Terapia Intensiva Pediátrica \\
\hline DDH & Decúbito dorsal horizontal \\
\hline downregulatio & $\begin{array}{l}\text { Redução do número ou da expressão de receptores para uma } \\
\text { substância ou droga sobre superfícies celulares em uma } \\
\text { determinada área. }\end{array}$ \\
\hline DVSVD & Dupla via de saída do ventrículo direito \\
\hline EACA & Ácido épsilon-aminocapróico \\
\hline ECG & Eletrocardiograma \\
\hline ECG & Eletrocardiograma \\
\hline ELISA & Ensaio imunoenzimático \\
\hline EP & Estenose pulmonar \\
\hline EV & Endovenoso \\
\hline FAP & Fator ativador de plaquetas \\
\hline Fator XIIa & Fator XII (Hageman) ativado \\
\hline FC & Freqüência cardíaca \\
\hline FE & Fração de ejeção \\
\hline fmol & Fentomol \\
\hline FOP & Forame oval patente \\
\hline $\mathbf{h}$ & Hora \\
\hline $\mathrm{Hb}$ & Hemoglobina \\
\hline HP & Hipertensão pulmonar \\
\hline $\mathrm{Ht}$ & Hematócrito \\
\hline IAM & Infarto agudo do miocárdio \\
\hline ICC & Insuficiência cardíaca congestiva \\
\hline
\end{tabular}




\begin{tabular}{|c|c|}
\hline IL-10 & Interleucina-10 \\
\hline IL-1及 & Interleucina-1 beta \\
\hline IL-6 & Interleucina-6 \\
\hline IL-8 & Quimiocina Interleucina-8 \\
\hline INR & International normalised ratio \\
\hline kg & Quilograma \\
\hline kg & Quilograma \\
\hline I & Litro \\
\hline mg & Miligrama \\
\hline ml & Mililitro \\
\hline $\mathrm{mmHg}$ & Milímetros de mercúrio \\
\hline n/a & Não se aplica \\
\hline ng & Nanograma \\
\hline NOS & Óxido nítrico sintetase \\
\hline Nt-proBNP & Fração aminoterminal do peptídeo natriurético tipo B \\
\hline $\mathrm{PaCO} 2$ & Pressão parcial arterial de gás carbônico \\
\hline PAM & Pressão arterial média \\
\hline \multirow[t]{2}{*}{$\mathrm{PaO} 2 / \mathrm{FiO} 2$} & Relação pressão parcial arterial de oxigênio com a fração \\
\hline & Inspirada de oxigênio \\
\hline PAR1 & Receptor protease-ativada 1 \\
\hline PCA & Persistência do canal arterial \\
\hline pg & Picograma \\
\hline PO & Pós-operatório \\
\hline PRISM & Pediatric Risk Index Score for Mortality \\
\hline proBNP & Precursor do peptídeo natriurético tipo $B$ \\
\hline PVC & Pressão venosa central \\
\hline PVP-I & Polivinil pirrolidona iodo (iodopovidona) \\
\hline RACSH-1 & Risk adjustment for congenital heart surgery \\
\hline SECS & Síndrome do extravazamento capilar sistêmico \\
\hline SRIS & Síndrome da resposta inflamatória sistêmica \\
\hline TCA & Tempo de coagulação ativada \\
\hline TGO & Transaminase glutâmico-oxalacética (aspartato-aminotransferase) \\
\hline TNF- $\alpha$ & Fator de necrose tumoral - alfa \\
\hline TP & Tempo de protrombina \\
\hline TTPA & Tempo de tromboplastina parcial ativada \\
\hline UIC & Unidades inibidoras de calicreína \\
\hline upregulate & $\begin{array}{l}\text { Aumento do número ou da expressão de receptores para uma substância } \\
\text { ou droga sobre superfícies celulares em uma dada área na qual as células } \\
\text { são mais reativas aos efeitos do agente }\end{array}$ \\
\hline VD & Ventrículo direito \\
\hline VE & Ventrículo esquerdo \\
\hline
\end{tabular}


VM Ventilação mecânica

VSVD Via de saída do ventrículo direito

VSVE Via de saída do ventrículo esquerdo

$\mu \mathrm{g} \quad$ Micrograma

$\mu \mathrm{M} \quad$ Micromol 
RESUMO 
Introdução. A Aprotinina parece reduzir o uso de transfusões, o processo inflamatório e o dano miocárdico, pós-CEC. Material e Métodos. Estudo prospectivo randomizado em crianças de 30 dias a 4 anos de idade, submetidas à correção de cardiopatia congênita acianogênica, com CEC e divididas em dois grupos, um denominado Controle $(n=9)$ e o outro, Aprotinina $(n=10)$. Neste, a droga foi administrada imediatamente antes da CEC. A resposta inflamatória sistêmica e disfunções hemostáticas e multiorgânicas foram analisadas por marcadores clínicos e bioquímicos. Foram consideradas significantes as diferenças com $p<0,05$. Resultados. Os grupos foram semelhantes quanto às variáveis demográficas e intraoperatórias, exceto por maior hemodiluição no Grupo Aprotinina. Não houve benefício quanto aos tempos de ventilação pulmonar mecânica, permanência no CTIP e hospitalar, nem quanto ao uso de inotrópicos e função renal. A relação $\mathrm{PaO} 2 / \mathrm{FiO} 2$ (pressão parcial de oxigênio arterial/fração inspirada de oxigênio) apresentou queda significativa com 24 h PO, no Grupo Controle. Ocorreu preservação da concentração plaquetária com a Aprotinina enquanto no grupo Controle houve plaquetopenia desde o início da CEC. As perdas sangüíneas foram semelhantes nos dois grupos. No grupo Aprotinina surgiu leucopenia significativa, em CEC, seguida de leucocitose. Fator de necrose tumoral alfa (TNF- $\alpha$ ), Interleucinas (IL)-6, IL-8, IL-10, proporção IL-6/IL-10, troponina I cardíaca (cTnl), fração MB da creatinofosfoquinase (CKMB), transaminase glutâmico-oxalacética (TGO) e fração amino-terminal do peptídio natriurético tipo B (NT-proBNP) não apresentaram diferenças marcantes intergrupos. A proporção IL-6/IL-10 PO aumentou no grupo Controle. A lactatemia e acidose metabólica pós-CEC foi mais intensa no grupo Aprotinina. Não houve complicações com o uso da Aprotinina. Conclusão. A Aprotinina não minimizou as manifestações clínicas e os marcadores séricos de resposta inflamatória sistêmica e miocárdicos, mas preservou quantitativamente as plaquetas. 
ABSTRACT 
Introduction. Aprotinin seems to reduce the need for transfusion, the inflammatory process and myocardial damage after extracorporeal circulation (ECC). Material and Methods. A prospective randomized study was conducted on children aged 30 days to 4 years submitted to correction of acyanogenic congenital heart disease with ECC and divided into two groups: Control $(n=9)$ and Aprotinin $(n=10)$. In the Aprotinin Group the drug was administered immediately before ECC and the systemic inflammatory response and hemostatic and multiorgan dysfunctions were analyzed on the basis of clinical and biochemical markers. Differences were considered to be significant when $P<0.05$. Results. The groups were similar regarding demographic and intraoperative variables, except for a greater hemodilution in the Aprotinin Group. The drug had no benefit regarding time of mechanical pulmonary ventilation, permanence in the postoperative ICU and length of hospitalization, or regarding the use of inotropic drugs and renal function. The partial arterial oxygen pressure/inspired oxygen fraction ratio $\left(\mathrm{PaO}_{2} / \mathrm{FiO}_{2}\right)$ was significantly reduced $24 \mathrm{~h}$ after surgery in the Control Group. Platelet concentration was preserved with the use of Aprotinin, whereas thrombocytopenia occurred in the Control Group since the beginning of ECC. Blood loss was similar for both groups. Significant leukopenia was observed in the Aprotinin Group during ECC, followed by leukocytosis. Tumor necrosis factor alpha (TNF- $\alpha$ ), interleukins (IL)-6, IL-8, IL-10, IL-6/IL-10 ratio, cardiac troponin I (cTnI), creatine kinase MB fraction (CKMB), glutamic-oxaloacetic transaminase (GOT) and the aminoterminal fraction of natriuretic peptide type B (NT-proBNP) ndid not differ significantly between groups. The postoperative IL-6/IL-10 fraction increased significantly in the Control Group. Post-ECC blood lactate concentration and metabolic acidosis was more intense in the Aprotinin Group. There were no complications with the use of Aprotinin. Conclusion. Aprotinin did not minimize the clinical manifestations or serum markers of the inflammatory, systemic and myocardial response, but quantitatively preserved the platelets. 
INTRODUÇÃO 
A morbi-mortalidade da circulação extracorpórea (CEC) decorre, em grande parte, da limitada biocompatibilidade dos materiais nela utilizados que, rapidamente, ativam, por contato, fatores bioquímicos e elementos figurados do sangue. Esses, por sua vez, desencadeiam resposta inflamatória sistêmica, potencialmente grave, de cunho, primordialmente, endotelial (LARMANN et al., 2004; LI et al., 2005; RINDER et al., 2006).

A disfunção sistêmica multiorgânica pós-perfusão, expressa por depressão miocárdica, disfunção vasomotora, insuficiências respiratória, renal e hepática, desajustes cognitivos e de regulação térmica, e sangramento por coagulopatia (KIRKLIN, 1991), caracteriza a síndrome da resposta inflamatória sistêmica (SRIS) (BONE et al., 1992; LEVY et al, 2003).

Entre os mediadores bioquímicos, destacam-se as citocinas IL-1 $\beta$, TNF- $\alpha$, IL-6 e IL-8, ativadas em cascata (MOURA et al., 2001; SHERWOOD et al., 2004; DAY et al., 2005) e que, em conjunto com outros reagentes, determinam importante ativação leucocitária, endotelial, plaquetária e de células parenquimatosas (LAFFEY et al., 2002; SEGHAYE, 2003). Esses agentes bioquímicos, além de desencadear adesão endotelial de neutrófilos e monócitos, ativam os sistemas de contato (calicreína-cininogênio-cinina), do complemento e de coagulação e fibrinólise (WACHTFOGEL et al., 1989; PETÄJÄ et al., 1996; LAFFEY et al., 2002).

Dentre outros fatores desencadeadores da SRIS, encontram-se os tempos de CEC e isquemia miocárdica, os fenômenos de reperfusão tecidual, a mudança do padrão de fluxo, de pulsátil para laminar, a eventual hipoperfusão cérebral, hepática, renal e intestinal, a hipotermia tecidual, a endotoxemia, a lesão de cisalhamento dos elementos figurados do sangue, a disfunção hemostática induzida por hemodiluição e transfusões, e paraefeitos da utilização de heparina e protamina (BRIX-CHRISTENSEN, 2001; LAFFEY et al., 2002; MENASCHE et al., 2003; RINDER, 2006).

Curiosamente, o trauma cirúrgico, por si só, pode ser muito mais importante do que a CEC, na indução da SRIS (MENGER et al., 2004; PRONDZINSKI et al., 2005). Por outro lado, embora os adultos, na maioria, 
se recuperem bem (ROYSTON et al., 2003; RINDER, 2006), as crianças de baixo peso corpóreo, em especial neonatos e lactentes, com freqüência, apresentam SRIS e sangramento pós-op. excessivo (POUARD, 1998). Essas complicações determinam exposição a mais doadores de hemoderivados, tempo prolongado de hemostasia na sala de operações, necessidade, por vezes, de fechamento esternal tardio, com conseqüente prolongamento da ventilação mecânica e da estadia na CTIP, e preocupante morbi-mortalidade associada à elevados custos hospitalares (POUARD, 1998).

Esse fato ajuda a explicar porque a taxa de artigos sobre complicações pós-operatórias em cirurgia cardíaca pediátrica, em relação ao total de publicações cirúrgicas na especialidade $(31 \%=295 / 951)$ é, proporcionalmente, 14 vezes maior do que a observada $(2,3 \%=209$ / 8973) em relação aos adultos (Levantamento pela PubMed, em 05/07/2006).

Além dessas disfunções orgânicas pós-operatórias englobadas como SRIS (PAPARELLA et al., 2002), neonatos e lactentes são susceptíveis a outra síndrome, denominada síndrome do extravasamento capilar sistêmico (SECS), com mediadores específicos ainda desconhecidos, caracterizando-se por edema tecidual generalizado, efusões pericárdicas, pleurais e/ou ascite (SEGHAYE et al., 1996; ZHANG et al., 2004).

Devido às preocupações com a morbi-mortalidade e incremento de custos decorrentes dessas complicações, particularmente, nas crianças de baixo peso e/ou desnutridas, estratégias para prevê-la, evitá-la ou combatêla são de intenso interesse (REDDY et al., 1995; SHEN et al., 2003).

Nesse sentido, ganharam destaque os escores pré-operatórios de estratificação do risco, o refinamento anestésico e cirúrgico, e a otimização dos circuitos de CEC (LAFFEY et al., 2002; PAPARELLA et al., 2002 CARMONA, 2006; MATTOS et al., 2006).

Continua, entretanto, controversa a aplicação profilática e/ou terapêutica antiinflamatória e/ou hemostática de agentes farmacológicos (BRASIL et al., 1999; ASIMAKOPOULOS et al., 2003; MAHARAJ et al., 2004; LARMANN et al., 2004;), como os corticóides, os ácidos tranexâmico 
e épsilon-aminocapróico (EACA), a Aprotinina, e o azul de metileno, introduzido no Brasil para reversão da vasoplegia pós-CEC (ANDRADE et al., 1996; ÉVORA, 2000; RIBEIRO et al., 2004).

A Aprotinina é um inibidor de serina protease constituída por uma cadeia polipeptídica de 6512 Daltons, hidrofílica e básica, tem como sítio ativo o resíduo lisina na posição 15, capaz de ligar-se à serina de proteases como a calicreína e a tripsina, formando complexos inativos, estequiometricamente reversíveis (PETERS et al., 1999; ALSTON, 2004). Esse mecanismo de ação dificulta estabelecer a posologia ideal para obterse o efeito inibitório substancial e persistente sobre uma protease específica, cuja concentração se desconhece, especialmente ao considerar a coexistência de muitas outras (ROYSTON, 1996).

A propriedade hemostática da Aprotinina expressa pela redução de perdas sanguíneas pós-CEC, foi descoberta casualmente no Hospital Hammersmith, pois investigava-se seu papel antiinflamatório com posologia denominada de alta dose, inibidora da calicreína (ROYSTON et al., 1987). Mais tarde identificou-se que embora concentrações plasmáticas de, aproximadamente, 50 a $125 \mathrm{UIC} / \mathrm{ml}(\sim 1 \mu \mathrm{M})$ inibam a plasmina, a inibição da calicreína, dos fatores de coagulação e da elastase neutrofílica requer concentrações maiores, de 200 a $400 \mathrm{UIC} / \mathrm{ml}(\sim 4$ - $8 \mu \mathrm{M})$ (ROYSTON, 1992; DAVIS et al., 1995).

É importante salientar que doses muito superiores a essas parecem bem toleradas, uma vez que não ocorreram efeitos colaterais em pacientes politraumatizados tratados com 17,5 milhões de UIC da droga, num período de 24 h (CLASEN et al., 1987).

Conquanto a eficácia hemostática do fármaco pareça depender de concentrações plasmáticas entre 127-191 UIC/ml, conformes ao protocolo original de ROYSTON et al. (1992) e capazes de inibir mais a atividade excessiva da plasmina que a calicreína (WEGNER, 2003), essa relação dose/resposta se dá de forma inconstante e explica as controvérsias posológicas, em adultos operados com CEC (BEATH et al., 2000; ROYSTON et al., 2001). No entanto, devido à curta meia-vida bifásica 
plasmática, com meias vidas de distribuição e eliminação de 0,32 a 0,50h e 5,25 a $8,28 \mathrm{~h}$ para as duas fases, respectivamente (ANDERSON et al., 2004), há consenso quanto à recomendação de infusão contínua (HOFFMANN et al., 1989).

Nas doses hemostáticas, o efeito antiinflamatório da Aprotinina inclui a manutenção da função e da contagem plaquetária, graças à antagonização da proteólise do principal receptor de trombina existente nas plaquetas, denominado receptor protease ativada 1 (PAR1) (DAY et al., 2004; WEGNER, 2003; LEVY et al., 2003). Paralelamente, há redução da expressão de P-selectina e da formação de conjugados plaqueta-leucócitos (WEERASINGHE et al., 1998), bem como da liberação de elastase (WENDEL et al., 1996), com menor ativação do complemento (HIMMELFARB et al., 1994) e inibição da "up-regulation" de moléculas de adesão de monócitos e granulócitos (GILLILAND et al., 1999), e redução da transmigração endotelial de neutrófilos (GREILICH et al., 2004; PRUEFER et al., 2003; ASIMAKOPOULOS et al., 2000).

A Aprotinina também diminui a concentração plasmática de IL-1 $\beta$, IL-6, IL-8, e TNF- $\alpha$ (TÜRKOZ et al., 2001), reduz a produção de IL-8 nas vias aéreas e aumenta o nível sérico da citocina antiinflamatória IL-10 (HILL et al., 1998; LEl et al., 2003). Além do mais, como inibe competitivamente as óxido nítrico sintases, pode amenizar a lesão de isquemia-reperfusão em diferentes órgãos, inclusive o coração (FRUMENTO et al., 2003; KHAN et al., 2004; SHIMOYAMA et al., 2005).

Embora discutível, LEVI et al. (1999), em uma meta-análise, concluíram que, em adultos submetidos à cirurgia cardíaca com CEC, a Aprotinina reduz as taxas de mortalidade (1,5\% vs $2,8 \%)$, de transfusão $(42,5 \%$ vs $62,7 \%)$ e de reexploração cirúrgica $(1,8 \%$ vs $5,0 \%)$. Outras informações são as de que reduz em $30 \%$ a proporção de pacientes expostos ao menos a uma unidade de concentrado de hemácias (HENRY et al., 2001) e em 39\%, a taxa de pacientes transfundidos (SEDRAKYAN et al., 2004). 
Não se conseguiu demonstrar, ainda, por meta-análises, aumento de infarto miocárdico, insuficiência renal e acidente vascular cerebral (SEDRAKYAN et al., 2006; ROYSTON et al., 2006), embora MANGANO et al. (2006) em um estudo observacional não aleatório tenham relatado o oposto. No entanto, esse artigo é visto como tendencioso, pois incluiu pacientes de alto risco, com maior número de comorbidades e de operações prévias (FERRARIS et al., 2006; HUNTER, 2006; BLANLOEIL, 2006).

Atualmente, é quase inconteste 0 benefício hemostático da Aprotinina em adultos com predisposição a sangramento (OZIER et al., 2006).

Não obstante crianças com menos de um ano de vida sangrem mais e recebam mais hemoderivados que as demais, com incidência de até $35 \%$ de perda sangüínea PO excessiva (SILVEIRA et al.,1998), podendo ultrapassar $100 \mathrm{ml} / \mathrm{Kg}$ em 12 horas e implicar na exposição de até 6 doadores diferentes (MANNO et al., 1991), os estudos pediátricos com Aprotinina pecam por difícil interpretação (OLIVER et al., 2004).

Isso se deve à ampla variação na posologia, à grande variabilidade do metabolismo e da ação antifibrinolítica da Aprotinina em neonatos (ZENKER et al., 2002), à hemodiluição (MOSSINGER et al., 2003), à dispersão na idade das coortes estudadas, às diferentes intervenções cirúrgicas efetuadas, com conseqüente variabilidade nos tempos de CEC e cirurgia (OLIVER et al., 2004).

Os primeiros trabalhos datam dos anos 80 (MASIAK et al., 1980; POPOV-CENIC et al., 1982; URBAN et al., 1984) e embora o uso da Aprotinina em crianças operadas com CEC tenha aumentado a partir de 1987, os resultados publicados nos anos 90 foram conflitantes (ELLIOTT et al., 1990; HAZAN et al., 1991; MÜLLER et al., 1992; DIETRICH et al., 1993; BOLDT et al., 1993; BOLDT et al., 1994; RANUCCI et al., 1994; JAVORSKI et al., 1995; PENKOSKE et al., 1995; GOMAR et al., 1995).

É importante salientar que o primeiro estudo pediátrico placebocontrolado foi feito no Brasil, por HERYNKOPF et al, em 1994. De trinta crianças envolvidas, 14 delas receberam Aprotinina, em baixa dose $(7 \mathrm{mg} / \mathrm{Kg}$ 
ou $50.000 \mathrm{UIC} / \mathrm{Kg}$ ), $40 \%$ dela após indução, $40 \%$ no perfusato e os $20 \%$ restantes, como dose de manutenção. O sangramento intra-operatório foi reduzido em $30 \%$ e o PO em 31\%, e implicou em menos transfusão de concentrado de hemácias, em que pese não se tenha podido confirmar menor atividade fibrinolítica, devido à subdosagem. Contudo, além de não informar o volume do perfusato, nem as operações efetuadas, a coorte estudada foi bastante heterogênea, pois incluiu pacientes com idades entre um mês e 11 anos, com peso corpóreo de $5 \mathrm{Kg}$ a $60 \mathrm{Kg}$.

Investigação semelhante, em população mais homogênea, foi relatada por D'ERRICO et al. (1996), comparando doses alta e baixa de Aprotinina com placebo, em reoperações com CEC. A Aprotinina reduziu o número de transfusões sangüíneas, diminuiu o tempo de sala cirúrgica, encurtou a duração da hospitalização e reduziu as despesas hospitalares. Merece referência que, embora planejada para 80 pacientes, a investigação foi encerrada após a inclusão de 61 deles, devido à constatação de significante diminuição de transfusões no grupo tratado com Aprotinina na dose de Hammersmith, tornando antiética a inclusão aleatória de novos casos. Essa pesquisa também salientou que a avaliação subjetiva do aspecto do campo cirúrgico, se exangue ou não, deveria ser valorizada, não obstante a dificuldade de quantificação.

Acresce que TWEDELL et al. (1996) demonstraram que a Aprotinina reduz a drenagem torácica em intervenções paliativas de ventrículo único, de modo a refletir um provável efeito antiinflamatório.

CARRELL et al. (1998), por sua vez, compararam a eficácia de duas doses de Aprotinina, uma baixa e outra alta, em crianças abaixo de $15 \mathrm{Kg}$ e concluíram que somente nos casos de operação de Jatene, reputada como de alto risco de sangramento, e tratados com dose alta, houve redução significativa, tanto das perdas sangüíneas, como no consumo de hemoderivados.

No mesmo sentido, em uma investigação multicêntrica envolvendo 226 crianças menores de 16 anos, notou-se tendência a menor necessidade 
de hemoderivados em pacientes tratados com dose alta de Aprotinina (CONIFF, 1998).

A preservação e/ou recuperação da função miocárdica mediada por alta dose de Aprotinina, e expressa por menos suporte inotrópico nas primeiras 48h pós-CEC, foi demonstrada por WIPPERMAN et al. (1999), num estudo randomizado de 34 crianças, sendo 17 tratadas com Aprotinina.

CHAUHAN et al. (2000) investigaram 300 crianças portadoras de cardiopatia congênita cianogênica, tratadas com baixa dose de Aprotinina, EACA, uma combinação de ambos, ou com placebo. O tempo para fechamento esternal, o sangramento nas primeiras $24 \mathrm{~h}$ de $\mathrm{PO}$ e as transfusões diminuíram significativamente com a associação Aprotinina/ EACA, em relação ao grupo controle. A combinação das drogas foi ligeiramente mais efetiva, provavelmente, por ação complementar, uma vez que a EACA inibe a ativação do plasminogênio e a Aprotinina, a plasmina, a calicreína e outras proteases.

Coube, por sua vez, a BROCHE et al. (2002) relatarem a redução da geração de radicais livres e do estresse oxidativo sistêmico, pela Aprotinina, em crianças sob suporte cardio-respiratório mecânico, com redução secundária da síndrome de baixo débito cardíaco e de arritmias, enquanto MÖSSINGER et al. (2003) demonstraram, em 60 crianças com cardiopatias acianogênicas e cianogênicas, que a droga reduz índices de disfunção pulmonar e hemostática.

COSTELLO et al (2003) relataram que a Aprotinina diminui o tempo de fechamento do tórax, e BULUTCU et al. (2005), num estudo prospectivo, randomizado, duplo-cego, com 100 crianças portadoras de cardiopatia cianogênica, submetidas à correção com CEC, verificaram ainda que tanto a Aprotinina quanto o ácido tranexâmico foram efetivos na redução de sangramento e de transfusões. Entretanto, a combinação de Aprotinina e ácido tranexâmico não sobrepujou cada uma das drogas, isoladamente.

Em 2006, ARNOLD et al., numa meta-análise de 12 estudos randomizados, envolvendo 612 crianças submetidas à CEC, constataram, com a Aprotinina, redução de $33 \%$ na taxa de transfusão, sem que 
ocorresse diminuição no volume total transfundido nem na intensidade da drenagem torácica pós-operatoria.

Os estudos publicados sobre a utilização da Aprotinina em cirurgia cardíaca pediátrica na literatura, entre 1980 e 2006, estão relacionados na tabela 1 do Anexo I.

Embora, como nos adultos, os benefícios pareçam ganhar evidência nos casos mais complexos (ALSTON, 2004), 83\% dos 36 centros da Pediatric Cardiac Intensive Care Society (22 deles localizados nos Estados Unidos) empregam rotineiramente a droga em cirurgia cardíaca pediátrica, com CEC, não obstante o custo elevado da medicação (CHECCHIA et al., 2005).

Com base no exposto, o presente trabalho foi efetuado na tentativa de demonstrar a utilidade da Aprotinina num subgrupo de crianças com alta prevalência nos Serviços de Cardiologia Pediátrica e que tem recebido pouca atenção dos investigadores. 
OBJETIVO

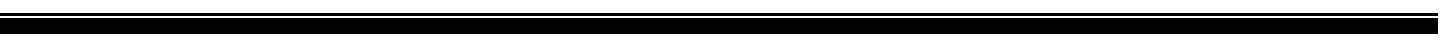


Verificar os efeitos hemostático, antiinflamatório e na proteção do miocárdio da Aprotinina, quando administrada no intra-operatória, em crianças submetidas à correção de cardiopatias congênitas acianogênicas com CEC. 
CASUÍSTICA E MÉTODOS 


\section{PACIENTES}

\subsection{População}

Foram estudadas 19 crianças, de ambos os sexos, submetidas à correção de cardiopatia congênita acianogênica, com CEC, de janeiro a dezembro de 2004. Essas crianças foram distribuídas, aleatoriamente, em dois grupos: Grupo Aprotinina $(n=10)$ e Grupo Controle $(n=9)$.

O estudo foi prospectivo, não cego, e executado pelas mesmas equipes, anestésica, cirúrgica, de perfusão e de terapia intensiva, sendo previamente aprovado pelo Comitê de Ética em Pesquisa em Seres Humanos do HC FMRP-USP. Os pais ou o responsável legal assinaram termo de consentimento informado (anexo 4).

Os critérios de inclusão foram operações eletivas e idade entre um mês e quatro anos e os de exclusão: operação cardiovascular prévia, exposição à Aprotinina nos seis meses anteriores à intervenção cirúrgica; uso de salicilatos até 7 dias antes da operação; distúrbios alergoimunológicos, hepáticos, renais ou de coagulação e episódios de parada cardíaca, sepses e vasculite, há menos de dois meses.

\section{METODOLOGIA}

\subsection{Sorteio}

A distribuição dos pacientes, nos dois grupos, deu-se por sorteio. No início do estudo, após a indução anestésica, extraiu-se, às cegas, de dentro de uma caixa, uma cédula dentre 20 idênticas, 10 das quais identificadas com Aprotinina e 10 sem Aprotinina, não sendo repostas.

\subsection{Técnicas Anestésica e Cirúrgica}

$\mathrm{Na}$ sala de pré-anestesia, puncionou-se uma veia periférica utilizando-se cateteres Insyte ${ }^{\circledR}$ ou Abocath ${ }^{\circledR}$ de vialon, 22 ou 24 GA e a seguir foi administrado midazolan $(0,2 \mathrm{mg} / \mathrm{Kg} \mathrm{EV})$. Em sala cirúrgica, as 
crianças foram posicionadas em DDH, sobre colchão térmico (Gaymar®, Medi-Therm, Gaymar Industries, INC., Orchand Park, NY, EUA) e mantidas sob fluxo de ar aquecido (aquecedor Thermacare ${ }^{\circledR}$, Gaymar Industries, INC., Orchand Park, NY, EUA).

Foram colocados eletrodos adesivos de ECG, e dois oxímetros de pulso digitais e/ou auricular conectados ao oxicapnógrafo (DIXTAL CO2 SMO Dx 7100 ETCO2/SpO2, Biomédica Ind. e Com. Ltda., Zona Franca de Manaus, AM, BR). Mediu-se a PA não-invasiva, no membro inferior. A indução anestésica constou de injeções EV de midazolan $(0,10$ a 0,20 $\mathrm{mg} / \mathrm{kg}$ ), fentanil (10 a $125 \mu \mathrm{g} / \mathrm{kg}$ ), ou sulfentanil $(5,0$ a $10,0 \mu \mathrm{g} / \mathrm{kg}$ ), e o relaxamento muscular, com vecurônio ou pancurônio $(0,15$ a 0,80 $\mathrm{mg} / \mathrm{kg} / \mathrm{EV}$ ). O plano anestésico foi mantido com infusão EV contínua de fentanil ou sulfentanil $(2 \mathrm{mcg} / \mathrm{kg} / \mathrm{h})$, associada à inalação de isofluorane (01\%) e a doses extras de midazolan e vecurônio ou pancurônio.

Após intubação orotraqueal, foi iniciada ventilação mecânica (ventilador Takaoka NIKKEI®, K. TAKAOKA Ind. e Com. Ltda., São Paulo, $\mathrm{SP}, \mathrm{BR}$ ), procurando obter-se $\mathrm{SvO}_{2}$ de 40-60\%, antes, e de 70 a 100\%, após a CEC. A monitorização invasiva da PA, na artéria radial, preferencialmente, por punção percutânea (cateter BD Insyte ${ }^{\circledR}$ ou Abocath ${ }^{\circledR}$ de vialon, 22 ou 24 GA) foi iniciada. A artéria femoral foi puncionada quando houve insucesso na punção radial.

A veia jugular interna $D$ ou a femoral foi canulada (cateter de poliuretano ARROW® International, Erding, Germany, de duplo-lúmen, 5 ou 7F) para infusão de líquidos e controle da PVC, as temperaturas orofaríngea e periférica (face plantar do pé) foram registradas por meio de termistores CE PHILIPS, CE, Medizin Systeme, Boeblingen, Germany, e a diurese foi medida por sondagem vesical de demora (sonda de silicone 6 ou 8, FOLYSIL, MENTOR, Minnesota, Canadá).

Anestesia peridural caudal com morfina e clonidina foi executada em 3 pacientes do grupo Aprotinina e em 3 do grupo Controle, a critério da equipe anestésica. Não foi utilizado corticosteróides. 
Após a indução anestésica, administrou-se Amicacina 7,5 mg/kg EV associada à Cefazolina (40 mg/kg EV) para as crianças internadas há menos de 48h. Nas demais, a associação foi com vancomicina (10 mg/kg EV). Uma dose adicional de vancomicina $(5 \mathrm{mg} / \mathrm{kg}$ ) foi acrescentada no reservatório do oxigenador. Os antibióticos foram suspensos $48 \mathrm{~h}$ após iniciados.

A Aprotinina (Trasylol@, Bayer, Leverkusen, Germany), na dose de $240 \mathrm{mg} / \mathrm{m}^{2}$ EV (ROYSTON, 1992), foi infundida por 20 a $30 \mathrm{~min}$, a partir do início da incisão cirúrgica. Essa dose seguiu-se da infusão contínua de Aprotinina, de $56 \mathrm{mg} / \mathrm{m}^{2} / \mathrm{h}$, mantida até completar-se o curativo, no final do procedimento. A droga $\left(240 \mathrm{mg} / \mathrm{m}^{2}\right)$ foi também adicionada ao perfusato do oxigenador. Dez minutos antes do início do tratamento com Aprotinina, fezse teste de sensibilidade à droga, com minidose de 10.000 UIC (1 ml) EV.

Sob antissepsia tópica com PVP-I (Riodeine®, São José do Rio Preto, SP, BR), foi feita esternotomia mediana e timectomia total. Em seguida, fixou-se o pericárdio, aberto na linha mediana, à pele com fios de algodão e dois cateteres radiopacos 18 (Venocath $®$, Abbott, Sligo, Ireland) foram exteriorizados, por contra-abertura subcostal direita.

As crianças foram heparinizadas $(3 \mathrm{mg} / \mathrm{kg}$ - EV) com heparina sódica, (Roche, Basle, Suíça), sob controle do TCA (Hemotec ACT $\| \circledast$, Medtronic, Englewood, CO, EUA), de modo a mantê-la acima de 480s, nos dois grupos, com doses adicionais de heparina $(0,5 \mathrm{mg} / \mathrm{kg}-\mathrm{EV}), 15$ minutos após o início da CEC e a cada $60 \mathrm{~min}$, consecutivos.

A aorta ascendente (cânula reta DLP, 8 a 14, Medtronic $®$, Minneapolis, Minnesota, EUA) e as veias cavas (cânulas anguladas aramadas DLP, 12 a 20, Medtronic $®$ Minneapolis, Minnesota, EUA ) foram canuladas através de suturas em bolsa com fio de polipropileno (PROLENE® 6.0, ETHICON, Johnson \& Johnson Produtos profissionais Ltda, São José dos Campos, SP, BR). Na aorta usou-se bolsa dupla, na VCS, bolsa elíptica, e na VCI, bolsa em "U”, apoiada em selos de teflon ou pericárdo bovino.

$\mathrm{Na}$ CEC, efetuada com drenagem venosa passiva, utilizaram-se quatro tipos similares de oxigenadores, Polystan Safe Mini ou Micro 
(MAQUET Gmbh \& Co, KG, Medical Systems Com. Ind. Medica Ltda., SP, BR), D901 Lilliput 1 DIDECO (Cobe CV, Sorin Group Company, Mirandola, Italy), DMG Vital 1500 Baby (DMG Eq. Médicos Ltda, Duque de Caxias, RJ, BR, em parceria com DIDECO, Sorin Group Company, Mirandola, Italy), e Oxim II 06 (MACCHI, Engenharia Biomédica Ltda, SP, BR), com os respectivos filtros arteriais. Empregaram-se bombas de roletes, com fluxo arterial, em normotermia, de $2,5 \mathrm{I} / \mathrm{m}^{2} / \mathrm{min}$. A temperatura da orofaringe, na CEC, foi reduzida para $28^{\circ} \mathrm{C}$, por termopermutação, no oxigenador.

O perfusato foi calculado para resultar com Hto de $30 \%$ (SANT'ANNA et al., 1994) e consistiu de concentrado de hemácias, solução de Ringer, plasma fresco congelado, Manitol $®$ a $20 \%$ (J.P. Indústria Farmacêutica S.A., Ribeirão Preto, BR) 4 a $5 \mathrm{ml} / \mathrm{Kg}$, heparina sódica (Roche Pharma, Basle, Suíça) 1mg/10 ml de hemoderivado e Bicarbonato de sódio a 8,4\%® (Hypofarma, Instituto de Hypodermia e Farmácia Ltda, Ribeirão das Neves, MG, BR) $1 \mathrm{mEq} / \mathrm{kg}$. O volume inicial de perfusato foi de $147 \pm 40 \mathrm{ml}$ $($ mediana $=137,50 \mathrm{ml})($ Polystam Micro $), 350 \pm 130 \mathrm{ml}($ mediana $=363 \mathrm{ml})$ (Polystan Mini), $247 \pm 49 \mathrm{ml}$ (mediana $238 \mathrm{ml}$ )(Lilliput), $260 \mathrm{ml}$ (DMG) e 960 ml (Oxim II 6), sendo que no grupo Aprotinina, o volume da droga adicionado ao perfusato foi incluída no cálculo. Durante a CEC o Hto foi mantido por adição de concentrado de hemácias.

Um de dois hemoconcentradores similares, com membrana de poliariletersulfona, Aquamac HFO3 (Edwards Lifesciences AG, Irvine, CA, USA) ou Polystan BC 20 plus (MAQUET Gmbh \& co,. KG, Medical Systems Com. Ind. Medica Ltda., SP, BR) serviu para ultrafiltração, iniciada no reaquecimento.

Após o pinçamento aórtico realizou-se cardioplegia anterógrada hipercalêmica $(10 \mathrm{ml} / \mathrm{kg})$, a $4^{\circ} \mathrm{C}$ e suspensa a um metro de altura, em relação à mesa cirúrgica, que foi infundida passivamente, na raiz aórtica. $A$ cardioplegia foi repetida a cada $30 \mathrm{~min}$, sendo que a primeira dose foi cristalóide e as demais sangüíneas. 
$\mathrm{O}$ reaquecimento sistêmico, até $37^{\circ} \mathrm{C}$, foi iniciado simultaneamente com a infusão $(0,5$ a $1,5 \mu \mathrm{g} / \mathrm{Kg} / \mathrm{min})$ de nitroprussiato de sódio (Lebon Laboratórios, Porto Alegre, RS, BR) pelo reservatório do oxigenador.

Nos pacientes com hipertensão pulmonar pré-operatória antes do despinçamento aórtico, os dois cateteres transtorácicos foram posicionados no $A E$ e na artéria pulmonar, por via trans-atrial $D$. Nos demais, ambos os dois átrios foram cateterizados.

Terminada a CEC, a cânula da aorta e da veia cava superior foram removidas e a linha arterial conectada à cânula da veia cava inferior. $\mathrm{O}$ volume presente no oxigenador passou a ser ultrafiltrado, nos intervalos entre as reposições de volume e infundido pela cânula da veia cava inferior.

Administrou-se cloridrato de protamina (ICN Farmacêutica Ltda., Valeant Pharmaceuticals International, USA, filiada a Medley S/A Indústria Farmacêutica, Sumaré - SP) na proporção de 1:1, em relação à dose total de heparina utilizada, e confirmou-se o retorno do TCA aos níveis basais. O sangue restante no circuito da CEC foi recuperado em bolsas de transferência (JP Indústria Farmacêutica, Ribeirão Preto, SP) sem anticoagulante para, após a descanulação, infusão EV pelo cateter venoso.

Completada a descanulação, revisou-se a hemostasia e as bolsas foram reforçadas com pontos em $X$ de polipropileno (PROLENE® 6.0 ETHICON, Johnson \& Johnson Produtos Profissionais Ltda, São José dos Campos, SP, Brasil).

O pericárdio foi fechado, caso não gerasse instabilidade hemodinâmica. Nas crianças com até $10 \mathrm{~kg}$ de peso, a síntese esternal foi efetuada com pontos separados de poliglactina (VICRYL® 0, ETHICON, Johnson \& Johnson Produtos profissionais Ltda, São José dos Campos, SP, $\mathrm{BR}$ ) e nas demais empregou-se fio de aço 1 (ACIFLEX monofilamento, ETHICON, Johnson \& Johnson Produtos Profissionais Ltda, São José dos Campos, SP, BR). Um dreno mediastinal com suspiro foi implantado, sob aspiração de $20 \mathrm{~cm}$ de água. 


\subsection{Características Clínicas Pré-Operatórias}

Foram analisadas as variáveis demográficas (idade, sexo, peso, altura e superfície corpórea) e calculada as categoria de risco dos pacientes segundo os escores RACSH-1 e Aristóteles Básico (JENKINS et al., 2002; LACOUR-GAYET et al., 2004), bem como o de Ross e Reithmann, modificado (ROSS et al., 1992; REITHMANN et al., 1997), para ICC (Anexo I), que foram correlacionados com as condições clínicas pós-operatórias. Para as variáveis, foram incluídas comparações intragrupo dos subgrupos, cujo escore de Ross foi $>$ ou $<5$.

As medicações, eventualmente em uso, assim como os exames diagnósticos da cardiopatia (eletrocardiograma, radiografia do tórax ecoDopplercardiograma e Cateterismo cardíaco) e o diagnóstico cirúrgico foram registrados, bem como as variáveis hemodinâmicas documentadas no pré-operatório (pressão arterial pulmonar e sistêmica) e a presença de arritmias.

Também foi protocolado obter hemograma, coagulograma e testes de função renal (uréia e creatinina plasmáticas) e hepática (TGO e bilirrubinas).

\subsection{Dados Cirúrgicos}

Foram coletadas as seguintes informações: operação realizada, vias de acesso intracardíaco, duração da operação, da anestesia e da CEC, tempo de pinçamento aórtico e de parada circulatória total, temperatura mínima na orofaringe, balanço hídrico no centro cirúrgico, diurese pré, durante e a pós a CEC, volume de concentrado de hemácias e de plasma fresco durante e após a CEC, transfusão de concentrado de plaquetas, volume de albumina pós-CEC, TCA antes, durante e após a CEC e complicações intra-operatórias. 


\subsection{Condições Clínicas Pós-Operatórias}

Os pacientes foram tratados de acordo com um protocolo padronizado de tratamento intensivo PO (CARLOTTI, 2005). Na chegada na CTIP, foi calculado o escore PRISM (POLLACK et al.,1988). Os escores inotrópicos I e II (GESSLER et al., 2006; SARAIYA et al., 2005) e os critérios para SRIS e SECS (BONE et al., 1992; SEGHAYE et al., 1996; LEVY et al., 2003; GOLDSTEIN et al., 2005) (em anexo), foram verificados nas $48 \mathrm{~h}$ seguintes. Para algumas variáveis clínicas e laboratoriais, foram incluídas comparações intragrupo e intergrupo dos subgrupos com e sem SRIS I SECS.

Retrospectivamente, calculou-se o índice recentemente proposto por MATTOS et al (2006) (Anexo I).

Foram medidos os tempos de uso de inotrópicos, de drogas vasoativas EV, de óxido nítrico e de permanência na CTIP, bem como o decorrido até a alta hospitalar ou o óbito. O mesmo foi feito quanto à duração da ventilação pulmonar mecânica.

O sangramento PO acumulado nas 4, 12, 24 e 48h, e a utilização de hemoderivados, com 6 e $24 \mathrm{~h}$ de PO, foram expressos em $\mathrm{ml} / \mathrm{kg}$.

O grau de disfunção renal foi avaliado pelo volume horário de diurese e, laboratorialmente, pela dosagem de uréia e creatinina plasmáticas e depuração estimada de creatinina (SCHWARTZ et al., 1987). Os quadros hemodinâmico, respiratório e metabólico, escala de coma de Glasgow e a disfunção hepática foram computados (GOLDSTEIN et al., 2005) (vide anexo).

Complicações pós-operatórias de qualquer natureza, incluídas as hemorrágicas, da ferida cirúrgica, e do uso de Aprotinina foram investigados.

\subsection{Avaliação Bioquímica e Hematológica}

Amostras de sangue arterial $(3 \mathrm{ml})$ foram coletadas nos seguintes momentos:

T1 - Após indução da anestesia, antes do início da administração da Aprotinina 
T2 - 15 min após o início da CEC

T3 - Imediatamente antes do término da CEC.

T4 - Cinco min após a administração de protamina

T5 - Quatro h após T4

T6 - Doze h após T4

T7 - Vinte e quatro $h$ após T4

T8 - Quarenta e oito h após T4

No sangue venoso central, foram medidas no $\mathrm{POI}$ e nos dois dias subseqüentes, as concentrações dos íons $\mathrm{Na}, \mathrm{K}, \mathrm{Ca}$, de uréia, creatinina, CKMB, TGO e bilirrubinas, bem como os tempos de protrombina (TP) e tromboplastina parcial ativada (TTPA), por métodos padronizados no Laboratório Central do HC FMRP-USP. As taxas de $\mathrm{Hb}$ e Hto, contagens de leucócitos e plaquetas foram verificadas nos tempos T1 a T8. A gasometria e o lactato sérico foram determinados no sangue arterial (analisador Rapilab 860, Bayer AG, Leverkusen, Germany), nos tempos T1 a T8.

Três $\mathrm{ml}$ de sangue de cada amostra foram preservados a $4^{\circ} \mathrm{C}$, em tubos sem anticoagulante, com gel separador (BD Vacutainer Systems $®$, Belliver Industrial State, Plymouth, UK) e, posteriormente, centrifugados à mesma temperatura (10 min, a $3000 \mathrm{rpm}$ ). O soro obtido foi pipetado e armazenado à temperatura de $-70^{\circ} \mathrm{C}$, em tubos tipo Eppendorf, para posterior processamento por ensaio imunoenzimático (ELISA), para dosagem de TNF- $\alpha$, IL-6, IL-8 e IL-10 (BD OptEIA set e kit II, BD Biosciences Pharmingen, San Diego, CA, EUA) e cTnl (IMMULITE $®$, Diagnostic Products Corporation, Los Angeles, CA) em alíquotas de 150 $\mu$ l ou mais de plasma. A análise foi realizada no Laboratório de Endocrinologia do HC-FMRP-USP.

O Nt-proBNP foi dosado por imuno-ensaio enzimático competitivo (ALPCO ${ }^{\circledR}$, catálogo 04-BI-20852, Diagnostics Biomédica, Viena, Áustria), cujos valores de referência para indivíduos sadios são: < $250 \mathrm{fmol} / \mathrm{ml}$ resultado negativo; < 250 - $350 \mathrm{fmol} / \mathrm{ml}$ - resultado limítrofe; > $350 \mathrm{fmol} / \mathrm{ml}$ resultado positivo. 
O perfil cinético dos níveis séricos de citocinas TNF- $\alpha$, IL-6, IL-8 e IL-10, de cTnl e de Nt-proBNP foram quantificados e corrigidos para a hemodiluição pela albumina sérica. A albumina foi dosada no plasma, por método de colorimetria, em espectrofotômetro marca BAUSCH \& LOMB (Modelo SPECTRONIC 70.1, USA), nos tempos T1 a Tn (T2 a T4) (valores normais de 3,5 a $5,5 \mathrm{~g} / \mathrm{dl})$. A correção foi feita utilizando-se a seguinte fórmula:

\subsection{Análise Estatística}

As variáveis qualitativas foram expressas em freqüências relativas e absolutas e as quantitativas pelos valores mínimos e máximo, média, mediana e desvio-padrão. No texto, os valores referentes ao grupo Aprotinina sempre precederam aos do grupo Controle.

A comparação intergrupos por análise utilizando modelo misto (pacote PROC MIXED $\AA$, do programa SAS/STAT®, versão 9, SAS Institute Inc., Cary, NC, EUA) pressupôs distribuição normal, e foi complementada pelo coeficiente de correlação de Pearson (pacote PROC CORR®, do programa SAS/STAT®, versão 9, SAS Institute Inc., Cary, NC, EUA).

Nas comparações de subgrupos, bem como nas intra e intergrupos, foi utilizado o teste não-paramétrico exato de Wilcoxon (programa Software R Development Core Team (2005). R Foundation for Statistical Computing, Vienna, Austria. ISBN 3-900051-07-0, URL http://www.R-project.org).

Os valores de $p<0,05$ foram considerados estatisticamente significantes.

Nas figuras com representações tipo caixas, os limites horizontais correspondem ao $25^{\circ}$ e ao $75^{\circ}$ percentis, a linha no interior da caixa corresponde à mediana e os limites e linhas externas às caixas refletem a 
variância da variável. O ponto cheio expressa a média e os pontos vazios, os valores discrepantes. 
RESULTADOS 
Para melhor esclarecimento dos resultados, nas figuras, as diferenças estatisticamente significativas intragrupos, em relação a T1, estão identificadas por um asterisco $\left({ }^{*}\right)$, e as intergrupos, por dois $\left({ }^{* *}\right)$.

Sempre que for expressa a comparação entre as médias e desvios padrões dos grupos, as do grupo Aprotinina terão precedência.

Dados individuais encontram-se no anexo.

\section{CARACTERÍSTICAS DEMOGRÁFICAS}

Os grupos foram semelhantes quanto à idade e às variáveis antropométricas (Tabela. 1). Em ambos os grupos houve predomínio da raça branca, sendo que o sexo masculino foi predominante no grupo Aprotinina. (Anexo I)

TABELA 1. Idade (d), peso $(\mathrm{g})$, altura $(\mathrm{cm})$ e superfície corpórea $\left(\mathrm{m}^{2}\right)$ (média \pm desvio padrão), dos grupos Aprotinina e Controle. A mediana aparece entre parênteses.

\begin{tabular}{|c|c|c|}
\hline & \multicolumn{2}{|c|}{ Grupos } \\
\hline & Aprotinina $(n=10)$ & Controle $(n=9)$ \\
\hline Idade (d) & $300 \pm 406 \quad(123)$ & $286 \pm 449 \quad(132)$ \\
\hline Peso (g) & $6067 \pm 3714(4665)$ & $6173 \pm 4009(4800)$ \\
\hline Altura (cm) & $63 \pm 16$ & $63 \pm 14$ \\
\hline Superfície corpórea $\left(\mathrm{m}^{2}\right)$ & $0,31 \pm 0,14$ & $0,32 \pm 0,16 \quad(0,27)$ \\
\hline
\end{tabular}

Todos os pacientes receberam alta hospitalar, em boas condições clínicas e de cicatrização. 


\section{ESCORES DE RISCO CIRÚRGICO}

Exceto pelo escore de Ross, modificado, pouco mais acentuado no grupo Aprotinina (medianas 5,5 vs 3), os de RACHS-1 (mediana 2) e Aristóteles básico (mediana 6) foram idênticos nos dois grupos (Anexo I).

\section{VARIÁVEIS PERI-OPERATÓRIAS}

3.1. Achado cirúrgico, vias de acesso intracardíaco e operações realizadas

As malformações cardíacas foram similares nos dois grupos, e associaram-se a obstruções da via de saída do VD em dois pacientes do grupo Aprotinina e da via de saída do VE, em um paciente do grupo controle. As operações realizadas também foram semelhantes (Anexo II).

3.2. Duração da operação, anestesia, CEC e pinçamento aórtico, e temperatura orofaríngea mínima em CEC

Essas variáveis foram semelhantes em ambos os grupos (Anexo II), conforme demonstradas nas tabelas 2 e 3 . 
TABELA 2. Duração (min) da operação, anestesia, circulação extracorpórea (CEC) e do pinçamento aórtico, e temperatura orofaríngea mínima em CEC $\left({ }^{\circ} \mathrm{C}\right)$, nas crianças do grupo Aprotinina.

\begin{tabular}{cccccc}
\hline \hline Pacientes & $\begin{array}{c}\text { Tempo } \\
\text { operatório } \\
(\mathrm{min})\end{array}$ & $\begin{array}{c}\text { Tempo } \\
\text { anestesia } \\
(\mathrm{min})\end{array}$ & $\begin{array}{c}\text { Tempo CEC } \\
(\mathrm{min})\end{array}$ & $\begin{array}{c}\text { Tempo } \\
\text { pinçamento } \\
\text { aórtico }(\mathrm{min})\end{array}$ & $\begin{array}{c}\text { Temperatura } \\
\text { orofaríngea } \\
\left({ }^{\circ} \mathrm{C}\right)\end{array}$ \\
\hline 1 & 225 & 300 & 45 & 37 & 31,6 \\
7 & 220 & 340 & 80 & 40 & 26 \\
13 & 270 & 400 & 110 & 80 & 27 \\
24 & 180 & 270 & 35 & 20 & 30,9 \\
25 & 170 & 300 & 50 & 30 & 28 \\
32 & 205 & 320 & 65 & 23 & 31,6 \\
35 & 190 & 340 & 55 & 30 & 27,4 \\
37 & 150 & 265 & 65 & 45 & 30,7 \\
40 & 135 & 330 & 75 & 50 & 26,7 \\
45 & 180 & 330 & 60 & 35 & 29,5 \\
Média \pm & $192,5 \pm 39,3$ & $319,5 \pm 39,04$ & $64 \pm 21,05$ & $39 \pm 17,12$ & $28,9 \pm 2,1$ \\
desvio-padrão & 185 & 325 & 62,50 & 36 & 28,7 \\
Mediana & & & & & \\
\hline \hline
\end{tabular}


TABELA 3. Duração (min) da operação, anestesia, circulação extracorpórea (CEC) e do pinçamento aórtico, e temperatura orofaríngea mínima em CEC $\left({ }^{\circ} \mathrm{C}\right)$, nas crianças do grupo Controle.

\begin{tabular}{cccccc}
\hline Pacientes & $\begin{array}{c}\text { Tempo } \\
\text { operatório } \\
(\mathrm{min})\end{array}$ & $\begin{array}{c}\text { Tempo } \\
\text { anestesia } \\
(\mathrm{min})\end{array}$ & $\begin{array}{c}\text { Tempo CEC } \\
(\mathrm{min})\end{array}$ & $\begin{array}{c}\text { Tempo } \\
\text { pinçamento } \\
\text { aórtico }(\mathrm{min})\end{array}$ & $\begin{array}{c}\text { Temperatura } \\
\text { orofaríngea } \\
\left({ }^{\circ} \mathrm{C}\right)\end{array}$ \\
\hline 3 & 210 & 330 & 70 & 50 & 29,1 \\
6 & 220 & 320 & 85 & 45 & 23,6 \\
10 & 225 & 255 & 70 & 45 & 28,1 \\
11 & 180 & 270 & 55 & 30 & 29,7 \\
12 & 210 & 330 & 85 & 56 & 30,6 \\
34 & 130 & 250 & 65 & 45 & 24,2 \\
36 & 170 & 300 & 60 & 40 & 27,4 \\
49 & 240 & 270 & 65 & 41 & 30,4 \\
53 & 165 & 270 & 70 & 45 & 31 \\
\hline Média \pm & $194,44 \pm 35,30$ & $288,33 \pm 32,01$ & $69,44 \pm 10,13$ & $44,11 \pm 7,11$ & $28,2 \pm 2,7$ \\
Desvio-padrão & 210 & 270 & 70 & 45 & 29,1 \\
Mediana & & & & & \\
\hline
\end{tabular}

\subsection{Oxigenadores e hemofiltros empregados}

Os oxigenadores utilizados tiveram distribuição semelhante nos dois grupos. Uma criança de cada grupo não foi submetida à hemofiltração (em anexo), devido indisponibilidade do equipamento (Anexo II).

\subsection{Volume total de perfusato e volemia estimada}

O volume total de perfusato foi ligeiramente maior no grupo Controle $(384 \pm 185 \mathrm{ml}$ vs $430 \pm 206 \mathrm{ml})$. A volemia estimada foi semelhante nos dois grupos (Anexo II). 


\subsection{Dose total de aprotinina}

A quantidade total de Aprotinina administrada foi de 177,56 $\pm 77,76$ $\mathrm{mg}$, correspondendo a 126,84 $\pm 55,55 \mathrm{ml}$ de Trasylol (em anexo), correspondendo às doses inicial + infundida, continuamente, no intra-op. e adicionada ao perfusato. $\mathrm{O}$ grupo Controle não recebeu a droga.

\subsection{Dose total de heparina}

A quantidade total de heparina empregada nos dois grupos foi similar $(39,2 \pm 15,3 \mathrm{mg}$, mediana $=33,5 \mathrm{mg}$ vs $39,0 \pm 16,7 \mathrm{mg}$, mediana $=30$ $\mathrm{mg}$ ), e correspondeu, em média, a 7,4 $\pm 2,9$ vs $7,1 \pm 3,8 \mathrm{mg} / \mathrm{kg}$ do peso corpóreo (Anexo II).

\subsection{Utilização de concentrado de hemácias na CEC e volume} de hemofiltrado

A utilização de concentrado de hemácias, em CEC, foi similar em ambos os grupos (221 $\pm 55 \mathrm{ml}$ vs $248 \pm 73 \mathrm{ml}$ ) (Anexo II), como também em relação ao volume hemofiltrado $(378 \pm 244 \mathrm{ml} v s 335 \pm 319 \mathrm{ml})$.

\subsection{Albuminemia}

Ambos os grupos eram moderadamente hipoalbuminêmicos, com taxas basais (T1) semelhantes $(2,81 \pm 0,38 \mathrm{~g} / \mathrm{dl}$ vs $2,81 \pm 0,59 \mathrm{~g} / \mathrm{dl})$. A CEC (T2) reduziu acentuadamente essa variável nos dois grupos $(1,32 \pm 0,67 \mathrm{~g} / \mathrm{dl}$ vs 1,63 $\pm 0,47 \mathrm{~g} / \mathrm{dl}$ ), até o seu final. Entretanto, logo após a administração da protamina (T4), a albuminemia do grupo Aprotinina mostrou-se estatisticamente menor que a do grupo Controle (Fig.1). 


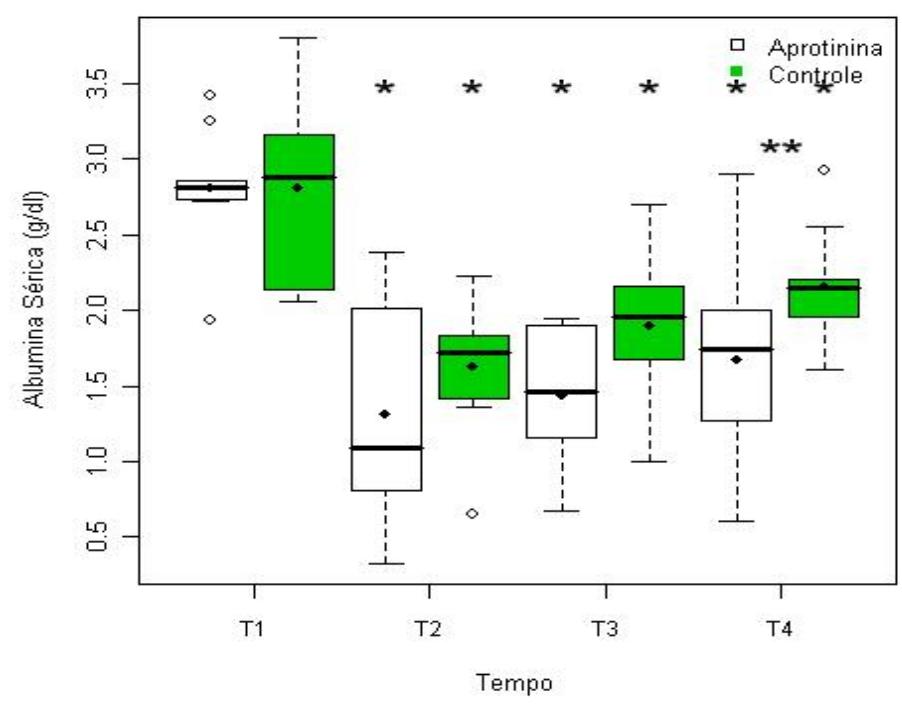

FIGURA 1. Albuminemia ( $\mathrm{g} / \mathrm{dl})$ dos grupos Aprotinina e Controle, nos tempos T1 a T4.

\subsection{Pressão arterial média (PAM) durante a CEC}

A PAM pré-CEC foi semelhante $(64,7$ vs $63,6 \mathrm{mmHg})$ e caiu no início da CEC nos dois grupos e no momento T2 (15 minutos de CEC), entretanto foi significativamente menor no Grupo Aprotinina $(54,1 \pm 11,7$ vs $70,2 \pm 23,0 \mathrm{mmHg}$ ), cuja diferença desapareceu em T3, imediatamente antes do final da CEC (62,0 vs 67,4 mmHg) (Fig. 2). 

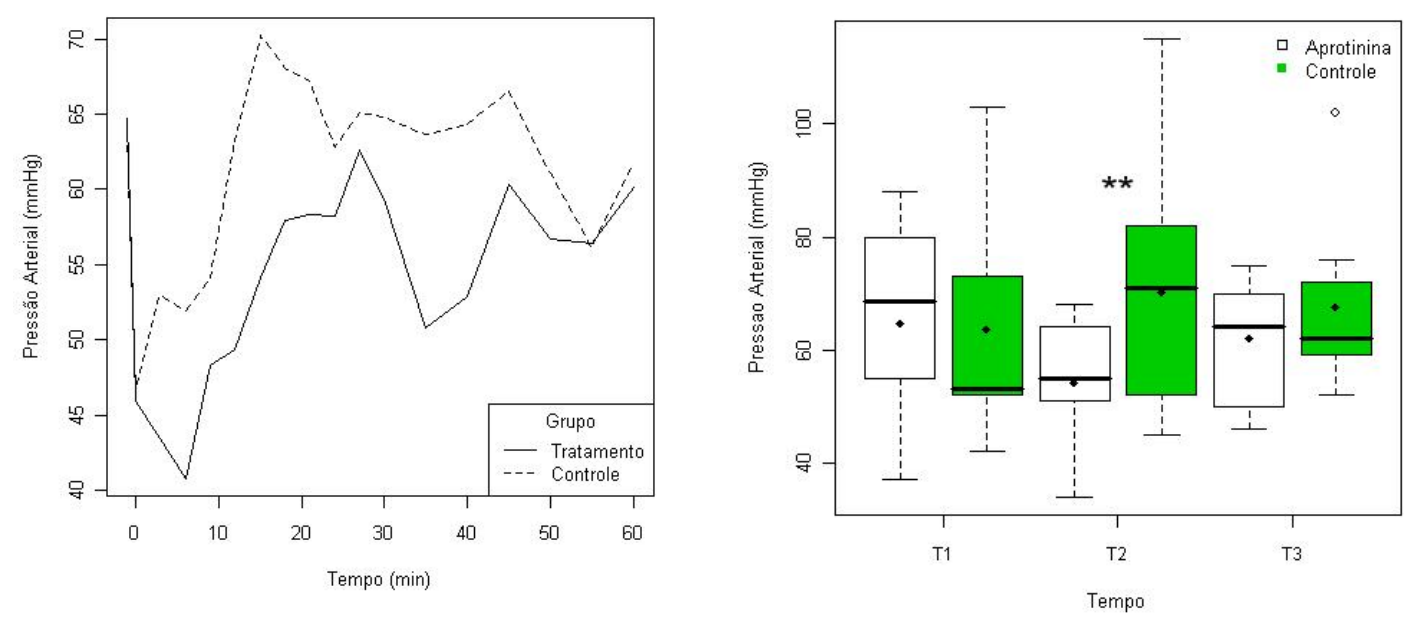

FIGURA 2. Pressão arterial média (PAM) ( $\mathrm{mmHg}$ ) durante a CEC nos Grupos Aprotinina (tratamento) e Controle. À esquerda, PAM antes e até 60 minutos de CEC. À direita, PAM nos tempos T1 (antes da CEC), T2 (15 min) e T3 (antes da saída de CEC).

\subsection{Temperatura orofaríngea média durante a CEC}

Essa variável foi quase igual nos dois grupos, antes da CEC $(36,2 \pm$ 0,9 vs $\left.36,5 \pm 0,7^{\circ} \mathrm{C}\right)$, no nadir da hipotermia $\left(29,7 \pm 1,9\right.$ vs $\left.28,9 \pm 2,3{ }^{\circ} \mathrm{C}\right)$ (T2) e após o reaquecimento, antes da saída de CEC (T3) (36,5 $\pm 0,3$ vs $\left.36,9 \pm 0,3^{\circ} \mathrm{C}\right)($ Fig. 3) 

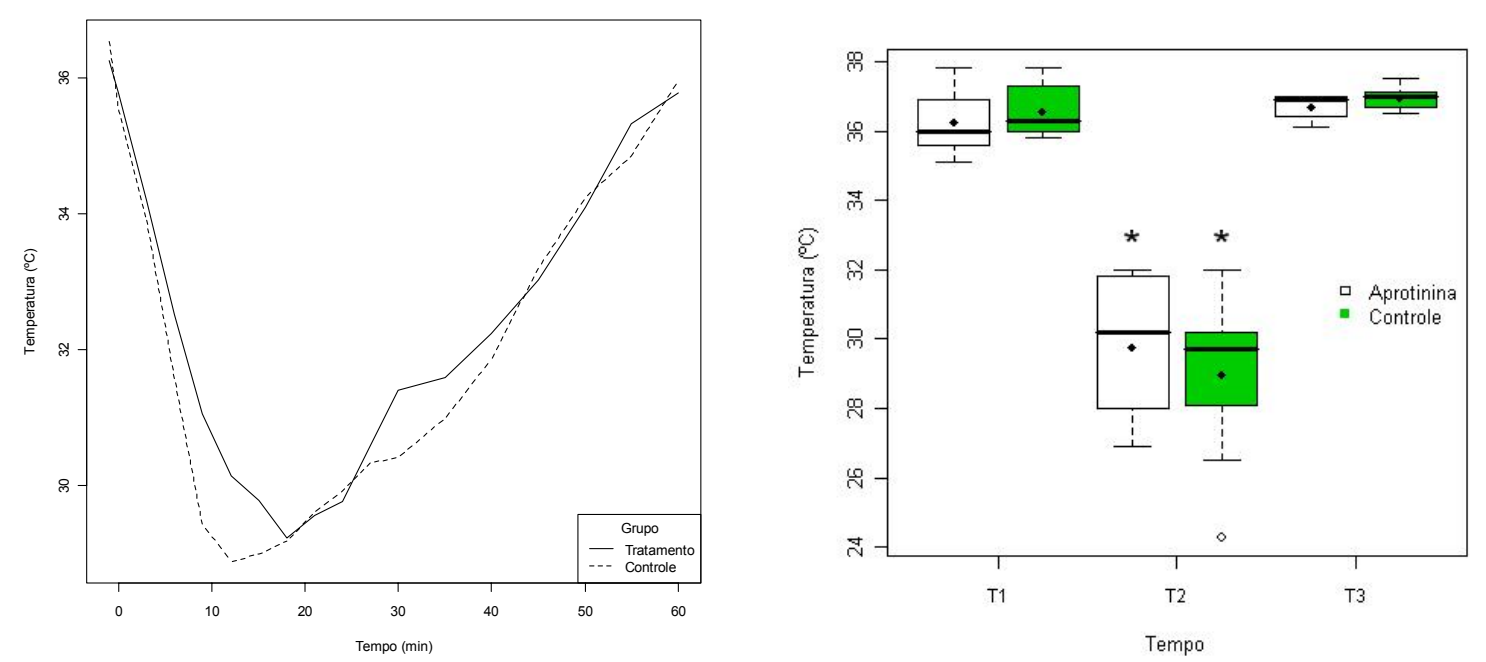

FIGURA 3. Temperatura orofaríngea média $\left({ }^{\circ} \mathrm{C}\right)$ durante a CEC nos Grupos Aprotinina (tratamento) e Controle. À esquerda, temperatura antes e até 60 minutos de CEC. À direita, temperatura nos tempos T1 (antes da CEC), T2 (15 min) e T3 (antes da saída de CEC).

\subsection{Diurese peri-operatória}

O comportamento da diurese $(\mathrm{ml} / \mathrm{kg})$ nos dois grupos, antes $(4,60 \pm$ $4,39$ vs $2,64 \pm 2,64)$, durante $(19,22 \pm 18,53$ vs $18,13 \pm 17,81)$ e após $(21,22$ $\pm 31,64$ vs $11,93 \pm 5,66$ ) a CEC, foi semelhante (Fig. 4). 


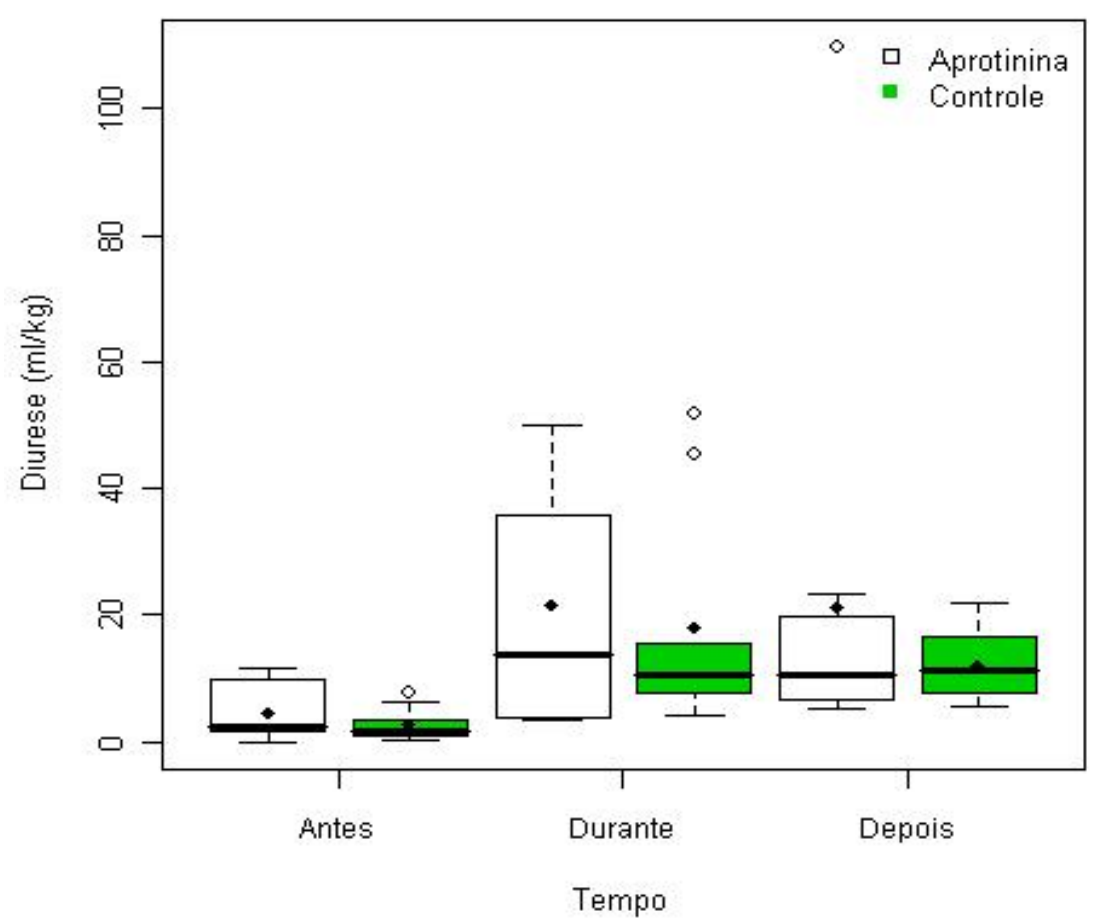

FIGURA 4. Diurese $(\mathrm{ml} / \mathrm{Kg})$, nos grupos Aprotinina e Controle, antes, durante e depois da CEC. As diferenças intergrupos não são estatisticamente significantes.

\subsection{Tempo de fechamento do tórax}

Os valores dessa variável foram quase superponíveis em ambos os grupos (28,5 $\pm 9,1 \mathrm{~min}$ vs $28,8 \pm 17,4 \mathrm{~min}$ ) (Anexo II)

\subsection{Balanço de sangue intra-operatório}

A figura 5 mostra acentuado contraste entre os grupos, pois houve forte tendência $(p=0,05)$ a balanço de sangue negativo, no grupo Aprotinina $(-12 \pm 166 \mathrm{ml}$, mediana $=15 \mathrm{ml} v s 125 \pm 81 \mathrm{ml}$, mediana $=150 \mathrm{ml})($ Anexo II). 


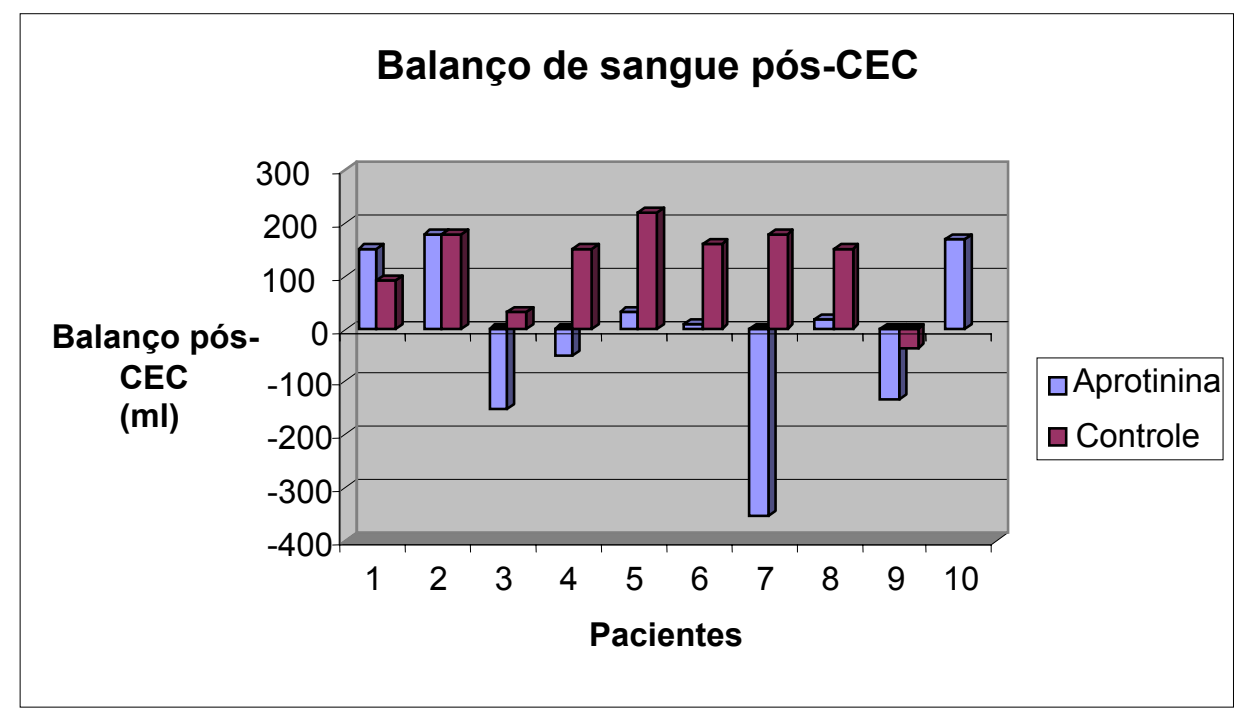

FIGURA 5. Balanço de sangue intra-operatório $(\mathrm{ml})$, nos pacientes dos grupos Aprotinina e Controle.

\section{VARIÁVEIS PÓS-OPERATÓRIAS}

\subsection{Balanço hídrico na admissão na CTIP}

Os resultados foram semelhantes em ambos os grupos $(24 \pm 77$ $\mathrm{ml} / \mathrm{kg}$, mediana= $25 \mathrm{ml} / \mathrm{Kg}$ vs $31 \pm 32 \mathrm{ml} / \mathrm{kg}$, mediana= $35 \mathrm{ml} / \mathrm{kg}$ ) (Anexo III).

\subsection{Escore PRISM, na admissão na CTIP}

O escore tendeu à piora no grupo Controle $(4,3 \pm 3,4$, mediana $=3$ vs $7,6 \pm 4,2$, mediana $=7$ ), porém sem diferença significativa. Escores individuais encontram-se no anexo III.

\section{3. Índice clínico-cirúrgico, segundo Mattos et al. (2006)}

Os dois grupos foram semelhantes quanto a esse índice $(5,3 \pm 2,2$, mediana $=5,5$ vs 4,7 $\pm 1,6$, mediana $=5)($ Anexo III). 
Pelo critério de idade, $70 \%$ das crianças do grupo Aprotinina e $88,8 \%$ das do grupo Controle estavam na categoria de risco intermediário (entre 1 mês e 1 ano).

Desnutrição protéico-calórica esteve presente em $90 \%$ vs $77,7 \%$ das crianças dos dois grupos e em quase todas, com critério de alto risco (abaixo do $5^{\circ}$ percentil). Devido, principalmente, à presença de insuficiência cardíaca, hipertensão pulmonar e/ou síndrome genética (fatores clínicos de risco associados), praticamente a metade das crianças dos dois grupos eram de alto risco (50\% vs $55,5 \%)$.

Por outro lado, enquanto todas as crianças do grupo Controle enquadraram-se na categoria de baixo risco quanto à complexidade cirúrgica (escore Aristóteles básico), ocorrendo em $80 \%$ do grupo Aprotinina.

Quanto ao tempo de CEC, todos os pacientes, exceto um do grupo Aprotinina, cujo tempo de CEC excedeu $90 \mathrm{~min}$, foram categorizados como de risco intermediário.

\subsection{Tempos de utilização de óxido nítrico, ventilação mecânica, permanência no CTIP e de estadia hospitalar}

Não houve diferenças significativas intergrupos (tabela 4). No entanto, as crianças dos dois grupos (6 vs 4 pacientes) com escore de Ross modificado $\geq 5$ apresentaram tempo significativamente maior de permanência no CTIP (medianas de 8,0 d vs $8,5 \mathrm{~d}$ ) que as demais (medianas de 2 d vs 1,6 d). O mesmo ocorreu quanto aos tempos de ventilação pulmonar mecânica (medianas de 133,5 h vs 168 h) em comparação às outras (medianas de $3 \mathrm{~h}$ vs $4 \mathrm{~h}$ ), e aos de internação hospitalar (medianas de 11,5 d vs $12 \mathrm{~d}$ ), em relação às crianças com escore $<5$ (medianas de $5 \mathrm{~d}$ vs $3 \mathrm{~d}$ ), respectivamente (vide anexo). 
TABELA 4. Tempos de utilização de óxido nítrico (h), ventilação mecânica (h), permanência no CTIP (dias), de estadia hospitalar (dias) e de uso de drogas inotrópicas, dos grupos Aprotinina e Controle.

\begin{tabular}{cccccc}
\hline \hline $\begin{array}{c}\text { Grupo } \\
\text { Aprotinina }\end{array}$ & $\begin{array}{c}\text { Tempo de } \\
\text { Óxido } \\
\text { nítrico } \\
\text { (horas) }\end{array}$ & $\begin{array}{c}\text { Tempo de } \\
\text { Ventilação } \\
\text { Pulmonar } \\
\text { Mecânica (horas) }\end{array}$ & $\begin{array}{c}\text { Tempo de } \\
\text { Permanência } \\
\text { CTIP (dias) }\end{array}$ & $\begin{array}{c}\text { Tempo de } \\
\text { Estadia } \\
\text { Hospitalar } \\
\text { (dias) }\end{array}$ & $\begin{array}{c}\text { Tempo de uso } \\
\text { inotrópicos (h) }\end{array}$ \\
\hline 1 & - & 123 & 6 & 8 & 144 \\
7 & +216 & 264 & 15 & 18 & 312 \\
13 & - & 18 & 2 & 5 & - \\
24 & - & 2 & 2 & 5 & 48 \\
25 & - & 144 & 7 & 9 & 144 \\
32 & - & 168 & 12 & 14 & 336 \\
35 & - & 0 & 2 & 6 & - \\
37 & - & 4 & 2 & 4 & 48 \\
40 & - & 24 & 9 & 17 & 72 \\
45 & - & 48 & 5 & 7 & 120 \\
\hline Média/ DP & - & $79,50 \pm 90,55$ & $6,4 \pm 4,92$ & $9,30 \pm 4,99$ & $122,40 \pm 118,36$ \\
Mediana & - & 36 & 5,5 & 7,5 & 132 \\
\hline \hline
\end{tabular}

\begin{tabular}{cccccc}
\hline $\begin{array}{c}\text { Grupo } \\
\text { Controle }\end{array}$ & $\begin{array}{c}\text { Tempo de } \\
\text { Oxido } \\
\text { nitrico } \\
\text { (h) }\end{array}$ & $\begin{array}{c}\text { Tempo de } \\
\text { Ventilação } \\
\text { Pulmonar } \\
\text { Mecânica (horas) }\end{array}$ & $\begin{array}{c}\text { Tempo de } \\
\text { Permanência } \\
\text { CTIP (dias) }\end{array}$ & $\begin{array}{c}\text { Tempo de } \\
\text { Estadia } \\
\text { Hospitalar } \\
\text { (dias) }\end{array}$ & $\begin{array}{c}\text { Tempo de uso } \\
\text { inotrópicos (h) }\end{array}$ \\
\hline 3 & - & 0 & 1,6 & 3 & 25 \\
6 & - & 39 & 3 & 8 & 17 \\
10 & - & 16 & 3,7 & 5 & 79 \\
11 & - & 3 & 1 & 3 & - \\
12 & - & 4 & 1,5 & 3 & 34 \\
34 & +144 & 312 & 14 & 39 & 192 \\
36 & - & 8 & 2 & 8 & 48 \\
49 & - & 72 & 5 & 7 & 48 \\
53 & +192 & 264 & 12 & 16 & 264 \\
\hline Média/ DP & - & $79,77 \pm 120,73$ & $4,86 \pm 4,80$ & $10,22 \pm 11,68$ & $78,55 \pm 89,40$ \\
Mediana & - & 16 & 3 & 5 & 48 \\
\hline \hline
\end{tabular}




\subsection{VARIÁVEIS HEMODINÂMICAS}

\subsubsection{Freqüência cardíaca média (FC)}

A FC basal (128+19 vs $123 \pm 23$ bpm) elevou-se, significativamente, no PO., tanto em T5 (145 vs 151 bpm) como em T7 (150 vs 144 bpm). Não houve diferença intergrupos (Anexo III).

\subsubsection{Pressão arterial média (PAM)}

A PAM basal foi semelhante $(68,3 \pm 10,4$ vs $60,4 \pm 17,5 \mathrm{mmHg})$. Exceto em T7, quando a PAM do grupo Controle foi significativamente maior (64,5 vs 71,0 mmHg), não ocorreram diferenças intergrupos (Anexo III).

\subsubsection{Pressão venosa central (PVC)}

As variações foram semelhantes, nos dois grupos, mantendo valores médios ao redor de $10 \mathrm{mmHg}$ (Anexo III).

\subsection{Tempo de uso de inotrópicos}

Os grupos assemelharam-se quanto à essa variável $(122,40 \pm$ $118,36 \mathrm{~h}$, mediana $=132 \mathrm{~h}$ vs 78,55 $\pm 89,40 \mathrm{~h}$, mediana = $48 \mathrm{~h}$ ). Contudo, no grupo Aprotinina, esse tempo foi significativamente maior nas crianças com escore de Ross modificado $\geq 5$, que nas demais (144 vs $24 \mathrm{~h}$ ).

\subsection{Escores inotrópicos I e II}

Houve tendência a maiores escores inotrópicos I e II no grupo Aprotinina. Nesse grupo, os dois escores foram significativamente maiores nas crianças com escore de Ross modificado $\geq 5$, comparadas às demais 
com escore < 5 (medianas de 6 vs 1 e 32,5 vs 2, respectivamente) (Anexo III).

4.8. Incidência de choque, anasarca, derrame pleural e congestão pulmonar, no pós-operatório

Detectou-se congestão pulmonar severa em 4 pacientes do grupo Aprotinina, sendo dois deles na forma de asma cardíaca, e em 3 pacientes do grupo Controle. Ocorreu choque circulatório em 5 pacientes do grupo Aprotinina e em três, do Controle. Anasarca foi detectada em quatro pacientes do grupo Aprotinina (dois deles com ascite), e em dois do Controle. Houve quatro casos de efusões pleurais, sendo dois em cada grupo (Anexo III).

\subsection{Temperatura esofágica no pós operatório}

Ambos os grupos (fig 6), apresentaram hipertermia $\left(37,8 \pm 1,2{ }^{\circ} \mathrm{C}\right.$ vs $\left.37,07 \pm 1,1{ }^{\circ} \mathrm{C}\right) 4 \mathrm{~h}$ após a administração de protamina (T5), mas, a temperatura esofágica manteve-se praticamente normal com 24 h (T7) e 48 h (T8.) de PO. No grupo Aprotinina, a normalização da temperatura atingiu significância estatística em relação a T5 (Anexo III). 


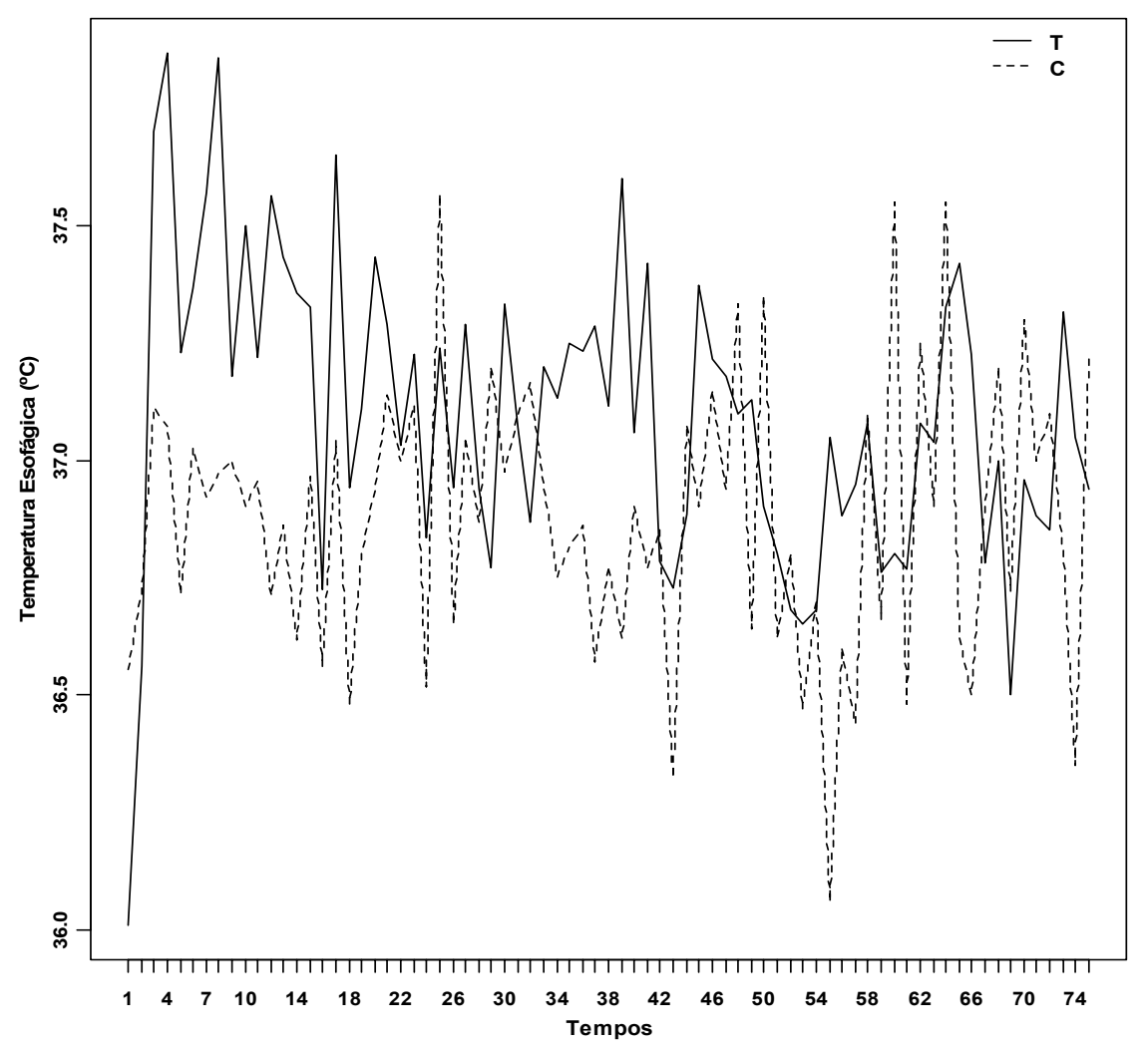

FIGURA 6. Temperatura esofágica $\left({ }^{\circ} \mathrm{C}\right)$ horária dos grupos Aprotinina $(\mathrm{T})$ e Controle (C), desde a admissão na CTIP até $76 \mathrm{~h}$ mais tarde.

\subsection{Relação $\mathrm{PaO}_{2} / \mathrm{FiO}_{2}$}

Essa variável teve comportamento semelhante, nos dois grupos (Fig. 7). Todavia, a queda em T7 em relação a T5 (246,38 \pm 129,39 vs $224,14 \pm 165,71$ ) foi significativo apenas no apenas no Grupo Controle. 


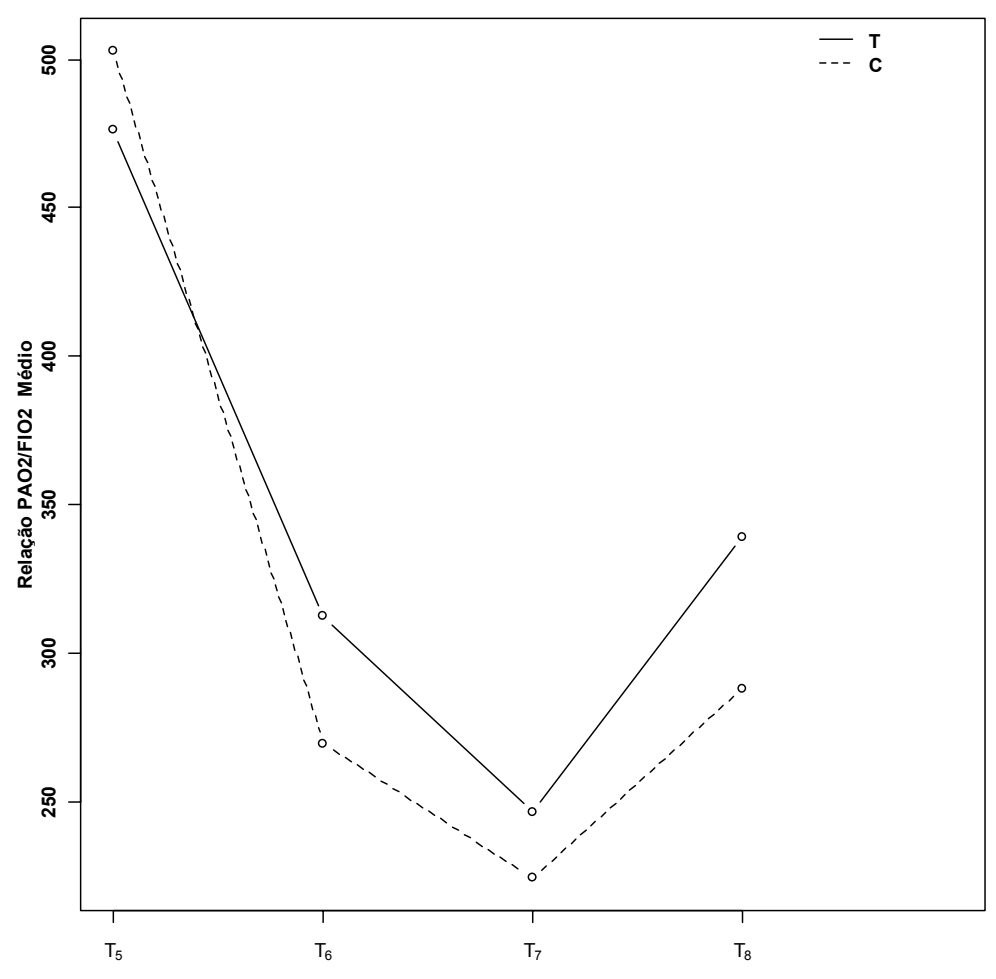

FIGURA 7. Relação $\mathrm{PaO}_{2} / \mathrm{FiO}_{2}$ dos grupos Aprotinina (T) vs Controle (C), nos tempos de T5 a T8. Não houve diferença significativa intergrupos.

\subsection{Perdas sangüíneas nas primeiras $48 \mathrm{~h}$ de pós operatório}

O sangramento nas primeiras $48 \mathrm{~h}$ de $\mathrm{PO}$ foi semelhante em ambos os grupos (17,6 vs 18,1 ml/kg), embora no momento T6 note-se tendência a menor drenagem mediastinal no grupo Aprotinina (Fig.8) (Anexo III). 


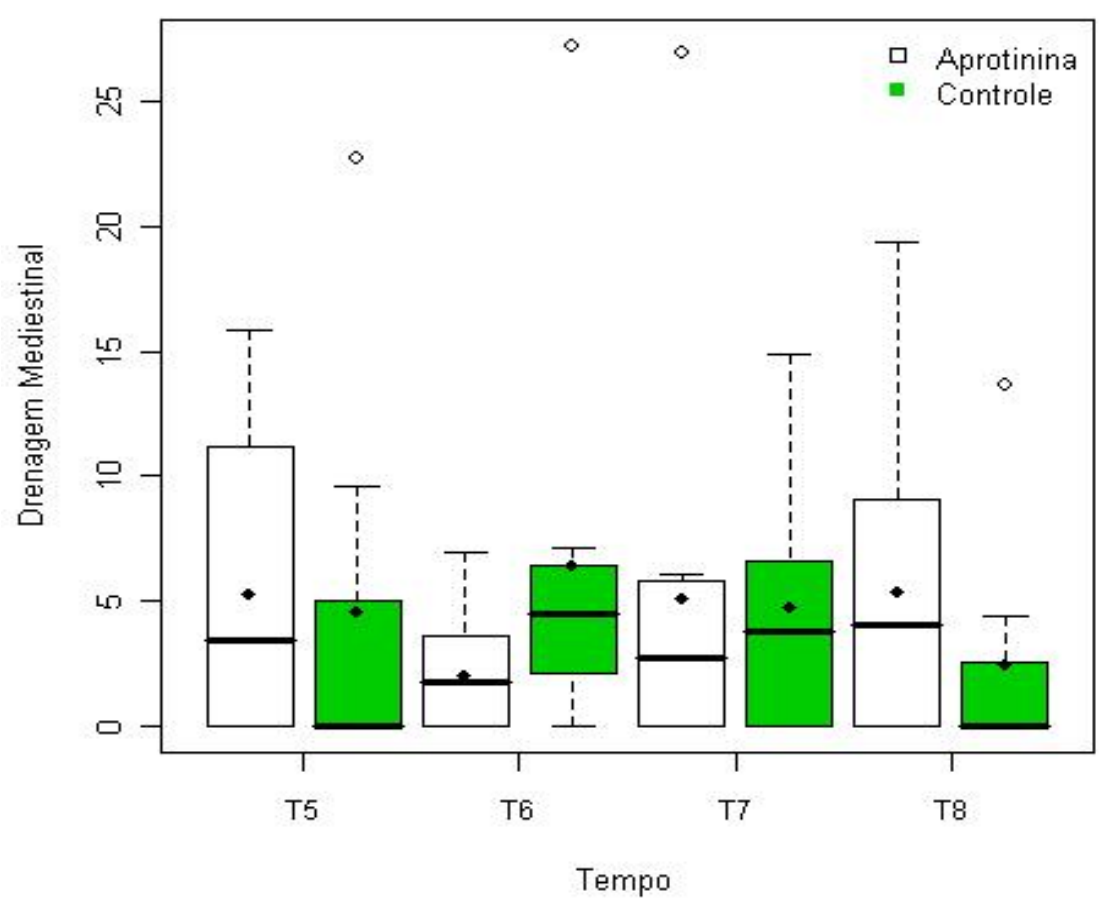

FIGURA 8. Drenagem mediastinal $(\mathrm{ml} / \mathrm{Kg})$ no PO dos grupos Aprotinina e Controle nos tempos de T5 a T8.

\subsection{Utilização de hemoderivados nas 48 horas PO.}

Um paciente do grupo Aprotinina foi transfundido com concentrado de hemácias $(10 \mathrm{ml} / \mathrm{kg})$, em T5. Houve tendência à maior consumo de albumina humana no grupo Aprotinina $(27,58 \pm 30,27$ vs 12,95 \pm 18,58 $\mathrm{ml} / \mathrm{kg}$ ). Concentrado de plaquetas $(12 \mathrm{ml} / \mathrm{kg}$ ) foi utilizado em dois pacientes do grupo Controle, nos tempos T6 e T7, respectivamente (Anexo III).

\subsection{Exposição a doadores de hemoderivados}

O número de doadores de hemoderivados (concentrado de hemácias e de plaquetas e plasma fresco congelado) a que foram expostas 
as crianças dos grupos Aprotinina e Controle foi semelhante, com mediana de 2, no período de internação hospitalar (Anexo III).

\subsection{Diurese e Provas de Função Renal}

\subsubsection{Diurese}

A diurese (Fig. 9), até T5 (4 h após protamina), foi semelhante nos dois grupos $(19,7 \pm 7,8$ vs $22,1 \pm 22,3 \mathrm{ml} / \mathrm{kg})$, seguindo-se de queda discreta em T6 (11,2 $\pm 5,6$ vs 14,7 $\pm 5,6 \mathrm{ml} / \mathrm{kg})$, com aumento significativo subseqüente, em ambos os grupos, em T8 (43,0 \pm 13,8 vs 69,7 $\pm 32,4)$ (Anexo III).

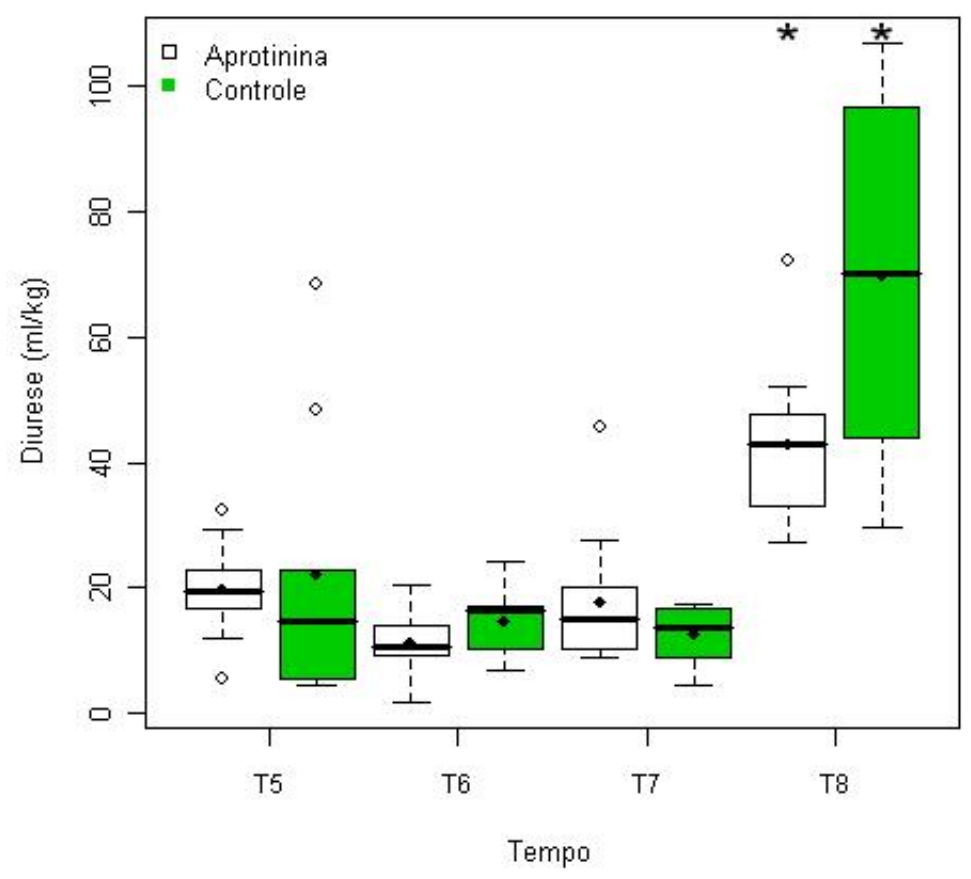

FIGURA 9. Diurese $(\mathrm{ml} / \mathrm{kg})$ dos grupos Aprotinina e Controle nos tempos de T5 a T8. As diferenças intergrupos estatisticamente significativas estão assinaladas. 


\subsubsection{Uremia e concentração plasmática de creatinina}

Em T5, houve grande semelhança intergrupos: Uremia $(18,0 \pm 5,2$ vs $17,4 \pm 6,9 \mathrm{~g} / \mathrm{dl})$ e concentração plasmática de creatinina $(0,3 \pm 0,1$ vs 0,3 $\pm 0,1 \mathrm{mg} / \mathrm{dl})$. Ambas as variáveis aumentaram significativamente de T5 para T8, momento em que a uremia correspondeu a $37,2 \pm 11,5$ vs $28,0 \pm 11,4$ $\mathrm{g} / \mathrm{dl}$, e a concentração plasmática de creatinina, a 0,56 $\pm 0,15$ vs $0,48 \pm 0,22$ $\mathrm{mg} / \mathrm{dl}$. Não houve diferença intergrupos.

\subsubsection{Depuração de creatinina}

Essa variável (Fig 10) manteve-se, praticamente, estável, até as primeiras $24 \mathrm{~h}$ de $\mathrm{PO}$ (Anexo III)

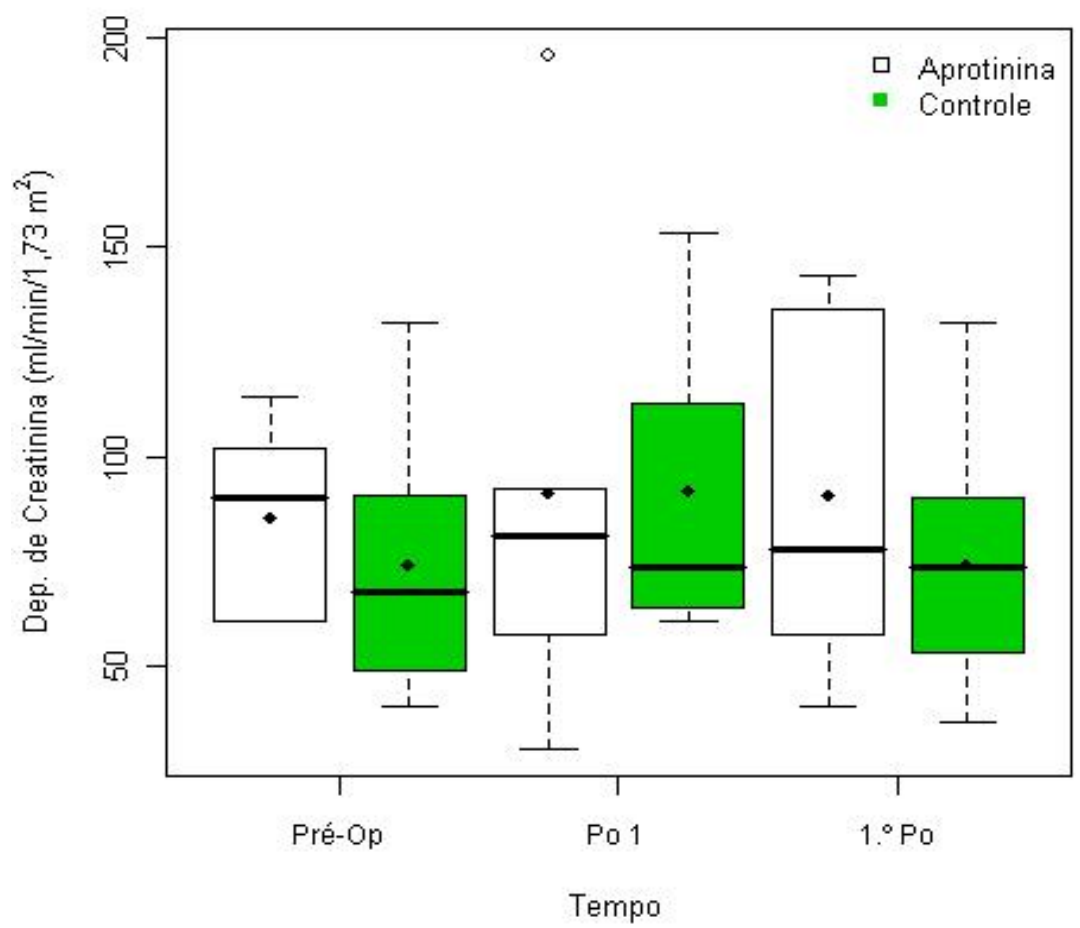

FIGURA 10. Depuração de creatinina dos grupos Aprotinina e Controle, no pré-operatório, no PO imediato (Pol) e no $1^{\circ}$ dia PO (10 $\left.\mathrm{PO}\right)$. Não houve diferenças estatisticamente significantes intergrupos. 
No $2^{\circ}$ dia de PO notou-se queda abaixo de $50 \mathrm{ml} / \mathrm{min} / 1,73 \mathrm{~m}^{2}$, em 3 pacientes do grupo Aprotinina e em 2, do Controle (Anexo III).

\section{15. HEMOGRAMA E ESTUDO BÁSICO DA HEMOSTASIA}

\subsubsection{Taxa de hemoglobina (Hb)}

A taxa de $\mathrm{Hb}$ basal foi discretamente menor no grupo Controle $(9,6$ $\pm 1,1$ vs $8,9 \pm 1,3)$. No grupo Aprotinina, a $\mathrm{Hb}$ teve queda significante de T1 para T2 $(7,6 \pm 1,9$ vs 9,59 $\pm 1,5 \mathrm{~g} / \mathrm{dl})$, sucedida por hemoconcentração progressiva até T5 $(12,1 \pm 1,9$ vs $12,7 \pm 2,9 \mathrm{~g} / \mathrm{dl})$, cujo valor foi estatisticamente maior que T1, em ambos os grupos. Em T2 e T3, a Hb foi significativamente menor, no grupo Aprotinina (Fig. 11).

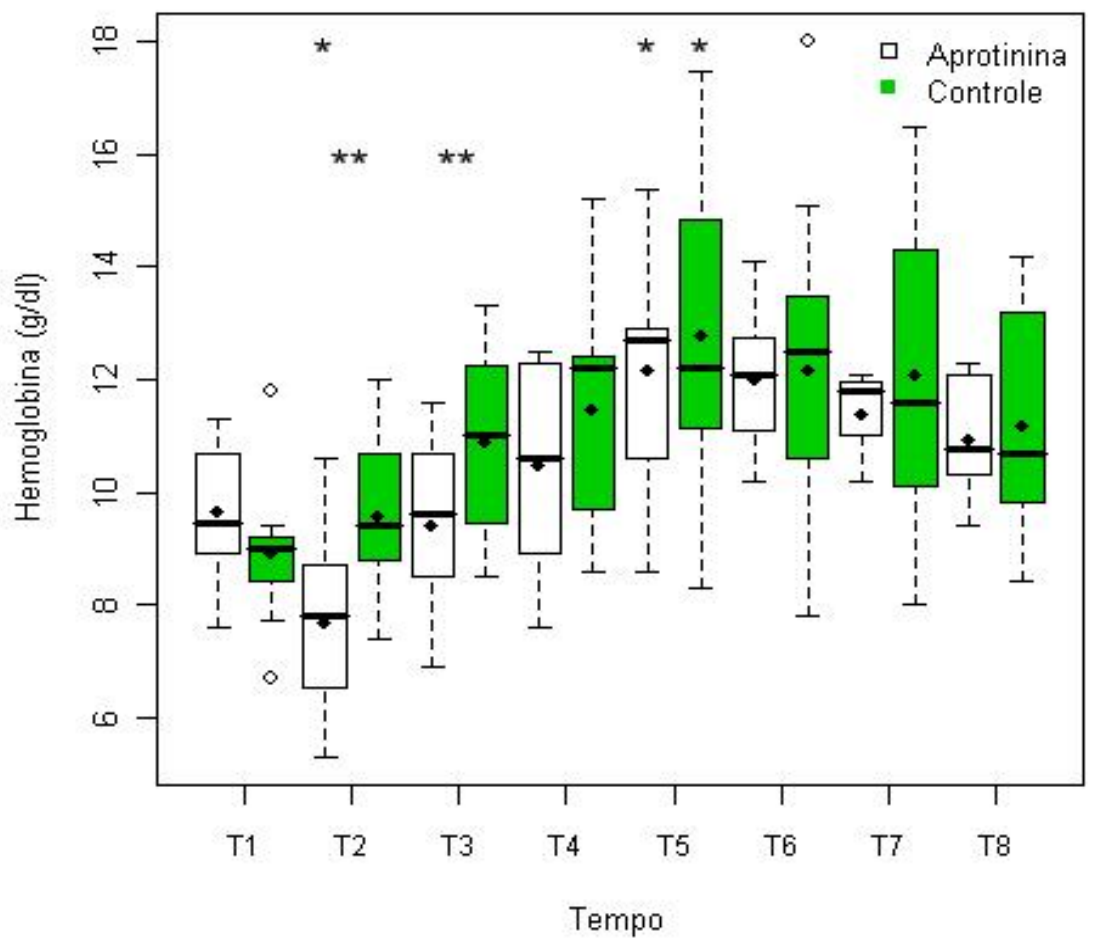

FIGURA 11. Taxa de hemoglobina (g/dl) nos grupos Aprotinina e Controle, nos tempos T1 a T8. As diferenças significativas estão assinaladas. 


\subsubsection{Hematócrito (Hto)}

A taxa de Hto basal foi discretamente menor no grupo Controle $(29,3 \pm 2,8$ vs $27,5 \pm 4,2 \%)$. No grupo Aprotinina, houve queda inicial significativa de T1 para T2 $(23,4 \pm 5,6$ vs $29,5 \pm 3,9 \%)$, seguida de elevação progressiva até T5, cujo valor foi estatisticamente maior que T1, em ambos os grupos $(37,6 \pm 4,9$ vs 40,2 \pm 8,6 \%). Em T2 e T3, o Hto foi significativamente menor, no grupo Aprotinina (Fig 12).

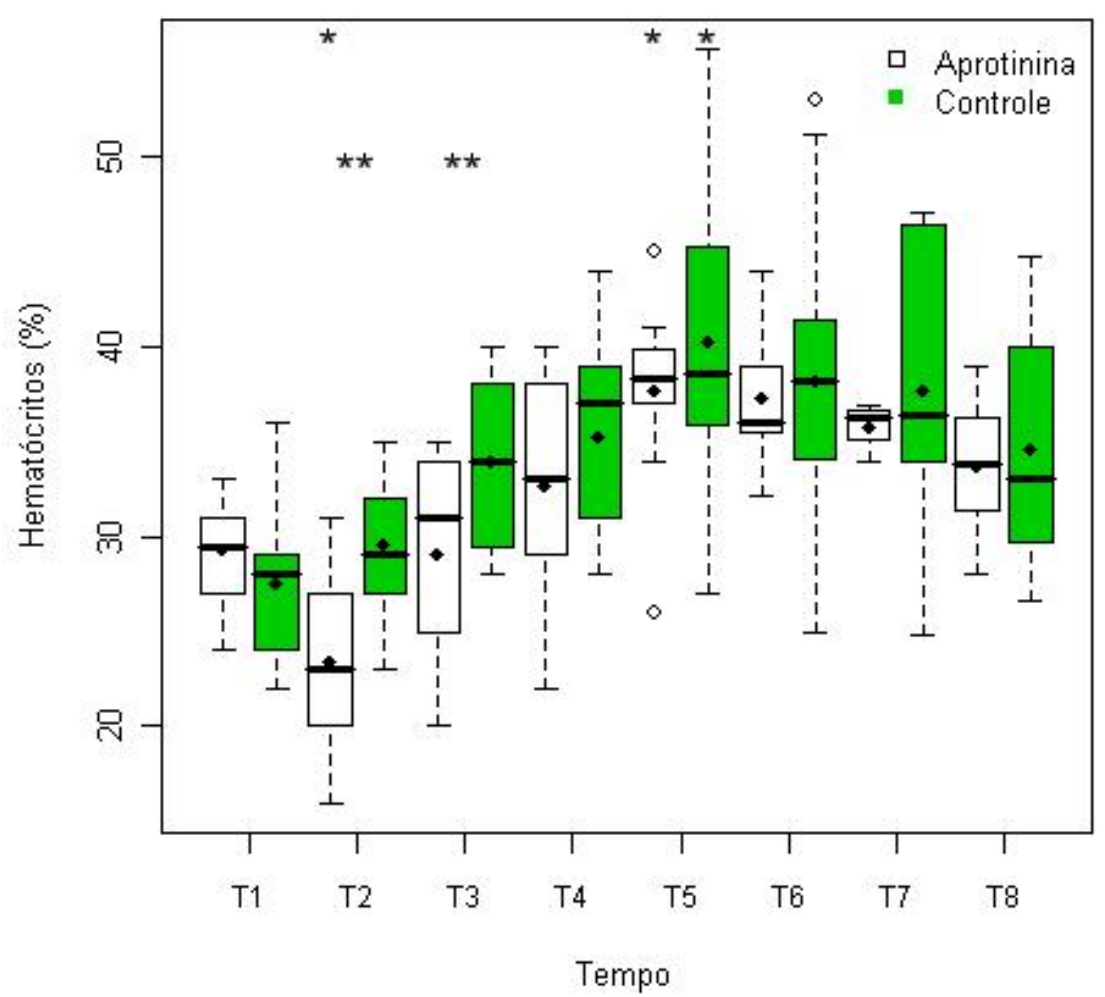

FIGURA 12. Taxa de hematócrito (\%) nos grupos Aprotinina e Controle, nos tempos T1 a T8. As diferenças estatisticamente significantes estão identificadas. 


\subsubsection{Contagem de plaquetas}

A contagem de plaquetas $\left(\mathrm{n}^{\circ} / \mathrm{mm}^{3}\right)$ em T1 foi semelhante nos dois grupos (183500 \pm 86053 vs $250777 \pm 597366)$. Com o início da CEC (T2), houve queda em ambos, com nadir em T4 (106700 \pm 56631 vs $82211 \pm$ 44655), ou seja, cinco min após a administração de protamina. No grupo Controle, essa queda manteve-se estatisticamente significante de T2 a T8, (exceto por T7). De T2 a T5, a contagem de plaquetas foi significativamente maior no grupo Aprotinina (fig 13).

Com 48h de PO (T8), a contagem de plaquetas tendeu à recuperação, apenas no grupo Aprotinina (141333 \pm 31878$)$, enquanto no grupo Controle, permaneceu significativamente menor que em T1.

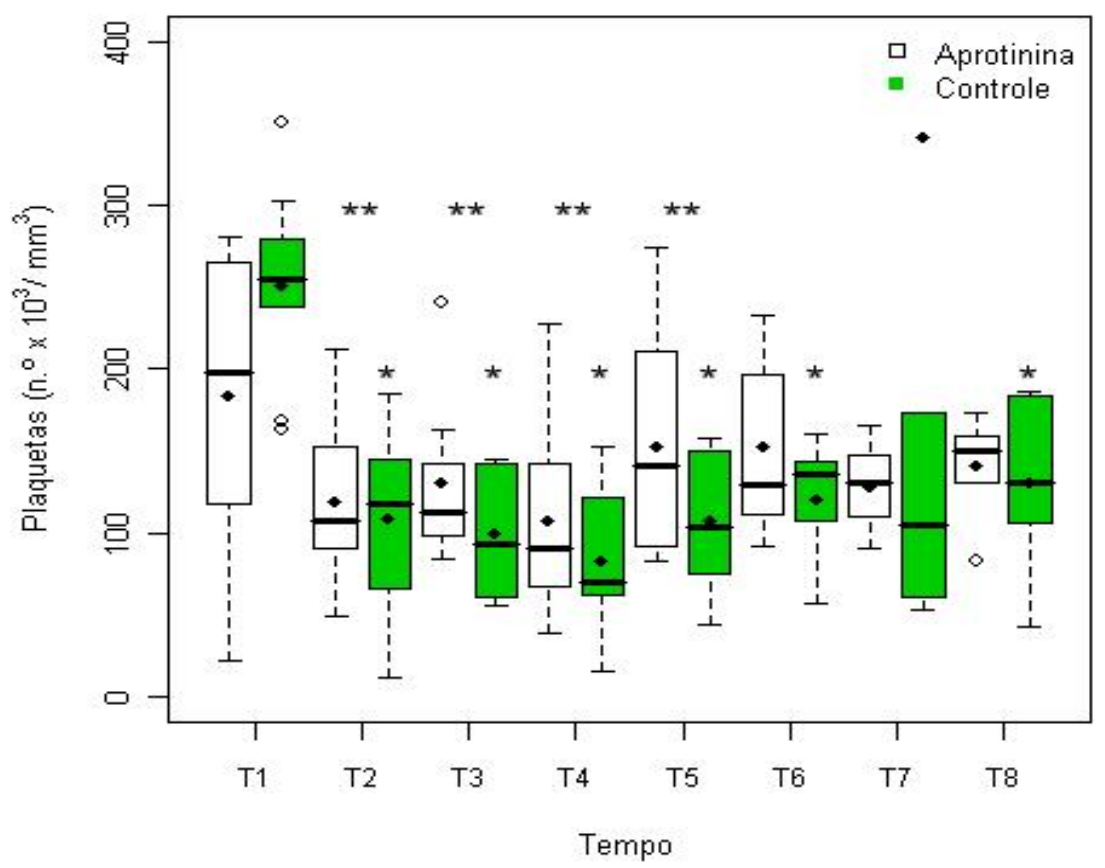

FIGURA 13. Contagem de plaquetas $\left(n^{\circ} \times 10^{3} / \mathrm{mm}^{3}\right)$ nos grupos Aprotinina e Controle. As diferenças intragrupos e intergrupos estatisticamente significativas estão assinaladas. 


\subsubsection{Tempo de tromboplastina parcial ativada (TTPA)}

Houve aumento estatisticamente significativo no Grupo Aprotinina em T5 (4 horas após protaminização) (2,64 versus 1,56). Em ambos os grupos, o TTPA manteve-se discretamente aumentado, em T6 (12 h após a protaminização).

\subsubsection{Tempo de protrombina (TP)}

Houve aumento significativo do INR nos dois grupos, em T5 (4 h após a infusão de protamina) (1,97 vs 1,61), sendo significativa a diferença intergrupos. Em T6 (12 h após protamina), o INR normalizou-se no grupo controle (INR = 1,32), mas manteve-se significativamente elevado no Grupo Aprotinina (INR = 1,74).

\subsubsection{Contagem de leucócitos}

A contagem leucocitária $\left(\mathrm{n}^{\circ}\right.$ células $\left./ \mathrm{mm}^{3}\right)$, semelhante nos dois grupos $(7580 \pm 2948$ vs $6711 \pm 1835)$, em T1, caiu em ambos os grupos com o início da CEC (T2), Esse nadir alcançou significância estatística intragrupo apenas no grupo Aprotinina (3722 \pm 1115 vs $5411 \pm 2599)$. Nesse momento (T2), a diferença intergrupos também foi estatisticamente significativa. Antes da saída de CEC (T3), a contagem de leucócitos tendeu à recuperação, apenas no grupo Controle $(7675 \pm 2961)$, enquanto no grupo Aprotinina, permaneceu pouco abaixo de T1 (6422 + 3574) (Fig 14).

Após a CEC, a leucocitose foi significativa de T4 a T8 nos dois grupos, com pico em T7 (15866 £ 8991 vs $16680+4646,72)$. Não houve diferença significativa intergrupos de T3 a T8. 


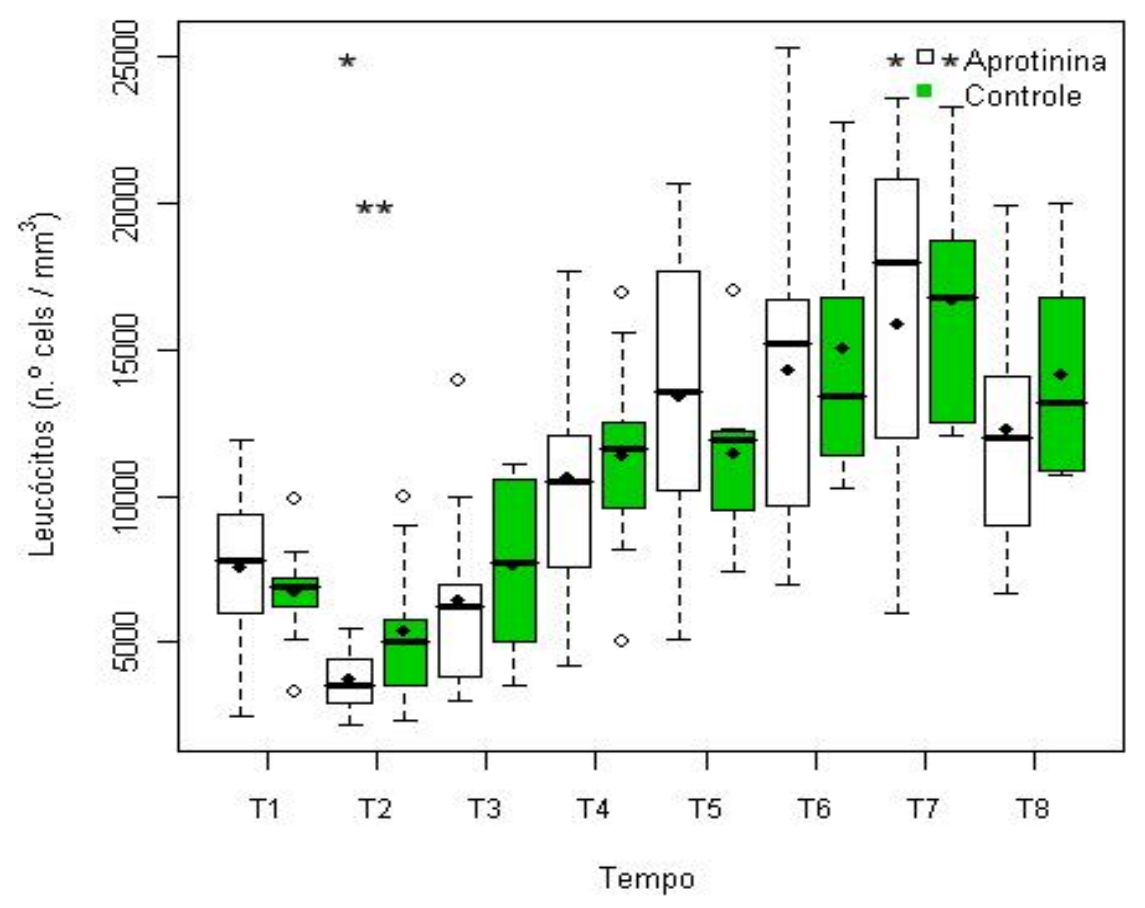

FIGURA 14. Contagem de leucócitos $\left(\mathrm{n}^{\circ} / \mathrm{mm}^{3}\right)$ nos grupos Aprotinina e Controle, nos tempos T1 a T8. As diferenças intragrupos e intergrupos estatisticamente significativas estão assinaladas.

\section{MARCADORES DA RESPOSTA INFLAMATÓRIA SISTÊMICA}

\subsection{Concentração sérica do Fator de Necrose Tumoral - alfa} (TNF- $\alpha)$

O TNF- $\alpha$ basal foi detectável e semelhante nos dois grupos $(13,18 \pm$ 12,28 , mediana $=9,0$ vs $6,81 \pm 5,40$, mediana $=3,98 \mathrm{pg} / \mathrm{ml}$ ) e seguiu-se de dois picos de elevação no decorrer do estudo (fig.15). Com o início da CEC (T2), ocorreu elevação em ambos os grupos $(39,83 \pm 78,43$, mediana $=8,67$ vs 19,35 $\pm 15,82$, mediana $=13,05)$, embora significativa, intragrupo, apenas no grupo controle. Houve outro pico, em T4, no Grupo Aprotinina $(34,49 \pm$ 
54,67 mediana $=17,80)$ e um, mais discreto, em T5, no Grupo Controle $(12,21 \pm 17,60$, mediana $=9,60)$, seguido de queda em T7 e T8. Não houve diferença intergrupos de T2 a T8. (Anexo 3)

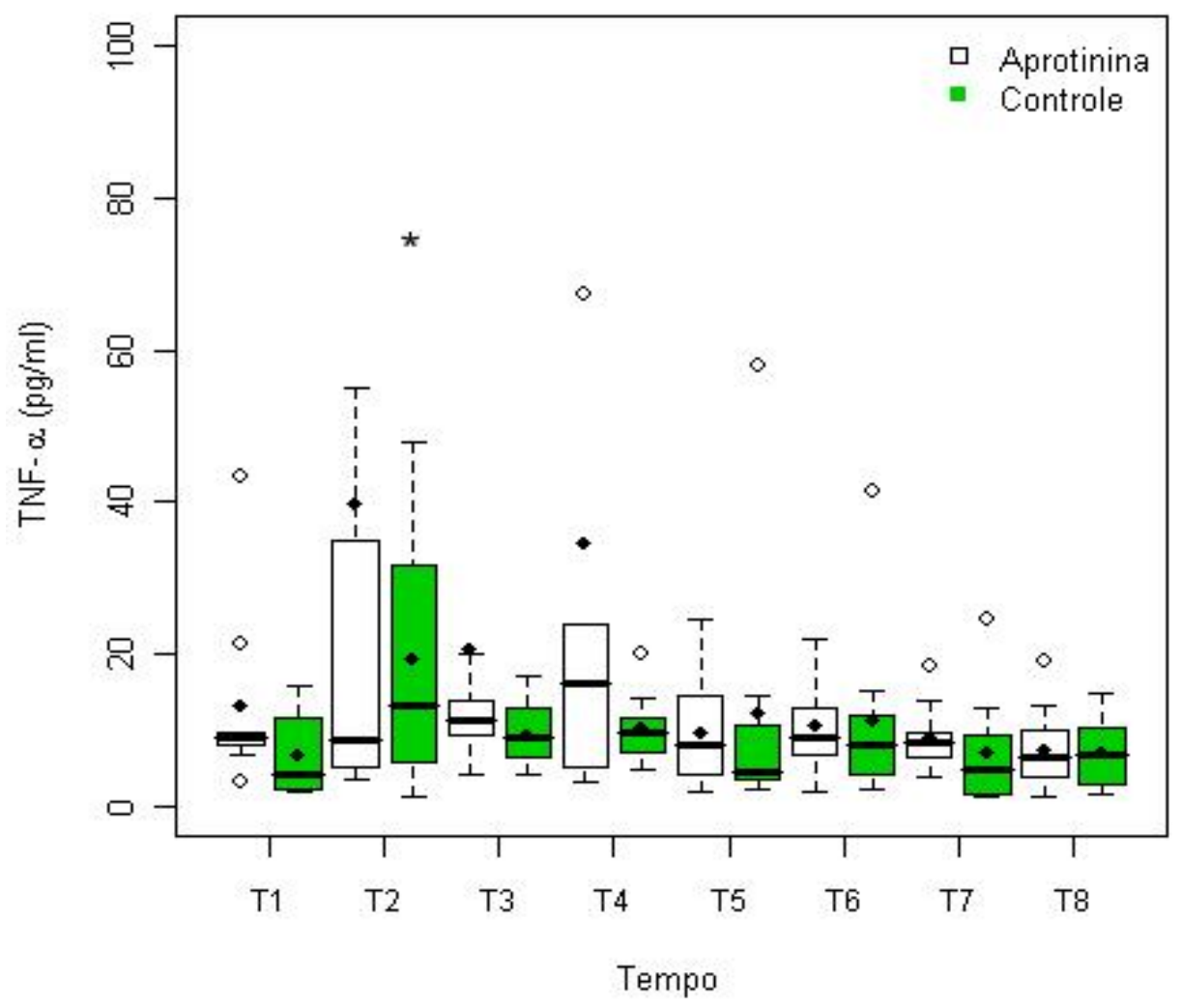

FIGURA 15. Perfil sérico bifásico da concentração sérica do Fator de Necrose Tumoral alfa (TNF- $\alpha$ ) em $\mathrm{pg} / \mathrm{ml}$ nos grupos Aprotinina e Controle, nos tempos de T1 a T8. As diferenças estatisticamente significativas intragrupo estão apontadas

\subsection{Concentração sérica de interleucina 6 (IL-6)}

Os níveis basais dos dois grupos (fig 16) foram supranormais e semelhantes $(160,34 \pm 217,46$, mediana $=93,97$ vs 40,54 $\pm 42,94 \mathrm{pg} / \mathrm{ml}$, mediana $=26,87 \mathrm{pg} / \mathrm{ml}$ ), com comportamento ulterior bifásico. 
No Grupo Aprotinina houve uma primeira elevação, significativa, com o início da CEC (T2) $(249,83 \pm 226,74$, mediana $=234,24 \mathrm{pg} / \mathrm{ml})$, e outra de T4 $(374,00 \pm 186,78 \mathrm{pg} / \mathrm{ml}$, mediana $=456,29 \mathrm{pg} / \mathrm{ml})$ a $\mathrm{T} 5$, ao passo que, no Grupo Controle, a IL-6 elevou-se, significativamente, a partir de T3, com um primeiro pico em T4 $(315,88 \pm 313,09$, mediana $=190,17)$ e outro, emT6 $(329,40 \pm 236,26 \mathrm{pg} / \mathrm{ml}$, mediana $=340,25 \mathrm{pg} / \mathrm{ml})$.

O aumento da IL-6 persistiu até T7 em ambos os grupos. Em T8, no Grupo Controle, houve redução para valor $(189,67 \pm 170,37$ pg/ml, mediana $=173,59 \mathrm{pg} / \mathrm{ml}$ ) ainda significativamente maior que o basal. No grupo Aprotinina, ocorreu redução mais acentuada em T8, com nível muito semelhante ao basal $(164,44 \pm 178,43 \mathrm{pg} / \mathrm{ml}$, mediana $=82,52 \mathrm{pg} / \mathrm{ml})$.

Não houve diferença intergrupos de T2 a T8. (Anexo 3)

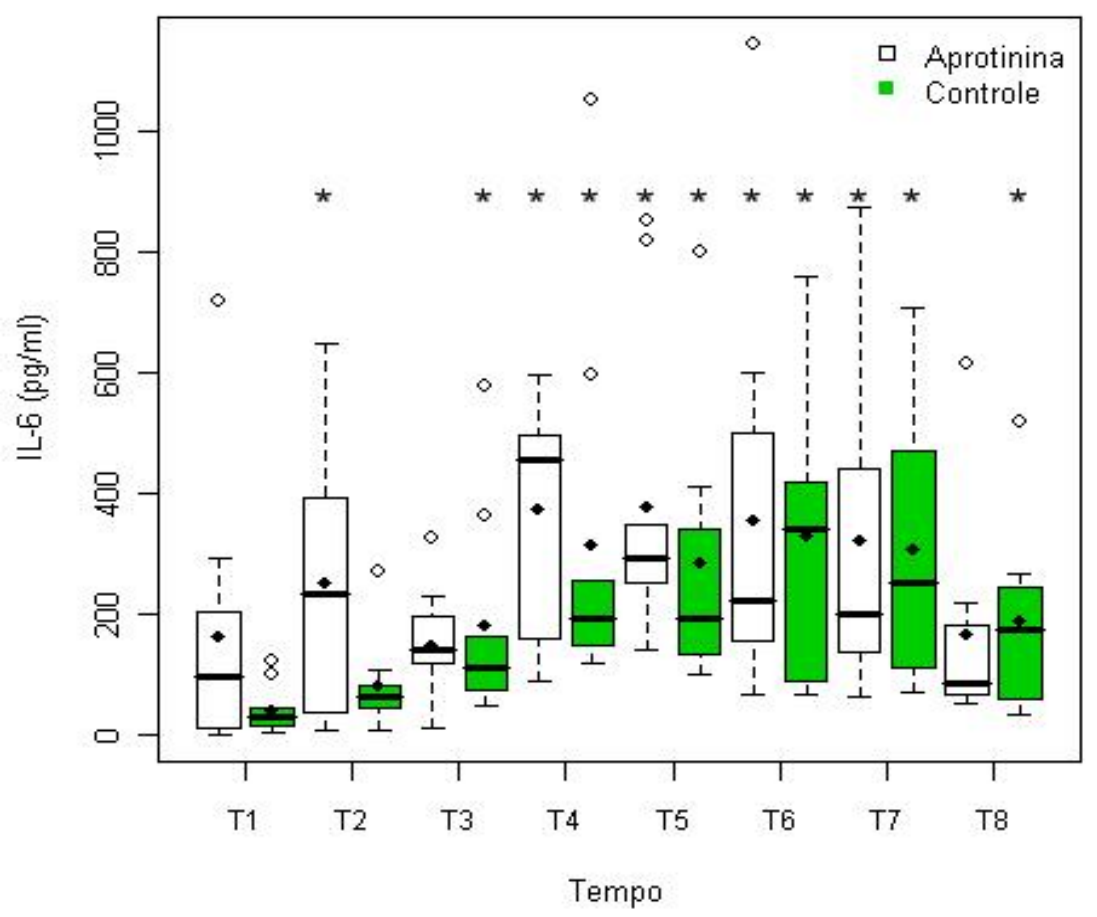

FIGURA 16. Níveis séricos de IL-6 (pg/ml) nos grupos Aprotinina e Controle, nos tempos T1 a T8. As diferenças intragrupos, estatisticamente significativas, estão expostas. 


\subsection{Concentração sérica de interleucina 8 (IL-8)}

Os níveis séricos de $\mathrm{IL}-8(\mathrm{pg} / \mathrm{ml})$ foram semelhantes nos dois grupos $(10,27 \pm 4,16$, mediana $=9,24$ vs 13,38 \pm 8,53, mediana = 10,26) .

Os níveis significativamente elevaram-se desde T2 a T8 nos dois grupos, em relação à T1, alcançando pico 5 minutos após a protamina (T4) $(281,50+275,21$, mediana $=170,63$ vs $165,62+84,32$, mediana $=141,61)$. Os níveis diminuíram de 4 até 48 horas após protamina (T8), permanecendo ainda maiores que T1 $(70,05 \pm 88,87$, mediana $=50,82$ vs $37,22 \pm 30,72$ mediana $=17,91)($ fig 17$)$.

Não houve diferença intergrupos de T2 a T8. (Anexo 3)

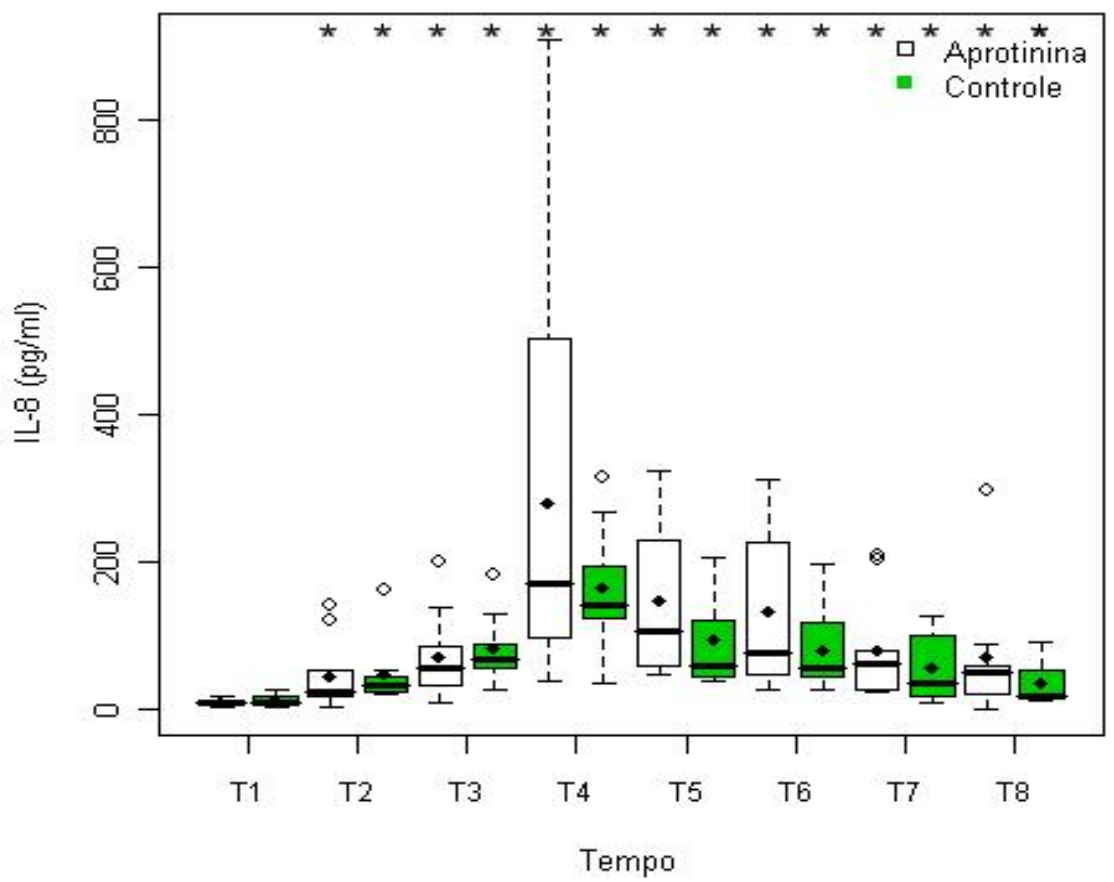

FIGURA 17. Níveis séricos de IL-8 (pg/ml) nos grupos Aprotinina e Controle, nos tempos T1 a T8. As diferenças estatisticamente significativas intra-grupo estão indicadas. 


\subsection{Concentração sérica de interleucina 10 (IL-10)}

Os níveis séricos basais de IL-10 (fig.18) foram também supranormais e semelhantes nos dois grupos $(19,42 \pm 18,17$, mediana $=$ 11,17 vs $10,77 \pm 10,43$, mediana $=7,71 \mathrm{pg} / \mathrm{ml}$ ) e elevaram-se, ainda mais, de T2 a T7 com pico em T4 $(266,30 \pm 250,17$, mediana $=233,97$ vs 449,72 \pm 659,08, mediana $=214,33)$. Embora regredissem em T8 $(22,15 \pm 14,36$, mediana $=17,46$ vs $20,43 \pm 11,66 \mathrm{pg} / \mathrm{ml}$, mediana $=17,42 \mathrm{pg} / \mathrm{ml}$ ), no grupo Controle, a IL-10 continuou significativamente maior que a basal.

Não houve diferença intergrupos de T2 a T8, exceto em T3 (antes da saída da CEC), quando a IL-10 do grupo controle foi maior $(69,04 \pm$ 68,14 , mediana $=56,20$ vs $156,48 \pm 262,12 \mathrm{pg} / \mathrm{ml}$, mediana $=78,09 \mathrm{pg} / \mathrm{ml}$ ). (Anexo 3)

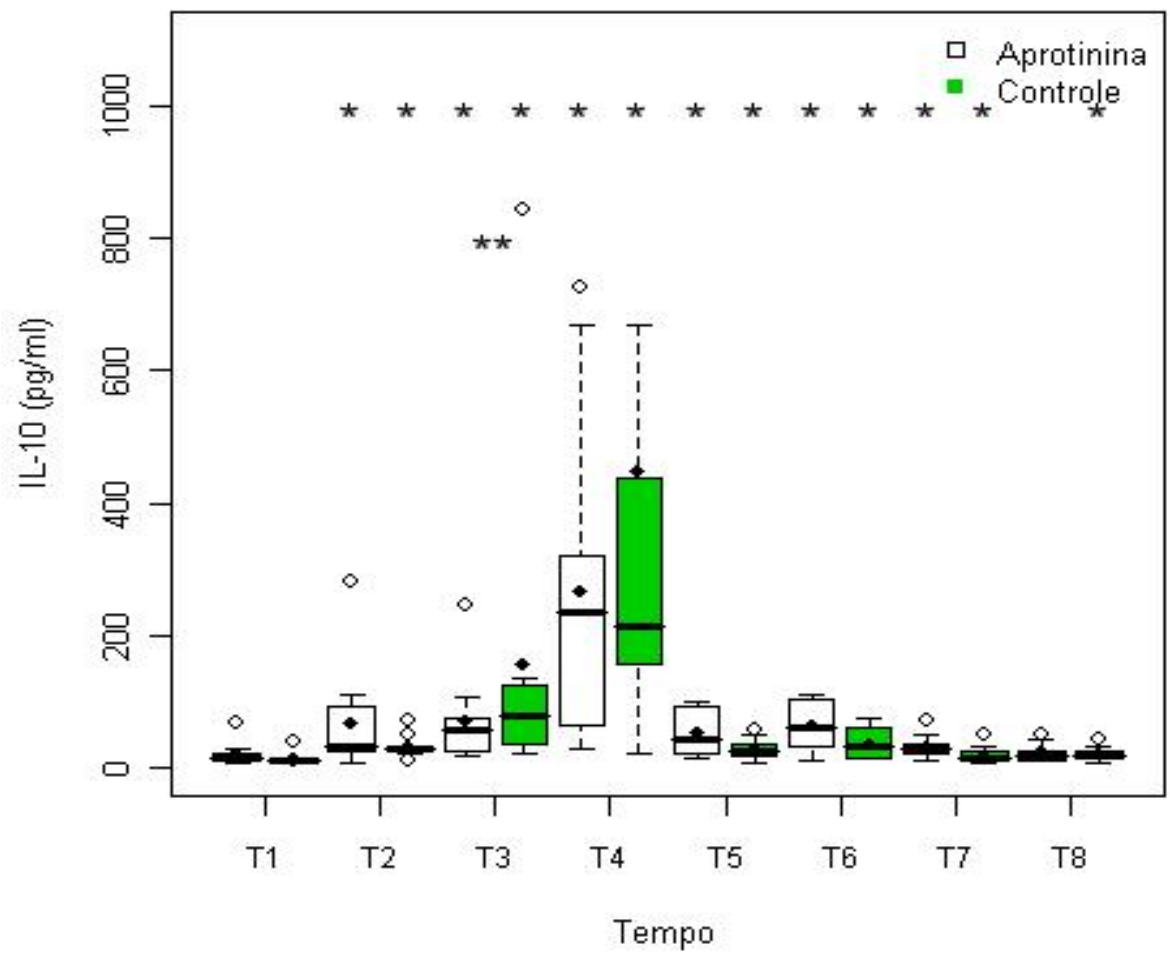

FIGURA 18. Níveis séricos de $\mathrm{lL}-10(\mathrm{pg} / \mathrm{ml})$ nos grupos Aprotinina e Controle, nos tempos T1 a T8. As diferenças estatisticamente significativas, intra e intergrupos estão indicadas. 


\subsection{Proporção IL - 6 / IL - 10}

A proporção IL-6/IL-10 (fig 19) foi maior no grupo Aprotinina (19,14 $31,98$, mediana $=10,55$ vs 5,72 $\pm 7,59$, mediana $=2,36)$, em T1. Nesse grupo, a CEC induziu queda acentuada, com posterior tendência à recuperação, expressa por dois picos, um em T5 e outro, maior, em T7 $(13,77 \pm 14,08$, mediana $=6,88)$, sem, no entanto, atingir o valor constatado em T1., permanecendo abaixo da basal em T8 $(12,10 \pm 11,43$, mediana $=$ $5,28)$.

No grupo Controle, a proporção variou menos, com a CEC, mas também teve aumento bifásico, em T5 $(14,07 \pm 14,97$, mediana $=10,35)$ e T7 $(20,58 \pm 16,74$, mediana $=15,70)$. Nesse grupo, ambos os picos foram significativamente maiores que T1, permanecendo com tendência acima da basal em T8 $(10,59 \pm 14,07$, mediana $=6,40)$.

Não houve diferença intergrupos. (Anexo 3)

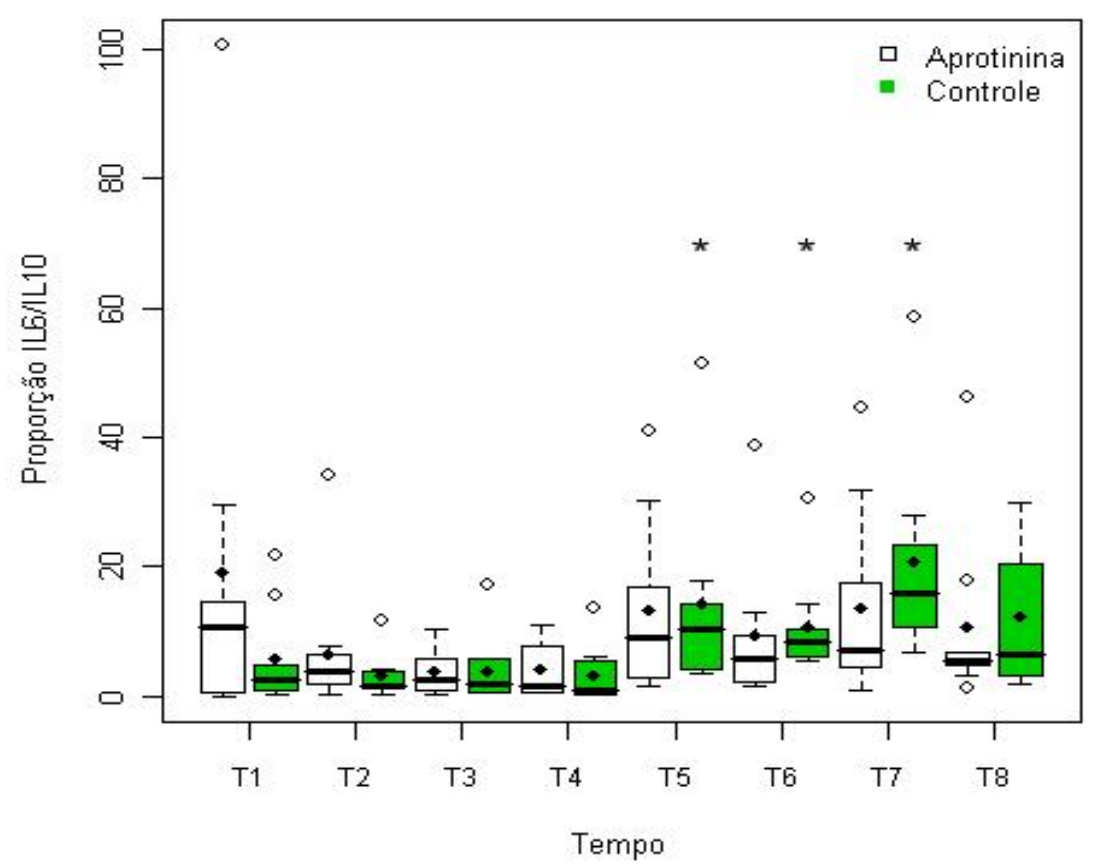

FIGURA 19. Proporção IL-6/IL10 nos grupos Aprotinina e Controle, nos tempos T1 a T8. As diferenças estatisticamente significativas intra-grupo estão assinaladas. 


\section{MARCADORES DE LESÃO E FUNÇÃO MIOCÁRDICA}

\subsection{Concentração sérica de troponina-I cardíaca (cTnl)}

Os níveis séricos basais de cTnl (fig 20) foram semelhantes nos dois grupos $(0,20 \mathrm{ng} / \mathrm{ml})$ e aumentaram, acentuadamente, com a CEC, nos dois grupos. No grupo Aprotinina, o padrão de elevação foi bifásico, com picos em T4 $(19,04 \pm 27,93$, mediana $=6,2)$ e em T6 $(18,29 \pm 17,32$, mediana $=10,05)$, enquanto no grupo Controle, notou-se somente um pico, em T5 $(18,82 \pm 8,43$, mediana $=15,2)$. Nos dois grupos, os valores pico foram significativamente maiores que os basais. Observou-se nítida tendência à queda de cTnl, nos dois grupos, em T7 e T8 $(9,06 \pm 8,45$, mediana $=5,7$ vs $5,05 \pm 4,40$, mediana $=3,6$ ), embora continuasse acima dos níveis basais. Não houve diferença intergrupos de T2 a T8. (Anexo 3 )

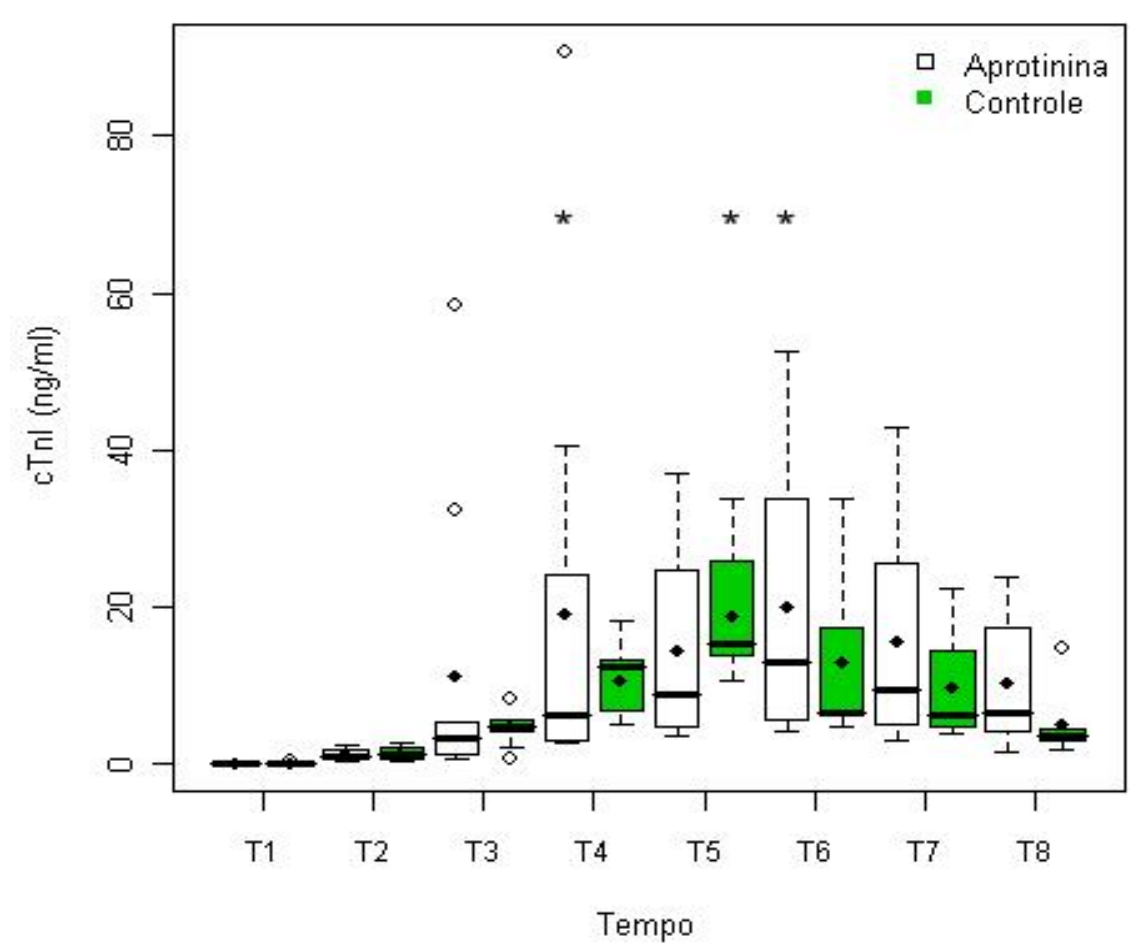

FIGURA 20. Troponina I cardíaca (cTnl) ( $\mathrm{ng} / \mathrm{ml}$ ), nos grupos Aprotinina e Controle. As diferenças intragrupo estatisticamente significativas estão assinaladas. 


\subsection{Concentração sérica de CK-MB}

A concentração sérica de CK-MB foi semelhante nos dois grupos, 4 $(100,01 \pm 51,10$ vs $94,34 \pm 44,72 \mathrm{U} / \mathrm{l})$ e $12 \mathrm{~h}(69,97 \pm 14,94 \mathrm{U} / \mathrm{l}$ vs $62,51 \pm$ $30,93)$ após administração da protamina.

\subsection{Nt-proBNP}

Os níveis séricos de Nt-proBNP (fmol/l) (fig 21) apresentaram-se supranormais e semelhantes nos dois grupos $(403,64 \pm 401,1$, mediana $=$ $304,22$ vs $380,79 \pm 324,84$, mediana $=409,99)$, com $45 \%$ das crianças apresentando valores acima de $400 \mathrm{fmol} / \mathrm{ml}$. Os dois grupos tiveram comportamento quase superponível, com aumento progressivo de T4 a T6 $(1282,23 \pm 888,01$, mediana $=971,47$ vs 1245,78 $\pm 1118,67$, mediana $=$ 804,88), quando atingiu significância estatística. Embora tenha ocorrida queda progressiva, a partir de T6, os valores, em T8 $(876,42 \pm 427,43$, mediana $=717,31$ vs $885,87+963,82$, mediana $=675,69$ ), ainda estavam muito superiores aos níveis basais. Não houve diferença intergrupos de T2 a T8. (Anexo 3)

Mesmo excluindo o caso 45 (grupo Aprotinina) da análise, porque seus valores basais $(1484,50 \mathrm{fmol} / \mathrm{ml})$ e picos em T4 $(14596 \mathrm{fmol} / \mathrm{ml})$ e em T6 $(3273,30 \mathrm{fmol} / \mathrm{ml})$ foram discrepantes, muito superiores aos dos demais pacientes, retornando próximo ao basal em T8 $(1529,10 \mathrm{fmol} / \mathrm{ml})$, não houve diferenças significativas intergrupos, exceto em T2, quando os níveis de NtproBNP foram menores no grupo Aprotinina (Fig. 22). 


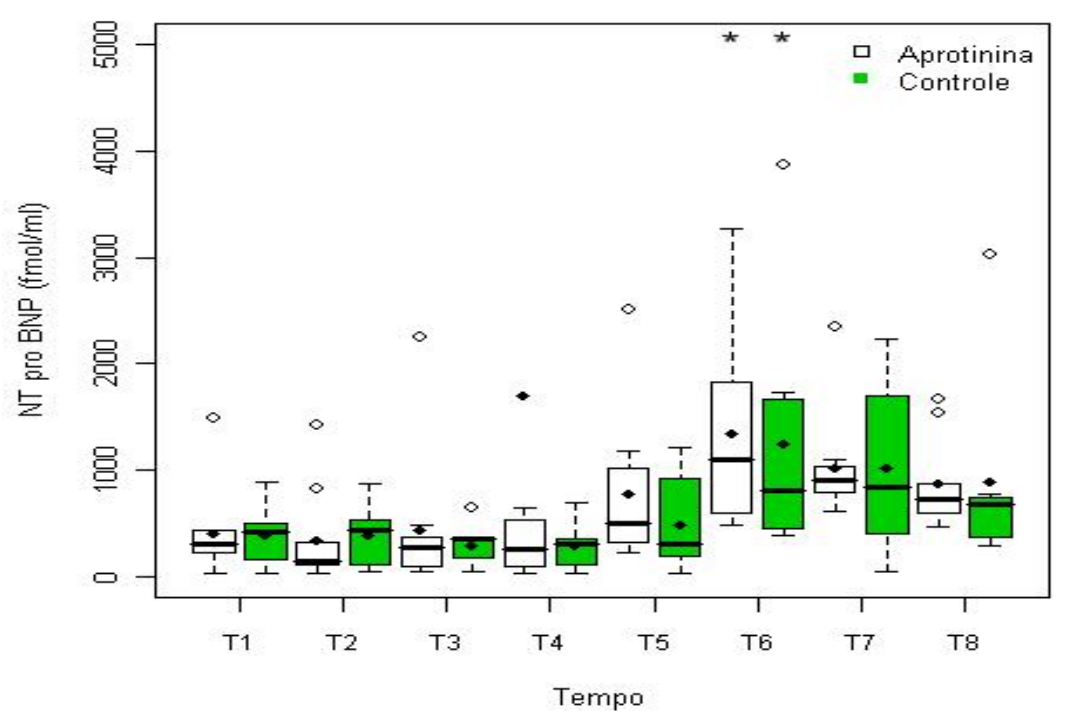

FIGURA 21. Níveis de NT-proBNP (fmol/ml) nos grupos Aprotinina e Controle, nos tempos T1 a T8. As diferenças intra-grupo estatisticamente significativas estão assinaladas.

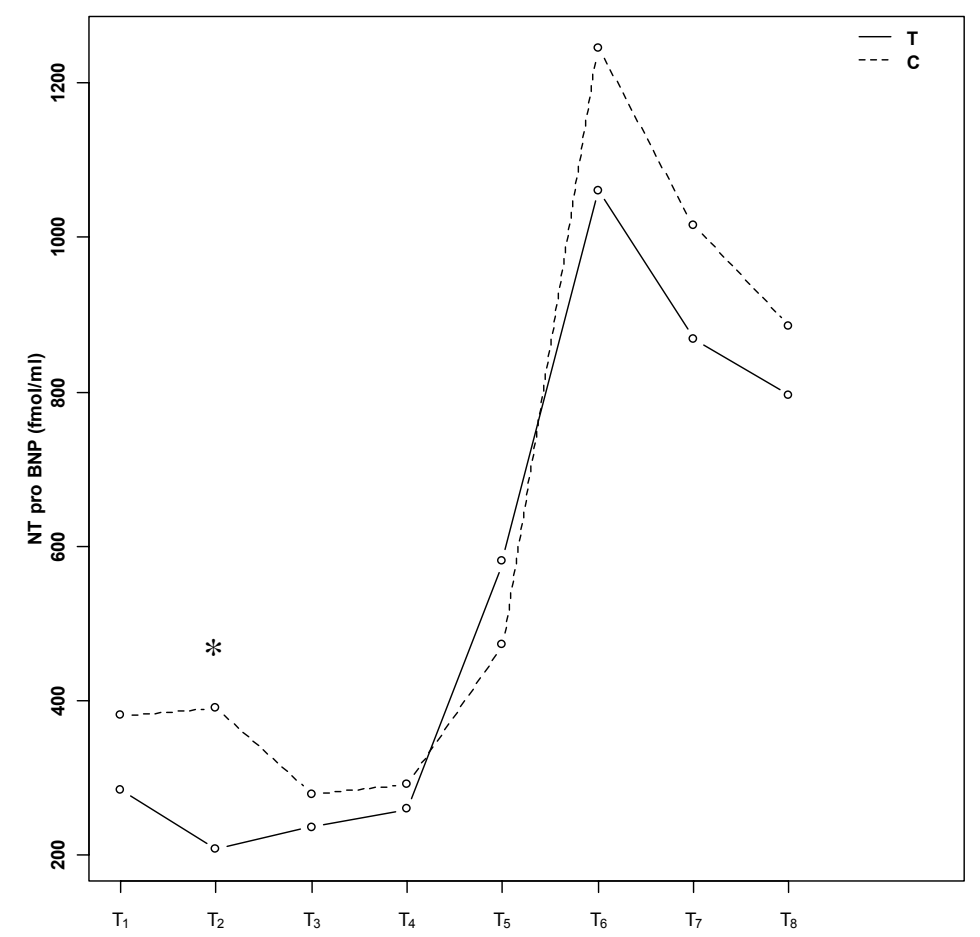

FIGURA 22. Níveis séricos médios de NT-proBNP (fmol/ml) nos grupos Aprotinina (T) vs grupo Controle (C), excluindo o caso 45. Houve diferença estatisticamente significativa intergrupos no tempo T2. 


\section{FUNÇÃO HEPÁTICA}

A dosagem da enzima transaminase glutâmico oxalacética (TGO) foi semelhante nos dois grupos, $4 \mathrm{~h}(106,18 \pm 41,96$ vs 92,37 \pm 44,72) e $12 \mathrm{~h}$ $(107,00 \pm 54,78$ vs $98,42 \pm 37,49)$ após administração da protamina.

\section{LACTATO SÉRICO E EQUILÍBRIO ÁCIDO-BÁSICO}

\subsection{Lactato sérico arterial}

Os níveis basais foram semelhantes nos dois grupos $(0,98 \pm 0,24$ vs $1,35 \pm 0,51 \mathrm{mmol} / \mathrm{l})$ e seguiram-se, em ambos, de acentuada elevação , com o início da CEC (T2) $((3,67 \pm 2,00$ vs 3,11 $\pm 2,83 \mathrm{mmol} / \mathrm{l})$. Nos dois grupos, houve um segundo pico 5 min após administração da protamina (T4) (3,67 \pm $2,00$ vs $2,89 \pm 1,45)$. No PO, a lactatemia diminiu nos dois grupos até normalizar-se em 48 horas (Fig 23).

A hiperlactatemia foi estatisticamente significativa de T2 a T8 no grupo Aprotinina, e de T2 até T5 no Grupo Controle. Houve diferença intergrupos estatisticamente significativa nos tempos T3, T4 e T6.

Acidose láctica (acidose metabólica com lactato do sangue arterial $\geq 45 \mathrm{mg} / \mathrm{dl}(5 \mathrm{mmol} / \mathrm{l})$ e $\mathrm{pH}$ arterial < 7,357) (KOLISKI, 2005), transitória, verificou-se em 2 pacientes (casos 25 e 35) do grupo Aprotinina, em T4 e T5, respectivamente, e em 1 paciente do grupo Controle (caso 34), em T2 e T4. 


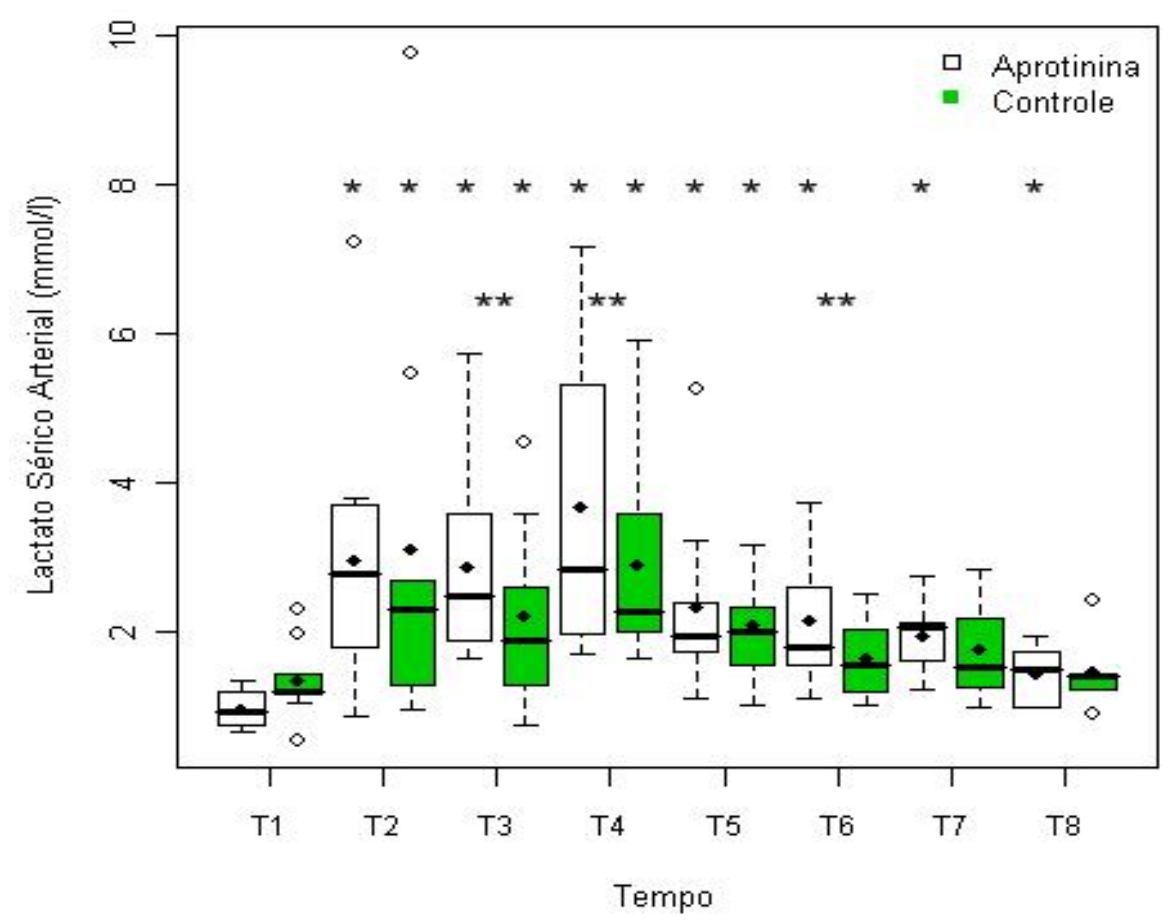

FIGURA 23. Lactatemia ( $\mathrm{mmol} / \mathrm{l})$ nos grupos Aprotinina e Controle, nos tempos T1 a T8. As diferenças significativas intra e intergrupos estão assinaladas.

\section{2. $\mathrm{pH}$ arterial}

A medida do $\mathrm{pH}$ do sangue arterial foi significativamente menor no grupo Aprotinina $(7,31$ vs 7,43$)$ após indução anestésica (T1), em virtude de acidose respiratória em $50 \%$ de seus pacientes.

Com o início da CEC (T2), o pH mostrou-se normal nos dois grupos $(7,40$ vs 7,44$)$, até o final do estudo (T8), com diferenças intergrupos em T4 (Fig 24).

Em relação aos níveis basais, o aumento do $\mathrm{pH}$ foi com tendência altamente significativa em T2 e T3 no grupo Aprotinina. 


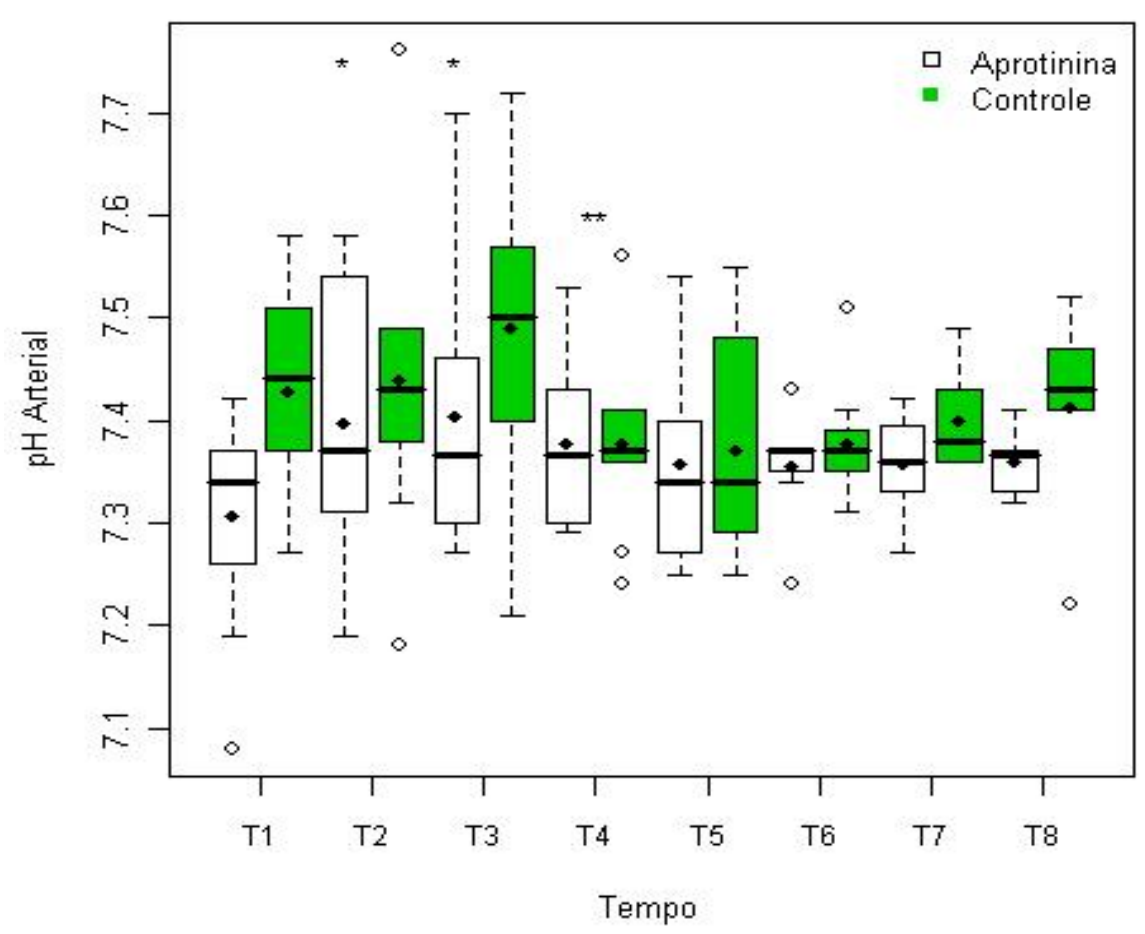

FIGURA 24. Medidas do pH nos grupos Aprotinina e Controle, nos tempos T1 a T8. As diferenças significativas intra e intergrupos estão assinaladas.

\section{3. $\mathrm{PaCO}_{2}$}

A $\mathrm{PaCO}_{2}$ (fig 25) cursou maior e supranormal no grupo Aprotinina $(48,03 \pm 15,95$ vs $38,12 \pm 5,45 \mathrm{mmHg})$ após indução anestésica (T1), embora sem diferença significativa intergrupos. No grupo Aprotinina, 50\% dos pacientes (casos 7, 13, 37, 40 e 45) apresentaram acidose respiratória em T1 $(\mathrm{pH}=7,23 \pm 0,10$ e $\mathrm{pCO} 2=58,7 \pm 16 \mathrm{mmHg})$, o que não ocorreu no grupo Controle. Durante a $\mathrm{CEC}$, a $\mathrm{PaCO}_{2}$ foi normal nos dois grupos, seguindo-se de significativa queda no grupo Aprotinina, 4 e $12 \mathrm{~h}$ após a protaminização (T5 e T6) (33,48 \pm 9,17 e 34,60 \pm 7,18 mmHg, respectivamente). A diferença inter-grupos, em T5, foi estatisticamente significante. 
Observou-se, em T5, alcalose respiratória em 6 pacientes (casos 1, 7, 13, 25, 40 e 45) do grupo Aprotinina e acidose respiratória em 2 pacientes (casos 10 e 49) do grupo Controle.

Em T5 e T6, 70\% dos pacientes do grupo aprotinina, e 66,6\% e $55,5 \%$, respectivamente, dos pacientes do controle, estavam em ventilação pulmonar mecânica.

$\mathrm{A} \mathrm{PaCO}$ foi normal nos dois grupos em 24 e 48 horas $\mathrm{PO}$.

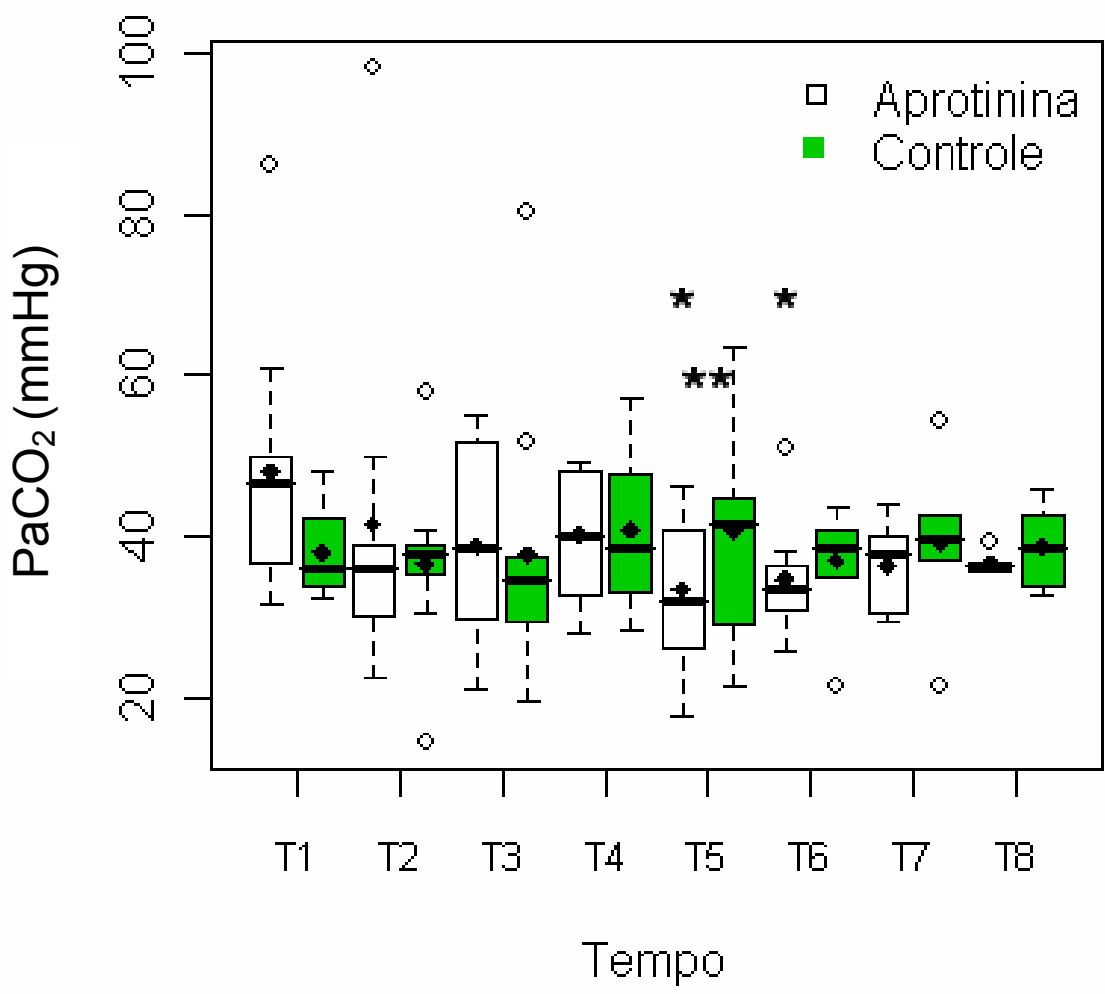

FIGURA 25. $\mathrm{PaCO}_{2}(\mathrm{mmHg})$ nos grupos Aprotinina e Controle, nos tempos T1 a T8. As diferenças significativas intra e intergrupos estão assinaladas.

\subsection{Concentração arterial de bicarbonato}

A concentração arterial basal de bicarbonato foi semelhante nos dois grupos (23 vs 25,36 mmol/l). Do início da CEC até $5 \mathrm{~min}$ após a administração da protamina, os valores permaneceram normais, nos dois 
grupos. No entanto, no grupo Aprotinina, houve queda significativa de T5 a T7, com nadir em T6 $(18,94 \pm 2,02 \mathrm{mmol} / \mathrm{l})$, enquanto no grupo Controle, o nadir também ocorreu significativamente em T6 (21,42 \pm 3,22 mmol/l).

Acidose metabólica ocorreu em T6 nos dois grupos, principalmente no grupo Aprotinina (6 vs 2 pacientes).

Entretanto, não houve diferença estatística intergrupos.

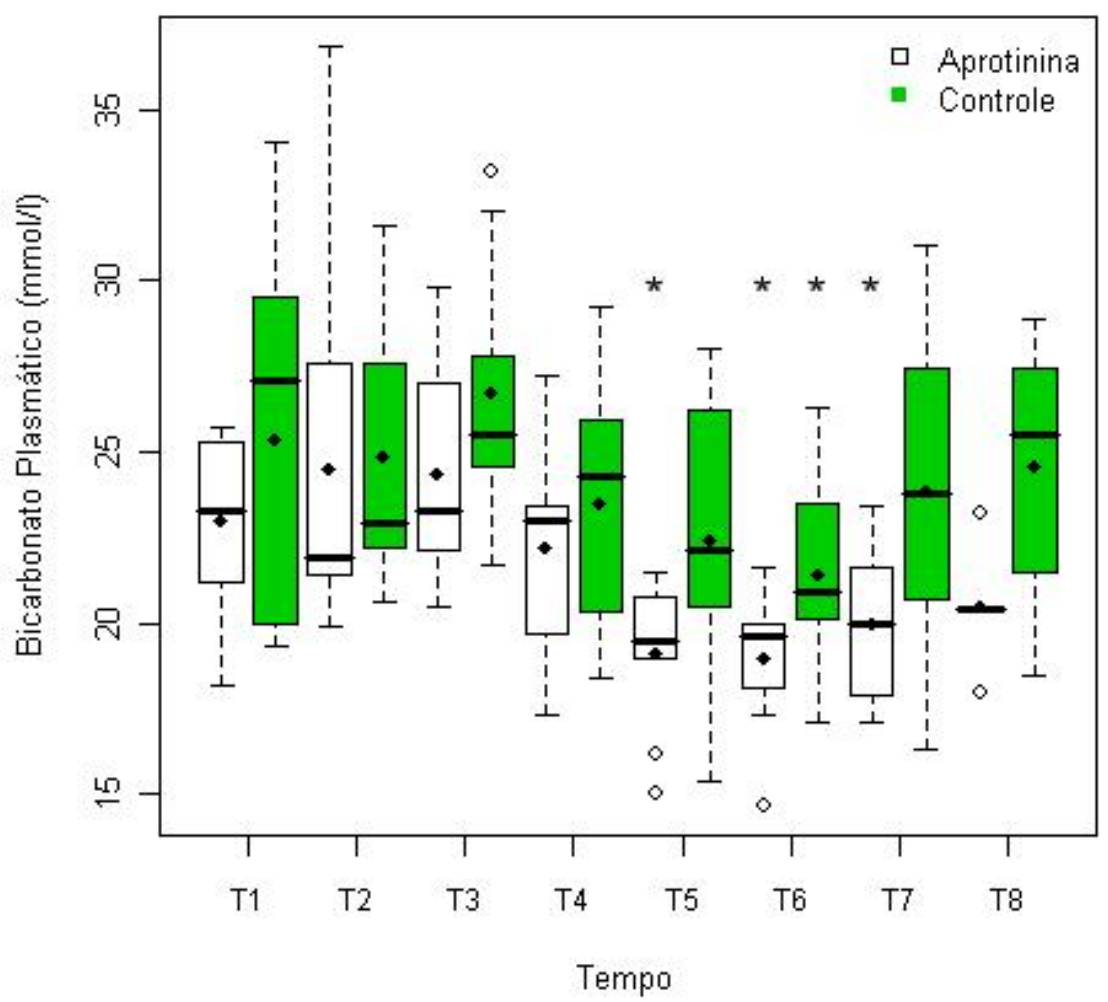

FIGURA 26. Concentração arterial de bicarbonato ( $\mathrm{mmol} / \mathrm{l})$ nos grupos Aprotinina e Controle, nos tempos T1 a T8. As diferenças estatisticamente significativas intragrupo estão representadas. 


\section{INCIDÊNCIA DE SÍNDROME DA RESPOSTA INFLAMATÓRIA SISTÊMICA (SRIS), DE SÍNDROME DO EXTRAVASAMENTO CAPILAR SISTÊMICO NO PO}

A SRIS ocorreu em $30 \%$ dos casos do grupo Aprotinina e em $44,4 \%$ do grupo controle. A SECS incidiu, respectivamente, em $40 \%$ e $22,2 \%$ deles (Anexo III). Dos pacientes que desenvolveram SIRS, dois apresentavam escore clínico de Ross modificado de 7 a 8 e de 2 a 8 , respectivamente, enquanto nos demais, esses escores foram de 0 a 7 e de 0 a 6 . O índice clínico-cirúrgico de Mattos nesses pacientes e/ou naqueles com SIRS e/ou SECS, a mediana foi 6 e, nos demais, 4,5 a 5,0.

Nos dois grupos, ocorreram disfunções cardiovasculares (60 vs $33,3 \%$ ), renais (30 vs $22,2 \%$ ) e respiratórias ( 40 vs $22,2 \%$ ), sem diferença estatisticamente significativa. Duas crianças do grupo Controle sofreram disfunção hematológica. Complicações pulmonares infecciosas ocorreram em ambos os grupos (20 vs 33,3\%) e não houve casos de disfunção neurológica ou hepática.

\section{INFLUÊNCIA DA PRESENÇA DE SRIS E/OU SECS NASVARIÁVEIS CLÍNICAS PO}

No grupo Aprotinina, os tempos de ventilação mecânica e de suporte inotrópico foram significativamente maiores na presença de SRIS e/ou SECS, em relação às demais, com medianas de 144 vs $11 \mathrm{~h}$ e 144 vs $48 \mathrm{~h}$, respectivamente. O mesmo notou-se em relação aos escores inotrópicos I (medianas 6 vs 2, respectivamente) e II (medianas 35 vs 4,5 respectivamente). Curiosamente, essas diferenças significantes não se repetiram no grupo Controle e nem atingiram significância estatística as diferenças intergrupos (Anexo III).

Com a presença de SRIS e/ou SECS, nos dois grupos, os tempos de ventilação mecânica (medianas $144 \mathrm{~h}$ vs $72 \mathrm{~h}$ ) e de suporte inotrópico (medianas de $144 \mathrm{~h}$ e $48 \mathrm{~h}$ ) e os escores inotrópicos I (medianas 6 vs 2) e II (medianas 35 vs 7,5) tenderam a ser maiores no Grupo Aprotinina . 
Por sua vez, os tempos de internação no CTIP e hospitalar não foram alterados significativamente pela SRIS e/ou SECS.

\section{PERFIL DOS MARCADORES PARA SIRS E MIOCÁRDICAS NOS PACIENTES COM SRIS}

Não houve diferença significativa entre os pacientes com e sem SIRS quanto às variáveis TNF- $\alpha$, IL-8, cTnl, NT-proBNP, CK-MB e TGO. Apenas no grupo Aprotinina, essa mesma comparação mostrou, nos casos com SRIS, níveis (em mediana) de IL-6 significativamente menores em T5 (177,65 vs $336,18 \mathrm{pg} / \mathrm{ml})$, os de IL-10 maiores em T1 $(25,76 \mathrm{vs} 9,65 \mathrm{pg} / \mathrm{ml})$ e a proporção IL-6 / IL-10 menor em T5 (1,73 vs 2,05$)$ e T6 (9,20 vs 16,43), comparados aos pacientes sem SRIS.

No Grupo Controle, não houve diferenças entre todas estas variáveis e não houve diferenças intergrupos.

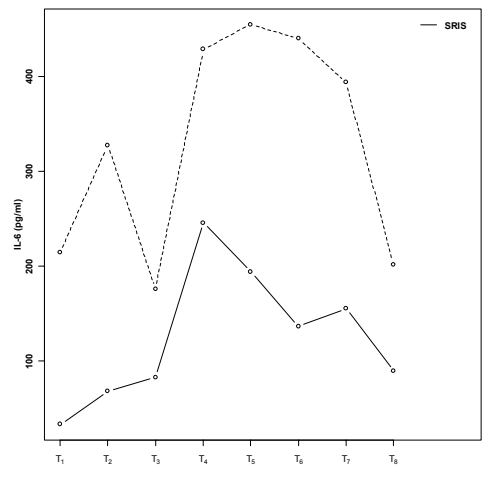

IL-6 (pg/ml)

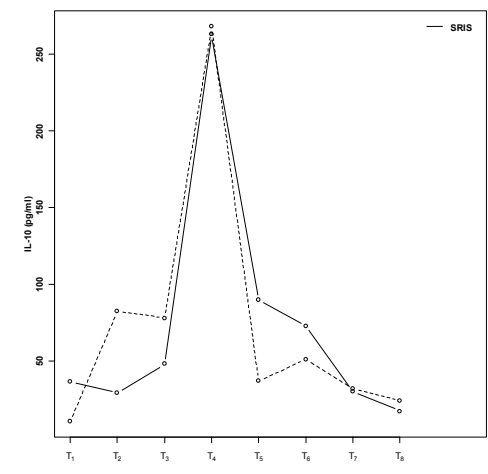

$\mathrm{IL}-10(\mathrm{pg} / \mathrm{ml})$

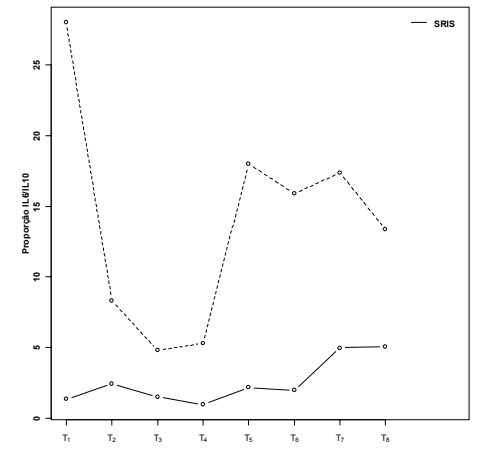

Proporção Il-6/IL-10

FIGURA 27. Níveis de IL-6 (pg/ml), IL-10 (pg/ml) e proporção IL-6/lL-10 no grupo Aprotinina, nos pacientes com critérios para SRIS (linha cheia contínua) comparado com aos demais (linha descontínua), 


\section{AVALIAÇÃO ECODOPLLERCARDIOGRÁFICA NO PO}

Essa avaliação demonstrou bom resultado cirúrgico em todos os pacientes (Anexo III).

\section{MORBIDADE}

\subsection{Complicações respiratórias}

No Grupo Aprotinina houve derrame pleural em duas crianças, atelectasia pulmonar em cinco, uma delas decorrente de paresia frênica esquerdo, edema de glote em uma, pneumonia em três, crise de hipertensão pulmonar em uma e hipoxemia aguda por distúrbio ventilatório em duas crianças.

No Grupo Controle ocorreu derrame pleural em uma criança, atelectasia pulmonar em outra, pneumonia em duas, em uma das quais foi confirmado após alta hospitalar; bronquiolite obliterante, traqueobronquite aguda em uma e crise de hipertensão pulmonar em dois casos.

\subsection{Complicações neurológicas}

No Grupo Aprotinina não houve distúrbios neurológicos, mas esses ocorreram em três pacientes do Grupo Controle, que apresentaram, respectivamente, agitação psicomotora e sonolência, crise convulsiva parcial complexa e crise convulsiva generalizada tônico-clônica.

\subsection{Complicações cardíacas}

No Grupo Aprotinina, houve um caso de bloqueio AV total transitório e episódios de bradicardia, em outro. No Grupo Controle, um paciente apresentou episódios de taquicardia supraventricular paroxística (TSVP). 


\subsection{Complicações hemorrágicas}

No Grupo Controle, apenas dois pacientes apresentaram sangramento $\mathrm{PO}$ maior que o esperado, mas nenhum deles necessitou de reintervenção cirúrgica.

\subsection{Complicações renais}

No grupo Aprotinina, três crianças e no Controle, duas apresentaram depuração de creatinina abaixo de $50 \mathrm{ml} / \mathrm{min} / 1,73 \mathrm{~m}^{2}$. Somente uma das cinco crianças teve oligo-anúria (caso 53, grupo Controle).

\subsection{Complicações da ferida cirúrgica (esternotomia)}

No grupo Aprotinina, ocorreu infecção superficial envolvendo pele e tecido celular subcutâneo em um paciente e deiscência da ferida cirúrgica em outro. No grupo Controle houve infecção superficial de ferida cirúrgica em um paciente e pseudoartrose esternal em outro.

\subsection{Outras complicações}

No grupo Aprotinina, uma criança apresentou monilíase oral e outra teve lesões fúngicas de pele, candidíase oral e perineal.

\subsection{Complicações relacionadas à Aprotinina}

Não se observaram problemas alérgicos, hipotensão e tampouco trombose, como efeitos adversos da Aprotinina. 
DISCUSSÃO 
A utilização da Aprotinina em Cirurgia Cardíaca é cercada de discussão quanto à relação custo-benefício (MILLER et al., 1998; SMITH et al., 2004), pois muitos julgam que o custo e os eventuais efeitos adversos contra-indiquem seu emprego em casos de menor risco, (LEVY, 2006; KARKOUTI et al., 2006).

Todavia, pairam, atualmente, poucas dúvidas acerca de sua utilidade potencial em crianças predispostas à síndrome de hiperpermeabilidade capilar, a sangramento excessivo e à falência miocárdica PO (OLIVER et al., 2004; ARNOLD et al., 2006), como as de peso corpóreo cada vez mais baixo, geralmente decorrente de importante grau de desnutrição, operadas no Brasil (SILVEIRA et al., 1998).

Essas considerações suscitaram a presente investigação, para avaliar o papel da droga em cardiopatias congênitas acianogênicas, operadas com CEC, em nossa instituição.

A faixa etária dos pacientes foi restrita ao período entre 30 dias a quatro anos de vida, a fim de reduzir a grande dispersão da idade, que ofusca os estudos semelhantes (POUARD, 1998). Os neonatos foram excluídos, devido à maior propensão às complicações da CEC (MATTOS et al., 2006), secundárias à intensa resposta neuro-endócrina à lesão tecidual (OKUR et al., 1995), à grande liberação de citocinas (ALCARAZ et al., 2005) e à menor resposta neutrofílica (ASHRAF et al., 1997).

O encontro de acidose respiratória após a indução anestésica, em muitos dos pacientes do grupo Aprotinina, desnutridos e com peso corpóreo inferior a $5 \mathrm{~kg}$, salienta a presença de casos de ICC grave, com intenso hiperfluxo e congestão pulmonares, determinantes de provável edema intersticial do órgão, com maior risco de morte (ABELLAN et al., 2000; MOURA et al., 1988).

Não obstante a estimativa de mortalidade intra-hospitalar ou em 30 dias, de 1 a $5 \%$, com base nos escores de risco mais difundidos (RACHS-1 e Aristóteles), não ocorreram óbitos neste estudo. No entanto, o bom resultado cirúrgico ficou reforçado por um outro índice clínico-cirúrgico, mais recente, proposto no Brasil (MATTOS et al., 2006), cujos escores, nos 
grupos Aprotinina e Controle atingiram, respectivamente, 5,5 e 5, correspondendo a riscos de morte de $11,70 \%$ a $23,98 \%$ e devidos, principalmente, à prevalência de baixo peso corpóreo, inferior ao $5^{\circ}$ percentil, indicativo de desnutrição, bem como de síndromes genéticas, hipertensão pulmonar e ICC.

Estes fatores certamente influenciaram na morbidade PO desta tese, associada ao escore de Ross modificado $\geq 5$, que se acompanhou de maiores tempos de permanência na CTIP, de ventilação mecânica e de uso de inotrópicos, bem como de maior escore inotrópico, no grupo Aprotinina.

Como se acredita que a Aprotinina reduza o sangramento e a necessidade de transfusões por mecanismo dose-dependente (ROYSTON, 1992; MOSSINGER et al., 2003; OLIVER et al., 2004), optou-se pela utilização do protocolo pioneiro (Hammersmith Hospital), denominado de alta dose, proporcional à superfície corpórea, com o intuito de aperfeiçoar o benefício clínico (D’ERRICO, 1998). Do contrário, as atividades prócoagulante e fibrinolítica do fármaco poderiam ficar restritas à fase inicial da CEC (JAQUISS et al., 1995), além da ação antiinflamatória não ser eficaz (SEGHAYE et al., 1996).

Tivemos, por essa razão, o cuidado de acrescentar uma dose adicional de Aprotinina no perfusato (MOSSINGER et al., 2003) e uma infusão de manutenção intra-operatória (HOFFMANN et al., 1989 e SPRAY et al., 1998), para manter uniforme os níveis plasmáticos da droga (OLIVER et al., 2004). Infelizmente, essas doses adicionais e o "bolus" inicial, com certeza, tiveram o efeito colateral de introduzir um viés de maior hemodiluição no grupo tratado, uma vez que os volumes de perfusato, hemofiltrado e cardioplegia, bem como de concentrado de hemácias, a diurese e os tempos de perfusão e de anóxia foram semelhantes aos do Controle.

A ausência de reações de hipersensibilidade à Aprotinina era esperada uma vez que o risco dessa complicação é baixo em crianças, situando-se ao redor de 1\%, na primeira exposição e de 1,6 a 2,9\%, nas 
seguintes (DIETRICH et al., 2001; JAQUISS et al., 2002; BEIERLEIN et al., 2005).

Limitações comerciais determinaram a inclusão de quatro modelos de oxigenadores, falha potencialmente grave, pela possível diferença de respostas biomaterial-dependentes nas interações sangue-circuito de CEC (RUBENS et al., 2004). É, no entanto, razoável supor que isso não tenha ocorrido, pois além da distribuição dos oxigenadores ter sido semelhante nos dois grupos, DUBOIS et al (2004), demonstraram desempenho e grau de hemólise semelhantes de dois (Lilliput e Safe Micro) mais empregados nesta pesquisa. Além disso, JENSEN et al, em 2003, constataram que oxigenadores de membrana de fibra oca, aqui empregados, atuam de forma semelhante, tanto nos sistemas de coagulação e fibrinólise, como nas concentrações séricas de citocinas TNF- $\alpha$, IL-6 e IL-8, as quais mostraramse, inclusive, similares quando se utilizaram outros oxigenadores, recobertos de heparina (EISSES et al., 2004).

Devido à maior redução da contagem plaquetária na CEC hipotérmica (WEERASINGHE et al., 1998), suspeita-se que nela a ação plaqueta-protetora da Aprotinina seja mais substancial (SHORELESSERSON et al., 1999). Além disso, como a resposta inflamatória à CEC em cirurgia cardíaca pediátrica parece independente da temperatura adotada (CAPUTO et al., 2005), empregou-se, neste estudo, hipotermia moderada, a fim de salientar a ação da Aprotinina (BOLDT et al., 1993).

A semelhança do sangramento $\mathrm{PO}$ total entre os grupos Aprotinina e Controle $(17,62$ vs $18,11 \mathrm{ml} / \mathrm{Kg} / 48 \mathrm{~h})$ foi inesperada e, provavelmente, deve ter sido gerada pelo empenho na hemostasia intra-operatória minuciosa e pelo menor risco de sangramento nos portadores de cardiopatias acianogênicas (CHAUHAN et al., 2000). Essa hipótese é reforçada pelo fato de que os volumes de sangramento PO representam cerca da metade do encontrado na faixa etária de um a 12 meses, e um pouco menos do que os $20,1 \mathrm{ml} / \mathrm{Kg} / 12 \mathrm{~h}$, verificados em crianças operadas por cardiopatia de um e 5 anos, segundo WILLIAMS et al (1999). 
Embora uma criança de $15 \mathrm{~kg}$ (caso 35) do grupo Aprotinina tenha sido transfundida por anemia $(\mathrm{Hb}=8,6 \mathrm{~g} / \mathrm{dl})$, seu sangramento foi muito pequeno e a conduta obedeceu ao rígido protocolo do CTIP. Esse fato reforça as conhecidas críticas aos limiares protocolares de transfusão, dentre as quais a de dificultarem a comparação das pesquisas publicadas (KOH et al., 2003; OZIER et al., 2006).

O caolin, poderoso adsorvente da Aprotinina, rapidamente a remove do plasma, impedindo sua influência sobre os reagentes da coagulação nos "kits" de dosagem do TCA (ALSTON et al., 2004). Por essa razão, O TCA com esse reagente, mantido acima de $480 \mathrm{~s}$, foi empregado no controle da heparinização, embora se saiba que, em crianças, pode não refletir com exatidão, na presença de Aprotinina, a concentração de heparina circulante. Essa dificuldade surge em razão da concomitância de hemodiluição, ativação dos fatores hemostáticos, hipotermia e ativação plaquetária (DESPOTIS et al., 1995; CHAN et al., 1997).

Não se observaram quadros trombóticos, nem evidências de heparinização insuficiente, em CEC, como trombos ou fibrina nos oxigenadores, reservatórios e tubos. Essa constatação coaduna-se com as instituições de grande experiência com a Aprotinina em cirurgia cardíaca pediátrica (POUARD, 1998; WILLIAMS et al., 1999; TWEDDELL et al., 2002), em que pesem vozes discordantes a esse respeito (CARREL et al., 1998; PENKOSKE et al., 1995).

As causas mais comuns de sangramento pós-CEC incluem disfunção plaquetária e hiperfibrinólise (WEGNER et al., 2003), considerando-se que a primeira é mais importante (SILVEIRA et al., 1998; WILLIAMS et al., 1999), e passível de exarcebação pela plaquetopenia, típica da CEC com hemodiluição, pela adesão e consumo no circuito extracorpóreo e pelo efeito agregante plaquetário da heparina (DAY et al., 2004; LAGA et al., 2005).

Nesta presente pesqusa, a Aprotinina preservou quantitativamente as plaquetas circulantes, ao passo que o grupo Controle cursou com 
plaquetopenia desde o início da CEC, até o término do estudo, de modo a corroborar os achados de MASIAK et al (1980) e de ROYSTON et al. (1987).

Como as plaquetas sofrem dano mecânico direto por forças de cisalhamento e acabam seqüestradas por vários órgãos (BRIXCHRISTENSEN, 2001), a preservação numérica plaquetária pela Aprotinina pode ter decorrido da atenuação do seqüestro e do acúmulo de plaquetas na microcirculação (BIRK-SORENSEN et al., 1999).

A preservação da concentração circulante de plaquetas decorrente do menor seqüestro microcirculatório tem efeito salutar, diminui o risco de trombose vascular, de microembolizações e vasoconstrição associadas à CEC e deve ter sido determinada pela inibição tanto da ativação de receptores protease-ativados (PAR) como da produção de tromboxano. Como resultado, a agregação plaquetária mediada pela trombina é bloqueada (NAGAOKA et al., 1991; KHAN et al., 2005).

Sabe-se que a adesão de proteínas plasmáticas, como o fibrinogênio, à superfície do circuito de CEC, promove forte ativação e deposição plaquetária local. Por essa razão, WENDEL et al (1999) argumentam que altas doses de Aprotinina podem competir no revestimento do circuito de CEC, tornando-o mais biocompatível e, conseqüentemente, favorecem a manutenção da população plaquetária e sua viabilidade, de modo a contribuir para a hemostasia pós-CEC (POULLIS et al., 2000).

Por outro lado, a afinidade da Aprotinina pelas proteínas GPIlb-IIla do receptor plaquetário também é citoprotetora, pois impede a ligação das plaquetas às superfícies estranhas dos circuitos de CEC (WEERASINGHE et al., 1998). Também se sabe que a Aprotinina reduz a ligação da heparina nas plaquetas. Como resultado, a disfunção plaquetária induzida por esse anticoagulante é minimizada pela droga (WEGNER et al., 2003) e pode, inclusive, ser restaurada a capacidade de adesão das plaquetas tornadas disfuncionais pelo anticoagulante (BRADFIELD et al., 2003).

É importante ressaltar que no grupo Controle, os dois pacientes $(22 \%)$ que tiveram sangramento mais intenso, um pelo dreno mediastinal $(49,97 \mathrm{ml} / \mathrm{Kg})$ e o outro pelos acessos vasculares, apresentaram 
plaquetopenia $\left(70.000\right.$ e 73.000 plaquetas $/ \mathrm{mm}^{3}$, respectivamente) e precisaram receber transfusão de plaquetas.

A dramática redução da contagem plaquetária subseqüente à infusão da protamina, embora seja mais expressiva no grupo Controle, reflete que o efeito agregante plaquetário da protamina não é intensamente anulado pela Aprotinina (NAGAOKA et al., 1991).

Habitualmente, logo após o término da CEC, o TTPa normaliza-se, em crianças entre um mês e 5 anos de idade (WILLIAMS et al., 1999). Embora o teste possa se prolongar, levemente, até os três meses de idade (GUAY, 2006), devido a menores taxas circulantes dos fatores de contato XII, pré-calicreína e cininogênio, apenas três pacientes em cada grupo achavam-se nessa faixa etária. No entanto, o medido $4 \mathrm{~h}$ após a administração de protamina estava significativamente prolongado no grupo Aprotinina. Por conseguinte, pode-se conjecturar que nesse grupo, persistiu o efeito terapêutico da droga (que prolonga o TTPa) (DESPOTIS et al., 1995), ou o prolongamento do TTPa foi causado por resíduos e/ou efeito rebote da heparina (SILVEIRA et al., 1998), cuja ação é potencializada pela Aprotinina (DESPOTIS, 1996).

DESPOTIS et al (1995) demonstraram que a Aprotinina não prolonga o TP. Destarte, o discreto e transitório aumento do INR dos dois grupos, 4h após a protaminização, denota que o consumo de fatores de coagulação durante a CEC não foi inteiramente evitado pela droga (SILVEIRA et al., 1998).

No grupo Aprotinina, a contagem leucocitária foi significativamente menor que no Controle e permaneceu abaixo dos valores basais, do início ao término da CEC. Isso pode ter resultado da ação da droga sabidamente capaz, mesmo em baixas doses, de reduzir a mobilização neutrofílica, no final da CEC (SEGHAYE et al., 1996).

No entanto, a Aprotinina não afetou a leucocitose PO, com pico 24 horas após protaminização, reconhecida como parte da resposta inflamatória sistêmica (SEGHAYE et al., 1996), e que deve ter resultado da mobilização de neutrófilos marginados, liberação de novas células pela medula óssea, 
menor leucopedese tecidual e/ou elevação do número de precursores intramedulares (KUMAR et al., 2005).

Conforme esperado (ROTH-ISIGKEIT et al., 2001; CHEW et al., 2001), as citocinas pró-inflamatórias circulantes, indetectáveis em crianças sadias, mostraram-se elevadas nas amostras pré-operatórias desta investigação, o mesmo valendo para a relação IL6/IL-10.

Como foram excluídos os casos com evidências clínicas, laboratoriais e radiográficas de infecção ou inflamação, esse achado sugere a presença de condição inflamatória subclínica (MOU et al., 2002; HÖVENS-GÜRICH et al., 2002) gerada por grave disfunção hemodinâmica crônica, indutora de síntese miocárdica de citocinas (QING, 2003), exacerbada por retro-alimentação pelos seus níveis sistêmicos (TORREAMIONE et al., 1996; DUVAL et al., 1999; HÖVELS-GÜRICH et al., 2002).

Um terço das crianças de cada grupo apresentava síndromes genéticas, consideradas fatores de risco associados ao resultado pósoperatório (MATTOS et al., 2006), principalmente a de Down, que cursa com up regulation de IL-6 (LICASTRO et al., 2001), o que pode também contribuir para explicar a grande variabilidade intragrupos, na liberação de citocinas (ROTH-ISIGKEIT et al., 2001).

A detecção pré-operatória de TNF- $\alpha$, usualmente relacionada à endotoxemia (LEQUIER et al., 2000), cujo aumento, em geral, antecede ao das demais citocinas (MOU et al., 2002), pode ter sido influenciada pela indução anestésica (BRANCACCIO et al., 2005) e, juntamente com certa liberação adicional durante a CEC, pode ter desencadeado a cascata de manifestações clínicas pós-operatória, citocina dependentes (LAFFEY et al., 2002), constituídas por febre, hipotensão arterial sistêmica, SECS, SRIS, coagulopatia e disfunção renal (HALL et al., 1997; KHABAR et al., 1997; PAPARELLA et al., 2002).

Apesar da Aprotinina inibir a calicreína, o consumo de cininogênio e a formação de cininas (CONTI, 2001), sugerindo ação benéfica em cirurgia cardíaca pediátrica com CEC (NEUHOF et al., 2003), a semelhança intergrupos do quadro clínico PO refletiu ausência de efeito profilático 
antiinflamatório da Aprotinina, como já haviam relatado SEGHAYE et al (1996) e MOSSINGER et al (2003). Todavia, cabe considerar que algumas dessas complicações podem ter sido deflagradas pela redução do clearance de complexos heparina-protamina, como determinada por homozigose "C4A null", com desencadeamento de ativação do complemento e SECS (ZHANG et al., 2005).

Por outro lado, como as citocinas são mensageiras locais, as taxas circulantes podem não refletir a produção e efeitos em certos tecidos, onde reinam mecanismos autócrinos e parácrinos (BRIX-CHRISTENSEN et al., 2003; LARMANN et al., 2004).

Sabe-se, ainda, que o uso de concentrado de hemácias no perfusato pode fornecer citocinas exógenas e causar e/ou contribuir para o aumento da IL-6, tanto durante a CEC, como no PO (ROYSTON, 1997). Além disso, a autotransfusão na CEC ativa neutrófilos e gera citocinas, podendo ter influenciado na ocorrência de SRIS nos dois grupos (LAFFEY et al., 2002). Por sinal, duas crianças (casos 6 e 12) do grupo Controle receberam concentrados de plaquetas, que também contêm IL-6 e TNF- $\alpha$ (ARNESTAD et al., 1994; STACK et al., 1994).

O perfil cinético das citocinas, também não foi afetado pela Aprotinina e expressou típica elevação transitória, de padrão bifásico, com picos precoces de TNF- $\alpha$ no início da CEC e $4 \mathrm{~h}$ após a protaminização (KHABAR et al., 1997; OZAWA et al., 2000; MOU et al., 2002; ALCARAZ et al., 2005), precedendo o prolongado aumento da IL-6 e da quimiocina IL-8, reguladora da leucodiapedese para sítios de inflamação (BRIXCHRISTENSEN, 2001; PAPARELLA et al., 2002; LEVY et al., 2003).

Embora a Aprotinina, como a prednisolona, possa inibir a produção de TNF- $\alpha$ durante a CEC (HILL et al., 1995; ALONSO et al., 1999), isso não ocorreu nesta tese, à semelhança de outros estudos, em adultos (DEFRAIGNE et al., 2000; SCHMARTZ et al., 2003). Em investigação similar realizada em nosso Serviço, por CARMONA (2006), em 52 crianças operadas sob tratamento com Aprotinina, o perfil cinético de TNF- $\alpha$ foi similar ao deste presente trabalho. 
Embora, curiosamente, também tenha atividade antiinflamatória (OPAL et al., 2000; MENGER et al., 2004), a IL-6 é marcador de lesão celular, com efeitos pirógeno e inflamatório prolongados, em crianças submetidas à CEC (HALL et al., 1997; ALCARAZ et al., 2005). Sua elevação tardia correlaciona-se positivamente com a liberação de TNF- $\alpha$ (ROTHISIGKEIT et al., 2001), os tempos de CEC (SAAVEDT et al., 1995), de pinçamento aórtico (KAWAMURA et al., 1993), bem como com o volume de sangue transfundido no intra-operatório (HAUSER et al., 1998), variáveis essas semelhantes nos dois grupos desta tese.

O fato da Aprotinina não ter atenuado a liberação dessa citocina concordante com os dois outros únicos estudos aleatórios precedentes, efetuados em crianças (SEGHAYE et al., 1996; MÖSSINGER et al., 2003) e com o estudo observacional de CARMONA (2006).

SEGHAYE et al (1996) investigaram crianças de $9 \mathrm{~m}$ a 5 a de idade, com cardiopatia acianogênica e obtiveram níveis similares de IL-6 com e sem Aprotinina. Entretanto, além de dose baixa da droga, utilizaram dexametasona na indução anestésica. MÖSSINGER et al (2003) detectaram perfil sérico de IL-6 semelhante ao observado neste estudo, embora com valores menores, também não atenuados pelo uso de Aprotinina. No entanto, o protocolo de uso de Aprotinina foi diferente, sendo estudadas crianças portadoras de cardiopatias acianogênicas e cianogênicas, bem como neonatos. Finalmente, no estudo de CARMONA et al. (2006), onde utilizou-se a mesma dose de aprotinina desta tese, o perfil sérico de IL-6 foi muito semelhante ao encontrado nos dois grupos há pouco citados.

Todavia, as crianças que receberam Aprotinina e apresentaram SRIS (casos 1, 25 e 32) cursaram com menores níveis circulantes de IL-6, $4 \mathrm{~h}$ após administração da protamina e com tendência também a menores valores até $48 \mathrm{~h}$ de pós-operatório. Esse achado é surpreendente, pois está em contradição com estudos nos quais os maiores níveis de IL-6 foram encontrados em crianças com maior escore PRISM, SRIS com extravasamento capilar pós-operatório e em não sobreviventes (HAUSER et al., 1998). A Aprotinina pode atenuar a produção e/ou liberação sistêmica de 
IL-6 nestes pacientes e pode ter colaborado com a antiinflamação sistêmica (MUNFORD et al., 2001; MENGER et al., 2004). Entretanto, essa hipótese ainda não tem respaldo da literatura.

A IL-8, produzida por macrófagos, embora com papel fisiopatológico tido como limitado e controverso (OZAWA et al., 2000; GESSLER et al., 2003), é uma das quimiocinas mais estudadas (KUMAR et al., 2005), devido à potente ação recrutadora de leucócitos para focos inflamatórios, particularmente, pulmonares, mediando além da SRIS (HALL, 1997), a disfunção miocárdica (HÖVELS-GURICH et al., 2002; CARMONA, 2006).

Observou-se aumento intergrupos progressivo e similar de IL-8, coincidente com o da IL-6, sucedendo o reaquecimento e o despinçamento aórtico, com pico 5 min após a protaminização. Esse achado foi similar ao de outros estudos, em crianças (ASHRAF et al., 1997; OZAWA et al., 2000; GESSLER et al., 2003; ALCARAZ et al., 2005; CARMONA, 2006). Esta tese é concordante também com os estudos de MÖSSINGER et al (2003) e CARMONA (2006) ambos em crianças, e com outros, em adultos (TASSANI et al., 1999; DEFRAIGNE et al., 2000; SCHMARTZ et al., 2003), nos quais não se verificou diminuição da IL-8 com a administração de Aprotinina, em que pesem relatos recentes, em adultos, imputando à Aprotinina efeito comparável ao de corticóides, no que se refere à redução da IL-8 (TÜRKOZ et al., 2001; MING et al., 2001; GREILICH et al., 2003).

Resultado direto da interação do sangue com o circuito de CEC (McBRIDE et al., 1996), os níveis de IL-8 dependem da duração da CEC e do tempo de pinçamento aórtico (SEGHAYE et al., 1996; ALCARAZ et al., 2005), bem como da temperatura sistêmica (HALL et al., 1997; ALCARAZ et al., 2005), variáveis que não diferiram entre os grupos desta investigação. Não houve, inclusive, diferenças significativas quanto ao perfil sérico de IL-8, entre as crianças que desenvolveram critérios para SRIS e as demais.

A IL-10, cuja produção é estimulada pela TNF $\alpha$ (ABBAS et al., 2005), inibe a síntese das citocinas TNF $\alpha$, IL-1 $1 \beta$ e IL-6, pode induzir down regulation da produção de IL-8 e inativar macrófagos e monócitos (PAPARELLA et al., 2002; CAPUTO et al., 2005). 
Nesse estudo, observou-se aumento significativo da IL-10 sérica, desde o início da CEC até 48h após a infusão de protamina, com pico após 5 min da infusão da protamina. Este padrão está compatível com estudos prévios em crianças (SUGITA et al., 1996; TÁRNOK et al., 1998; ALCARAZ et al., 2002; CARMONA et al., 2006) que indicam liberação precoce de IL-10, com máxima concentração sérica durante a reperfusão, e regressão completa, um dia após, comportamento esse similar ao encontrado em adultos (TABARDEL et al., 1996; CAPUTO et al., 2005).

Em que pese a discordância com o dados, em adultos (HILL et al., 1998; HARIG et al., 1999; LEI et al., 2003; WEGNER et al., 2003), nesta Tese, o aumento da IL-10 sérica não foi afetado pela Aprotinina, achado esse similar aos obtidos em outros estudos, também, com crianças (MÖSSINGER et al., 2003; CARMONA, 2006).

No estudo de SEGHAYE et al (1996), ocorreram dois picos de liberação de IL-10, na CEC e 24 horas após a operação, e notou-se forte influência da hipotermia em CEC sobre a elevação dos níveis séricos da citocina. Essa observação sugeriu que a temperatura modula a geração da IL-10, como confirmaram experimentalmente QING et al (2001). Contudo, a controvérsia a esse respeito repareceu quando CAPUTO et al (2005) demonstraram que, pelo contrário, ocorre maior liberação de IL-10 em crianças operadas com CEC normotérmica. Nesta tese, o grau de hipotermia foi semelhante entre os grupos.

Houve diminuição significativa da relação $\mathrm{PaO}_{2} / \mathrm{FiO}_{2} \mathrm{PO}$ no grupo Controle, compatível com lesão pulmonar aguda. Como esta queda não foi significativa no grupo aprotinina, pode-se inferir seu efeito protetor, embora fosse clinicamente ineficaz. Essa observação é contrária ao relato de MOSSINGER et al (2003), que observaram redução do tempo de ventilação mecânica com o uso da droga.

O fato da Aprotinina não ter atenuado a liberação sistêmica da TNFa, IL-6 e de IL-8 é intrigante e desafiador, consubstanciando a necessidade de associá-la a corticosteróides e/ou circuitos de CEC e oxigenadores revestidos de heparina (INUI et al., 1999), além de filtros de leucodepleção 
(OLIVENCIA-YURVATI et al., 2004), embora essa conduta, nem sempre, tenha bons resultados (TASSANI et al., 1999; DEFRAIGNE et al., 2000).

Segundo TANIGUCHI et al (1999), nos pacientes que morreram por choque séptico e insuficiência de múltiplos órgãos, as concentrações de IL-6 aumentam gradualmente, enquanto surge downregulation da IL-10, fazendo com que a proporção IL-6/IL-10 cresça. Por isso, a proporção IL-6/IL-10 é um reconhecido previsor de mau resultado na sepsis (DOUGHTY et al., 1996).

Nessa tese, observou-se que essa fração aumentou a partir de $4 \mathrm{~h}$ após a administração da protamina, com pico em $24 \mathrm{~h}$, nos dois grupos, mas foi significativa apenas no grupo Controle. Esse achado é de difícil discussão devido à falta de observações prévias, em estudos semelhantes a este.

Todavia, nas crianças tratadas com Aprotinina e que apresentaram SRIS (casos 1, 25 e 32), o aumento da proporção IL-6/IL-10 foi menos intenso que nos casos no grupo Controle, que também foram afetados (casos 6, 11, 34 e 49), o que pode sugerir um discreto benefício da droga.

Conforme esperado, as concentrações séricas pré-operatório de lactato e troponina-I estavam dentro da normalidade, indicando que nenhum paciente apresentava isquemia miocárdica ou insuficiência cardíaca terminal.

O escore PRISM, na admissão na CTIP, de três, no grupo Aprotinina, e de sete, no grupo Controle, sugeriu que a droga favoreceu a estabilidade metabólica e hemodinâmica. Portanto, embora a evolução clínica dos grupos tenha sido similar, cabe lembrar que a sensibilidade preditiva do resultado do escore PRISM é muito menor nos pacientes operados $(17 \%)$ que nos não operados (71\%) (BALAKRISHNAN et al., 1992).

A similaridade dos grupos quanto à duração, associações e dose de inotrópicos nas primeiras 48h pós-CEC, assim como quanto aos tempos de ventilação mecânica e de permanência na UTI, implica que a Aprotinina não influenciou favoravelmente nestas variáveis clínicas. Isto está em desacordo com estudos nos quais a Aprotinina reduziu o uso de inotrópicos 
(WIPPERMANN et al., 1999), a incidência de síndrome de baixo débito e arritmias (BROCHE et al., 2002), a permanência na CTIP, a internação hospitalar (MILLER et al., 1998) e a duração da ventilação mecânica (MÖSSINGER et al., 2003).

No grupo Aprotinina, houve, praticamente, o dobro de incidência de de disfunções orgânicas, tanto cardiovasculares (60\% vs 33,3\%) quanto respiratórias (40\% vs 22,2\%), embora sem diferença significativa. Entretanto, essas taxas situaram-sedentro do esperado para a faixa etária, pois aceitase que cerca de $50 \%$ dos pacientes apresentem disfunções pulmonares e cardiovasculares (SEGHAYE et al., 1993; HOFFMAN et al., 2003).

A hiperlactatemia é freqüentemente observada em crianças submetidas à cirurgia cardíaca, mas a acidose láctica pode ocorrer em 10\% dos casos (MURRAY et al., 2004). Níveis plasmáticos de lactato $>5 \mathrm{mmol} / \mathrm{l}$, necessários para provocar acidose láctica, ocorreu transitoriamente em 2 crianças do grupo Aprotinina e em uma, do Controle. Acredita-se que surja, em geral, devido à intensa hemodiluição, associado à hipotensão, nas fases iniciais da CEC (KOLISKI et al., 2005; GESSLER et al., 2006). A redução inicial do hematócrito na CEC, no grupo Aprotinina, resultou em queda de $25 \%$ da pressão arterial do valor inicial, por diminuição da viscosidade plasmática não contrabalançada pela elevação da resistência vascular periférica e maior viscosidade sangüínea secundária à hipotermia (SANT'ANNA et al., 1994).

Neste trabalho, a hiperlactatemia, embora considerada discreta, de 2 a $4 \mathrm{mmol} / \mathrm{l}$ (ATIK et al., 2004), foi surpreendentemente maior no grupo Aprotinina. Segundo KOLISKI et al (2005), o maior nível de lactato, ao final da CEC e 5 min após administração da protamina pode ter decorrido de hipoperfusão e inadequada oxigenação tecidual secundárias à hemodiluição intra-operatória, que provavelmente não foram suficientemente eliminadas pelo fluxo arterial (SANT'ANNA et al., 1994), e sua neutralização pode ter ocorrido parcialmente com a reposição de concentrado de hemácias durante a CEC e com a hemoconcentração próximo ao final da CEC. Usualmente, os níveis de lactato são menores quando se utiliza perfusato sangüíneo 
(GESSLER et al., 2006; TODA et al., 2005). Os valores foram semelhantes aos de CARMONA (2006), especialmente nas crianças sem disfunção miocárdica. Pode ter ocorrido influência da Aprotinina nesse achado, embora esta possibilidade não tenha sido detectada por WIPPERMANN et al (1999).

A hiperlactatemia $12 \mathrm{~h}$ após protaminização, no grupo Aprotinina, com $\mathrm{Hb}$ normalizada, pode ter resultado de melhor perfusão tecidual, desencadeado pelo aumento da glicólise anaeróbica induzida por catecolaminas (ATIK, 2004) ou então por um efeito paradoxal decorrente de "wash out" tecidual resultante de reexpansão volêmica PO e vasodilatação periférica (MIANA et al., 2004). O escore inotrópico e a reposição volêmica tenderam a aumentar no grupo aprotinina, quiçá, como efeitos colaterais indesejáveis da maior hemodiluição a que foi submetido.

HATHERILL et al (1997) salientam que vários fatores de confundimento interferem na lactatemia, como a redução na extração de oxigênio tecidual, o desequilíbrio entre a produção e o clearance hepático, e a técnica e duração da perfusão e da anestesia. Não houve disfunção hepática clínicamente evidente, embora, laboratorialmente, houvesse aumento de TGO, mas que não diferiu entre os grupos.

A acidose metabólica observada no período de 4 a 12 horas $\mathrm{PO}$, principalmente em 6 de 10 pacientes do grupo Aprotinina, não deve ser decorrente dos níveis de lactato $(<4 \mathrm{mmol} / \mathrm{l})$. Uma possibilidade explicativa consiste em eventual acidose hiperclorêmica ou aumento de ácidos teciduais não mensurados (cetoácidos e ácidos orgânicos como sulfatos) (MURRAY et al., 2004).

Com base em achados experimentais de MARIN-GREZ et al (1995), é ainda possível que a acidose metabólica possa estar relacionada ao bloqueio da calicreína renal pela aprotinina. Este para-efeito adicional da droga requer, no entanto, maiores investigações.

Tendo em conta que as incisões cardíacas e os tempos de CEC e de pinçamento aórtico foram semelhantes, não ocorrendo diferença significativa intergrupos. Quanto à cTnl, a ausência de efeito miocárdioprotetor da Aprotinina se contrapôs tanto a relatos prévios, indicativos de 
benefício (PRUEFER et al., 2002; BULL et al., 2003), como a outros, em que foi detrimental (BUKHARI et al., 1995; MANGANO et al., 2006). O mesmo vale para as dosagens de $\mathrm{CKMB}$, com perfil sérico semelhante aos de outros estudos em crianças, com ou sem disfunção miocárdica (CARMONA., 2006).

O NT-proBNP, sensível marcador neuro-humoral de disfunção ventricular (MUELLER et al., 2004; COHEN et al., 2005; GESSLER et al., 2006), advém dos ventrículos, na forma de um pró-hormônio inativo (próBNP). Da clivagem enzimática deste último, na circulação, resultam o BNP biologicamente ativo e o marcador, como resíduo inativo (LEVIN et al., 1998).

Os níveis de NT-proBNP aumentam na insuficiência cardíaca congestiva (MIR et al., 2002; WU et al., 2005) e nas cardiopatias congênitas (GESSLER et al., 2006), sendo controversa a possibilidade de up-regulation do BNP cardíaco por citocinas inflamatórias (MA et al., 2004; GESSLER et al., 2006; CARMONA et al., 2006).

Nesta pesquisa, a detecção de taxas basais elevadas de NTproBNP em, praticamente, metade dos casos, certamente, deveu-se à presença de ICC. A Aprotinina não interferiu na concentração circulante desse resíduo bioquímico, cuja concentração elevou-se, de forma semelhante, no final da CEC, com pico $12 \mathrm{~h}$ após a administração de protamina, conforme também verificaram $\mathrm{KOCH}$ et al, em 2006, com valores obtidos não sugestivos de disfunção miocárdica moderada ou grave (CARMONA, 2006).

Não ocorreram diferenças significativas intergrupos quanto à diurese, nem quanto aos níveis séricos de uréia e creatinina, à depuração de creatinina e à ocorrência de insuficiência renal aguda. Esses achados, embora superponíveis a vários estudos (POUARD, 1998; SCHWEIZER et al., 2000; MOSSINGER et al., 2003; CARMONA, 2006), contrastam com os que detectaram prejuízo da função renal (BLAUHUT et al., 1991; RANUCCI et al., 1994; ROYSTON, 1996; MANGANO et al., 2006), embora, em geral, sem repercussão clínica (PETERS et al., 1999). 
Considerando que os pacientes estudados incluíam-se na categoria de risco 2 pelo escore RACHS-1, a incidência esperada de diálise peritoneal situava-se entre 12 e 17\% (CHAN et al, 2003).

Uma criança do grupo Aprotinina apresentou disfunção renal transitória, revertida no $3^{\circ} \mathrm{PO}$, que também se manifestou em outros quatro pacientes, dois de cada grupo, com peso inferior a 4,5Kg. Essas crianças desenvolveram SECS, com anasarca e derrame pleural, associada a importante disfunção cardiovascular e escores inotrópicos elevados, e evoluíram com ventilação mecânica prolongada, duas delas com hipertensão pulmonar tratada com óxido nítrico, mas não chegaram a necessitar de diálise peritoneal. Essas observações concordam com a sugestão de CHAN et al (2003), de que o baixo peso corpóreo, a síndrome do baixo débito cardíaco e a hipertensão pulmonar PO constituem fatores de risco para insuficiência renal aguda.

Eventos neurológicos relacionados à cirurgia cardíaca com CEC ocorreram somente no grupo Controle, com dois casos de crise convulsiva e um de agitação psicomotora e sonolência, mas o tamanho da amostra não permite imputar efeito neuroprotetor à Aprotinina (ALSTON et al., 2000).No entanto, MURKIN et al (2002) e FRUMENTO et al (2003) relataram menor incidência de lesão cerebral com altas doses de Aprotinina.

Não houve diferença intergrupos quanto à incidência de infecção PO Embora em algumas investigações clínicas com Aprotinina argumentase que a droga aumenta o risco de mediastinite (PENKOSKE et al., 1995; CARREL et al., 1998), ao mesmo tempo, há outros grupos que a empregam em transplantes cardíacos e pulmonares, sem incremento na taxa de infecção (JAQUISS et al., 1995).

Embora o tema seja controverso (GAYNOR, 2003; BRANCACCIO et al., 2005), julga-se que a hemofiltração tenha efeitos antiinflamatórios benéficos (LARMANN et al., 2004), particularmente em crianças (LAFFEY et al., 2002), graças à remoção de mediadores pró-inflamatórios como TNF-a, e interleucinas 1, 6, 8 e 10, além de C3a e mieloperoxidase (CHEW, 2004). 
Por outro lado, em cirurgia cardíaca pediátrica, argumenta-se que aumenta a estabilidade hemodinâmica, melhora a oxigenação no PO precoce e reduz tanto o sangramento $\mathrm{PO}$, como a duração da ventilação mecânica (JOURNOIS et al., 1994) e o uso de hemoderivados durante e pós-CEC (SOUZA et al., 2004), devido à redução do acúmulo de água corporal durante a CEC (MALUF et al., 1999; CHEW et al., 2004) e, por essa razão, foi adotada neste estudo. O volume ultrafiltrado foi semelhante nos dois grupos.

É discutível se a Aprotinina é também removida pela ultrafiltração (McDONOUGH et al., 2003). Relatos iniciais (CLAR et al., 1995) sugerem que sim, pois a molécula, de 6512 daltons, é suficientemente pequena para atravessar as membranas de hemofiltração. No entanto, como a carga elétrica da droga é negativa, sua passagem, através das membranas, também negativamente carregadas, pode ser tolhida (CLAR et al., 1995).

De fato, os níveis séricos de Aprotinina em pacientes submetidos à cirurgia com CEC prolongada e ultrafiltração não diferem muito dos detectados na ausência da última (DIETRICH et al., 1990; VAN NORMAN et al, 2000) e não há, até o momento, evidência de que a eficácia clínica da Aprotinina seja afetada pela hemofiltração. 
CONCLUSÕES

20.0. 
Pode-se concluir que:

A Aprotinina preservou quantitativamente as plaquetas, mas não influiu significativamente no sangramento pós-operatório e não minimizou manifestações clínicas e marcadores séricos de resposta inflamatória sistêmica e miocárdicos. 
REFERÊNCIAS BIBLIOGRÁFICAS 
ABBAS,A.K.; LICHTMAN,A.H. Imunologia Celular e Molecular. Trad. Reali,C., do original Cellular and Molecular Immunology, Rio de Janeiro, RJ: Elsevier Editora Ltda., 5a ed.; 2005.

ABELLAN,D.M.; GIMENEZ,S.C. Insuficiencia cardíaca congestiva diagnóstico e tratamento. In: SANTANA,M.V.T. Cardiopatias Congênitas no Recém-nascido - diagnóstico e tratamento, $1^{\mathrm{a} e d}$. São Paulo (SP), Rio de Janeiro (RJ), Belo Horizonte (MG): Editora Atheneu, cap.9, p. 102-114; 2000.

ALCARAZ,A.J.; MANZANO,L.; SANCHO,L.; VIGIL,M.D.; ESQUIVEL,F.; MAROTO,E.; REYES,E.; ALVAREZ-MON,M. Different proinflammatory cytokine serum pattern in neonate patients undergoing open heart surgery. Relevance of IL-8. J Clin Immunol, 25(3): 238- 245, 2005.

ALCARAZ,A.J.; SANCHO,L.; MANZANO,L.; ESQUIVEL,F.; CARRILLO,A.; PRIETO,A.; BERNSTEIN,E.D.; ALVAREZ-MON,M. Newborn patients exhibit an unusual pattern of interleukin 10 and interferon $y$ serum levels in response to cardiac surgery. J Thorac Cardiovasc Surg, 123: 451-458; 2002.

ALEXI-MESKISHVILI,V.; STILLER,B.; KOSTER,A.; BÖTTCHER,W.; HÜBLER,M.; PHOTIADIS,J.; LANGE,P.E.; HETZER,R. Correction of congenital heart defects in Jehovah's Witness children. Thorac Cardiovasc Surg, 52: 141-146; 2004.

ALONSO,A.; WHITTEN,C.W.; HILL,G.E. Pump prime only aprotinin inhibits cardiopulmonary bypass-induced neutrophil CD11b up-regulation. Ann Thorac Surg, 67: 392-395, 1999.

ALSTON,R.P.; SOUTER,M.J. Cerebral sequelae of cardiac surgery. Curr Opin Crit Care, 6: 92-97, 2000.

ALSTON,T.A. Aprotinin. Int Anesthesiol Clin, 42 (4): 81-91, 2004. 
ANDERSON,B.J.; MORTON,G.; McKENZIE,I. The use of antifibrinolytic drugs in paediatric cardiac surgery. Paed Perinatal Drug Ther, 6(1): 4-13; 2004.

ANDRADE,J.C.S.; BATISTA FILHO,M.L.; ÉVORA,P.R.B.; TAVARES,J.R.; BUFFOLO,E.; RIBEIRO,E.E. Utilização do azul de metileno no tratamento da síndrome vasoplégica após cirurgia cardíaca. Rev Bras Cir Cardiovasc, 11:107-14; 1996.

ARNESTAD,J.P.; BENGTSSON,A.; BENGTSON,J.P. Formation of cytokines by retransfusion of shed whole blood. Br J Anaesth, 72: 422-425; 1994.

ARNOLD, D.M.; FERGUSSON, D.A.; CHAN, A.K.C.; COOK, R.J.; FRASER, G.A.; LIM,W.; BLAJCHMAN,M.A.; COOK,D.J. Avoiding transfusions in children undergoing cardiac surgery: a meta-analysis of randomized trilas os aprotinin. Anesth Analg, 102: 731-737; 2006.

ASHRAF,S.S.; TIAN,Y.; COWAN,D.; SHAIKH,R.; PARSLOE,M.; MARTIN,P.; WATTERSON,K.G. Proinflammatory cytokine release during cardiopulmonary bypass: influence of centrifugal and roller pumps. $\mathbf{J}$ Cardiothorac Vasc Anesth, 11 (6): 718-722; 1997.

ASHRAF,S.S.; TIAN,Y.; ZACHARRIAS,S.; COWAN,D.; MARTIN,P.; WATTERSON,K. Effects of cardiopulmonary bypass on neonatal and paediatric inflammatory profiles. Eur J Cardio-thorac Surg, 12: 862-868; 1997.

ASIMAKOPOULOS,G.; GOURLAY,T. A review of anti-inflammatory strategies in cardiac surgery. Perfusion, 18: 7-12, 2003.

ASIMAKOPOULOS,G.; THOMPSON,R.; NOURSHARGH,S.; LIDINGTON,E.A.; MASON,J.C.; RATNATUNGA,C.P.; HASKARD,D.O.; TAYLOR,K.M.; LANDIS,R.C. An anti-inflammatory property of aprotinin 
detected at the level of leukocyte extravasation. J Thorac Cardiovasc Surg, 120: 361-369; 2000.

ATIK,F.A. Monitorização hemodinâmica em cirurgia cardíaca pediátrica. Arq Bras Cardiol, 82(2): 199-208; 2004.

BALAKRISHNAN,G.; AITCHISON,T.; HALLWORTH,D.; MORTON,N.S. Prospective evaluation of the Paediatric Risk of Mortality (PRISM) score. Arch Dis Child, 67(2): 196-200; 1992.

BEATH,S.M.; NUTTALL,G.A.; FASS,D.N.; OLIVER,W.C.; ERETH,M.H.; OYEN,L.J. Plasma aprotinin concentrations during cardiac surgery: fullversus half-dose regimens. Anesth Analg, 91: 257-264, 2000.

BEIERLEIN,W.; SCHEULE,A.M.; DIETRICH,W.; ZIEMER,G. Forty years of clinical aprotinin use: a review of 124 hypersensitivity reactions. Ann Thorac Surg, 79: 741-748; 2005.

BIRK-SORENSEN,L.; FUGLSANG,J.; SORENSEN,H.B.; KERRIGAN,C.L.; PETERSEN,L.C.; RAVN,H.B.; HJORTDAL,V.E. aprotinin attenuates platelet accumulation in ischaemia-reperfusion-injured porcine skeletal muscle. Blood Coagul fibrinolysis, 10(4): 157-165; 1999.

BLANLOEIL,Y. Aprotinine en chirurgie cardiaque: un article de l'année ou une provocation du New England Journal of Medicine. Ann Franç d'Anesth Réanim, 25: 683-685; 2006.

BLAUHUT,B.; $\quad$ GROSS,C.; NECEK,S.; DORAN,J.E.; $\quad$ SPÄTH,P.; LUNDSGAARD-HANSEN,P. Effects of high-dose aprotinin on blood loss, platelet function, fibrinolysis, complement, and renal function after cardiopulmonary bypass. J Thorac Cardiovasc Surg, 101: 958-967; 1991. 
BOLDT,J.; KNOTHE,C.; ZICKMANN,B.; WEGE,N.; DAPPER,F.; HEMPELMANN,G. Platelet function in cardiac surgery: influence of temperature and aprotinin. Ann Thorac Surg, 55 (3): 652-658; 1993.

BOLDT,J.; KNOTHE,C.; ZICKMANN,B.; WEGE,N.; DAPPER,F.; HEMPELMANN,G. Aprotinin in pediatric cardiac operations: platelet function, blood loss, and use of homologous blood. Ann Thorac Surg, 55: 1460-1466; 1993.

BOLDT,J.; KNOTHE,C.; ZICKMANN,B.; WEGE,N.; DAPPER,F.; HEMPELMANN,G. Comparison of two aprotinin dosage regimens in pediatric patients having cardiac operations. Influence on platelet function and blood loss. J Thorac Cardiovasc Surg, 105 (4): 705-711; 1993.

BOLDT,J.; ZICKMANN,B.; SCHINDLER,E.; WELTERS,A.; DAPPER,F.; HEMPELMANN,G. Influence of aprotinin on the thrombomodulin/protein $C$ system in pediatric cardiac operations. J Thorac Cardiovasc Surg, 107 (5): 1215-1221; 1994.

BONE,R.C.; BALK,R.A.; CERRA,F.B.; DELLINGER,R.P.; FEIN,A.M.; KNAUS,W.A.; SCHEIN,R.M.; SIBBALD,W.J. Definitions for sepsis and organ failure and guidelines for the use of innovative therapies in sepsis. The ACCP/SCCM Consensus Conference Committee. American College of Chest Physicians/Society of Critical Care Medicine. Chest, 101(6): 16441655; 1992.

BRADFIELD,J.F.; BODE,A.P. Aprotinin restores the adhesive capacity of dysfuncictional platelets. Thromb Res, 109: 181-188; 2003.

BRANCACCIO,G.; VILLA,E.; GIROLAMI,E.; MICHIELON,G.; FELTRI,C.; MAZZERA,E.; COSTA,D.; ISACCHI,G.; IANNACE,E.; AMODEO,A.; Di DONATO,R.M. Inflammatory cytokines in pediatric cardiac surgery and variable effect of the hemofiltration process. Perfusion,20(5): 263-268; 2005. 
BRASIL,L.A.; $\quad$ GOMES,W.J.; $\quad$ SALOMÃO,R.; $\quad$ FONSECA,J.H.P.; BRANCO,J.N.R.; BUFFOLO,E. Uso de corticóide como inibidor da resposta inflamatória sistêmica induzida pela circulação extracorpórea. Rev Bras Cir Cardiovasc, 14(3): 254-268, 1999.

BRIX-CHRISTENSEN,V. The systemic inflammatory response after cardiac surgery with cardiopulmonary bypass in children. Acta Anaesthesiol Scand, 45: 671-679, 2001.

BRIX-CHRISTENSEN,V.; VESTERGAARD,C.; CHEW,M. Plasma cytokines do not reflect expression of pro- and anti-inflammatory cytokine mRNA at organ level after cardiopulmonary bypass in neonatal pigs. Acta Anaesthesiol Scand, 47: 525-531; 2003.

BROCHE,F.; ROMERO,A.; OLEMBE,E.; CÉSPEDES,E.; PEÑA,M.; ROMAY,C.; GARCÍA,J.C. Aprotinin mediated antioxidant effect in cardiosurgery with mechanical cardiorespiratory support (CMCS). J Cardiovasc Surg, 43: 429-436, 2002.

BROCHE,V.F.; SUÀREZ,A.R.; OLEMBE,E.; FERNÀNDEZ,G.E.; CÉSPEDES,E.M.; GARCIA,J.C.; REYNOSO,E.; NÙÑEZ,P.; PRIETO,E. Aprotinina effects related to oxidative stress in cardiosurgery with mechanical cardiorespiratory support (CMCS). Ann N Y Acad Sci, 793: 521-524; 1996.

BUKHARI,E.A.; KRUKENKAMP,I.B.; BURNS,P.G.; GAUDETTE,G.R.; SCHULMAN,J.J.; AL-FAGIH,M.R.; LEVITSKY,S. Does aprotinin increase the myocardial damage in the setting of ischemia and preconditioning? Ann Thorac Surg, 60: 307-310; 1995.

BULL,D.A.; MAURER,J. Aprotinin and preservation of myocardial function after ischemia-reperfusion injury. Ann Thorac Surg, 75: S735-S739; 2003. 
BULUTCU,F.S.; ÖZBEK,U.; $\quad$ POLAT,B.; $\quad$ YALÇIN,Y.; $\quad$ KARACI,A.R.; BAYINDIR,O. Which may be effective to reduce blood loss after cardiac operations in cyanotic children: tranexamic acid, aprotinin or a combination? Pediat Anesth, 15:41-46; 2005.

CAPUTO,M.; BAYS,S.; ROGERS,C.A.; PAWADE,A.; PARRY,A.J.; SULEIMAN,S.; ANGELINI,G.D. Randomized comparison between normothermic and hypothermic cardiopulmonary bypass in pediatric openheart surgery. Ann Thorac Surg, 80: 982-988; 2005.

CARLOTTI, A.P.C.P. Manual de Rotina de Terapia Intensiva Pediátrica. São Paulo, SP: Tecmedd, $1^{\text {a }}$ edição, 2005.

CARMONA,F. Avaliação dos fatores de risco para disfunção miocárdica e mortalidade intra-hospitalar em neonatos e lactentes submetidos a cirurgia cardíaca com circulação extracorpórea. Ribeirão Preto, SP. Dissertação (Mestrado) - Faculdade de Medicina de Ribeirão Preto da Universidade de São Paulo; 2006.

CARREL,T.P.; SCHWANDA,M.; VOGT,P.R.; TURINA,M.I. Aprotinin in pediatric cardiac operations: a benefit in complex malformations and with high-dose regimen only. Ann Thorac Surg, 66: 153-158; 1998.

CHAN,A.K.; LEAKER,M.; BURROWS,F.A.; WILLIAMS W.G.; GRUENWALD,C.E.; WHYTE,L.; ADAMS,M.; BROOKER,L.A.; ADAMS,H.; MITCHELL,L.; ANDREW,M. Coagulation and fibrinolytic profile of paediatric patients undergoing cardiopulmonary bypass. Thromb Haemost, 77(2): 270$277 ; 1997$.

CHAN,K.-I.; IP,P.; CHIU,C.S.W.; CHEUNG,Y.-f. Peritoneal dialysis after surgery for congenital heart disease in infants and young children. Ann Thorac Surg, 76: 1443-1449, 2003. 
CHAUHAN,S.; KUMAR,B.A., RAO,B.H.; RAO,M.S.; DUBEY,B.; SAXENA,N.; VENUGOPAL,P. Efficacy of aprotinin, epsilon aminocaproic acid, or combination in cyanotic heart disease. Ann Thorac Surg, 70: 1308-1312; 2000.

CHECCHIA,P.A.; BRONICKI,R.A.; COSTELLO,J.M.; NELSON,D.P. Steroid use before pediatric cardiac operations using cardiopulmonary bypass: na international survey of 36 centers. Pediatr Crit Care Med, 6 (4): 441-444, 2005.

CHEW,M.S. Does modified ultrafiltration reduce the systemic inflammatory response to cardiac surgery with cardiopulmonary bypass? Perfusion, 19: S57-S60, 2004.

CHEW,M.S.; BRANDSLUND,I.; BRIX-CHRISTENSEN,V.; RAVN,H.B.; HJORTDAL,V.E.; PEDERSEN,J.; HJORTHOLM,K.; HANSEN,O.K.; TONNESEN,E. Tissue injury and the inflammatory response to pediatric cardiac surgery with cardiopulmonary bypass. A descriptive study. Anesthesiology, 94: 745-753; 2001.

CLAR,A.; LARSON,D.F. Hemofiltration: determinants of drug loss and concentration. J Extra Corpor Technol, 27(3): 158-163; 1995.

CLASEN,C.; JOCHUM,M.; MUELLER-ESTERL,W. Feasibility study of very high aprotinin dosage in polytrauma patients. Prog Clin Biol Res, 236A: 175; 1987.

COHEN,S.; SPRINGER,C.; AVITAL,A.; PERLES,Z.; REIN,A.J.J.T.; ARGAMAN,Z;; NIR,A. amino-terminal pro-brain-type natriuretic peptide: heart or lung disease in pediatric respiratory distress? Pediatrics, 115: 1347-1350; 2005. 
CONIFF,R.F. The Bayer 022 Compassionate-Use Pediatric study. Ann Thorac Surg, 65: S-31-S34; 1998.

CONTI,V.R. Vasodilation and cardiopulmonary bypass. The role of bradykinin and the pulmonary vascular endothelium. Chest, 120(6): 1759$1760 ; 2001$.

COSTELLO,J.M.; BACKER,C.L.; de HOYOS,A.; BINNS,H.J.; MAVROUDIS,C. Aprotinin reduces operative closure time and blood product use after pediatric bypass. Ann Thorac Surg, 75: 1261-1266; 2003.

DAVIS,R.; WHITTINGTON,R. Aprotinin. A review of its pharmacology and therapeutic efficacy in reducing blood loss associated with cardiac surgery. Drugs, 49(6): 955-983; 1995

DAVIES,M.J.; ALLEN,A.; KORT,H.; WEERASENA,N.A.; ROCCO,D.; PAUL,C.L.; HUNT,B.J.; ELLIOTT,M.J. Prospective, randomized, double-blind study of high-dose aprotinin in pediatric cardiac operations. Ann Thorac Surg, 63: 497-503; 1997.

DAY,J.R.S.; PUNJABI,P.P.; RANDI,A.M.; HASKARD,D.O.; LANDIS,R.C.; TAYLOR,K.M. Clinical inhibition of the seven-transmembrane thrombin receptor (PAR1) by intravenous aprotinin during cardiothoracic surgery. Circulation, 110: 2597-2600; 2004.

DAY,J.R.S.; TAYLOR,K.M. The systemic inflammatory response syndrome and cardiopulmonary bypass. Int J Surg, 3(2): 129-140; 2005.

DEFRAIGNE,J.-O.; PINCEMAIL,J.; LARBUISSON,R.; BLAFFART,F.; LIMET,R. Cytokine release and neutrophil activation are not prevented by heparin-coated circuits and aprotinin administration. Ann Thorac Surg, 69: 1084-1091; 2000. 
D'ERRICO,C.C. Pharmacoeconomics analysis in a pediatric population. Ann Thorac Surg, 65: S52-S55; 1998.

D'ERRICO,C.C.; SHAYEVITZ,J.R.; MARTINDALE,S.J.; MOSCA,R.S.; BOVE,E.L. The efficacy and cost of aprotinin in children undergoing reoperative open heart surgery. Anesth Analg, 83: 1193-1199; 1996.

DESPOTIS,G.J.; ALSOUFIEV,A.L.; GOODNOUGH,L.T.; LAPPAS,D.G. Aprotinin prolongs whole blood activated partial thromboplastin time but not whole blood prothrombin time in patients undergoing cardiac surgery. Anesth Analg, 81: 919-924; 1995.

DESPOTIS,G.J.; FILOS,K.S.; LEVINE,V.; ALSOUFIEV,A.; SPITZNAGEL,E. Aprotinin prolongs activated and nonactivated whole blood clottin time and potentiates the effect of heparin in vitro. Anesth Analg, 82: 1126-1131; 1996.

DESPOTIS,G.J.; JOIST,H.; JOINER-MAIER,D.; $\quad$ ALSOUFIEV,A.L.; TRIANTAFILLOU,A.N.; GOODNOUGH,L.T.; SANTORO,S.A.; LAPPAS,D.G. Effect of aprotinin on activated clotting time, whole blood and plasma heparin measurements. Ann Thorac Surg, 59: 106-111; 1995.

DIETRICH,W.; MÖSSINGER,H.; SPANNAGL,M.; JOCHUM,M.; WENDT,P.; BARANKAY,A.; MEISNER,H.; RICHTER,J.A. Hemostatic activation during cardiopulmonary bypass with different aprotinin dosages in pediatric patients having cardiac operations. J Thorac Cardiovasc Surg, 105 (4): 712-720; 1993.

DIETRICH,W.; SPANNAGL,M.; JOCHUM,M.; WENDT,P.; SCHRAMM,W.; BARANKAY,A.; SEBENING,F.; RICHTER,J.A. Influence of high-dose aprotinin treatment on blood loss and coagulation patterns in patients undergoing myocardial revascularization. Anesthesiology, 73: 1119-1126; 1990. 
DIETRICH,W.; $\quad$ SPÄTH,P.; $\quad$ ZÜHLSDORF,M.; $\quad$ DALICHAU,H; KIRCHHOFF,P.G.; KUPPE,H.; PREISS,D.U.; MAYER,G. Anaphylactic reactions to aprotinin reexposure in cardiac surgery. Relation to antiaprotinin immunoglobulin $\mathrm{G}$ and $\mathrm{E}$ antibodies. Anesthesiology, 95(1): 64-71; 2001.

DIETRICH,W.; BUSLEY,R.; KRINER,M. High-dose aprotinin in cardiac surgery: is high-dose high enough? An analysis of 8281 cardiac surgical patients treated with aprotinin. Anesth Analg, 103: 1074-1081; 2006.

DOUGHTY,L.; KAPLAN,S.; CARCILLO,J.A. Inflammatory cytokine and nitric oxide responses in pediatric sepsis and organ failure. Crit Care Med, 24 (7): 1137-1143; 1996.

DUBOIS,J.; JAMAER,L.; MEES,U.; PAUWELS,J.; BRIERS,F.; LEHAEN,J.; HENDRIKX,M. Ex vivo evaluation of a new neonatal/infant oxygenator: comparison of the Terumo CAPIOX Baby RX with Dideco Lilliput 1 and Polystan Safe Micro in the piglet model. Perfusion, 19(5): 315-321; 2004.

DUVAL,E.L.I.M.; KAVELAARS,A.; VEENHUIZEN,L.; van VUGHT,A.J.; van de WAL,H.J.C.M.; HEIJNEN,C.J. Pro- and anti-inflammatory cytokine patterns during and after cardiac surgery in young children. Eur $\mathbf{J}$ Pediatr, 158:387-393, 1999.

EISSES,M.J.; BRADFORD,H.M.; CHANDLER,W.L. $\quad$ X-Coating $^{\text {TM }}$ of oxygenator alone does not reduce hemostatic activation during $\mathrm{CPB}$ in children. Anesthesiology, 101: A1456; 2004.

ELLIOTT,M.J.; ALLEN,A. Aprotinin in paediatric cardiac surgery. Perfusion, 5 (suppl): 73-75; 1990.

ÉVORA,P.R. Should methylene blue be the drug of choice to treat vasoplegias caused by cardiopulmonary bypass and anaphylactic shock? J Thorac Cardiovasc Surg, 119:632-634; 2000 
FERRARIS,V.A.; BRIDGES,C.R.; ANDERSON,R.P. Aprotinin in cardiac surgery. N Engl J Med, 354(18): 1953-1957; 2006.

FRUMENTO,R.J.; O'MALLEY,C.M.N.; BENNETT-GUERRERO,E. Stroke after cardiac surgery: a retrospective analysis of the effect of aprotinin dosing regimens. Ann Thorac Surg, 75: 479-484; 2003.

GAYNOR,J.W. Use of ultrafiltration during and after cardiopulmonary bypass in children. J Thorac Cardiovasc Surg, 125: S98-S100, 2003.

GESSLER,P.; KNIRSCH,W,; SCHMITT,B.; ROUSSON,V.; von ECKARDSTEIN,A. Prognostic value of plasma $\mathrm{N}$-terminal pro-brain natriuretic peptide in children with congenital heart defects and open-heart surgery. J Pediatr, 148: 372-376; 2006.

GESSLER,P.; PFENNINGER,J.; PFAMMATTER,J.-P.; CARREL,T.; BAENZIGER,O.; DAHINDEN,C. Plasma levels of interleukin-8 and expression of interleukin-8 receptors on circulating neutrophils and monocytes after cardiopulmonary bypass in children. J Thorac Cardiovasc Surg, 126: 718-725, 2003.

GILLILAND,H.E.; $\quad$ ARMSTRONG,M.A.; $\quad$ UPRICHARD,S.; $\quad$ CLARKE,G.; McMURRAY,T.J. The effect of aprotinin on interleukin-8 concentration and leukocyte adhesion molecule expression in an isolated cardiopulmonary bypass system. Anaesthesia, 54: 427-433, 1999.

GOLDSTEIN,B.; GIROIR,B.; RANDOLPH,A.; Members of the International Consensus conference on Pediatric Sepsis. International pediatric sepsis consensus conference: definitions for sepsis and organ dysfunction in pediatrics. Pediatr crit Care Med, 6:2-8; 2005. 
GOMAR,C.; Del POZO,D.; FITA,G.; SALVADOR,L.; NALDA,M.A.; MULET,J. Aprotinin in paediatric cardiac surgery: blood loss and use of blood products. Br J Anaesth, 74 (Suppl.2): 33; 1995.

GREILICH,P.E.; $\quad$ BROUSE,C.F.; RINDER,C.S.; $\quad$ SMITH,B.R.; SANDOVAL,B.A.; RINDER,H.M.; EBERHART,R.C.; JESSEN.M.E. Effects of e-aminocaproic acid and aprotinin on leukocyte-platelet adhesion in patients undergoing cardiac surgery. Anesthesiology, 100: 225-233, 2004.

GREILICH,P.E.; BROUSE,C.F.; WHITTEN,C.W.; CHI,L.; DiMAIO,J.M.; JESSEN,M.E. Antifibrinolytic therapy during cardiopulmonary bypass reduces proinflammatory cytokine levels: a randomized, double-blind, placebo-controlled study of e-aminocaproic acid and aprotinin. J Thorac Cardiovasc Surg, 126: 1498-1503; 2003.

GUAY,J.; de MOERLOOSE,P.; LASNE,D. Minimizing perioperative blood loss and transfusions in children. Can J Anesth, 53(6): S59-S67; 2006.

HALL,R.I.; SMITH,M.S.; ROCKER,G. The systemic inflammatory response to cardiopulmonary bypass: pathophysiological, therapeutic,and pharmacological considerations. Anesth Analg, 85: 766-782, 1997.

HATHERILL,M.; SAJJANHAR,T.; TIBBY,S.M.; $\quad$ CHAMPION,M.P.; ANDERSON,D.; MARSH,M.J.; MURDOCH,I.A. serum lactate as a predictor of mortality after paediatric cardiac surgery. Arch Dis Child, 77: 235-238; 1997.

HAUSER,G.J.; BEN-ARI,J.; COLVIN,M.P.; DALTON,H.J.; HERTZOG,J.H.; BEARB,M.; HOPKINS,R.A.; WALKER,S.M. Interleukin-6 levels in serum and lung lavage fluid of children undergoing open heart surgery correlate with postoperative morbidity. Int Care Med, 24: 481-486; 1998. 
HAZAN,E.; PASAOGLU,I.; DEMIRCIN,M.; BOZER,A.Y. The effect of aprotinin (trasylol) on postoperative bleeding in cyanotic congenital heart disease. Turk J Pediatr, 33: 89-110,1991.

HENRY,D.A.; MOXEY,A.J.; $\quad$ CARLESS,P.A.; O'CONNELL,D.; McCLELLAND,B.; HENDERSON,K.M.; SLY,K.; LAUPACIS,A.; FERGUSSON,D. Anti-fibrinolytic use for minimising perioperative allogeneic blood transfusion. Cochrane Database Syst Rev, (1): CD001886; 2001.

HERYNKOPF,F.; LUCCHESE,F.; PEREIRA,E.; KALIL,R.; PRATES,P.; NESRALLA,I.A. Aprotinin in children undergoing correction of congenital heart defects. J Thorac Cardiovasc Surg, 108 (3): 517-521; 1994.

HILL,G.E.; ALONSO,A.; SPURZEM,J.R.; STAMMERS,A.H.; ROBBINS,R.A. Aprotinin and methylprednisolone equally blunt cardiopulmonary bypassinduced inflammation in humans. J Thorac Cardiovasc Surg, 110 (6): 1658$1662 ; 1995$.

HILL,G.E.; $\quad$ DIEGO,R.P.; $\quad$ STAMMERS,A.H.; HUFFMAN,S.M.; POHORECKI,R. Aprotinin enhances the endogenous release of interleukin10 after cardiac operations. Ann Thorac Surg, 65: 66-69; 1998.

HIMMELFARB,J.; HOLBROOK,D.; McMONAGLE,E. Effects of aprotinin on complement and granulocyte activation during ex vivo hemodialysis. Am J Kid Dis, 24(6): 901-906; 1994.

HOFFMAN,T.M.; WERNOVSKY,G.; ATZ,A.M.; KULIK,T.J.; NELSON,D.P.; CHANG,A.C.; BAILEY,J.M.; AKBARY,A.; KOCSIS,J.F.; KACZMAREK,R.; SPRAY,T.L.; WESSEL,D.L. Efficacy and safety of milrinone in preventing low cardiac output syndrome in infants and children after corrective surgery for congenital heart disease. Circulation, 107: 996-1002, 2003. 
HOFFMANN,H.; SIEBECK,M.; THETTER,O.; JOCHUM,M.; FRITZ,H. aprotinin concentrations effective for the inhibition of tissue kallikrein and plasma kallikrein in vitro and in vivo. Adv Exp Med Biol, 247 B: 35-42; 1989.

HOGUE,C.W.; LONDON,M.J.; Aprotinin use during cardiac surgery: a new or continuing controversy? Anesth Analg, 103 (3): 1067-1070; 2006.

HÖVELS-GÜRICH,H.; VAZQUEZ-JIMENEZ,J.F.; VILVESTRI,A.; SCHUMACHER,K.; MINKENBERG,R.; DUCHATEAU,J.; MESSMER,B.J.; von BERNUTH,G.; SEGHAYE,M.-C. Production of proinflammatory cytokines and myocardial dysfunction after arterial switch operation in neonates with transposition of the great arteries. J Thorac Cardiovasc Surg, 124 (4): 811820; 2002.

HÖVELS-GÜRICH,H.H.; SCHUMACHER,K.; VAZQUEZ-JIMENEZ,J.F.; QING,M.; HÜFFMEIER,U.; BUDING,B.; MESSMER,B.J.; von BERNUTH,G.; SEGHAYE,M.-C. Cytokine balance in infants undergoing cardiac operation. Ann Thorac Surg, 73: 601-609, 2002.

HUNTER,D. Focus on research: first, gather the data. N Engl J Med, 354(4): 329-331; 2006.

IMAI,M.; YAMAGUCHI,M.; OHASHI,H.; AOYAMA,M.; TANAKA,T.; OGAWA,K. Effects of aprotinin on blood loss reduction in children undergoing repair of tetralogy of Fallot. Nippon Kyobu Geka Gakkai Zasshi, 45(10): 1706-1709; 1997.

INUI,K.; SHIMAZAKI,Y.; WATANABE,T.; TAKAHASHI,T.; MINOWA,T.; TAKEDA,H.; YANAGAWA,N.; SOTODA,Y. Effects of Duraflo II heparincoated cardiopulmonary bypass circuits on the coagulation system, endothelial damage, and cytokine release in patients with cardiac operation employing aprotinin and steroids. Artif Organs, 23(12): 1107-1112, 1999. 
JAQUISS,R.D.B.; GHANAYEM,N.S.; ZACHARISEN,M.C.; MUSSATTO,K.A.; TWEDDELL,J.S.; LITWIN,S.B. Safety of aprotinin use and re-use in pediatric cardiothoracic surgery. Circulation, 106 (supl.I): I-90-I94; 2002.

JAQUISS,R.D.B.; HUDDLESTON,C.B.; SPRAY,T.L. Use of aprotinin in pediatric lung transplantation. J Heart Lung Transplant, 14:302-307; 1995.

JAVORSKI,J.J.; BURROWS,F.A. Pediatric cardiac anesthesia. Curr Opin Anaesthesiol, 8: 62-67; 1995.

JENKINS,K.J.; GAUVREAU,K.; NEWBURGER,J.W.; $\quad$ SPRAY,T.L.; MOLLER,J.H.; IEZZONI,L.I. Consensus-based method for risk adjustment for surgery for congenital heart disease. J Thorac Cardiovasc Surg, 123: 110$118 ; 2002$.

JENSEN,E.; ANDREASSON,S.; BENGTSSON,A.; BERGGREN,H.; EKROTH,R.; LINDHOLM,L.; OUCHTERLONY,J. Influence of two different perfusion systems on inflammatory response in pediatric heart surgery. Ann Thorac Surg, 75(3): 919-925; 2003.

JOURNOIS,D.; POUARD,P.; GREELEY,W.J.; MAURIAT,P.; VOUHE,P.; SAFRAN,D. Hemofiltration during cardiopulmonary bypass in pediatric cardiac surgery. Effects on hemostasis, cytokines, and complement components. Anesthesiology, 81(5): 1181-1189; 1994.

KARKOUTI,K.; BEATTIE,W.S. Aprotinin is useful as a hemostatic agent in cardiopulmonary surgery: no. J Thromb Haemost, 4: 1879-1881; 2006.

KAWAMURA,T.; WAKUSAWA,R.; OKADA,K.; INADA,S. Elevation of cytokines during heart surgery with cardiopulmonary bypass: participation of interleukin 8 and 6 in reperfusion injury. Can J Anaesth, 40(11): 1016-1021; 1993. 
KHABAR,K.S.A.; EIBARBARY,M.A.; KHOUQEER,F.; DEVOL,E.; ALGAIN,S.; AL-HALEES,Z. Circulating endotoxin and cytokines after cardiopulmonary bypass: differential correlation with duration of bypass and systemic inflammatory response/multiple organ dysfunction syndromes. Clin Immunol Immunopathol, 85(1): 97-103; 1997.

KHAN,T.A.; BIANCHI,C.; VOISINE,P.; FENG,J.; BAKER,J.; HART,M.; TAKAHASHI,M.; STAHL,G.; SELLKE,F.W. Reduction of myocardial reperfusion injury by aprotinin after regional ischemia and cardioplegic arrest. J Thorac Cardiovasc Surg, 128: 602-608; 2004.

KHAN,T.A.; BIANCHI,C.; VOISINE,P.; SANDMEYER,J.; FENG,J.; SELLKE,F.W. Aprotinin inhibits protease-dependent platelet aggregation and thrombosis. Ann Thorac Surg, 79: 1545-1550, 2005.

KIRKLIN,J.K. Prospects for understanding and eliminating the deleterious effects of cardiopulmonary bypass. Ann Thorac Surg, 51: 529-531; 1991.

KOCH,A.; KITZSTEINER,T.; ZINK,S.; CESNJEVAR,R.; SINGER,H. Impact of cardiac surgery on plasma levels of B-type natriuretic peptide in children with congenital heart disease. Int J Cardiol, 3,[epub ahead of print]; 2006.

KOH,M.B.C.; HUNT,B.J. The management of perioperative bleeding. Blood Rev, 17: 179-185; 2003.

KOLISKI,A.; CAT,I.; GIRALDI,D.J.; CAT,M.L. Lactato sérico como marcador prognóstico em crianças gravemente doentes. J Pediatr (Rio J), 81(4): 287292; 2005.

KUMAR,V.; ABBAS,A.K.; FAUSTO,N. Inflamação aguda e crônica. In: Robbins e Cotran Patologia - bases Patológicas das Doenças, $7^{\mathrm{a}}$ ed. Rio de Janeiro, RJ: Elsevier Editora Ltda, cap. 2, p. 490-89; 2005. 
LACOUR-GAYET,F.; CLARKE,D.; JACOBS,J.; COMAS,J.; DAEBRITZ,S.; DAENEN,W.; GAYNOR,W.; HAMILTON,L.; JACOBS,M.; MARUSZSEWSKI,B.; POZZI,M.; SPRAY,T.; STELLIN,G.; TCHERVENKOV,C.; MAVROUDIS,C.; The Aristotle Committee. The Aristotle score: a complexity-adjusted method to evaluate surgical results.Eur $\mathbf{J}$ cardio-thorac Surg, 25: 911-924; 2004.

LAFFEY,J.G.; BOYLAN,J.F.; CHENG,D.C.H. The systemic inflamatory response to cardiac surgery. Implications for the anesthesiologist. Anesthesiology, 97: 215-252; 2002.

LAGA,S.; BOLLEN,H.; ARNOUT,J.; HOYLAERTS,M.; MEYNS,B. Heparin influences human platelet behavior in cardiac surgery with or without cardiopulmonary bypass. Artif Organs, 29(7): 541-546; 2005.

LARMANN,J.; THEILMEIER,G. Inflammatory response to cardiac surgery: cardiopulmonary bypass versus non-cardiopulmonary bypass surgery. Best Pract Res Clin Anaesthesiol, 18(3): 425-438, 2004.

LEI,Y.; HAIDER,H.K.; CHUSNSHENG,W.; ZHIQIANG,C.; HAO,C.; KEJIAN,H.; QIANG,Z. Dose-dependent effect of aprotinin on aggravated proinflammatory cytokines in patients with pulmonary hypertension following cardiopulmonary bypass. Cardiovasc Drugs Ther, 17: 343-348; 2003.

LEQUIER,L.L.; $\quad$ NIKAIDOH,H.; $\quad$ LEONARD,S.R.; $\quad$ BOKOVOY,J.L.; WHITE,M.L.; SCANNON,P.J.; GIROIR,B.P. Preoperative and postoperative endotoxemia in children with congenital heart disease. Chest, 117:17061712, 2000.

LEVI,M.; CROMHEECKE,M.E.; de JONGE,E.; PRINS,M.H.; de MOL,B.J.M.; BRIËT,E.; BÜLLER,H.R. Pharmacological strategies to decrease excessive blood loss in cardiac surgery: a meta-analysis of clinically relevant endpoints. Lancet, 354: 1940-1947; 1999. 
LEVIN,E.R.; GARDNER,D.G.; SAMSON,W.K. Natriuretic peptides. N Engl J Med, 339: 321-328; 1998.

LEVY,J.H.; TANAKA,K.A. Inflammatory response to cardiopulmonary bypass. Ann Thorac Surg, 75:S715-S720; 2003.

LEVY,M.M.; FINK,M.P.; MARSHALL,J.C.; ABRAHAM,E.; ANGUS,D.; COOK,D.; COHEN,J.; OPAL,S.M.; VINCENT,J.-L.; RAMSAY,G.; International Sepsis definitions conference. 2001 SCCM/ESICM/ACCP/ATS/SIS International Sepsis Definitions Conference. Crit Care Med, 31:1250-1256; 2003.

LEVY,J.H. Aprotinin is useful as a hemostatic agent in cardiopulmonary surgery: yes. J Thromb Haemost, 4: 1875-1878; 2006.

LI,S.; PRICE,R.; PHIROZ,D.; SWAN,K.; CRANE,T.A. Systemic inflammatory response during cardiopulmonary bypass. J Extracorpor Technol, 37: 180188; 2005.

LICASTRO,F.; MARIANI,R.A.; FALDELLA,G.; CARPENÈ,E.; GUIDICINI,G.; RANGONI,A.; GRILLI,T.; BAZZOCCHI,G. Immune-endocrine status and coeliac disease in children with Down's syndrome with zinc and cognitive efficiency. Brain Res Bull, 55(2): 313-317; 2001.

MA,K.K.; OGAWA,T.; de BOLD,A.J. Selective upregulation of cardiac brain natriuretic peptide at the transcriptional and translational levels by proinflammatory cytokines and by conditioned medium derived from mixed lymphocyte reactions via p38 MAP kinase. J Mol Cell Cardiol, 36: 505-513; 2004.

MAHARAJ,C.; LAFFEY,J.G. New strategies to control the inflammatory response in cardiac surgery. Curr Opin Anaesthesiol, 17: 35-48, 2004. 
MALUF,M.A.; MANGIA,C.; BERTUCCEZ,J.; SILVA,C.; CATANI,R.; CARVALHO,W.; CARVALHO,A.; BUFFOLO,E. Estudo comparativo da ultrafiltração convencional e associação de ultrafiltração convencional e modificada na correção de cardiopatias congênitas com alto risco cirúrgico . Rev Bras Cir Cardiovasc, 14 (3): 221-236; 1999

MANGANO,D.T. Aprotinin in cardiac surgery. N Engl J Med, 354(18): 19531957; 2006.

MANGANO,D.T.; TUDOR,I.C.; DIETZEL,C. The risk associated with aprotinin in cardiac surgery. N Engl J Med, 354(4): 353-365; 2006.

MANNO,C.S.; HEDBERG,K.W.; KIM,H.C.; BUNIN,G.R.; NICOLSON,S.; JOBES,D.; SCHWARTZ,E.; NORWOOD,W.I. Comparison of the hemostatic effects of fresh whole blood, stored whole blood, and components after open heart surgery in children. Blood, 77(5): 930-936; 1991.

MARTÍN BURCIO,S.; GONZÁLEZ,J.V.; DOMÍNGUEZ,F.; BALDA,J.I.D.; MARTÍNEZ,M.; VELLIBRE,D. Utilización de aprotinina en cirugía cardíaca pediátrica. Rev Esp Anestesiol Reanim, 48: 212-216, 2001.

MASIAK,M.; BROSS,W. Zastosowanie Trasylolu jako leku hamujacego proteazy ukladu fibrynolizy w krazeniu pozaustrojowym (ECC). Folia Med Cracov, 22 (3-4): 455-461; 1980.

MATTOS,S.S; NEVES,J.R.; COSTA,M.C.; HATEM,T.P.; LUNA,C.F. An index for evaluating in paediatric cardiac intensive care. Cardiol Young, 16: 369$377 ; 2006$.

McBRIDE,W.T.; ARMSTRONG,M.A.; GILLILAND,H.; McMURRAY,T.J. The balance of pro and anti- inflammatory cytokines in plasma and bronchoalveolar lavage (BAL) at paediatric cardiac surgery. Cytokine, 8(9):724-729, 1996. 
McDONOUGH,J.; GRUENWALD,C. The use of aprotinin in pediatric patients: a review. J Extra-Corpor Technol, 35 (4): 346-349; 2003.

MENASCHE,P.; EDMUNDS,L.H. Extracorporeal circulation: the inflammatory response. In: Cohn,L.H., Edmunds,L.H.Jr., eds. Cardiac Surgery in the adult. New York: McGrawHill: 349-360; 2003.

MENGER,M.D.; VOLLMAR,B. Surgical trauma: hyperinflammation versus immunosuppression? Langenbecks Arch Surg, 389: 475-484, 2004.

MIANA,L.A.; ATIK,F.A.; MOREIRA,L.F.; HUEB,A.C.; JATENE,F.B.; AULER Jr.,J.O.; OLIVEIRA,S.A. Fatores de risco de sangramento no pós-operatório de cirurgia cardíaca em adultos. Rev Bras Cir Cardiovasc, 19(3): 280-286; 2004.

MILLER,B.E.; TOSONE,S.R.; TAM,V.K.H.; KANTER,K.R.; GUZZETTA,N.A.; BAILEY,J.M.; LEVY,J.H. Hematologic and economic impact of aprotinin in reoperative pediatric cardiac operations. Ann Thorac Surg, 66: 535-541; 1998.

MING,W.; YUN-BI,L.; BO,J.; SHI-WEI,X.; RU-KUN,C.; HAN-LIANG,Z. Effects of methylprednisolone and aprotinin on phospholipase $D$ activity of leukocytes in systemic inflammatory response induced by cardiopulmonary bypass. Acta Pharmacol Sin, 22(10): 913-917, 2001.

MIR,T.S.; MAROHN,S.; LÄER,S.; EISELT,M.; GROLLMUS,O.; WEIL,J. Plasma concentrations of $\mathrm{N}$-terminal pro-brain natriuretic peptide in control children from the neonatal to adolescent period and in children with congestive heart failure. Pediatrics, 110(6):e76; 2002

MÖSSINGER,H.; DIETRICH,W. Activation of hemostasis during cardiopulmonary bypass and pediatric aprotinin dosage. Ann Thorac Surg, 65: S45-S51; 1998. 
MÖSSINGER,H.; DIETRICH,W.; BRAUN,S.L.; JOCHUM,M.; MEISNER,H.; RICHTER,J.A. High-dose aprotinin reduces activation of hemostasis, allogeneic blood requirement, and duration of postoperative ventilation in pediatric cardiac surgery. Ann Thorac Surg, 75: 430-437; 2003.

MOU,S.S; HAUDEK,S.B.; LEQUIER,L.; PEÑA,O.; LEONARD,S.; NIKAIDOH,H.; GIROIR,B.P.; STROMBERG,D. Myocardial inflammatory activation in children with congenital heart disease. Crit Care Med, 30: 827832; 2002.

MOURA,H.V.; POMERANTZEFF,P.M.A.; GOMES,W.J. Síndrome da resposta inflamatória sistêmica na circulação extracorpórea: papel das interleucinas. Rev Bras Cir Cardiovasc, 16(4): 376-387, 2001.

MOURA,M.R. Emergências em cardiologia pediátrica. In: MACRUZ,R.; SNITCOWSKY,R. Cardiologia pediátrica, $1^{\text {a }}$ ed. São Paulo, SP: Sarvier Editora de Livros Médicos Ltda, cap 49, p. 657-674; 1988.

MUELLER,T.; GegenHUBER,A.; DIEPLINGER,B.; POELZ,W.; HALTMAYER,M. Long-term stability of endogenous B-type natriuretic peptide (BNP) and amino terminal proBNP (NT-proBNP) in frozen plasma samples. Clin Chem Lab Med, 42(8): 942-944; 2004.

MÜLLER,H.; ALKEN,A.; ZIEMER,G.; LUHMER,I.; HIRT,S.; SCHAPS,D. Aprotinin in paediatric cardiopulmonary bypass surgery. J Cardiothorac Vasc Anesth, 6 (suppl. 1): 100; 1992.

MUNFORD,R.S.; PUGIN,J. Normal responses to injury prevent systemic inflammation and can be immunosuppressive. Am J Respir Crit Care Med, 163: 316-321; 2001.

MURKIN,J.M.; MAURER,J.; NIEMCRYK,S. Full dose aprotinin administration with a significant decrease in perioperative stroke in patients undergoing 
elective cardiac surgery: a meta-analysis. Ann Thorac Surg, 73: S374; 2002.

MURRAY,D.M.; OLHSSON,V.; FRASER, J.I. Defining acidosis in postoperative cardiac patients using Stewart's method of strong ion difference. Pediatr Crit Care Med, 5 (3): 240-245; 2004.

NAGAOKA,H.; INNAMI,R.; MURAYAMA,F.; FUNAKOSHI,N.; HIROOKA,K.; WATANABE,M.; SATOH,M. Effects of aprotinin on prostaglandin metabolism and platelet function in open heart surgery. J Cardiovasc Surg, 32: 31-37; 1991.

NEUHOF,C.; WALTER,O.; DAPPER,F.; BAUER,J.; ZICKMANN,B.; FINK,E.; TILLMANNS,H.; NEUHOF,H. Bradykinin and histamine generation with generalized enhancement of microvascular permeability in neonates, infants, and children undergoing cardiopulmonary bypass surgery. Pediatr Crit Care Med, 4(3): 299-304, 2003.

OHUCHI,H.; OKABE,H.; NAGATA,N.; KANEKO,Y. Aprotinin reduces homologous blood transfusions when pediatric cardiac surgery must be redone. Nippon Kyobu Geka Gakkai Zasshi, 44(11): 1980-1985; 1996.

OKUR,H.; KÜÇÜKAYDIN,M.; ÜSTDAL,M. The endocrine and metabolic response to surgical stress in the neonate. J Pediatr Surg, 30(4): 626-630; 1995.

OLIVENCIA-YURVATI,A.H.; WALLACE,N.; FORD,S.; MALLET,R.T. Leukocyte filtration and aprotinin: synergistic anti-inflammatory protection. Perfusion, 19: S-13 - S19, 2004.

OLIVER,W.C., Jr.; $\quad$ FASS,D.N.; NUTTALL,G.A.; DEARANI,J.A.; SCHRADER,L.M.; SCHROEDER,D.R.; ERETH,M.H.; PUGA,F.J. Variability 
of plasma aprotinin concentrations in pediatric patients undergoing cardiac surgery. J Thorac Cardiovasc Surg, 127: 1670-1677, 2004.

OPAL,S.M.; DePALA,V.A. Anti-inflammatory cytokines. Chest, 117: 1162$1172 ; 2000$.

OZAWA,T.; YOSHIHARA,K.; KOYAMA,N.; WATANABE,Y.; SHIONO,N.; TAKANASHI,Y. Clinical efficacy of heparin-bonded bypass circuits related to cytokine responses in children. Ann Thorac Surg, 69: 584-590; 2000.

OZIER,Y.; SCHLUMBERGER,S. Pharmacological approaches to reducing bood loss and transfusions in the surgical patient. Can J Anesth, 53(6): S21S29; 2006.

PAPARELLA,D.; YAU,T.M.; YOUNG,E. Cardiopulmonary bypass induced inflammation: pathophysiology and treatment. An update. Eur J Cardiothorac Surg, 21: 232-244; 2002.

PENKOSKE,P.A.; ENTWISTLE,L.M.; MARCHAK,E.; SEAL,R.F.; GIBB,W. Aprotinin in children undergoing repair of congenital heart defects. Ann thorac Surg, 60: S529-S532, 1995.

PETÄJÄ,J.; PELTOLA,K.; SAIRANEN,H.; LEIJALA,M.; KEKOMÄKI,R.; VAHTERA,E.; LIC,P.; SIIMES,M.A. Fibrinolysis, antithrombin III, and protein $C$ in neonates during cardiac operations. J Thorac Cardiovasc Surg, 112: 665-671; 1996.

PETERS,D.C.; NOBLE,S. Aprotinin. An update of its pharmacology and therapeutic use in open heart surgery and coronary artery bypass surgery. Drugs, 57(2): 233-260; 1999.

POLLACK,M.M.; RUTTIMANN,U.E.; GETSON,P.R. Pediatric risk of mortality (PRISM) score. Crit Care Med, 16(11): 1110-1116; 1988. 
POPOV-CENIC,S.; URBAN,A.E.; NOË,G. Studies on the cause of bleeding during and after surgery with a heart-lung machine in children with cyanotic and acyanotic congenital cardiac defects and their prophylactic treatment. In: Mc Coonn, R., ed. Role of chemical mediators in the pathophysiology of acute illness and injury. New York, Raven Press : 229-242; 1982.

POUARD,P. Review of efficacy parameters. Ann Thorac Surg, 65: S40-S44; 1998.

POULLIS,M.; MANNING,R.; LAFFAN,M.; HASKARD,D.O.; TAYLOR,K.M.; LANDIS,R.C. The antithrombotic effect of aprotinin: actions mediated via the protease-activated receptor 1. J Thorac Cardiovasc Surg, 120:370-378; 2000.

PRONDZINSKY,R.; KNÜPFER,A.; LOPPNOW,H.; REDLING,F.; LEHMANN,D.W.; STABENOW,I.; WITTHAUT,R.; UNVERZAGT,S.; RADKE,J.; ZERKOWSKI,H.-R.; WERDAN,K. Surgical trauma affects the proinflammatory status after cardiac surgery to a higher degree than cardiopulmonary bypass. J Thorac Cardiovasc Surg, 129: 760-766,2005.

PRUEFER,D.; BUERKE,U.; KHALIL,M.; DAHM,M.; DARIUS,H.; OELERT,H.; BUERKE,M. Cardioprotective effects of the serine protease inhibitor aprotinin after regional ischemia and reperfusion on the beating heart. $\mathbf{J}$ Thorac Cardiovasc Surg, 124: 942-949; 2002.

PRUEFER,D; MAKOWSKI,J.; DAHM.M.; GUTH,S.; OELERT,H.; DARIUS,H.; BUERKE,M. Aprotinin inhibits leukocyte-endothelial cell interactions after hemorrhage and reperfusion. Ann thorac Surg, 75: 210-216; 2003.

QING,M.; SCHUMACHER,K.; HEISE,R.; WÖLTJE,M.; VAZQUEZJIMENEZ,J.F.; RICHTER,T.; ARRANDA-CARRERO,M.; HESS,J.; von BERNUTH,G.; SEGHAYE,M.-C. Intramyocardial synthesis of pro- and anti- 
inflammatory cytokines in infants with congenital cardiac defects. J Am Coll Cardiol, 41(12): 2266-2274,2003.

QING,M; VAZQUEZ-JIMENEZ,J.F.; KLOSTERHALFEN,B.; SIGLER,M.; SCHUMACHER,K.; DUCHATEAU,J.; MESSMER,B.J.; von BERNUTH,G.; SEGHAYE,M.-C. Influence of temperature during cardiopulmonary bypass on leukocyte activation, cytokine balance, and post-operative organ damage. Shock, 15(5): 372-377; 2001.

RANUCCI,M.; CORNO,A.; PAVESI,M.; CIRRI,S.; MENICANTI,L.; FRIGIOLA,A.; CELORIA,R.; DITTA,A.; BONCILLI,A.; CONTI,D. Renal effects of low dose aprotinin in pediatric cardiac surgery. Min Anestesiol, 60: 361366; 1994.

REDDY VM, LIDDICOAT JR, HANLEY FL. Primary bidirectional superior cavopulmonary shunt in infants between 1 and 4 months of age. Ann Thorac Surg., 59:1120-1125; 1995; discussion 1125-1126.

REITHMANN,C.; REBER,D.; KOZLIK-FELDMANN,R. A post-receptor defect of adenylyl cyclase in severely failing myocardium from children with congenital heart disease. Eur J Pharmacol, 330: 79-86; 1997.

RIBEIRO,N.A.M.; STOLF,N.A.G.; JUNIOR,A.F.S.; VIANA,V.J.C.; CARVALHO,E.N.; ATHANÁZIO,R.; REIS,M.G.; OLIVEIRA,S.A. Efeito do azul de metileno na resposta inflamatória e hemodinâmica em pacientes submetidos à cirurgia de revascularização miocárdica com circulação extracorpórea. Rev Bras Cir Cardiovasc, 19(1): 17-23; 2004.

RINDER,C. Cellular inflammatory response and clinical outcome in cardiac surgery. Curr Opin Anaesthesiol, 19: 65-68; 2006.

ROSS,R.D.; BOLLINGER,R.O.; PINSKY,W.W. Grading the severity of congestive heart failure in infants. Pediatr Cardiol, 13(2): 72-75; 1992. 
ROTH-ISIGKEIT,A.; HASSELBACH,L.; OCKLITZ,E.; BRÜCKNER,S.; ROS,A.; GEHRING,H.; SCHMUCKER,P.; RINK,L.; SEYFARTH,M. Interindividual differences in cytokine release in patients undergoing cardiac surgery with cardiopulmonary bypass. Clin Exp Immunol, 125: 80-88; 2001.

ROYSTON,D.; BIDSTRUP,B.P.; TAYLOR,K.M.; SAPSFORD,R.N. Effect of aprotinin on need for blood transfusion after repeat open-heart surgery. Lancet, 330: 1289-1291; 1987.

ROYSTON,D. High-dose aprotinin therapy: a review of the first five year's experience. J Cardiothorac Vasc Anesth, 6 (1): 76-100; 1992.

ROYSTON,D. Preventing the inflammatory response to open-heart surgery: the role of aprotinin and other protease inhibitors. Int J Cardiol, 53 (suppl): S11- S37; 1996.

ROYSTON,D. The inflammatory response and extracorporeal circulation. J Cardiothorac Vasc Anesth, 11(3): 341-354, 1997

ROYSTON,D.; CARDIGAN,R.; GIPPNER-STEPPERT,C.; JOCHUM,M. Is perioperative plasma aprotinin concentration more predictable and constant after a weight-related dose regimen? Anesth Analg, 92: 830-836, 2001.

ROYSTON,D.; KOVEZI,T.; MARCZIN,N. The unwanted response to cardiac surgery: time for a reappraisal? J Thorac Cardiovasc Surg, 125 (1): 32-35; 2003.

ROYSTON,D.; LEVY,J.H.; FITCH,J.; DIETRICH,W.; BODY,S.C.; MURKIN,J.M.; SPIESS,B.D.; NADEL,A. Full-dose aprotinin use in coronary artery bypass graft surgery: an analysis of perioperative pharmacotherapy and patient outcomes. Anesth Analg, 103: 1082-1088; 2006. 
RUBENS,F.D.; MESANA,T. The inflamatory response to cardiopulmonary bypass: a therapeutic overview. Perfusion, 19: S5-S12, 2004.

SAATVEDT,K.; LINDBERG,H.; GEIRAN,O.R.; MICHELSEN,S.; AASEN,A.O.; PEDERSEN,T.; MOLLNES,T.E. Complement activation and release of tumour necrosis factor alpha, interleukin-2, interleukin-6 and soluble tumour necrosis factor and interleukin-2 receptors during and after crdiopulmonary bypass in children. Scand J Clin Lab invest, 55: 79-86; 1995.

SANT'ANNA,J.R.M.; LUCCHESE,F.A. Circulação extracorpórea para cirurgia cardíaca. In: NESRALLA,I. Cardiologia Cirúrgica: perspectivas para o ano 2000, $1^{\text {a }}$ ed. São Paulo, SP: Fundo Editorial BYK, Cap.15,.244-263; 1994.

SARAIYA,N.; SUN,L.S.; JONASSEN,A.E.; PESCE,M.A.; QUEAGEBEUR, J.M. Serum cardiac troponin-I elevation in neonatal cardiac surgery is lesiondependent. J Cardiothorac Vasc Anesth, 19(5): 620-625; 2005.

SCHMARTZ,D.; TABARDEL,Y.; PREISER,J.-C.; BARVAIS,L.; d'HOLLANDER,A.; DUCHATEAU,J.; VINCENT,J.-L. Does aprotinin influence the inflammatory response to cardiopulmonary bypass in patients? $\mathbf{J}$ Thorac Cardiovasc Surg, 125 (1): 184-190; 2003.

SCHWARTZ,G.J.; BRION,L.P.; SPITZER,A. The use of plasma creatinine concentration for estimating glomerular filtration rate in infants, children and adolescents. Pediatr Clin North Am, 34(3): 571-590; 1987.

SCHWEIZER,A., HÖHN,L.; MOREL,D.R.; KALANGOS,A.; LICKER,M. Aprotinin does not impair renal haemodynamics and function after cardiac surgery. Br J Anaesth, 84(1): 16-22; 2000. 
SEDRAKYAN,A.; ATKINS,D.; TREASURE,T. The risk of aprotinin: a conflict of evidence. Lancet, 367: 1376-1377; 2006.

SEDRAKYAN,A.; TREASURE,T.; ELEFTERIADES,J.A. Effect of aprotinin on clinical outcomes in coronary artery bypass graft surgery: a systematic review and meta-analysis of randomized clinical trials. J Thorac Cardiovasc Surg, 128 (3): 442-448; 2004.

SEGHAYE,M.-C.; DUCHATEAU,J.; BRUNIAUX,J.; DEMONTOUX,S.; BOSSON,C.; SERRAF,A.; LECRONIER,G.; MOKHFI,E.; PLANCHÉ,C. Interleukin-10 release related to cardiopulmonary bypass in infants undergoing cardiac operations. J Thorac Cardiovasc Surg, 111: 545-553; 1996.

SEGHAYE,M.-C.; DUCHATEAU,J.; GRABITZ,R.G.; FAYMONVILLE,M.L.; MESSMER,B.J.; BURO-RATHSMANN,K.; von BERNUTH,G. Complement activation during cardiopulmonary bypass in infants and children: relation to postoperative multiple system organ failure. J Thorac Cardiovasc Surg. 106: 978-987; 1993.

SEGHAYE,M.-C.; DUCHATEAU,J.; GRABITZ,R.G.; JABLONKA,K.; WENZL,T.; MARCUS,C.; MESSMER,B.J.; von BERNUTH,G. Influence of low-dose aprotinin on the inflammatory reaction due to cardiopulmonary bypass in children. Ann Thorac Surg, 61: 1205-1211; 1996.

SEGHAYE,M.-C.;GRABITZ,R.G.; DUCHATEAU,J.; BUSSE,S.; DÄBRITZ,S.; KOCH,D.; ALZEN,G.; HÖRNCHEN,H.; MESSMER,B.J.; von BERNUTH,G. Inflammatory reaction and capillary leak syndrome related to cardiopulmonary bypass in neonates undergoing cardiac operations. $\mathbf{J}$ Thorac Cardiovasc Surg, 112: 687-697; 1996. 
SEGHAYE, M.-C. The clinical implications of the systemic inflammatory reaction related to cardiac operations in children. Cardiol Young, 13: 228239; 2003.

SHEN,I.; GIACOMUZZI,C.; UNGERLEIDER,R.M. Current strategies for optimizing the use of cardiopulmonary bypass in neonates and infants. Ann Thorac Surg, 75: S729-S734; 2003.

SHERWOOD,E.R.; TOLIVER-KINSKY,T. Mechanisms of the inflammatory response. Best Pract Res Clin Anaesthesiol, 18(3): 385-405, 2004.

SHIMOYAMA,T.; TABUCHI,N.; KOJIMA,K.; AKAMATSU,H.; ARAI,H.; TANAKA,H.; SUNAMORI,M. Aprotinin attenuated ischemia-reperfusion injury in an isolated rat lung model after 18-hours preservation. Eur J Cardiothorac Surg, 23: 1-7, 2005.

SHINFELD,A.; ZIPPEL,D.; LAVEE,J.; LUSKY,A.; SHINAR,E.; SAVION,N.; MOHR,R. Aprotinin improves hemostasis after cardiopulmonary bypass better than single-donor platelet concentrate. Ann Thorac Surg, 59: 872876; 1995.

SHORE-LESSERSON,L. Aprotinin has direct platelet protective properties: fact or fiction? J Cardiothorac Vasc Anesth, 13(4): 379-381; 1999.

SILVEIRA,F.M.R.C.; LOURENÇO,D.M.; MALUF,M.; CARVALHO,W.B.; BUFFOLO,E.; CARVALHO,A.C. Alterações da hemostasia em crianças submetidas a cirurgia cardíaca com circulação extracorpórea. Arq Bras Cardiol, 70(1): 29-35; 1998.

SOUZA,D.D.; BRAILE,D.M. Avaliação de nova técnica de hemoconcentração e da necessidade de transfusão de hemoderivados em pacientes submetidos à cirurgia cardíaca com circulação extracorpórea. Rev Bras Cir Cardiovasc. 19(3): 287-294; 2004. 
SPRAY,T.L. Use of aprotinin in pediatric organ transplantation. Ann Thorac Surg, 65: S71-S73; 1998.

STACK,G.; SNYDER,E.L. Cytokine generation in stored platelet concentrates. Transfusion, 34: 20-25; 1994.

SUGITA,T.; $\quad$ WATASIDA,S.; KATSUYAMA,K.; $\quad$ NAKAJIMA,Y.; YAMAMOTO,R.; MORI,A. Interleukin-10 concentration in children undergoing cardiopulmonary bypass. J Thorac Cardiovasc Surg, 112: 1127-1128; 1996.

TABARDEL,Y.; DUCHATEAU,J.; SCHMARTZ,D. Corticosteroids increase blood interleukin-10 levels during cardiopulmonary bypass in men. Surgery, 119: 76-80; 1996.

TANIGUCHI,T.; KOIDO,Y.; $\quad$ AIBOSHI,J.; YAMASHITA,T.; SUZAKI,S.; KUROKAWA,A. Change in the ratio of interleukin- 6 to interleukin-10 predicts a poor outcome in patients with systemic inflammatory response syndrome. Crit Care Med, 27 (7): 1262-1264; 1999.

TÁRNOK,A.; HAMBSCH,J.; SCHNEIDER,P. Cardiopulmonary bypassinduced increase of serum interleukin-10 levels in children. J Thorac Cardiovasc Surg, 115(2): 475-477; 1998.

TASSANI,P.; RICHTER,J.A.; BARANKAY,A.; BRAUN,S.L.; HAEHNEL,C.; SPAETH,P.; SCHAD,H.; MEISNER,H. Does high-dose methylprednisolone in aprotinin-treated patients attenuate the systemic inflammatory response during coronary artery bypass grafting procedures? J Cardiothorac Vasc Anesth, 13(2): 165-172, 1999.

TODA,Y.; DUKE,T.; SHEKERDEMIAN,L.S. influences on lactate levels in children early after cardiac surgery: prime solution and age. Crit Care Resusc, 7(2): 87-91; 2005. 
TORRE-AMIONE,G.; KAPADIA,S.; BENEDICT,C.; ORAL,H.; YOUNG,J.B.; MANN,D.L. Proinflammatory cytokine levels in patients with depressed left ventricular ejection fraction: a report the studies of left ventricular dysfunction (SOLVD). J Am Coll Cardiol, 27: 1201-1206; 1996.

TÜRKÖZ,A.; ÇIGLI,A.; BUT,K.; SEZGIN,N.; TÜRKÖZ,R.; GÜLCAN,Ö.; ERSOY,Ö. The effects of aprotinin and steroids on generation of cytokines during coronary artery surgery. J Cardiothorac Vasc Anesth, 15(5): 603-610, 2001.

TWEDDELL,J.S.; BERGER,S.; FROMMELT,P.C.; PELECH,A.N.; LEWIS,D.A.; FEDDERLY,R.T.; FROMMELT,M.A.; McMANUS,T.S.; MUSSATTO,K.A.; KESSEL,M.W.; LITWIN,S.B. Aprotinin improves outcome of single-ventricle palliation. Ann Thorac Surg, 62: 1329-1336; 1996.

TWEDDELL,J.S.; HOFFMAN,G.M.; MUSSATTO,K.A.; FEDDERLY,R.T.; BERGER,S.; JAQUISS,R.D.B.; GHANAYEM,N.S.; FRISBEE,S.J.; LITWIN,S.B. Improved survival of patients undergoing palliation of hypoplastic left heart syndrome: lessons learned from 115 consecutive patients. Circulation, 106 (suppl I): I-82 - I89, 2002.

URBAN,A.E.; POPOV-CENIC,S.; NOË,G.; KULZER,R. Aprotinin in openheart surgery of infants and children using the heart-lung machine. Clin Ther, 6 (4): 425-433; 1984.

Van NORMAN,G.A.; PATEL,M.A.; CHANDLER,W.; VOCELKA,C. Effects of hemofiltration on serum aprotinin levels in patients undergoing cardiopulmonary bypass. J Cardiothorac Vasc Anesth, 14(3): 253-256; 2000.

WACHTFOGEL,Y.T.; HARPEL,P.C.; EDMUNDS,L.H.; COLMAN,R.W. Formation of C1s-C1-inhibitor, kallikrein-C1-inhibitor, and plasmin-a2- 
plasmin-inhibitor complexes during cardiopulmonary bypass. Blood, 73(2): 468-471; 1989.

WEERASINGHE,A.; TAYLOR,K.M. The platelet in cardiopulmonary bypass. Ann Thorac Surg, 66: 2145-2152, 1998.

WEGNER,J. Biochemistry of serine protease inhibitors and their mechanisms of action: a review. J Extra-Corpor Technol, 35: 326-338; 2003.

WENDEL,H.P.; HELLER,W.; GALLIMORE,M.J. heparin-coated devices and high-dose aprotinin optimally inhibit contact system activation in an in vitro cardiopulmonary bypass model. Immunopharmacology, 32: 128-130; 1996.

WENDEL,H.P.; SCHULZE,H.-J.; HELLER,W.; HOFFMEISTER,H.-M. Platelet protection in coronary artery surgery: benefits of heparin- coated circuits and high-dose aprotinin therapy. J Cardiothorac Vasc Anesth, 13(4): 388-392, 1999.

WILLIAMS,G.D.; RAMAMOORTHY,C. Con: The routine use of aprotinin during pediatric cardiac surgery is not a benefit. J Cardiothorac Vasc Anesth, 13(6): 785-788; 1999.

WILLIAMS.G.D.; $\quad$ BRATTON,S.L.; RILEY,E.C.; RAMAMOORTHY,C. Coagulation tests during cardiopulmonary bypass correlate with blood loss in children undergoing cardiac surgery. J Cardiothorac Vasc Anesth, 13(4): 398-404; 1999.

WIPPERMANN,C.F.; SCHMID,F.X.; $\quad$ EBERLE,B.; $\quad$ HUTH,R.G.; KAMPMANN,C.; SCHRANZ,D.; OELERT,H. Reduced inotropic support after aprotinin therapy during pediatric cardiac operations. Ann Thorac Surg, 67: 173-176; 1999. 
WU,Y.R.; CHEN,S.B.; HUANG,M.R.; ZHANG,Y.Q.; SUN,K.; CHEN,S. Diagnostic value of plasma concentration of pro-brain natriuretic peptide in congestive heart failure in pediatric patients with ventricular septal defects [article in chinese]. Zhonghua Er Ke Za Zhi, 43 (3): 161-164; 2005.

ZENKER M, RIES M. Differences between neonates and adults in plasmin inhibitory and antifibrinolytic action of aprotinin. Thromb Res 2002; 107: 1721.

ZHANG,S.; WANG,S.; LI,Q.; YAO,S; ZENG,B.; ZIEGELSTEIN,R.; HU,Q. Capillary leak syndrome in children with C4A- deficiency undergoing cardiac surgery with cardiopulmonary bypass: a double-blind, randomised controlled study. Lancet, 366(13): 556-562, 2005.

ZHANG,S.; WANG,S.; YAO,S. Evidence for development of capillary leak syndrome associated with cardiopulmonary bypass in pediatric patients with the homozygous C4A Null phenotype. Anesthesiology, 100 (6): 1387-1393, 2004. 
ANEXOS 


\section{ANEXO I}

TABELA 1: Comparação dos estudos publicados na literatura (1980 - 2006) do uso da aprotinina em crianças operadas com circulação extracorpórea (CEC) para correção de defeitos cardíacos congênitos ou transplantes cardíaco / pulmonar

\begin{tabular}{|c|c|c|c|c|}
\hline $\begin{array}{c}\text { AUTOR } \\
\text { (REFERÊNCI A) }\end{array}$ & $\begin{array}{l}\text { TIPO DE } \\
\text { ESTUDO }\end{array}$ & $\begin{array}{c}\text { No/ TIPO/ PESO } \\
\text { MÉDI O(Kg) PACIENTES }\end{array}$ & DOSE DE APROTI NI NA (ESQUEMA ) & RESULTADOS/ BENEFICIOS \\
\hline $\begin{array}{l}\text { MASIAK et al } \\
(1980)\end{array}$ & Prospectico observacional & Total $=79$ & $\begin{array}{l}\text { Sugrupos de } 100000 \text { a } 800000 \mathrm{UIC/} \\
10 \mathrm{~kg} \text { dose única no perfusato }\end{array}$ & $\begin{array}{c}\text { Doses menores que } 100000 \mathrm{UIC} / 10 \mathrm{~kg} \text { insuficientes. } \\
\text { Doses de } 200000 \text { UI C/kg impedem fibrinólise em } \\
\text { alguns casos, geralmente não suficiente para } \\
\text { proteger contra sangramento } \\
\text { Dose ideal de } 300 \text { a } 400 \text { mil / } 10 \mathrm{~kg} \text {, mantendo maior } \\
\text { quantidade de plaquetas } \\
\text { Dose }>500-800 \text { mil/10kg aumenta número de } \\
\text { plaquetas }\end{array}$ \\
\hline $\begin{array}{l}\text { POPOV-CENIC } \\
\text { et al (1982) }\end{array}$ & $\begin{array}{l}\text { Estudo comparativo com } \\
\text { e sem antiplasmina } \\
\text { (aprotinina) }\end{array}$ & $\begin{array}{c}\text { Total }=105 \\
\text { (idade de } 9 \text { dias a } 15 \text { anos, } \\
\text { peso de } 2,9 \text { a } 52 \mathrm{~kg} \text { ) } \\
\text { Grupos tratamento }=17 \\
\text { cianóticas e } 29 \text { acianóticas }\end{array}$ & 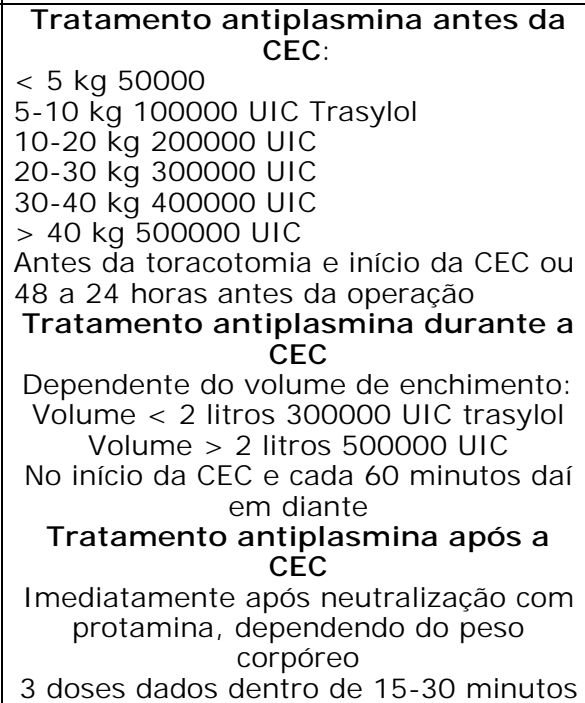 & $\begin{array}{c}\text { Entre o fechamento do tórax e à meia-noite do dia } \\
\text { da operação, as perdas sangüíneas médias no grupo } \\
\text { não tratado foram de } 6,4 \mathrm{ml} / \mathrm{kg} / \mathrm{h} \text { (cianóticas) a } 2,4 \\
\mathrm{ml} / \mathrm{kg} / \mathrm{hora} \text { (acianóticas), e nos grupos tratados, de } \\
2,6 \mathrm{ml} / \mathrm{kg} / \mathrm{h} \text { (cianóticas e acianóticas). } \\
\text { Nos grupos sem aprotinina, houve média de perda } \\
\text { sangüínea de } 1,0 \mathrm{ml} / \mathrm{kg} / \mathrm{h} \text { e } 0,9 \mathrm{ml} / \mathrm{kg} / \mathrm{hora} \text { e nos } \\
\text { grupos tratados, de } 0,7 \mathrm{ml} / \mathrm{kg} / \mathrm{hora} \text {, nas } 12 \text { horas } \\
\text { pós-operatórias. }\end{array}$ \\
\hline $\begin{array}{l}\text { URBAN et al } \\
(1984)\end{array}$ & $\begin{array}{l}\text { Estudo com grupo com } \\
\text { aprotinina e grupo } \\
\text { controle sem aprotinina }\end{array}$ & $\begin{array}{c}\text { Total }=122 \\
\text { Grupo tratado }=63\end{array}$ & $\begin{array}{c}\text { Dose de } 10000 \text { a } 15000 \text { UIC/kg cada } 4 \\
\text { horas antes e após CEC. A aprotinina foi } \\
\text { adicionada na máquina coração-pulmão } \\
\text { durante e ao final da CEC, e } \\
\text { administrada após neutralização com } \\
\text { protamina e posteriormente. }\end{array}$ & $\begin{array}{c}\text { Tratamento reduziu perda sangüínea e necessidades } \\
\text { transfusionais. }\end{array}$ \\
\hline
\end{tabular}




\begin{tabular}{|c|c|c|c|c|}
\hline $\begin{array}{l}\text { ELLI OTT et al } \\
\quad(1990)\end{array}$ & $\begin{array}{l}\text { Estudo piloto com } \\
\text { controle histórico }\end{array}$ & $\begin{array}{c}\text { Total }=28 \text { pacientes de } 8 \text { dias } \\
\text { a } 17 \text { anos de idade }\end{array}$ & $\begin{array}{l}240 \mathrm{mg} / \mathrm{m}^{2} \text { após indução anestésica e } \\
\text { no circuito o "priming", seguido de } \\
\text { infusão contínua de } 56 \mathrm{mg} / \mathrm{m}^{2} / \text { hora }\end{array}$ & $\begin{array}{c}\text { Diferença significativa observada no tempo entre a } \\
\text { protamina administrada e transferência para a UTI. } \\
\text { Média de tempo de fechamento tórax foi de } 42+/-9 \\
\text { minutos no grupo aprotinina versus } 138+/-75 \text { min } \\
\text { no grupo controle. }\end{array}$ \\
\hline $\begin{array}{l}\text { HAZAN et al } \\
(1991)\end{array}$ & $\begin{array}{l}\text { Prospectivo não } \\
\text { randomizado, controle } \\
\text { sem tratamento }\end{array}$ & $\begin{array}{c}\text { Total }=20 \text { crianças cianóticas } \\
\text { Aprotinina }=10 \text { pacientes }\end{array}$ & $\begin{array}{l}30000 \mathrm{U} / \mathrm{kg} \text { em } 20-30 \text { minutos no início } \\
\text { da anestesia , após dose inicial, } 100000 \\
\text { U/hora até o final da anestesia. } 500000 \\
\text { U foi adicionada para cada litro de } \\
\text { sangue adicionado ao paciente. } \\
1000000 \text { U adicionado ao volume } \\
\text { "priming". }\end{array}$ & $\begin{array}{l}\text { Redução na perda sangüínea pós-operatória em } \\
\text { doença cardíaca cianogênica, reduzindo a } \\
\text { necessidade de sangue do banco e transfusão. }\end{array}$ \\
\hline $\begin{array}{l}\text { MÜLLER et al } \\
\quad(1992)\end{array}$ & $\begin{array}{c}\text { Prospectivo não } \\
\text { randomizado, Controle } \\
\text { histórico sem tratamento }\end{array}$ & $\begin{array}{l}\text { Total }=205 \text { crianças } \\
\text { Aprotinina }=105\end{array}$ & $\begin{array}{l}\text { Dosagem de } 35000 \text { - } 50000 \mathrm{UIC/} \mathrm{kg} \\
\text { após indução anestésica, a mesma } \\
\text { quantia no volume do "prime" } \\
\text { oxigenador e } 20000 \text { - } 30000 \\
\text { UIC/kg/hora durante a operação }\end{array}$ & $\begin{array}{c}\text { Necessidade de sangue homólogo intra-operatório } \\
\text { menor, com menor perda sangüínea pelo dreno } \\
\text { torácico. }\end{array}$ \\
\hline $\begin{array}{l}\text { RANUCCI et al } \\
(1994)\end{array}$ & Retrospectivo & $\begin{array}{c}\text { Total=30 Aprotinina=15 } \\
\text { (cianótico / acianótico) }\end{array}$ & 30000 UIC/Kg no "prime" & $\begin{array}{l}\text { Nenhuma diferença no sangramento pós-operatório. } \\
\text { Necessidade de transfusão não estabelecida. } \\
\text { Aumento dos níveis séricos de uréia e creatinina na } \\
\text { admissão UTI e no 1o dia de pós-operatório no grupo } \\
\text { aprotinina comparado ao controle }\end{array}$ \\
\hline $\begin{array}{l}\text { BOLDT et al } \\
(1993)\end{array}$ & $\begin{array}{l}\text { Prospectivo, } \\
\text { randomizado, } \\
\text { Paralelo, controle sem } \\
\text { tratamento }\end{array}$ & $\begin{array}{c}\text { Total }=48 \\
\text { Aprotinina }=24 \\
\text { Pesos: } \\
\text { G1 }(12)=5,4 \\
\mathbf{C 1}(12)=5,0 ; \mathbf{G 2}(12)=16,3 \\
\mathbf{C 2}(12)=16,8 \\
\text { Idade }=21,1 \pm 8,2 \mathrm{~kg}\end{array}$ & $\begin{array}{c}\text { G1: 3,5mg }(25000 \mathrm{UIC}) / \mathrm{Kg} \text { endovenoso } \\
\text { em "bolus", } 3,5 \mathrm{mg} / \mathrm{Kg} \text { adicionados ao } \\
\text { fluido perfusão e infusão de } 3,5 \mathrm{mg} / \mathrm{Kg} \\
\text { durante CEC; } \\
\text { G2: igual Gi } \\
\text { C1 e C2: } \begin{array}{l}\text { grupos controles sem } \\
\text { aprotinina }\end{array}\end{array}$ & $\begin{array}{c}\text { Perda sangüínea } 5 \text { horas após da operação: sem } \\
\text { diferenças; } \\
\text { Perda sangüínea } 24 \text { horas após a operação: sem } \\
\text { diferenças entre } G 1 \text { e C1; maior perda no C2 que no } \\
\text { G2 ( } p<0,05) \text {. Maiores quantidades de unidades papa } \\
\text { de hemácias e plasma fresco congelado em G1 vs C1 } \\
\text { e G2 vs C2, respectivamente }(p<0,05), 24 \text { horas } \\
\text { após operação. }\end{array}$ \\
\hline $\begin{array}{l}\text { BOLDT et al } \\
(1993)\end{array}$ & $\begin{array}{l}\text { Prospectivo, } \\
\text { randomizado, } \\
\text { Paralelo, controle sem } \\
\text { tratamento }\end{array}$ & $\begin{array}{c}\text { Total }=42 \\
\text { Aprotinina }=28 \\
\text { Controle }=14 \\
\text { Pesos } \\
\text { G1 }(14)=9,8 \\
\text { G2 }(14)=7,5 \\
\mathrm{C}(14)=7,2 \\
\text { Peso médio }=12,3 \pm 4,6 \mathrm{~kg} \\
\text { Idade }=13,2 \pm 7,6 \text { meses }\end{array}$ & $\begin{array}{c}\text { G1: 4,9mg/Kg (35000 U/Kg) } \\
\text { endovenoso em "bolus", } 4,9 \mathrm{mg} / \mathrm{Kg} \\
\text { (35000 U/Kg) adicionados ao fluido da } \\
\text { perfusão da CEC e infusão de } 10000 \\
\mathrm{U} / \mathrm{Kg} / \mathrm{min} \text { durante CEC (alta dose) } \\
\mathrm{G} 2: 2,8 \mathrm{mg} / \mathrm{Kg} \text { (20000 U/Kg) } \\
\text { endovenoso em "bolus", } 2,8 \mathrm{mg} / \mathrm{Kg} \\
\text { (20000 U/Kg) adicionados ao fluido da } \\
\text { perfusão da CEC e infusão de } \\
\text { 2,8mg/Kg/h (20000 U/Kg/h) durante } \\
\text { CEC (baixa dose). }\end{array}$ & $\begin{array}{c}\text { Perda sangüínea } 24 \text { horas após operação semelhante } \\
\text { nos } 3 \text { grupos; } \\
\text { Utilização semelhante de unidades de papa de } \\
\text { hemácias e plaquetas para os } 3 \text { grupos; quantidades } \\
\text { maiores de plasma fresco congelado utilizados no G2 } \\
\text { vs controle }(p<0,05) \text {. }\end{array}$ \\
\hline
\end{tabular}




\begin{tabular}{|c|c|c|c|c|}
\hline $\begin{array}{l}\text { BOLDT et al } \\
(1994)\end{array}$ & $\begin{array}{l}\text { Prospectivo, } \\
\text { randomizado, controle } \\
\text { nenhum tratamento }\end{array}$ & $\begin{array}{c}\text { Total }=30 \\
\text { Aprotinina }=15(\text { peso }=11,7) \\
\text { Controle }=15 \\
\text { (peso }=10,2) \\
\text { Idade }=33,6 \pm 10,5\end{array}$ & $\begin{array}{c}30000 \mathrm{UIC} / \mathrm{Kg} \text { após indução anestesia e } \\
30000 \mathrm{UIC} / \mathrm{kg} \text { adicionados ao fluido da } \\
\text { perfusão e adicional } 30000 \mathrm{UIC} / \mathrm{Kg} / \mathrm{h} \\
\text { até o final da CEC }\end{array}$ & $\begin{array}{l}\text { Não houve nenhuma diferença significativa na perda } \\
\text { sangüínea e necessidade de sangue homólogo entre } \\
\text { os dois grupos. }\end{array}$ \\
\hline $\begin{array}{c}\text { DIETRI CH et al } \\
(1993)\end{array}$ & $\begin{array}{l}\text { Prospectivo, } \\
\text { randomizado, } \\
\text { Paralelo, controle nenhum } \\
\text { tratamento }\end{array}$ & $\begin{array}{c}\text { Total }=60 \\
\text { G1: Aprotinina }=20(\text { alta dose }) \\
\text { (Peso=6,3) } \\
\text { G2: Aprotinina }=20(\text { baixa } \\
\text { dose) }(\text { Peso }=6,1) \\
\text { Controle }(\text { (sem trato })=20 \\
\text { (peso }=5,4) \\
\text { Idade }=9,1 \pm 7,6 \text { meses }\end{array}$ & $\begin{array}{c}\text { G1 H: } 4,2 \mathrm{mg} / \mathrm{Kg}(30000 \mathrm{U} \mathrm{C} / \mathrm{Kg}) \\
\text { endovenoso em "bolus" e } 4,2 \mathrm{mg} / \mathrm{Kg} \\
\text { (30000UIC/Kg) adicionados ao fluido da } \\
\text { perfusão da CEC; } \\
\text { G2 L: } 2,1 \mathrm{mg} / \mathrm{Kg}(15000 \mathrm{U} \mathrm{C} / \mathrm{Kg}) \\
\text { endovenoso em "bolus" e } 2,1 \mathrm{mg} / \mathrm{Kg} \\
\text { (15000UI C/Kg) adicionados ao fluido } \\
\text { da perfusão da CEC } \\
\text { Oxigenador "primed" com } 500 \mathrm{ml} \text { sangue } \\
\text { homólogo e } 100 \text { a } 300 \mathrm{ml} \text { de solução } \\
\text { cristalóide }\end{array}$ & $\begin{array}{l}\text { Perda sangüínea } 6 \mathrm{~h} \text { após operação: foi significativa- } \\
\text { mente mais baixa nos grupos G1 versus G2 e C, } \\
\text { respectivamente }(99+/-32 \text { vs } 160+/-106 \text { e } 164+/- \\
\left.\quad 87 \mathrm{ml} / \mathrm{m}^{2}\right)(\mathrm{p}<0,05) ; \\
\text { Perda sangüínea } 24 \text { horas após operação: ausência } \\
\text { de diferença entre os grupos. }\end{array}$ \\
\hline $\begin{array}{l}\text { HERYNKOPF } \\
\text { Et al (1994) }\end{array}$ & $\begin{array}{c}\text { Prospectivo, } \\
\text { randomizado, paralelo, } \\
\text { duplo-cego, controlado } \\
\text { com placebo }\end{array}$ & $\begin{array}{c}\text { Total }=30 \\
\text { Aprotinina }=14 \\
\text { Placebo }=16 \\
\text { Peso }=6,1 \text { a } 36(16,4 \text { média }) \\
\text { Idade }=8-132 \text { meses }\end{array}$ & $\begin{array}{c}\text { 7mg/ } \mathrm{Kg} \text { em doses divididas: } \\
2,8 \mathrm{mg} / \mathrm{Kg} \text { endovenoso em } \\
\text { "bolus"; } 2,8 \mathrm{mg} / \mathrm{Kg} \text { adicionados ao } \\
\text { volume de fluido de perfusão da CEC e } \\
1,4 \mathrm{mg} / \mathrm{Kg} / \mathrm{h} \text { por infusão contínua } \\
\text { durante CEC }\end{array}$ & $\begin{array}{c}\text { Perdas sangüíneas } 24 \mathrm{~h} \text { após operações mais baixas } \\
(12,1 \text { vs } 17,7 \mathrm{ml} / \mathrm{Kg}) \text { e de hemoglobina }(0,66 \text { vs } 1,21 \\
\mathrm{gm}) \text { relatadas em pacientes tratados versus não } \\
\text { tratados ( } \mathrm{p}=0,07) \\
\text { Uso global de derivados de sangue não foi diferente } \\
\text { nos grupos; } \mathrm{n} \text { o significativamente maior no grupo } \\
\text { aprotinina não recebeu transfusões pós-operatórias } \\
(64,2 \% \text { vs } 25 \% ; \mathrm{p}=0,03) \text {. Aumento da diurese } \\
\text { durante a perfusão }(4,3 \mathrm{ml} / \mathrm{kg} \text { grupo tratado versus } \\
1 \mathrm{ml} / \mathrm{kg} \text { controle) }\end{array}$ \\
\hline $\begin{array}{c}\text { PENKOSKE et al } \\
\text { (1995) }\end{array}$ & $\begin{array}{l}\text { Prospectivo, aberto, } \\
\text { controle histórico }\end{array}$ & $\begin{array}{c}\text { Total }=135 \\
\text { Aprotinina }=80 \\
\text { (reoperações, neonatos, } \\
\text { cianóticos e outros reparos } \\
\text { complexos) }\end{array}$ & $9 \mathrm{mg} / \mathrm{Kg}$ em doses divididas & $\begin{array}{l}\text { Redução significativa na drenagem pelo tubo } \\
\text { torácico, no tempo de fechamento da pele e } \\
\text { na necessidade de transfusão sangüínea. }\end{array}$ \\
\hline $\begin{array}{c}\text { GOMAR et al } \\
(1995)\end{array}$ & $\begin{array}{c}\text { Randomizado e } \\
\text { prospectivo controlado }\end{array}$ & $\begin{array}{c}\text { Total }=25 \\
\text { Aprotinina }=12 \\
\text { (crianças com cardiopatia } \\
\text { cianótica e acianótica) } \\
\text { Idade não referida } \\
\text { Peso }>10 \mathrm{Kg}\end{array}$ & $\begin{array}{l}\text { Após indução anestésica, } 240 \mathrm{mg} / \mathrm{m}^{2}, \\
\text { seguido de infusão contínua de } \\
50 \mathrm{mg} / \mathrm{m}^{2} \text { administrada a cada } 60 \\
\text { minutos até final da operação e } \\
50 \mathrm{mg} / \mathrm{m}^{2} \text { adicionado no "prime" do } \\
\text { circuito de CEC. }\end{array}$ & $\begin{array}{l}\text { Alta dose de aprotinina não reduziu perda sangüínea } \\
\text { ou a necessdade de hemoderivados e sangue } \\
\text { homólogo em comparação com crianças não tratadas }\end{array}$ \\
\hline
\end{tabular}




\begin{tabular}{|c|c|c|c|c|}
\hline $\begin{array}{l}\text { D'ERRICO et al } \\
\text { (1996) }\end{array}$ & $\begin{array}{l}\text { Prospectivo, } \\
\text { randomizado, duplo-cego, } \\
\text { placebo-controlado }\end{array}$ & $\begin{array}{c}\text { Total }=61 \\
\text { Aprotinina }=37 \\
\text { ( reoperações) } \\
\text { Idade }=30 \text { meses (mediana) } \\
(3,6-153,6) \\
\text { Peso }=14,9 \pm 9,3\end{array}$ & $\begin{array}{l}\text { Altas doses: } 240 \mathrm{mg} / \mathrm{m}^{2} \text { endovenoso em } \\
\text { "bolus" e no "prime", } 56 \mathrm{mg} / \mathrm{m}^{2} / \mathrm{h} \\
\text { infusão contínua, } \\
\text { Baixas doses: } 120 \mathrm{mg} / \mathrm{m}^{2} \text { "bolus" e no } \\
\text { "prime", } 28 \mathrm{mg} / \mathrm{m}^{2} / \mathrm{h} \text { infusão contínua }\end{array}$ & $\begin{array}{c}\text { Poucos pacientes nos grupos com aprotinina } \\
\text { receberam sangue e derivados nas primeiras } 24 \\
\text { horas de pós-operatório. Economia de custos } \\
\text { hospitalares. }\end{array}$ \\
\hline $\begin{array}{l}\text { TWEDDELL et } \\
\quad \text { al ( 1996) }\end{array}$ & Retrospectivo & $\begin{array}{c}\text { Total }=46 \text { (anastomose } \\
\text { cavopulmonar bidirecional e } \\
\text { Fontan) } \\
\text { Aprotinina }=18 \\
\text { Controle }=28 \\
\text { I dade de } 1 \text { mês a } 93 \text { meses }\end{array}$ & $\begin{array}{l}\text { Dose teste de } 1,4 \mathrm{mg} \text { e após } 240 \mathrm{mg} / \mathrm{m}^{2} \\
\text { endovenoso em "bolus" e no "prime" e } \\
56 \mathrm{mg} / \mathrm{m}^{2} / \mathrm{h} \text { infusão contínua }\end{array}$ & $\begin{array}{l}\text { Uso de aprotinina em paliação de ventrícuo único } \\
\text { associado com redução no gradiente transpulmonar } \\
\text { e aumento na saturação de oxigênio. Drenagem } \\
\text { torácica mediastinal e pleural durante as primeiras } \\
24 \text { horas e a duração da drenagem foram } \\
\text { significativamente reduzidas apenas no grupo desvio } \\
\text { cardiopulmonar bidirecional. }\end{array}$ \\
\hline $\begin{array}{l}\text { OHUCHI et al } \\
\text { (1996) } \\
\text { (abstract) }\end{array}$ & Retrospectivo & $\begin{array}{c}\text { Total }=36 \\
\text { Aprotinina }=14 \\
\text { (reoperações) }\end{array}$ & $\begin{array}{l}30000 \mathrm{UIC} / \mathrm{Kg} \text { no "prime" e } 10000 \\
\text { UIC/Kg a cada hora de CEC }\end{array}$ & $\begin{array}{l}\text { Redução significativa na perda sangüínea e no uso } \\
\text { de sangue homólogo }\end{array}$ \\
\hline $\begin{array}{l}\text { BROCHE et al } \\
\quad(1996)\end{array}$ & $\begin{array}{l}\text { Prospectivo, } \\
\text { randomizado, duplo-cego }\end{array}$ & $\begin{array}{c}\text { Total }=19 \\
\text { Aprotinina }=8 \\
\text { (crianças 1-6anos em cardio- } \\
\text { cirurgia com suporte } \\
\text { cardiorrespiratório mecânico) }\end{array}$ & $\begin{array}{c}30000 \mathrm{UIC} / \mathrm{kg} \text { antes abertura pele, } \\
30000 \mathrm{UIC} / \mathrm{kg} \text { no sistema e } \\
10000 \mathrm{UIC} / \mathrm{kg} / \text { hora até término da } \\
\text { operação }\end{array}$ & $\begin{array}{l}\text { Efeito antioxidante da aprotinina sob condições de } \\
\text { isquemia-reperfusão. Baixo débito cardíaco e } \\
\text { arritmias em } 10 \% \text { e } 30 \% \text {, respectivamente, do } \\
\text { grupo tratado, versus } 30 \% \text { e } 60 \% \text { do grupo controle }\end{array}$ \\
\hline $\begin{array}{l}\text { SEGHAYE et al } \\
(1996)\end{array}$ & $\begin{array}{c}\text { Prospectivo, } \\
\text { randomizado, aberto, } \\
\text { controle sem tratamento }\end{array}$ & $\begin{array}{c}\text { Total }=25 \\
\text { Aprotinina } \\
\text { baixa- dose }=11 \\
\text { Controle }=14 \\
\text { Idade }=77 \text { meses }(9,5-151) \\
\text { Peso }=\text { não relatado }\end{array}$ & $\begin{array}{c}20000 \mathrm{UIC} / \mathrm{Kg}(2,8 \mathrm{mg} / \mathrm{Kg}) \text {, sendo } \\
10000 \mathrm{UIC} / \mathrm{Kg} \text { por infusão endovenosa } \\
\text { antes da esternotomia e } 10000 \mathrm{UIC} / \mathrm{Kg} \\
\text { na solução de perfusão da CEC }\end{array}$ & $\begin{array}{c}\text { As perdas sangüíneas dentro das primeiras } 24 \text { horas } \\
\text { de pós-operatório e a quantia de produtos } \\
\text { sanguíneos transfundidos não foram diferentes nos } \\
\text { dois grupos. } \\
\text { Baixa dose de aprotinina afeta somente a } \\
\text { mobilização neutrofílica ao final da CEC (pequena } \\
\text { influência na resposta inflamatória sistêmica). }\end{array}$ \\
\hline $\begin{array}{l}\text { I MAl et al } \\
\text { (1997) }\end{array}$ & $\begin{array}{c}\text { Prospectivo } \\
\text { Controle sem tratamento }\end{array}$ & $\begin{array}{c}\text { Total }=41 \\
\text { Correção tetralogia Fallot } \\
\text { Aprotinina }=21 \\
\text { Idade }=5 \text { a } 13 \text { anos } \\
\text { (média }=7 \text { ) } \\
\text { Peso }=18,3 \pm 3,7 \mathrm{~kg}\end{array}$ & $\begin{array}{c}30000 \mathrm{UIC} / \mathrm{kg} \text { como dose inicial da CEC } \\
10000 \mathrm{~kg} / \mathrm{kg} / \mathrm{h} \text { ora durante CEC }\end{array}$ & $\begin{array}{l}\text { Redução perda sangüínea intra-operatória } \\
\text { Redução do tempo operatório e do fechamento da } \\
\text { pele a partir do final da CEC }\end{array}$ \\
\hline
\end{tabular}




\begin{tabular}{|c|c|c|c|c|}
\hline $\begin{array}{l}\text { DAVIES et al } \\
(1997)\end{array}$ & $\begin{array}{l}\text { Prospectivo, } \\
\text { randomizado, duplo-cego, } \\
\text { placebo-controlado }\end{array}$ & $\begin{array}{c}\text { Total }=42 \\
\text { Aprotinina }=19 \\
3 \text { grupos: } \\
\mid-\leq 1 \text { ano } \\
\| 1->1 \text { ano até } 5 \text { anos } \\
\text { III->1 ano e submetidos à } \\
\text { reoperação por esternotomia } \\
\text { Idade }=44,8 \pm 16,3 \\
\text { Peso }=13 \pm 4,7\end{array}$ & $\begin{array}{c}\text { Crianças com superfície corpórea } \\
<1,16 \mathrm{~m}^{2}: 140 \mathrm{UIC} / \mathrm{m}^{2} \text { endovenoso em } \\
\text { "bolus", } 240 \mathrm{UIC} \mathrm{m} \mathrm{m}^{2} \text { no "prime" e } 56 \\
\text { UIC/m² } / \mathrm{h} \text { infusão até fechamento pele } \\
\text { Crianças com superfície corpórea } \\
>1,16 \mathrm{~m}^{2}: 250 \mathrm{UIC} / \mathrm{m}^{2} \text { endovenoso em } \\
\text { "bolus", } 280 \mathrm{UIC} / \mathrm{m}^{2} \text { no "prime" e } 70 \\
\text { UI } \mathrm{C} / \mathrm{m}^{2} / \mathrm{h}\left(9,8 \mathrm{mg} / \mathrm{m}^{2} / \mathrm{h}\right) \text { infusão até } \\
\text { fechamento pele }\end{array}$ & Nenhum benefício clínico \\
\hline $\begin{array}{l}\text { MI LLER et al } \\
(\mathbf{1 9 9 8 )}\end{array}$ & $\begin{array}{l}\text { Prospectivo, grupo } \\
\text { controle nenhum } \\
\text { tratamento }\end{array}$ & $\begin{array}{c}\text { Total }=45 \\
\text { Aprotinina }=30 \\
\text { (reoperações) } \\
\text { Idade }=52,8 \pm 50,4 \text { meses } \\
\text { Peso }=15,4 \pm 7,9 \mathrm{Kg}\end{array}$ & $\begin{array}{c}\text { Baixa dose: } 20000 \mathrm{UIC/Kg} \text { endovenoso } \\
\text { "bolus", } 20000 \text { UI C/Kg no "prime" e } \\
10000 \text { UI C/hora de infusão até fechar } \\
\text { pele } \\
\text { Alta dose: } 40000 \text { UIC/Kg endovenoso } \\
\text { "bolus", } 40000 \text { UI C/Kg no "prime" e } \\
20000 \text { UI C/h infusão até fechar pele }\end{array}$ & $\begin{array}{l}\text { Decréscimo transfusão de produtos sangüineos, } \\
\text { encurtamento do tempo de fechamento da pele e } \\
\text { redução da duração permanência na unidade de } \\
\text { cuidados intensivos e hospitalares. Reduziu custos. }\end{array}$ \\
\hline $\begin{array}{l}\text { CARREL et al } \\
(1998)\end{array}$ & $\begin{array}{l}\text { Prospectivo, não- } \\
\text { randomizado }\end{array}$ & $\begin{array}{c}\text { Total }=168<15 \mathrm{~kg} \\
\text { Aprotinina=113 (defeito de } \\
\text { septo ventricular, tetralogia } \\
\text { de Fallot e transposição de } \\
\text { grandes artérias) }\end{array}$ & $\begin{array}{c}\text { Baixa dose: } 500000 \text { UIC somente no } \\
\text { "prime" da bomba de CEC } \\
\text { Alta dose: } 50000 \text { UIC/Kg durante } \\
\text { indução } \\
50000 \text { UIC/Kg no "prime" } \\
20000 \text { UIC/Kg infusão contínua }\end{array}$ & $\begin{array}{l}\text { Redução significativa na perda sangüínea e } \\
\text { transfusão sangüínea de hemácias e de plaquetas } \\
\text { pós-operatória com altas doses de aprotinina em } \\
\text { transposição de grandes artérias somente. }\end{array}$ \\
\hline $\begin{array}{l}\text { JAQUISS et al } \\
\text { (1995) } \\
\text { SPRAY et al } \\
(1998)\end{array}$ & $\begin{array}{l}\text { Retrospectivo, não- } \\
\text { randomizado }\end{array}$ & $\begin{array}{c}\text { Total }=42 \text { transplantes } \\
\text { pulmonares ( } 39 \text { duplos) com } \\
\text { CEC } \\
\text { Grupo I- } 25 \text { aprotinina } \\
\text { Grupo II- } 19 \text { controle }\end{array}$ & $\begin{array}{l}\text { Crianças superfície corpórea }<1,16 \mathrm{~m}^{2}: \\
240 \mathrm{mg} / \mathrm{m}^{2} \text { endovenoso em "bolus" em } \\
20 \mathrm{minutos} \text { e no "prime", } \\
56 \mathrm{mg} / \mathrm{m}^{2} / \text { hinfusão contínua; } \\
\text { Crianças superfície corpórea }>1,16 \mathrm{~m}^{2} \text { : } \\
280 \mathrm{mg} / \mathrm{m}^{2} \text { endovenoso em "bolus" e no } \\
\text { "prime", } 70 \mathrm{mg} / \mathrm{m}^{2} / \mathrm{h} \text { infusão contínua }\end{array}$ & $\begin{array}{l}\text { Reduziu a quantia de sangramento peri-operatório } \\
\text { no grupo de crianças de alto risco para sangramento } \\
\text { (grupo I). }\end{array}$ \\
\hline $\begin{array}{l}\text { CONIFF (1998) } \\
\text { The Bayer 022 } \\
\text { Compassione- } \\
\text { Use pediatric } \\
\text { study }\end{array}$ & $\begin{array}{l}\text { Randomizado, placebo- } \\
\text { controlado }\end{array}$ & $\begin{array}{c}\text { Total }=116 \text { com idade } \leq 16 \\
\text { anos de idade }\end{array}$ & $\begin{array}{l}\text { Quatro grupos tratamento: } \\
\text { - Alta dose - "full" dose do } \\
\text { regime Hammersmith } \\
\text { - Baixa dose } \\
\text { - Somente na bomba de CEC } \\
\text { ( "prime" } \\
\text { - Placebo }\end{array}$ & $\begin{array}{c}\text { Tendência para maior benefício com uso de } \\
\text { aprotinina, como mensurado pela necessidade de } \\
\text { sangue e hemoderivados, em pacientes com mais de } \\
1 \text { ano de idade, particularmente nas reoperações do } \\
\text { que na operação por esternotomia primária. }\end{array}$ \\
\hline $\begin{array}{l}\text { WIPPERMANN } \\
\text { et al ( 1999) }\end{array}$ & $\begin{array}{l}\text { Randomizado, duplo-cego } \\
\text { e placebo-controlado }\end{array}$ & $\begin{array}{c}\text { Total }=34 \text { (média } 2,5 \text { anos de } \\
\text { idade) } \\
\text { Aprotinina }=17(11,3 \mathrm{Kg}) \\
\text { Controle }=17(9,5 \mathrm{Kg})\end{array}$ & $\begin{array}{l}\text { Após indução anestésica, } 28000 \mathrm{UIC} / \mathrm{Kg} \\
\text { (3,9mg/Kg), seguido de infusão } \\
\text { contínua de } 7000 \mathrm{UIC} / \mathrm{Kg} / \mathrm{h} \\
\text { (1mg/Kg/h); dose adicional de } 28000 \\
\text { UIC/Kg no "prime". }\end{array}$ & $\begin{array}{c}\text { O estado clínico-hemodinâmico dos pacientes } \\
\text { tratados com aprotinina foi semelhante aos tratados } \\
\text { com placebo nas primeiras } 48 \text { horas após CEC. O } \\
\text { grupo placebo necessitou mais suporte inotrópico } \\
\text { com enoximona (inibidor de fosfodiesterase) que o } \\
\text { grupo da aprotinina. }\end{array}$ \\
\hline
\end{tabular}




\begin{tabular}{|c|c|c|c|c|}
\hline $\begin{array}{l}\text { CHAUHAN et al } \\
\qquad(2000)\end{array}$ & $\begin{array}{l}\text { Prospectivo, } \\
\text { randomizado, grupo } \\
\text { controle nenhum } \\
\text { tratamento }\end{array}$ & $\begin{array}{c}\text { Total }=300 \\
\text { Aprotinina }=100 \\
\text { Aprotinina }+ \text { EACA }=60 \\
\text { Idade }=49,2 \pm 14,4 \text { meses } \\
\text { Peso }=6,2 \pm 2,2 \mathrm{Kg}\end{array}$ & $\begin{array}{c}\text { Baixa dose }=10000 \text { UIC/Kg após } \\
\text { indução } \\
10000 \text { UIC/Kg no 'prime" } \\
10000 \text { UIC/Kg por } 3 \text { horas após saída } \\
\text { de CEC }\end{array}$ & $\begin{array}{c}\text { Redução no tempo de fechamento esternal, nas } \\
\text { perdas sangüíneas às } 24 \text { horas e necessidade de } \\
\text { sangue e de seus componentes com uso de } \\
\text { aprotinina ou de EACA. }\end{array}$ \\
\hline $\begin{array}{l}\text { MARTIN } \\
\text { BURCIO et al } \\
(2001)\end{array}$ & Retrospectivo & $\begin{array}{c}\text { Total }=71 \\
\text { Aprotinina }=36 \\
\text { (crianças com cardiopatia } \\
\text { cianótica) }\end{array}$ & $\begin{array}{c}\text { Dose teste de } 50000 \text { UIC em } 2 \text { min, } \\
\text { dose inicial e no circuito "prime" de } \\
1700000 \text { UIC ( } 170 \mathrm{ml} / \mathrm{m}^{2} \text { de superfície } \\
\text { corpórea) EV e dose manutenção de } \\
400000 \text { UIC ( } 40 \mathrm{ml} / \mathrm{m}^{2} / \text { hora) EV } \\
\text { suspensa duas horas após chegar na } \\
\text { UTI }\end{array}$ & $\begin{array}{c}\text { Aprotinina reduziu significativamente a perda } \\
\text { sangüínea e necessidade de transfusão sangüínea } \\
\text { homónloga. Diurese intra e pós-operatória não teve } \\
\text { diferença significativa. Nenhuma complicaçãa } \\
\text { observada. }\end{array}$ \\
\hline $\begin{array}{l}\text { BROCHE et al } \\
(2002)\end{array}$ & Não-randomizado & $\begin{array}{l}\text { Total }=26 \text { crianças } \\
\text { operadas em suporte cardio- } \\
\text { respiratório mecânico } \\
\text { Grupo tratado com aprotinina } \\
=12\end{array}$ & $\begin{array}{c}30000 \mathrm{UIC/kg} \text { durante } 20 \text { minutos antes } \\
\text { da abertura da pele e mesma dose } \\
\text { adicionado ao "priming" do circuito } \\
\text { extracorpóreo, } 10000 \mathrm{UIC} / \mathrm{kg} / \mathrm{h} \text { durante } \\
\text { a operação }\end{array}$ & $\begin{array}{l}\text { Inibição da geração de radicais de oxigênio } \\
\text { fagocitários. Redução do estresse oxidativo } \\
\text { sistêmico. Tendência melhora no perfil clínico. }\end{array}$ \\
\hline $\begin{array}{l}\text { MÖSSI NGER et } \\
\text { al (2003) }\end{array}$ & $\begin{array}{c}\text { Prospectivo, } \\
\text { randomizado, duplo-cego } \\
\text { e placebo-controlado }\end{array}$ & $\begin{array}{c}\text { Total }=60(\text { peso }<10 \mathrm{Kg}) \\
\text { Aprotinina }=30 \\
\text { I dade }=4,8 \text { meses (mediana) } \\
\text { Peso }=4,9 \mathrm{Kg} \text { (mediana) }\end{array}$ & $\begin{array}{c}\text { "Bolus" de } 3 \times 104 \text { (30000) UIC/kg } \\
\text { antes da canulação aórtica mais um } \\
\text { "bolus" de } 5 \times 105 \text { ( } 50000) \text { UIC } \\
\text { adicionado ao "prime" (sem ajuste por } \\
\text { peso). }\end{array}$ & $\begin{array}{l}\text { Redução da ativação hemostática, da perda } \\
\text { sangüínea e da necessidade de sangue alogênico. } \\
\text { Com esta dose relativamente alta de aprotinina, o } \\
\text { tempo de ventilação pós-operatória foi reduzido. }\end{array}$ \\
\hline $\begin{array}{c}\text { COSTELLO et al } \\
(2003)\end{array}$ & $\begin{array}{l}\text { Retrospectivo, } \\
\text { não-randomizado, } \\
\text { controle histórico }\end{array}$ & $\begin{array}{c}\text { Total }=53 \\
\text { Aprotinina }=18\end{array}$ & $\begin{array}{l}\text { Após indução, dose teste de } 1,4 \mathrm{mg} \\
\text { seguido de "bolus" de } 240 \mathrm{mg} / \mathrm{m}^{2} \\
\text { (máximo de } 280 \mathrm{mg} \text { ) e dose adicional de } \\
240 \mathrm{mg} / \mathrm{m}^{2} \text { (máximo } 280 \mathrm{mg} \text { ) foi } \\
\text { adicionado ao "prime". Infusão } \\
\text { contínua de } 56 \mathrm{mg} / \mathrm{m}^{2} / \text { hora (máximo de } \\
70 \mathrm{mg} / \mathrm{h} \text { ) até } 1 \text { hora antes do } \\
\text { fechamento da pele. }\end{array}$ & $\begin{array}{l}\text { Reduziu o tempo de fechamento na operação e a } \\
\text { exposição aos produtos sangüineos em pacientes } \\
\text { pediátricos submetidos à CEC com idade } \leq 6 \text { meses } \\
\text { ou submetidos reoperação por esternotomia }\end{array}$ \\
\hline $\begin{array}{l}\text { ALEXI- } \\
\text { MESKISHVI LI } \\
(2004)\end{array}$ & retrospectivo & $\begin{array}{c}\text { Total }=14 \text { crianças } \\
\text { testemunhas de J eová abaixo } \\
14 \text { anos (mediana }=2,9 \\
\text { anos) } \\
\text { Peso (mediana } 14 \mathrm{~kg} \text { ) }\end{array}$ & $\begin{array}{c}\text { Altas doses de aprotinina } \\
400000 \text { UIC paciente } \\
400000 \text { UIC "priming" } \\
100000 \text { UIC infusão contínua durante } \\
\text { CEC }\end{array}$ & $\begin{array}{l}\text { Utilização de suplementação ferro oral e } \\
\text { eritropoietina pré-operatório. Circuito CEC com } \\
\text { "priming" reduzido. Ultrafiltração modificada. Não } \\
\text { foram utilizados sangue ou produtos sangüíneos }\end{array}$ \\
\hline
\end{tabular}




\begin{tabular}{|c|c|c|c|c|}
\hline $\begin{array}{c}\text { BULUTCU et al } \\
(2005)\end{array}$ & $\begin{array}{l}\text { Estudo prospectivo, } \\
\text { randomizado, cego, } \\
\text { controlado }\end{array}$ & $\begin{array}{c}\text { Total }=100 \\
\text { Controle }=25 \\
\text { Aprotinina }=25 \\
\text { Ácido tranexânico }=25 \\
\text { Aprotinina }+ \text { ácido } \\
\text { tranexânico }=25 \\
\text { (crianças com cardiopatia } \\
\text { cianótica) }\end{array}$ & $\begin{array}{l}\text { Após indução anestesia, } 30000 \mathrm{UIC} / \mathrm{kg} \text {, } \\
30000 \mathrm{UIC} / \mathrm{kg} \text { no "prime" da bomba e } \\
30000 \mathrm{Ul} / \mathrm{kg} \text { após desmame da CEC. }\end{array}$ & $\begin{array}{l}\text { Ambos agentes foram efetivos na redução da perda } \\
\text { sangüínea e necessidade de transfusão sangüínea. A } \\
\text { combinação de aprotinina e ácido tranexânico não foi } \\
\text { mais efetiva do que cada droga isolada. }\end{array}$ \\
\hline
\end{tabular}




\section{ANEXO II}

TABELA 2 - Características demográficas das crianças operadas por cardiopatia congênita acianogênica com CEC no Grupo Aprotinina

\begin{tabular}{|l|l|l|l|l|l|l|}
\hline PACIENTES & Idade (dias) & Sexo & Raça & Peso (g) & Altura (cm) & SC (m $\mathbf{~}^{\mathbf{2}}$ \\
\hline $\mathbf{1}$ & 137 & F & B & 4300 & 58 & 0,25 \\
\hline $\mathbf{7}$ & 47 & M & B & 3450 & 51 & 0,21 \\
\hline $\mathbf{1 3}$ & 189 & M & N & 5150 & 61,5 & 0,29 \\
\hline $\mathbf{2 4}$ & 519 & M & B & 8175 & 71 & 0,39 \\
\hline $\mathbf{2 5}$ & 86 & M & N & 3320 & 54 & 0,21 \\
\hline $\mathbf{3 2}$ & 408 & M & B & 9000 & 74 & 0,41 \\
\hline $\mathbf{3 5}$ & 1366 & M & B & 15000 & 104 & 0,65 \\
\hline $\mathbf{3 7}$ & 110 & M & B & 5030 & 60 & 0,28 \\
\hline $\mathbf{4 0}$ & 109 & F & N & 3650 & 54 & 0,22 \\
\hline $\mathbf{4 5}$ & 33 & M & P & 3600 & 51 & 0,21 \\
\hline
\end{tabular}

TABELA 3 - Características demográficas das crianças operadas por cardiopatia congênita acianogênica com CEC no Grupo Controle

\begin{tabular}{|l|l|l|l|l|l|l|}
\hline \multicolumn{1}{|c|}{ PACIENTES } & Idade (dias) & Sexo & Raça & Peso (g) & Altura (cm) & SC $\left(\mathbf{m}^{\mathbf{2}}\right)$ \\
\hline $\mathbf{3}$ & 256 & F & B & 6870 & 67 & 0,34 \\
\hline $\mathbf{6}$ & 37 & M & B & 2200 & 49 & 0,19 \\
\hline $\mathbf{1 0}$ & 121 & M & B & 4800 & 60 & 0,27 \\
\hline $\mathbf{1 1}$ & 242 & F & B & 6650 & 68 & 0,34 \\
\hline $\mathbf{1 2}$ & 1468 & F & B & 15800 & 96 & 0,70 \\
\hline $\mathbf{3 4}$ & 63 & F & B & 2890 & 50 & 0,19 \\
\hline $\mathbf{3 6}$ & 185 & F & B & 7310 & 71 & 5,37 \\
\hline $\mathbf{4 9}$ & 77 & M & B & 4520 & 54 & 0,24 \\
\hline $\mathbf{5 3}$ & 132 & M & B & 4520 & 57 & 0,26 \\
\hline
\end{tabular}

TABELA 4. Quadro clínico e tratamento pré-operatório dos pacientes dos Grupos Aprotinina e Controle

\begin{tabular}{|c|c|c|}
\hline \multirow{2}{*}{ Variáveis Clínicas } & \multicolumn{2}{|c|}{ Grupo } \\
\hline & Tratamento $(n=10)$ & Controle $(n=9)$ \\
\hline \multicolumn{3}{|l|}{ Sexo } \\
\hline Feminino & 2 & 5 \\
\hline Masculino & 8 & 4 \\
\hline \multicolumn{3}{|l|}{ Raça } \\
\hline Branca & 6 & 9 \\
\hline Negra & 3 & 0 \\
\hline Parda & 1 & 0 \\
\hline \multicolumn{3}{|l|}{ Cardiomegalia } \\
\hline Ausente & 7 & 4 \\
\hline Presente & 3 & 5 \\
\hline \multicolumn{3}{|l|}{ Uso de Digitálico } \\
\hline "+" & 2 & 6 \\
\hline “-" & 8 & 3 \\
\hline \multicolumn{3}{|l|}{ Diurético } \\
\hline "+" & 3 & 6 \\
\hline “-" & 7 & 3 \\
\hline \multicolumn{3}{|l|}{ Vasodilatador } \\
\hline "+" & 1 & 1 \\
\hline “-” & 9 & 8 \\
\hline
\end{tabular}


TABELA 5. Escore clínico modificado de Ross e Reithmann (ROSS, 1992; REITHMANN, 1997)

\begin{tabular}{|c|c|c|c|}
\hline & \multicolumn{3}{|c|}{ Score (Points) } \\
\hline & 0 & 1 & 2 \\
\hline \multicolumn{4}{|l|}{ History } \\
\hline Diaphoresis & Head only & Head and body during exercise & Head and body at rest \\
\hline Tachypnea & Rare & Several times & Frequent \\
\hline \multicolumn{4}{|l|}{ Physical examination } \\
\hline Breathing & Normal & Retractions & Dyspnea \\
\hline \multicolumn{4}{|l|}{ Respiratory rate (respirations/min) } \\
\hline $0-1$ y & $<50$ & $50-60$ & $>60$ \\
\hline $1-6 y$ & $<35$ & $35-45$ & $>45$ \\
\hline $7-10 \mathrm{y}$ & $<25$ & $25-35$ & $>35$ \\
\hline $11-14 \mathrm{y}$ & $<18$ & $18-28$ & $>28$ \\
\hline \multicolumn{4}{|l|}{ Heart rate (beats/min) } \\
\hline $0-1 \mathrm{y}$ & $<160$ & $160-170$ & $>170$ \\
\hline $1-6 y$ & $<105$ & $105-115$ & $>115$ \\
\hline $7-10 \mathrm{y}$ & $<90$ & $90-100$ & $>100$ \\
\hline $11-14 \mathrm{y}$ & $<80$ & $80-90$ & $>90$ \\
\hline $\begin{array}{l}\text { Hepatomegaly (liver edge } \\
\text { from right costal margin) }\end{array}$ & $<2 \mathrm{~cm}$ & $2-3 \mathrm{~cm}$ & $>3 \mathrm{~cm}$ \\
\hline
\end{tabular}

TABELA 6. Escore de Ross modificado pré-operatório dos pacientes dos grupos Aprotinina e Controle.

\begin{tabular}{|l|c|c|c|}
\hline GRUPO APROTININA & ESCORE ROSS & GRUPO CONTROLE & ESCORE ROSS \\
\hline 1 & $\mathbf{7}$ & 3 & $\mathbf{2}$ \\
\hline 7 & $\mathbf{5}$ & 6 & $\mathbf{6}$ \\
\hline 13 & $\mathbf{1}$ & 10 & $\mathbf{3}$ \\
\hline 24 & $\mathbf{0}$ & 11 & $\mathbf{2}$ \\
\hline 25 & $\mathbf{7}$ & 34 & $\mathbf{0}$ \\
\hline 32 & $\mathbf{8}$ & 36 & $\mathbf{5}$ \\
\hline 35 & $\mathbf{1}$ & 49 & $\mathbf{2}$ \\
\hline 37 & $\mathbf{4}$ & 53 & $\mathbf{8}$ \\
\hline 40 & $\mathbf{7}$ & & $\mathbf{6}$ \\
\hline 45 & $\mathbf{6}$ & Mediana & $\mathbf{3}$ \\
\hline Mediana & $\mathbf{5 , 5}$ & Média & $\mathbf{3} \mathbf{2 , 5 8}$ \\
\hline Média & $\mathbf{4 , 6} \mathbf{2 , 9 5}$ & & \\
\hline
\end{tabular}

TABELA 7. Categorias de risco RACHS-1 pré-operatório dos pacientes dos grupos Aprotinina e Controle.

\begin{tabular}{|l|c|l|c|}
\hline GRUPO APROTININA & $\begin{array}{c}\text { CATEGORIA } \\
\text { RACHS-1 }\end{array}$ & GRUPO CONTROLE & $\begin{array}{c}\text { CATEGORIA } \\
\text { RACHS-1 }\end{array}$ \\
\hline 1 & $\mathbf{2}$ & 3 & $\mathbf{2}$ \\
\hline 7 & $\mathbf{2}$ & 6 & $\mathbf{2}$ \\
\hline 13 & $\mathbf{3}$ & 10 & $\mathbf{2}$ \\
\hline 24 & $\mathbf{2}$ & 11 & $\mathbf{1}$ \\
\hline 25 & $\mathbf{3}$ & 12 & $\mathbf{2}$ \\
\hline 32 & $\mathbf{2}$ & 34 & $\mathbf{2}$ \\
\hline 35 & $\mathbf{2}$ & 36 & $\mathbf{2}$ \\
\hline 37 & $\mathbf{2}$ & 49 & $\mathbf{2}$ \\
\hline 40 & $\mathbf{2}$ & 53 & $\mathbf{2}$ \\
\hline 45 & $\mathbf{2}$ & & $\mathbf{2}$ \\
\hline Mediana & $\mathbf{2}$ & Mediana & $\mathbf{1 , 8 8}$ \\
\hline Média & $\mathbf{2 , 2}$ & Média & \\
\hline
\end{tabular}


TABELA 8. Escore Aristóteles pré-operatório dos pacientes dos grupos Aprotinina e Controle.

\begin{tabular}{|l|r|r|r|}
\hline GRUPO APROTININA & \multicolumn{1}{|c|}{$\begin{array}{c}\text { ESCORE BÁSICO } \\
\text { ARISTÓTELES }\end{array}$} & $\begin{array}{r}\text { ESCORE BÁSICO } \\
\text { ARISTÓTELES }\end{array}$ \\
\hline 1 & $\mathbf{6}$ & 3 & $\mathbf{6}$ \\
\hline 7 & $\mathbf{6}$ & 6 & $\mathbf{6}$ \\
\hline 13 & $\mathbf{1 0 , 3}$ & 10 & $\mathbf{6}$ \\
\hline 24 & $\mathbf{5 , 6}$ & 11 & $\mathbf{3}$ \\
\hline 25 & $\mathbf{1 0 , 3}$ & 12 & $\mathbf{6 , 3}$ \\
\hline 32 & $\mathbf{6}$ & 34 & $\mathbf{6}$ \\
\hline 35 & $\mathbf{4}$ & 36 & $\mathbf{6}$ \\
\hline 37 & $\mathbf{6}$ & 49 & $\mathbf{6}$ \\
\hline 40 & $\mathbf{9}$ & 53 & $\mathbf{6}$ \\
\hline 45 & $\mathbf{5 , 6}$ & & \\
\hline Mediana & $\mathbf{6}$ & Mediana & \\
\hline Média & $\mathbf{6 , 8 8 + \mathbf { 2 , 1 7 }}$ Média & $\mathbf{6}$ \\
\hline
\end{tabular}

TABELA 9. Comparação dos escores pré-operatórias entre os grupos aprotinina e controle (Teste de Wilcoxon).

\begin{tabular}{ccc}
\hline Variável & $\begin{array}{c}\text { Mediana }\left(1 .^{\circ} \text { Quartil;3. }{ }^{\circ} \text { Quartil) }\right. \\
\text { Tratamento }\end{array}$ & $\begin{array}{c}\text { Tratamento } \times \text { Controle } \\
\text { Controle }\end{array}$ \\
\hline Escore de Ross & $5,50(1,75 ; 7,00)$ & $3,00(2,00 ; 6,00)$ \\
RACHS-1 & $2,00(2,00 ; 2,00)$ & 0,56 \\
Escore Aristóteles & $6,00(5,70 ; 8,25)$ & $2,00(2,00 ; 2,00)$ \\
\end{tabular}


TABELA 10 - Diagnóstico pré-operatório das crianças do grupo Aprotinina

\begin{tabular}{|c|c|c|c|}
\hline PAC & Diagnóstico & $\begin{array}{l}\text { Hipertensão Pulmonar (HP) } \\
\text { Fração de ejeção (FE) }\end{array}$ & Outros \\
\hline 1 & $\begin{array}{l}\text { CIV perimembranosa } 7 \times 8 \mathrm{~mm} \text { com gradiente pico } \\
\text { de } 25 \mathrm{mmHg} \text { e IT leve. Desempenho sistólico } \\
\text { ventrículos preservado. }\end{array}$ & $\begin{array}{l}\text { HP Moderada ( PSAP } 55 \mathrm{mmHg} \text { ) } \\
\text { FE } 68 \%\end{array}$ & Síndrome de Down \\
\hline 7 & $\begin{array}{l}\text { CIV perimembranosa } 7 \times 5 \mathrm{~mm} \text {, CIA fossa oval 4,2 } \\
\text { mm, PCA de 1,4 mm, IT moderada. Seio } \\
\text { coronariano dilatado sugerindo persistência } \\
\text { VCSE. Dilatação leve câmaras esquerdas e } \\
\text { dilatação moderada das câmaras direitas. } \\
\text { Desempenho sistólico preservado dos ventrículos. } \\
\text { Hipertrofia moderada VD }\end{array}$ & HP Importante (PSAP 80 mmHg) & \\
\hline 13 & $\begin{array}{l}\text { CIV perimembranosa 7x5mm com extensão } \\
\text { trabecular com gradiente de pico de } 18 \mathrm{mmHg} \text {. } \\
\text { DVSVD (achado intra-operatório) PCA de } 3 \mathrm{~mm} \text {, } \\
\text { FOP. Dilatação leve câmaras esquerdas. } \\
\text { Desempenho sistólico preservado dos ventrículos. } \\
\text { EP leve (gradiente pico } 18 \mathrm{mmHg} \text { ). Arco aórtico } \\
\text { para a direita. }\end{array}$ & $\begin{array}{l}\text { Presença indireta de HP (SIV } \\
\text { retificado) } \\
\text { FE } 74 \%\end{array}$ & $\begin{array}{l}\text { Síndrome fáscio- } \\
\text { aurículo-vertebral } \\
\text { (paralisia facial E, } \\
\text { atresia / displasia } \\
\text { conduto auditivo } \\
\text { externo) }\end{array}$ \\
\hline 24 & $\begin{array}{l}\text { EPV (gradiente pico } 66 \mathrm{mmHg} \text { ), PCA, hipertrofia e } \\
\text { dilatação moderada do VD }\end{array}$ & a & \\
\hline 25 & $\begin{array}{l}\text { CIV perimembranosa } 10 \mathrm{~mm} \text { que se estende para } \\
\text { via de saída com gradiente de pico de } 16 \mathrm{mmHg} \text {. } \\
\text { DVSVD (achado intraoperatório). Dilatação } \\
\text { moderada das câmaras esquerdas. Dilatação leve } \\
\text { e hipertrofia do VD. }\end{array}$ & $\begin{array}{l}\text { Moderada (PSAP } 41 \mathrm{mmHg} \text { ) } \\
\text { FE } 63 \%\end{array}$ & $\begin{array}{l}\text { Síndrome Pierre- } \\
\text { Robin }\end{array}$ \\
\hline 32 & $\begin{array}{l}\text { CIV perimembranosa de } 10 \times 9 \mathrm{~mm} \text {, fluxo } \\
\text { bidircional preferencial } \mathrm{D}-\mathrm{E} \text {, tronco pulmonar com } \\
\text { bandagem cirúrgica levando à estenose } \\
\text { acentuada (gradiente VD-TP de pico de } 102 \text { e } \\
\text { médio de } 65 \mathrm{mmHg} \text { ). Hipertrofia leve do VD. }\end{array}$ & $\begin{array}{l}\text { Gradiente pela bandagem } \\
(102 / 65 \mathrm{mmHg}) \\
\text { FE } 73 \%\end{array}$ & $\begin{array}{l}\text { Com } 18 \text { dias de } \\
\text { idade - Correção } \\
\text { cirúrgica CoAo, } \\
\text { Bandagem A. } \\
\text { Pulmonar e ligadura } \\
\text { PCA } \\
\text { Com } 160 \text { dias idade } \\
\text { - Correção cirúrgica } \\
\text { de ReCoAo }\end{array}$ \\
\hline 35 & $\begin{array}{l}\text { DSAV parcial . Valva AV única com insuficiência } \\
\text { leve e CIA OP 20mm. Ausência de CIV. } \\
\text { Desempenho VE sistólico preservado. }\end{array}$ & FE $74 \%$ & $\begin{array}{l}\text { Nefrectomia } \\
\text { esquerda com } 5 \\
\text { meses de idade } \\
\text { (malformação } \\
\text { congênita) }\end{array}$ \\
\hline 37 & $\begin{array}{l}\text { CIV muscular de } 5 \mathrm{~mm} \text {, entre a porção média e } \\
\text { basal do SIV. FOP. Valva pulmonar displásica } \\
\text { com abertura em cúpula e estenose moderada } \\
\text { (gradiente VD-TP de pico de } 64 \text { e médio de } 40 \\
\text { mmHg). Dilatação leve das câmaras esquerdas. } \\
\text { Desempenho sistólico preservado. Hipertrofia leve } \\
\text { do VD. }\end{array}$ & FE 76\% & \\
\hline 40 & $\begin{array}{l}\text { CIVs múltiplas na porção trabecular média apical } \\
\text { (apical ampla)com fluxo E-D. Aneurisma septo } \\
\text { interatrial com CIA OS ampla. Valva pulmonar } \\
\text { com EP leve com folhetos espessados e abertura } \\
\text { em cúpula Gradiente sistólico VD-TP } 30-35 \mathrm{mmHg} \\
\text { (ECO) e médio de } 16 \mathrm{mmHg} \text { (CATETERISMO) }\end{array}$ & $\begin{array}{l}\text { Leve (40/15/média 23) (CATE) } \\
\text { FE } 61 \%\end{array}$ & $\begin{array}{l}\text { Estigmas genétcos } \\
\text { a/e (clinodactilia, } \\
\text { hálux curto) }\end{array}$ \\
\hline 45 & $\begin{array}{l}\text { EPV acentuada, com valva pulmonar displásica, } \\
\text { com abertura em cúpula, gradiente VD-TP de pico } \\
132 \text { e médio } 75 \text { mmHg. IT moderada. PCA de } 2,2 \\
\text { mm. FOP, com fluxo D-E. Dilatação moderada } \\
\text { câmaras direitas. Hipertrofia acentuada de VD. }\end{array}$ & FE $80 \%$ & \\
\hline
\end{tabular}

Abreviaturas: CIV - comunicação interventricular; CIA - comunicação interatrial ; PCA persistência do canal arerial; DVSVD - dupla via de saída do ventrículo direito; EPV - estenose pulmonar valvar; AP- artéria pulmonar; FOP - forame oval patente; DSAV - defeito do septo atrioventricular; M SubAo- membrana subaórtica; FE - fração de ejeção; IT - insuficiência tricúspide. 
TABELA 11 - Diagnóstico pré-operatório das crianças do Grupo Controle

\begin{tabular}{|c|c|c|c|}
\hline PAC & Diagnóstico & $\begin{array}{l}\text { Hipertensão Pulmonar (HP) } \\
\text { Fração de ejeção (FE) }\end{array}$ & Outros \\
\hline 3 & $\begin{array}{l}\text { CIV perimembranosa de } 5 \mathrm{~mm} \text {, com gradiente de } \\
\text { pico de } 96 \mathrm{mmHg} \text {. Desempenho sistólico } \\
\text { ventrículos preservado. }\end{array}$ & FE 62\% & \\
\hline 6 & $\begin{array}{l}\text { CIV intermediária entre via de saída e via de } \\
\text { entrada. CIA fossa oval } 4 \mathrm{~mm} \text {. Desempenho } \\
\text { sistólico ventricular preservado., PCA }\end{array}$ & $\begin{array}{l}\text { Presença indireta de HP (baixa } \\
\text { velocidade de fluxo pela CIV) } \\
\text { FE } 72 \%\end{array}$ & $\begin{array}{l}\text { Onfalocele operada } \\
\text { no } 2^{\circ} \text { dia de vida, } \\
\text { ficando } 18 \text { dias } \\
\text { internada por } \\
\text { infecção pós- } \\
\text { operatória }\end{array}$ \\
\hline 10 & $\begin{array}{l}\text { CIV perimembranosa de } 5 \mathrm{~mm} \text {, com gradiente VE- } \\
\text { VD de } 50 \mathrm{mmHg} \text {. IMi e IT leves. }\end{array}$ & $\begin{array}{l}\text { Presença indireta de HP (baixa } \\
\text { velocidade de fluxo pela CIV) } \\
\text { FE } 74 \%\end{array}$ & $\begin{array}{l}\text { Disrafismo espinhal } \\
\text { oculto }\end{array}$ \\
\hline 11 & $\begin{array}{l}\text { CIA OS 10x7 mm. Dilatação moderada Câmaras } \\
\text { direitas. Desempenho sistólico preservado. }\end{array}$ & FE 67\% & \\
\hline 12 & $\begin{array}{l}\text { CIV de } 4 \mathrm{~mm} \text {. Membrana subaórtica a } 6 \mathrm{~mm} \text { da } \\
\text { valva aórtica. IAo leve. Desempenho sistólico } \\
\text { ventrículos preservado. }\end{array}$ & FE $70 \%$ & $\begin{array}{l}\text { Refluxo gastro- } \\
\text { esofágico. OMA de } \\
\text { repetição. }\end{array}$ \\
\hline 34 & $\begin{array}{l}\text { CIV perimembranosa de } 8 \mathrm{~mm} \text {. CIA fossa oval } \\
\text { pequena. Desempenho ventrículos preservado. }\end{array}$ & $\begin{array}{l}\text { Presença indireta de HP (baixa } \\
\text { velocidade de fluxo pela CIV e } \\
\text { SIV retificado) } \\
\text { FE } 61 \%\end{array}$ & Síndrome de Down \\
\hline 36 & $\begin{array}{l}\text { CIV perimembranosa de } 6 \times 9 \mathrm{~mm} \text {, com fluxo E-D } \\
\text { com gradiente de pico de } 16 \mathrm{mmHg} \text {. IT leve. }\end{array}$ & $\begin{array}{l}\text { HP moderada (PSAP }=60 \mathrm{mmHg}) \\
\text { FE } 67 \%\end{array}$ & Síndrome de Down \\
\hline 49 & $\begin{array}{l}\text { CIV perimembranosa e subaórtica, de } 5 \times 6 \mathrm{~mm} \text {, } \\
\text { com gradiente de pico de } 30 \mathrm{MMHg} \text {. Desempenho } \\
\text { sistólico dos ventrículos preservado. }\end{array}$ & FE 73\% & \\
\hline 53 & $\begin{array}{l}\text { CIV perimembranosa de } 7,1 \times 7,7 \mathrm{~mm} \text {, recoberta } \\
\text { com tecido subtricuspídio, com baixo gradiente } \\
\text { interventricular de } 6 \mathrm{mmHg} \text {. Hipertrofia leve/ } \\
\text { moderada do VD. FOP. }\end{array}$ & $\begin{array}{l}\text { Presença indireta de HP } \\
\text { importante (SIV retificado, } \\
\text { gradiente baixo pela CIV). } \\
\text { FE } 81 \%\end{array}$ & $\begin{array}{l}\text { Síndrome de Down. } \\
\text { Hipotireoidismo } \\
\text { congênito. }\end{array}$ \\
\hline
\end{tabular}

Abreviaturas: CIV - comunicação interventricular; CIA - comunicação interatrial ; PCA persistência do canal arerial; DVSVD - dupla via de saída do ventrículo direito; EPV - estenose pulmonar valvar; AP- artéria pulmonar; FOP - forame oval patente; DSAV - defeito do septo atrioventricular; M SubAo- membrana subaórtica; FE - fração de ejeção; IT - insuficiência tricúspide. 


\section{ANEXO III}

TABELA 12 - Vias de acesso intracardíaco e tipo de correção cirúrgica realizada nas crianças do Grupo Aprotinina

\begin{tabular}{|c|c|c|c|}
\hline PAC & Achado intra-operatório & $\begin{array}{l}\text { Vias de acesso } \\
\text { intracardíacos }\end{array}$ & Operação realizada \\
\hline 1 & $\begin{array}{l}\text { CIV perimembranosa } 7 \times 8 \mathrm{~mm}+\mathrm{PCA} \\
4 \mathrm{~mm}\end{array}$ & Atriotomia direita & $\begin{array}{l}\text { Timectomia total + ligadura canal arterial+ } \\
\text { ventriculoseptoplastia + plastia valvar } \\
\text { tricúspide }\end{array}$ \\
\hline 7 & $\begin{array}{l}\text { CIV perimembranosa } 7 \times 5 \mathrm{~mm}, \mathrm{CIA} \\
\text { fossa oval } 4,2 \mathrm{~mm} \text {, PCA de 1,4 mm, } \\
\text { IT moderada, Persistência VCSE de } \\
\text { igual calibre VCSD. Ausência de } \\
\text { veia inominada }\end{array}$ & Atriotomia direita & $\begin{array}{l}\text { Timectomia total + ligadura canal arterial + } \\
\text { ventriculoseptoplastia + atriosseptorrafia }\end{array}$ \\
\hline 13 & $\begin{array}{l}\text { DVSVD, CIV perimembranosa } \\
\text { 13x7mm subaórtica. PCA de } 3 \mathrm{~mm} \text {, } \\
\text { FOP. Arco aórtico para a direita. }\end{array}$ & $\begin{array}{l}\text { Atritomia direita } \\
\text { Ventriculotomia direita }\end{array}$ & $\begin{array}{l}\text { Timectomia total + ligadura canal arterial + } \\
\text { ventriculosseptoplastia tunelizando VE- Ao } \\
\text { + plastia tricúspide }\end{array}$ \\
\hline 24 & $\begin{array}{l}\text { EPV, com fusão comissural e } \\
\text { abertura em cúpula, PCA }\end{array}$ & $\begin{array}{l}\text { Atritomia direita } \\
\text { Arteriotomia pulmonar }\end{array}$ & $\begin{array}{l}\text { Timectomia total + ligadura do canal arterial } \\
\text { + Comissurotomia valvar pulmonar }\end{array}$ \\
\hline 25 & $\begin{array}{l}\text { DVSVD, CIV perimembranosa } 13 \\
\text { mm subtricuspídeo, PCA } 2 \mathrm{~mm} \text {, } \\
\text { Aorta anteriorizada }\end{array}$ & Atriotomia direita & $\begin{array}{l}\text { Timectomia total + Ligadura PCA + } \\
\text { Ventriculosseptoplastia tunelizando VE- Ao }\end{array}$ \\
\hline 32 & $\begin{array}{l}\text { CIV perimembranosa de } 10 \times 9 \mathrm{~mm} \text {, } \\
\text { tronco pulmonar com bandagem } \\
\text { cirúrgica, FOP }\end{array}$ & $\begin{array}{l}\text { Atriotomia direita } \\
\text { Transecção artéria } \\
\text { pulmonar }\end{array}$ & $\begin{array}{l}\text { Timectomia total + Ventriculosseptoplastia } \\
\text { + remoção do segmento de bandagem da } \\
\text { artéria pulmonar e anastomose término- } \\
\text { terminal + fechamento FOP }\end{array}$ \\
\hline 35 & $\begin{array}{l}\text { DSAV parcial. Valva AV única com } \\
\text { "cleft" mitral, CIA fossa oval } 5 \mathrm{~mm} \text {, } \\
\text { PCA } 3 \mathrm{~mm}\end{array}$ & Atriotomia direita & $\begin{array}{l}\text { Timectomia total + ligadura PCA + } \\
\text { fechamento "cleft" mitral + } \\
\text { atriosseptoplastia para correção do DSAV } \\
\text { parcial + atriosseptorrafia }\end{array}$ \\
\hline 37 & $\begin{array}{l}\text { CIV muscular de } 1,3 \times 5 \mathrm{~mm} \text {, entre a } \\
\text { porção média e basal do SIV. FOP. } \\
\text { Valva pulmonar displásica com } \\
\text { abertura anelar satisfatória com } \\
\text { calibração adequada para a } \\
\text { superfície corpórea }\end{array}$ & $\begin{array}{l}\text { Atriotomia direita } \\
\text { Arteriotomia pulmonar }\end{array}$ & $\begin{array}{l}\text { Timectomia total + ligadura canal arterial + } \\
\text { ventriculosseptoplastia + inspeção da valva } \\
\text { pulmonar }\end{array}$ \\
\hline 40 & $\begin{array}{l}\text { CIVs múltiplas na porção apical } \\
\text { (ponta VD) + PCA 3,5mm + Septo } \\
\text { interatrial fenestrado com CIA tipo } \\
\text { fossa oval ampla }\end{array}$ & Atriotomia direita & $\begin{array}{l}\text { Timectomia total + ligadura canal arterial + } \\
\text { ventriculosseptoplastia + atriosseptorrafia }\end{array}$ \\
\hline 45 & $\begin{array}{l}\text { EPV crítica com valva pulmonar } \\
\text { displásica, com abertura puntiforme } \\
\text { em cúpula, PCA de } 2,2 \mathrm{~mm} \text {. FOP. }\end{array}$ & $\begin{array}{l}\text { Atriotomia direita } \\
\text { Arteriotomia pulmonar } \\
\text { longitudinal com } \\
\text { ampliação transanular }\end{array}$ & $\begin{array}{l}\text { Timectomia total + ligadura canal arterial + } \\
\text { ampliação transanular pulmonar por } 1 \mathrm{~cm} \text { e } \\
\text { ressecção de } 2 \text { dos } 3 \text { folhetos pulmonares } \\
\text { e reconstrução com selo de pericárdio } \\
\text { bovino + fechamento FOP. }\end{array}$ \\
\hline
\end{tabular}

Abreviaturas: CIV - comunicação interventricular; CIA - comunicação interatrial ; PCA persistência do canal arerial; DVSVD - dupla via de saída do ventrículo direito; EPV - estenose pulmonar valvar; AP- artéria pulmonar; FOP - forame oval patente; DSAV - defeito do septo atrioventricular; M SubAo- membrana subaórtica; FE - fração de ejeção; IT - insuficiência tricúspide. 
TABELA 13 - Vias de acesso intracardíaco e tipo de correção cirúrgica realizada nas crianças do Grupo Controle

\begin{tabular}{|c|c|c|c|}
\hline PAC & Achado intra-operatório & $\begin{array}{l}\text { Vias de acesso } \\
\text { intracardíacos }\end{array}$ & Operação realizada \\
\hline 3 & $\begin{array}{l}\text { CIV perimembranosa de } 5 \mathrm{~mm}, \mathrm{PCA} \\
2,5 \mathrm{~mm}\end{array}$ & Atriotomia direita & $\begin{array}{l}\text { Timectomia total + ligadura do canal } \\
\text { arterial + ventriculosseptoplastia + plastia } \\
\text { valvar tricúspide }\end{array}$ \\
\hline 6 & $\begin{array}{l}\text { CIV perimembranosa } \\
\text { subtricuspídea, CIA fossa oval } 4 \\
\text { mm, PCA } 3 \mathrm{~mm}\end{array}$ & Atriotomia direita & $\begin{array}{l}\text { Timectomia total + ligadura do canal } \\
\text { arterial + ventriculosseptoplastia + } \\
\text { atriosseptorrafia }\end{array}$ \\
\hline 10 & $\begin{array}{l}\text { CIV perimembranosa tipo via de } \\
\text { entrada de } 5 \mathrm{~mm} \text {, Ligamento arterial }\end{array}$ & Atriotomia direita & $\begin{array}{l}\text { Timectomia total + clipagem do ligamento } \\
\text { arterial + ventriculosseptoplastia + plastia } \\
\text { valvar tricúspide }\end{array}$ \\
\hline 11 & CIA OS 20x10 mm & Atriotomia direita & Timectomia total + atriosseptorrafia \\
\hline 12 & $\begin{array}{l}\text { CIV subaórtica de } 13 \mathrm{~mm} \text { sob o } \\
\text { folheto coronariano direito da valva } \\
\text { aórtica, Membrana subaórtica, } \\
\text { Canal (Ligamento?) arterial de } 3 \mathrm{~mm}\end{array}$ & $\begin{array}{l}\text { Atriotomia direita } \\
\text { Aortotomia transversa }\end{array}$ & $\begin{array}{l}\text { Timectomia total + ligadura do canal } \\
\text { arterial + ventriculosseptoplastia + } \\
\text { ressecção membrana subaórtica + plastia } \\
\text { tricúspide }\end{array}$ \\
\hline 34 & $\begin{array}{l}\text { CIV perimembranosa subtricuspídea } \\
\text { de } 10 \mathrm{~mm} \text {. CIA fossa oval } 5 \mathrm{~mm} \text {. PCA } \\
5 \mathrm{~mm}\end{array}$ & Atriotomia direita & $\begin{array}{l}\text { Timectomia total + ligadura do canal } \\
\text { arterial + ventriculosseptoplastia + plastia } \\
\text { valvar tricúspide }\end{array}$ \\
\hline 36 & $\begin{array}{l}\text { CIV perimembranosa subtricuspídeo } \\
\text { de } 12 \mathrm{~mm}+\text { PCA } 2,5 \mathrm{~mm}\end{array}$ & Atriotomia direita & $\begin{array}{l}\text { Timectomia total + ligadura do canal } \\
\text { arterial + ventriculosseptoplastia + plastia } \\
\text { valvar tricúspide }\end{array}$ \\
\hline 49 & $\begin{array}{l}\text { CIV perimembranosa e subaórtica, } \\
\text { de } 5 \text { X6 mm, PCA } 2,5 \mathrm{~mm}\end{array}$ & Atriotomia direita & $\begin{array}{l}\text { Timectomia total + ligadura do canal } \\
\text { arterial + ventriculosseptoplastia + plastia } \\
\text { valvar tricúspide }\end{array}$ \\
\hline 53 & $\begin{array}{l}\text { CIV perimembranosa de } 8 \times 13 \mathrm{~mm} \\
\text { mm, recoberta com tecido } \\
\text { subtricuspídio, tipo via de entrada }\end{array}$ & Atriotomia direita & Timectomia total + ventriculosseptoplastia \\
\hline
\end{tabular}

Abreviaturas: CIV - comunicação interventricular; CIA - comunicação interatrial ; PCA persistência do canal arerial; DVSVD - dupla via de saída do ventrículo direito; EPV - estenose pulmonar valvar; AP- artéria pulmonar; FOP - forame oval patente; DSAV - defeito do septo atrioventricular; M SubAo- membrana subaórtica; FE - fração de ejeção; IT - insuficiência tricúspide.

TABELA 14: Comparação das variáveis clínicas intra-operatórias entre os grupos Aprotinina e Controle.

\begin{tabular}{cccc}
\hline Variável & Mediana $\left(1 .^{\circ}\right.$ Quartil;2. ${ }^{\circ}$ Quartil) & $\begin{array}{c}\text { Tratamento } x \\
\text { Controle } \\
\text { P-valor }\end{array}$ \\
\hline Tempo operatório (min) & $185,00(172,50 ; 216,25)$ & $210,00(170,00 ; 220,00)$ & 0,87 \\
Tempo anestesia (min) & $325,00(300,00 ; 337,50)$ & $270,00(270,00 ; 320,00)$ & 0,09 \\
Tempo CEC (min) & $62,50(51,25 ; 72,50)$ & $70,00(65,00 ; 70,00)$ & 0,27 \\
Hipotermia & $28,75(27,10 ; 30,52)$ & $29,10(27,40 ; 30,40)$ & 0,81 \\
Tempo anóxia (min) & $36,00(30,00 ; 43,75)$ & $45,00(41,00 ; 45,00)$ & 0,13 \\
Volume Perfusato & $348,25(304,25 ; 380,96)$ & $370,00(315,00 ; 479,00)$ & 0,45 \\
Volume circulante & $709,06(668,58 ; 1060,37)$ & $783,25(683,00 ; 1118,95)$ & 0,90 \\
Volume LEC (litros) & $1,35(1,12 ; 1,94)$ & $1,45(1,36 ; 1,88)$ & 0,87 \\
Balanço Sangüíneo & $15,00(-110,00 ; 120,00)$ & $150,00(90,00 ; 180,00)$ & 0,05 \\
Balanço hídrico (final / total) & $205,00(50,00 ; 313,75)$ & $160,00(80,00 ; 195,00)$ & 0,68 \\
Balanço hídrico (final / ml/kg) & $25,17(9,21 ; 71,54)$ & $35,00(28,80 ; 46,87)$ & 0,60 \\
Hemácias (total) & $215,00(200,00 ; 257,50)$ & $250,00(200,00 ; 265,00)$ & 0,64 \\
Hemácias (ml/kg) & $47,52(25,57 ; 63,69)$ & $52,08(29,11 ; 58,62)$ & 0,60 \\
\hline
\end{tabular}


TABELA 15. Oxigenadores de membrana utilizados e composição principal do perfusato com acréscimos no circuito da CEC

\begin{tabular}{|c|c|c|}
\hline Grupo APROTININA & Oxigenador membrana & $\begin{array}{l}\text { Perfusato ("prime") (volume e composição principal) } \\
\text { Volume total (ml) }\end{array}$ \\
\hline 1 & Polystan Micro & $\begin{array}{l}\mathrm{CH} 200 \mathrm{ml}+\text { Manitol 20ml + Trasylol 42ml } \\
262 \mathrm{ml}\end{array}$ \\
\hline 7 & Polystan Micro & $\begin{array}{l}\text { CH } 230 \mathrm{ml}+\text { Manitol } 31 \mathrm{ml}+\text { Trasylol 36ml } \\
297 \mathbf{~ m l}\end{array}$ \\
\hline 13 & Polystan Micro & $\begin{array}{l}\text { CH } 250 \mathrm{ml}+\text { Manitol 50ml + Trasylol 49,7 ml } \\
\mathbf{3 4 9 , 7} \mathbf{~ m l}\end{array}$ \\
\hline 24 & Polystan Mini & $\begin{array}{l}\text { CH } 200 \mathrm{ml}+80 \mathrm{ml} \text { Manitol + Trasylol 66,8 ml } \\
\mathbf{3 4 6 , 8} \mathbf{~ m l}\end{array}$ \\
\hline 25 & Lilliput & $\begin{array}{l}\text { CH } 300 \mathrm{ml}+30 \mathrm{ml} \text { Manitol + Trasylol } 36 \mathrm{ml} \\
\mathbf{3 6 6} \mathbf{~ m l}\end{array}$ \\
\hline 32 & Polystan Mini & $\begin{array}{l}\mathrm{CH} 260+\text { PFC } 100 \mathrm{ml}+\text { Manitol } 45 \mathrm{ml}+\text { Trasylol } 70 \mathrm{ml} \\
\mathbf{4 7 5} \mathrm{ml}\end{array}$ \\
\hline 35 & Oxim 06 & $\begin{array}{l}\text { CH } 200+\text { RS 500ml + } 150 \mathrm{ml} \text { Manitol + Trasylol 111,4 ml } \\
861,4 \mathbf{~ m l}\end{array}$ \\
\hline 37 & Lilliput & $\begin{array}{l}\mathrm{CH} 100+\text { Manitol } 25 \mathrm{ml}+\text { Trasylol } 48 \mathrm{ml} \\
173 \mathrm{ml}\end{array}$ \\
\hline 40 & DMG Vital 1500 Baby & $\begin{array}{l}\text { CH } 200 \mathrm{ml}+\text { PFC } 130 \mathrm{ml}+\text { Manitol 18,25 ml + Trasylol 37,7 m } \\
\mathbf{3 8 5 , 9 5} \mathbf{m l}\end{array}$ \\
\hline 45 & Lilliput & $\begin{array}{l}\mathrm{CH} 270 \mathrm{ml}+\text { Manitol } 20 \mathrm{ml}+\text { Trasylol } 36 \mathrm{ml} \\
\mathbf{3 2 6} \mathbf{~ m l}\end{array}$ \\
\hline
\end{tabular}

\begin{tabular}{|c|c|c|}
\hline Grupo CONTROLE & Oxigenador membrana & Perfusato (“prime”) \\
\hline 3 & Polystan Mini & $\begin{array}{l}\mathrm{CH} 200 \mathrm{ml}+\text { Manitol } 35 \mathrm{ml}+\mathrm{RS} 300 \mathrm{ml} \\
\mathbf{5 3 5} \mathbf{~ m l}\end{array}$ \\
\hline 6 & Polystan Micro & $\begin{array}{l}\mathrm{CH} 200 \mathrm{ml}+\mathrm{PFC} 100 \mathrm{ml}+\text { Manitol } 15 \mathrm{ml} \\
\mathbf{3 1 5} \mathbf{~ m l}\end{array}$ \\
\hline 10 & Polystan Micro & $\begin{array}{l}\mathrm{CH} 250 \mathrm{ml}+\text { Manitol } 25 \mathrm{ml} \\
\mathbf{2 7 5} \mathbf{~ m l}\end{array}$ \\
\hline 11 & Polystan Micro & $\begin{array}{l}\text { CH } 150 \mathrm{ml}+\text { Manitol } 68 \mathrm{ml} \\
\mathbf{2 1 8} \mathbf{~ m l}\end{array}$ \\
\hline 12 & Polystan Mini & $\begin{array}{l}\mathrm{CH} 200 \mathrm{ml}+\text { PFC } 200 \mathrm{ml}+\text { Manitol } 79 \mathrm{ml} \\
\mathbf{4 7 9} \mathbf{~ m l}\end{array}$ \\
\hline 34 & Lilliput & $\begin{array}{l}\mathrm{CHI} 340 \mathrm{ml}+\text { Manitol } 15 \mathrm{ml} \\
355 \mathrm{ml}\end{array}$ \\
\hline 36 & Lilliput & $\begin{array}{l}\mathrm{CH} 380 \mathrm{ml}+\mathrm{RS} 500 \mathrm{ml}+\text { Manitol } 36 \mathrm{ml} \\
916 \mathrm{ml}\end{array}$ \\
\hline 49 & Lilliput & $\begin{array}{l}\mathrm{CH} 250 \mathrm{ml}+\text { PFC } 100 \mathrm{ml}+\text { Manitol } 20 \mathrm{ml} \\
\mathbf{3 7 0} \mathbf{~ m l}\end{array}$ \\
\hline 53 & Lilliput & $\begin{array}{l}\mathrm{CH} 265 \mathrm{ml}+\mathrm{SF} 0,9 \% 120 \mathrm{ml}+\text { Albumina } 10 \mathrm{ml}+\text { Manitol } 20 \mathrm{ml} \\
\mathbf{4 1 5} \mathbf{~ m l}\end{array}$ \\
\hline
\end{tabular}


TABELA 16. Volemia sangüínea estimada e volume circulante total em CEC nos grupos Aprotinina e Controle.

\begin{tabular}{|c|c|c|c|c|c|}
\hline $\begin{array}{l}\text { GRUPO } \\
\text { APROTININA }\end{array}$ & Peso (kg) & $\begin{array}{c}\text { Volemia } \\
\text { estimada }(\mathrm{ml})\end{array}$ & $\begin{array}{l}\text { Volume } \\
\text { Aprotinina } \\
\text { "bolus" }\end{array}$ & $\begin{array}{c}\text { Volume } \\
\text { estimado } \\
\text { perfusato }(\mathrm{ml})\end{array}$ & $\begin{array}{c}\text { Volume circulante } \\
\text { total (VCT) estimado em } \\
\text { CEC (ml) sem "bolus"I } \\
\text { com "bolus" }\end{array}$ \\
\hline 1 & 4,30 & 365,50 & $\begin{array}{c}\mathbf{4 2 , 8} \mathbf{~ m l} \\
59,92 \mathrm{mg}\end{array}$ & 262,00 & $627,50 / 670,3$ \\
\hline 7 & 3,45 & 293,25 & $\begin{array}{l}36,0 \mathrm{ml} \\
50,4 \mathrm{mg} \\
\end{array}$ & 297,00 & $590,25 / 626,25$ \\
\hline 13 & 5,15 & 437,75 & $\begin{array}{l}\mathbf{4 9 , 7 1} \mathrm{ml} \\
69,59 \mathrm{mg}\end{array}$ & 349,70 & $787,45 / 837,16$ \\
\hline 24 & 8,17 & 694,45 & $\begin{array}{c}\mathbf{6 6 , 8} \mathbf{~ m l} \\
93,52 \mathrm{mg} \\
\end{array}$ & 346,80 & $1041,25 / 1134,77$ \\
\hline 25 & 3,32 & 282,20 & $\begin{array}{l}\mathbf{3 6 , 0} \mathbf{~ m l} \\
50,4 \mathrm{mg}\end{array}$ & 366,00 & $648,20 / 684,20$ \\
\hline 32 & 9,00 & 765,00 & $\begin{array}{l}70,28 \mathrm{ml} \\
98,39 \mathrm{mg}\end{array}$ & 475,00 & $1240,00 / 1310,28$ \\
\hline 35 & 15,00 & 1200,00 & $\begin{array}{c}111,42 \mathrm{ml} \\
155,98 \mathrm{mg}\end{array}$ & 861,40 & $2061,40 / 2172,82$ \\
\hline 37 & 5,03 & 427,55 & $\begin{array}{c}\mathbf{4 8 , 0} \mathbf{~ m l} \\
67,20 \mathrm{mg}\end{array}$ & 173,00 & $600,55 / 648,55$ \\
\hline 40 & 3,65 & 310,25 & $\begin{array}{l}37,71 \mathrm{ml} \\
52,79 \mathrm{mg} \\
\end{array}$ & 385,95 & $696,20 / 733,91$ \\
\hline 45 & 3,60 & 306,00 & $\begin{array}{l}36,0 \mathrm{ml} \\
50,4 \mathrm{mg}\end{array}$ & 326,00 & $632,00 / 668,00$ \\
\hline Média & 6,067 & 508,195 & $\begin{array}{l}\mathbf{5 3}, \mathbf{4 7} \mathrm{ml} \\
74,85 \mathrm{mg}\end{array}$ & 384,285 & $892,48 / 948,62$ \\
\hline
\end{tabular}

\begin{tabular}{|l|c|c|c|c|}
\hline $\begin{array}{l}\text { GRUPO } \\
\text { CONTROLE }\end{array}$ & Peso (kg) & $\begin{array}{c}\text { Volemia } \\
\text { Estimada (ml) }\end{array}$ & $\begin{array}{c}\text { Volume estimado } \\
\text { perfusato } \\
(\mathbf{m l})\end{array}$ & $\begin{array}{c}\text { Volume circulante } \\
\text { Total (VCT) estimado em CEC (mI) }\end{array}$ \\
\hline $\mathbf{3}$ & 6,87 & 583,95 & 535,00 & 5118,95 \\
\hline $\mathbf{6}$ & 2,20 & 187,00 & 315,00 & 683,00 \\
\hline $\mathbf{1 0}$ & 4,80 & 408,00 & 275,00 & 783,25 \\
\hline $\mathbf{1 1}$ & 6,65 & 565,25 & 218,00 & 1743,00 \\
\hline $\mathbf{1 2}$ & 15,80 & 1264,00 & 479,00 & 600,65 \\
\hline $\mathbf{3 4}$ & 2,89 & 245,65 & 355,00 & 1537,35 \\
\hline $\mathbf{3 6}$ & 7,31 & 621,35 & 916,00 & 754,20 \\
\hline $\mathbf{4 9}$ & 4,52 & 384,20 & 370,00 & 799,20 \\
\hline $\mathbf{5 3}$ & 4,52 & 384,20 & 415,00 & $\mathbf{9 4 6 , 8 4 4}$ \\
\hline Média & $\mathbf{6 , 1 7 3}$ & $\mathbf{5 1 5 , 9 5 5}$ & $\mathbf{4 3 0 , 8 8 8}$ & \\
\hline
\end{tabular}


TABELA 17. Dose de aprotinina infundida nos pacientes, considerando que $50 \mathrm{ml}$ de Trasylol ${ }^{\circledR}$ equivalem a 70 mg de aprotinina, com concentração de 10000 UIC aprotinina/ml.

\begin{tabular}{|c|c|c|c|c|c|}
\hline $\begin{array}{l}\text { Paciente } I \\
\text { Tempo CEC até } \\
\text { fechamento pele } \\
\text { (min) }\end{array}$ & $\begin{array}{l}\text { Superfície } \\
\text { corpórea }\left(\mathrm{m}^{2}\right)\end{array}$ & $\begin{array}{l}\text { Dose "bolus" } \\
\text { (ml e mg) } \\
240 \mathrm{mg} / \mathrm{m}^{2}\end{array}$ & $\begin{array}{l}\text { Dose "prime" } \\
\text { (ml e mg) } \\
240 \mathrm{mg} / \mathrm{m}^{2}\end{array}$ & $\begin{array}{l}\text { Dose } \\
\text { manutenção } \\
\text { (ml e mg) } \\
56 \mathrm{mg} / \mathrm{m}^{2} / \mathrm{h}\end{array}$ & $\begin{array}{l}\text { Dose total de } \\
\text { manutenção } \\
\text { infundida } \\
\text { (mg) }\end{array}$ \\
\hline $\begin{array}{l}1 \\
75\left(1 \mathrm{~h} 15^{\prime}\right)\end{array}$ & 0,25 & $\begin{array}{l}42,8 \mathrm{ml} \\
\mathbf{5 9 , 9 2} \mathbf{~ m g}\end{array}$ & $\begin{array}{l}42,0 \mathrm{ml} \\
\mathbf{5 8 , 8 0} \mathbf{~ m g}\end{array}$ & $\begin{array}{l}10 \mathrm{ml} / \mathrm{h} \\
14 \mathrm{mg} / \mathrm{h}\end{array}$ & $31,50 \mathrm{mg}$ \\
\hline $\begin{array}{l}7 \\
110 \\
\left(1 \mathrm{~h} 50^{\prime}\right)\end{array}$ & 0,21 & $\begin{array}{l}36,0 \mathrm{ml} \\
\mathbf{5 0 , 4} \mathbf{~ m g}\end{array}$ & $\begin{array}{l}36,0 \mathrm{ml} \\
\mathbf{5 0 , 4} \mathbf{~ m g}\end{array}$ & $\begin{array}{l}8,4 \mathrm{ml} / \mathrm{h} \\
11,76 \mathrm{mg} / \mathrm{h}\end{array}$ & $21,56 \mathrm{mg}$ \\
\hline $\begin{array}{l}13 \\
140 \\
\left(2 h^{\prime} 20^{\prime}\right)\end{array}$ & 0,29 & $\begin{array}{l}49,71 \mathrm{ml} \\
69,59 \mathrm{mg}\end{array}$ & $\begin{array}{l}49,71 \mathrm{ml} \\
69,59 \mathrm{mg}\end{array}$ & $\begin{array}{l}11,6 \mathrm{ml} / \mathrm{h} \\
16,24 \mathrm{mg} / \mathrm{h}\end{array}$ & $37,89 \mathrm{mg}$ \\
\hline $\begin{array}{l}24 \\
75 \\
\left(1 \mathrm{~h} 15^{\prime}\right)\end{array}$ & 0,39 & $\begin{array}{l}66,8 \mathrm{ml} \\
\mathbf{9 3 , 5 2} \mathbf{m g}\end{array}$ & $\begin{array}{l}\text { 66,8 ml } \\
93,52 \mathrm{mg}\end{array}$ & $\begin{array}{l}15,6 \mathrm{ml} / \mathrm{h} \\
21,84 \mathrm{mg} / \mathrm{h}\end{array}$ & $27,3 \mathrm{mg}$ \\
\hline $\begin{array}{l}25 \\
80 \\
\left(1 \mathrm{~h} 20^{\prime}\right)\end{array}$ & 0,21 & $\begin{array}{l}36,0 \mathrm{ml} \\
\mathbf{5 0 , 4} \mathbf{~ m g}\end{array}$ & $\begin{array}{l}36,0 \mathrm{ml} \\
\mathbf{5 0 , 4} \mathbf{~ m g}\end{array}$ & $\begin{array}{l}8,4 \mathrm{ml} / \mathrm{h} \\
11,76 \mathrm{mg} / \mathrm{h}\end{array}$ & $15,68 \mathrm{mg}$ \\
\hline $\begin{array}{l}32 \\
110 \\
\left(1 \mathrm{~h} 50^{\prime}\right)\end{array}$ & 0,41 & $\begin{array}{l}70,28 \mathrm{ml} \\
98,39 \mathrm{mg}\end{array}$ & $\begin{array}{l}70,0 \mathrm{ml} \\
98 \mathrm{mg}\end{array}$ & $\begin{array}{l}16,4 \mathrm{ml} / \mathrm{h} \\
22,96 \mathrm{mg} / \mathrm{h}\end{array}$ & $42,09 \mathrm{mg}$ \\
\hline $\begin{array}{l}35 \\
75 \\
\left(1 \mathrm{~h} 15^{\prime}\right)\end{array}$ & 0,65 & $\begin{array}{l}111,42 \mathrm{ml} \\
155,98 \mathrm{mg}\end{array}$ & $\begin{array}{l}111,4 \mathrm{ml} \\
155,98 \mathrm{mg}\end{array}$ & $\begin{array}{l}26,0 \mathrm{ml} / \mathrm{h} \\
36,4 \mathrm{mg} / \mathrm{h}\end{array}$ & $45,50 \mathrm{mg}$ \\
\hline $\begin{array}{l}37 \\
80 \\
\left(1 \mathrm{~h} 20^{\prime}\right)\end{array}$ & 0,28 & $\begin{array}{l}48,0 \mathrm{ml} \\
67,20 \mathrm{mg}\end{array}$ & $\begin{array}{l}48,0 \mathrm{ml} \\
67,20 \mathrm{mg}\end{array}$ & $\begin{array}{l}11,2 \mathrm{ml} / \mathrm{h} \\
15,68 \mathrm{mg} / \mathrm{h}\end{array}$ & $20,90 \mathrm{mg}$ \\
\hline $\begin{array}{l}40 \\
100 \\
\left(1 \mathrm{~h} 40^{\prime}\right)\end{array}$ & 0,22 & $\begin{array}{l}37,71 \mathrm{ml} \\
\mathbf{5 2 , 7 9} \mathbf{~ m g}\end{array}$ & $\begin{array}{l}37,70 \mathrm{ml} \\
52,78 \mathrm{mg}\end{array}$ & $\begin{array}{l}8,8 \mathrm{ml} / \mathrm{h} \\
12,32 \mathrm{mg} / \mathrm{h}\end{array}$ & $20,53 \mathrm{mg}$ \\
\hline $\begin{array}{l}45 \\
80 \\
\left(1 \mathrm{~h} 20^{\prime}\right)\end{array}$ & 0,21 & $\begin{array}{l}36,0 \mathrm{ml} \\
\mathbf{5 0 , 4} \mathbf{~ m g}\end{array}$ & $\begin{array}{l}36,0 \mathrm{ml} \\
\mathbf{5 0 , 4} \mathbf{~ m g}\end{array}$ & $\begin{array}{l}8,4 \mathrm{ml} / \mathrm{h} \\
11,76 \mathrm{mg} / \mathrm{h}\end{array}$ & $15,68 \mathrm{mg}$ \\
\hline Média & 0,312 & $\begin{array}{l}53,47 \mathrm{ml} \\
74,85 \mathrm{mg} \\
\end{array}$ & $\begin{array}{l}53,47 \mathrm{ml} \\
74,85 \mathrm{mg} \\
\end{array}$ & - & $27,86 \mathrm{mg}$ \\
\hline Desvio-padrão & $\pm 0,139$ & $\begin{array}{l} \pm 23,89 \mathrm{ml} \\
\pm 33,44 \mathrm{mg}\end{array}$ & $\begin{array}{l} \pm 23,89 \mathrm{ml} \\
\pm 33,44 \mathrm{mg}\end{array}$ & - & $\pm 10,88 \mathrm{mg}$ \\
\hline
\end{tabular}


TABELA 18. Dose total de heparina administrada em CEC nos pacientes operados

\begin{tabular}{|c|c|c|}
\hline \multicolumn{3}{|c|}{ HEPARINA (mg) GRUPO APROTININA } \\
\hline pac & Dose total & $\mathrm{mg} / \mathrm{kg}$ \\
\hline 1 & 43 & 10 \\
\hline 7 & 25,5 & 7,39 \\
\hline 13 & 71 & 13,78 \\
\hline 24 & 36 & 4,4 \\
\hline 25 & 25 & 7,53 \\
\hline 32 & 50 & 5,55 \\
\hline 35 & 55 & 3,66 \\
\hline 37 & 30 & 5,96 \\
\hline 40 & 31 & 8,49 \\
\hline 45 & 26 & 7,22 \\
\hline Média & 39,25 & 7,39 \\
\hline Desvio-pad & 15,33 & 2,90 \\
\hline Mediana & 33,5 & 7,30 \\
\hline \multicolumn{3}{|c|}{ HEPARINA (mg) GRUPO CONTROLE } \\
\hline Pac & Dose total & $\mathrm{mg} / \mathrm{kg}$ \\
\hline 3 & 60 & 8,73 \\
\hline 6 & 24 & 10,9 \\
\hline 10 & 25 & 5,2 \\
\hline 11 & 30 & 4,51 \\
\hline 12 & 70 & 4,43 \\
\hline 34 & 25 & 8,65 \\
\hline 36 & 47 & 6,42 \\
\hline 49 & 40 & 8,84 \\
\hline 53 & 30 & 6,63 \\
\hline Média & 39 & 7,14 \\
\hline Desv-pad & 16,75 & 3,80 \\
\hline Mediana & 30 & 6,63 \\
\hline
\end{tabular}


TABELA 19. Consumo de concentrado de hemácias dos grupos Aprotinina e Controle, no intra-operatório.

\begin{tabular}{|c|c|c|}
\hline $\begin{array}{l}\text { Grupo aprotinina } \\
\text { PACIENTE / peso (kg) }\end{array}$ & $\begin{array}{l}\text { Consumo de concentrado de } \\
\text { hemácias intra-operatório } \\
\text { (total) }\end{array}$ & $\begin{array}{l}\text { Consumo de concentrado de } \\
\text { hemácias intra-operatório } \\
(\mathrm{ml} / \mathrm{kg})\end{array}$ \\
\hline $\begin{array}{ll}1 & (4,30)\end{array}$ & 200 & 46,51 \\
\hline $7 \quad(3,45)$ & 230 & 66,66 \\
\hline $13(5,15)$ & 250 & 48,54 \\
\hline $24 \quad(8,17)$ & 200 & 24,47 \\
\hline $25 \quad(3,32)$ & 300 & 90,36 \\
\hline $32(9,00)$ & 260 & 28,88 \\
\hline $35 \quad(15,00)$ & 200 & 13,33 \\
\hline $37 \quad(5,03)$ & 100 & 19,88 \\
\hline $40 \quad(3,65)$ & 200 & 54,79 \\
\hline $45 \quad(3,60)$ & 270 & 75 \\
\hline Média & $221+55,26$ & $46,84+25,42$ \\
\hline $\begin{array}{l}\text { Grupo controle } \\
\text { PACIENTE / peso }(\mathrm{kg})\end{array}$ & $\begin{array}{l}\text { Consumo de concentrado de } \\
\text { hemácias intra-operatório } \\
\text { (total) }\end{array}$ & $\begin{array}{l}\text { Consumo de concentrado de } \\
\text { hemácias intra-operatório } \\
(\mathrm{ml} / \mathrm{kg})\end{array}$ \\
\hline $3 \quad(6,87)$ & 200 & 29,11 \\
\hline $\begin{array}{ll}6 \quad(2,20) \\
\end{array}$ & 200 & 90,90 \\
\hline $10(4,80)$ & 250 & 52,08 \\
\hline $11(6,65)$ & 150 & 22,55 \\
\hline $12(15,8)$ & 200 & 12,65 \\
\hline $34(2,89)$ & 340 & 117,64 \\
\hline $36(7,31)$ & 380 & 51,98 \\
\hline $49(4,52)$ & 250 & 55,30 \\
\hline $53(4,52)$ & 265 & 58,62 \\
\hline Média & $248,33+73,05$ & $54,53+33,08$ \\
\hline
\end{tabular}


TABELA 20. Diurese dos pacientes total e por peso corpóreo (entre parênteses) dos grupos Aprotinina e Controle, antes, durante e logo após a CEC, na sala operatória.

\begin{tabular}{|c|c|c|c|}
\hline $\begin{array}{l}\text { Grupo } \\
\text { Aprotinina }\end{array}$ & $\begin{array}{c}\text { Diurese Pré - CEC (total } \mathrm{ml} \mathrm{e} \\
\mathrm{ml} / \mathrm{kg} \text { ) }\end{array}$ & $\begin{array}{c}\text { Diurese durante CEC (total } \mathrm{ml} \mathrm{e} \\
\mathrm{ml} / \mathrm{kg} \text { ) }\end{array}$ & $\begin{array}{c}\text { Diurese pós - CEC (total } \mathrm{ml} \\
\text { e } \mathrm{ml} / \mathrm{kg} \text { ) }\end{array}$ \\
\hline $1 \quad(4,30)$ & 0 & $15(3,48)$ & $100(23,25)$ \\
\hline $7 \quad(3,45)$ & $40(11,59)$ & $110(31,88)$ & $20(5,79)$ \\
\hline $13(5,15)$ & $50(9,70)$ & $70(13,59)$ & $35(6,79)$ \\
\hline $24(8,17)$ & $15(1,83)$ & $30(3,67)$ & $100(12,23)$ \\
\hline $25 \quad(3,32)$ & 0 & $30(9,03)$ & $30(9,03)$ \\
\hline $32 \quad(9,00)$ & $26(2,88)$ & $34(3,77)$ & $46(5,11)$ \\
\hline $35(15,00)$ & $100(6,66)$ & 0 & $100(6,66)$ \\
\hline $37 \quad(5,03)$ & $10(1,98)$ & $180(35,78)$ & $100(19,88)$ \\
\hline $40 \quad(3,65)$ & $6(1,64)$ & $150(41,09)$ & $400(109,58)$ \\
\hline $45 \quad(3,60)$ & $35(9,72)$ & $180(50,00)$ & $50(13,88)$ \\
\hline $\begin{array}{l}\text { Média total } \\
\text { Média } \mathrm{ml} / \mathrm{kg}\end{array}$ & $\begin{array}{c}28,2 \pm 30,56 \\
4,60 \pm 4,39\end{array}$ & $\begin{array}{c}79,9 \pm 69,63 \\
19,22 \pm 18,53\end{array}$ & $\begin{array}{c}98,1 \pm 111 \\
21,22 \pm 31,64\end{array}$ \\
\hline
\end{tabular}

\begin{tabular}{|l|l|l|l|}
\hline $\begin{array}{l}\text { Grupo } \\
\text { Controle }\end{array}$ & $\begin{array}{l}\text { Diurese Pré - CEC (total } \mathbf{m l} \text { e } \\
\mathbf{m l} / \mathbf{k g})\end{array}$ & $\begin{array}{l}\text { Diurese durante CEC (total ml e } \\
\mathbf{m l} / \mathbf{k g})\end{array}$ & $\begin{array}{l}\text { Diurese } \\
\text { Pós - CEC (total ml e ml/kg) }\end{array}$ \\
\hline $\mathbf{3}(6,87)$ & $12(1,74)$ & $73(10,62)$ & $150(21,83)$ \\
\hline $\mathbf{6}(2,20)$ & $2(0,90)$ & $100(45,45)$ & $18(8,18)$ \\
\hline $\mathbf{1 0}(4,80)$ & $5(1,04)$ & $70(14,58)$ & $80(16,66)$ \\
\hline $\mathbf{1 1}(6,65)$ & $50(7,51)$ & $50(7,51)$ & $50(7,51)$ \\
\hline $\mathbf{1 2}(15,8)$ & $10(0,63)$ & $75(4,74)$ & $100(6,32)$ \\
\hline $\mathbf{3 4}(2,89)$ & $10(3,46)$ & $150(51,90)$ & $50(17,30)$ \\
\hline $\mathbf{3 6}(7,31)$ & $15(2,05)$ & $30(4,10)$ & $95(12,99)$ \\
\hline $\mathbf{4 9}(4,52)$ & $5(0,09)$ & $70(15,48)$ & $25(5,53)$ \\
\hline $\mathbf{5 3}(4,52)$ & $29(6,41)$ & $40(8,84)$ & $50(11,06)$ \\
\hline $\begin{array}{l}\text { Média total } \\
\text { Média } \mathbf{~ m l / k g}\end{array}$ & $15,3 \pm 15,2$ & $73,1 \pm 35,61$ & $68,6 \pm 41,74$ \\
\hline
\end{tabular}


TABELA 21. Tempo de fechamento do tórax nas crianças operadas dos grupos Aprotinina e Controle.

\begin{tabular}{|c|c|c|c|}
\hline Grupos & T4 (h) & $\begin{array}{c}\text { Final } \\
\text { Operação } \\
\text { (h) }\end{array}$ & $\begin{array}{c}\text { Tempo de } \\
\text { fechamento } \\
\text { do tórax (min) }\end{array}$ \\
\hline \multicolumn{4}{|c|}{ Aprotinina } \\
\hline 1 & $12: 00$ & $12: 30$ & 30 \\
\hline 7 & $13: 10$ & $13: 40$ & 30 \\
\hline 13 & $14: 30$ & $15: 00$ & 30 \\
\hline 24 & $12: 20$ & $13: 00$ & 40 \\
\hline 25 & 19:30 & $20: 00$ & 30 \\
\hline 32 & 19:30 & $20: 15$ & 45 \\
\hline 35 & $18: 50$ & $19 ; 10$ & 20 \\
\hline 37 & $17: 55$ & $18: 10$ & 15 \\
\hline 40 & $12: 50$ & $13: 15$ & 25 \\
\hline 45 & $13: 10$ & $13: 30$ & 20 \\
\hline Média & & & $28,5 \pm 9,14$ \\
\hline \multicolumn{4}{|c|}{ Controle } \\
\hline 3 & $12: 50$ & $13: 30$ & 40 \\
\hline 6 & $16: 20$ & $17: 00$ & 40 \\
\hline 10 & $20: 40$ & $21: 15$ & 35 \\
\hline 11 & $12: 20$ & $12: 30$ & 10 \\
\hline 12 & $19: 10$ & $20: 00$ & 50 \\
\hline 34 & $13: 10$ & $13: 20$ & 10 \\
\hline 36 & $12: 30$ & $12: 45$ & 15 \\
\hline 49 & $19: 30$ & $20: 20$ & 50 \\
\hline 53 & $17: 40$ & $17: 50$ & 10 \\
\hline Média & & & $28,8 \pm 17,46$ \\
\hline
\end{tabular}

TABELA 22. Balanço sangüíneo estimado total após a CEC nas crianças dos grupos Aprotinina e Controle

\begin{tabular}{|l|c|c|c|}
\hline $\begin{array}{l}\text { Grupo } \\
\text { Aprotinina }\end{array}$ & Balanço & $\begin{array}{c}\text { Grupo } \\
\text { Controle }\end{array}$ & Balanço \\
\hline 1 & +150 & 3 & 6 \\
\hline 7 & +180 & 10 & +180 \\
\hline 13 & -150 & 11 & +30 \\
\hline 24 & -50 & 12 & +150 \\
\hline 25 & +30 & 34 & +160 \\
\hline 32 & +10 & 36 & +180 \\
\hline 35 & -350 & 49 & +150 \\
\hline 37 & +20 & 53 & -35 \\
\hline 40 & -130 & & +1125 \\
\hline 45 & +170 & Soma Total & $+125 \pm \mathbf{8 1 , 7 0}$ \\
\hline Soma Total & -120 & & Média \\
\hline
\end{tabular}


TABELA 23. Balanço hídrico total e por peso corpóreo (entre parênteses), na admissão na UTIP, nos pacientes dos grupos Aprotinina e Controle.

\begin{tabular}{|c|c|c|c|}
\hline Grupo Aprotinina & $\begin{array}{l}\text { Balanço hídrico final } \\
\text { (ml) } \\
\text { Total e } \mathrm{ml} / \mathrm{kg}\end{array}$ & Grupo Controle & $\begin{array}{l}\text { Balanço hídrico final ( } \mathrm{ml} \text { ) } \\
\text { Total e } \mathrm{ml} / \mathrm{kg}\end{array}$ \\
\hline 1 & $+330(76,74 \mathrm{ml} / \mathrm{kg})$ & 3 & $+195(28,, 8 \mathrm{ml} / \mathrm{kg})$ \\
\hline 7 & $+250(72,46 \mathrm{ml} / \mathrm{kg})$ & 6 & $+55(25 \mathrm{ml} / \mathrm{kg})$ \\
\hline 13 & $+45(8,73 \mathrm{ml} / \mathrm{kg})$ & 10 & $+225(46,87 \mathrm{ml} / \mathrm{kg})$ \\
\hline 24 & $+265(32,3 \mathrm{ml} / \mathrm{kg})$ & 11 & $+80(12 \mathrm{ml} / \mathrm{kg})$ \\
\hline 25 & $+470(141,56 \mathrm{ml} / \mathrm{kg})$ & 12 & $-553(-35 \mathrm{ml} / \mathrm{kg})$ \\
\hline 32 & $+619(68,77 \mathrm{ml} / \mathrm{kg})$ & 34 & $+160(55,36 \mathrm{ml} / \mathrm{kg})$ \\
\hline 35 & $+160(10,66 \mathrm{ml} / \mathrm{kg})$ & 36 & $+600(82 \mathrm{ml} / \mathrm{kg})$ \\
\hline 37 & $-200(-39,76 \mathrm{ml} / \mathrm{kg})$ & 49 & $+140(31 \mathrm{ml} / \mathrm{kg})$ \\
\hline 40 & $-500(-143 \mathrm{ml} / \mathrm{kg})$ & 53 & $+185(40,92 \mathrm{ml} / \mathrm{kg})$ \\
\hline 45 & $+65(18,05 \mathrm{ml} / \mathrm{kg})$ & $\begin{array}{l}\text { Média total }(\mathrm{ml}) \\
\text { Média } \mathrm{ml} / \mathbf{k g} \\
\text { Mediana }(\mathrm{ml} / \mathbf{k g})\end{array}$ & $\begin{array}{l}+120,7 \pm 298,33 \\
+31,88+32,20 \\
35\end{array}$ \\
\hline $\begin{array}{l}\text { Média total }(\mathrm{ml}) \\
\text { Média }(\mathrm{ml} / \mathbf{k g}) \\
\text { Mediana }(\mathrm{ml} / \mathbf{k g})\end{array}$ & $\begin{array}{l}+150,4+323,40 \\
+24,65+77,04 \\
25,17\end{array}$ & & \\
\hline
\end{tabular}


TABELA 24. Escore "Pediatric Risk Index Score for Mortality" (PRISM) (POLLACK,1988)

\begin{tabular}{|c|c|c|c|}
\hline \multirow{2}{*}{$\begin{array}{c}\text { Variable } \\
\text { Systolic BP (mm Hg) }\end{array}$} & \multirow{2}{*}{\multicolumn{2}{|c|}{$\begin{array}{c}\text { Age Restriction } \\
\text { Ranges* }\end{array}$}} & \multirow[b]{2}{*}{ Score } \\
\hline & & & \\
\hline & $\begin{array}{c}\text { Infants } \\
130-160 \\
55-65 \\
>160 \\
40-54 \\
<40\end{array}$ & $\begin{array}{c}\text { Children } \\
150-200 \\
65-75 \\
>200 \\
50-64 \\
<50\end{array}$ & 2 \\
\hline Diastolic BP (mm Hg) & \multicolumn{2}{|c|}{$\begin{array}{l}\text { All ages } \\
>110\end{array}$} & 6 \\
\hline HR (beat/min) & $\begin{array}{c}\text { Infants } \\
>160 \\
<90\end{array}$ & $\begin{array}{c}\text { Children } \\
>150 \\
<80\end{array}$ & 4 \\
\hline Respiratory rate (breath/min) & $\begin{array}{l}\text { Infants } \\
61-90 \\
>90 \\
\text { Apnea }\end{array}$ & $\begin{array}{l}\text { Children } \\
51-70 \\
>70 \\
\text { Apnea }\end{array}$ & $\begin{array}{l}1 \\
5\end{array}$ \\
\hline $\mathrm{PaO}_{2} / \mathrm{FIO}_{2} \dagger$ & \multicolumn{2}{|c|}{$\begin{array}{l}\text { All ages } \\
200-300\end{array}$} & $\begin{array}{l}2 \\
3\end{array}$ \\
\hline $\mathrm{PaCO}_{2} \ddagger(\mathrm{mm} \mathrm{Hg})$ & \multicolumn{2}{|c|}{$\begin{array}{c}\text { All ages } \\
51-65\end{array}$} & $\begin{array}{l}1 \\
5\end{array}$ \\
\hline Glasgow Coma Score§ & \multicolumn{2}{|c|}{ All ages } & 6 \\
\hline Pupillary reactions & \multicolumn{2}{|c|}{$\begin{array}{c}\text { All ages } \\
\text { Unequal or dilated }\end{array}$} & 4 \\
\hline PT/PTT & \multicolumn{2}{|c|}{$\begin{array}{c}\text { Fixed and dilated } \\
\text { All ages }\end{array}$} & 10 \\
\hline Total bilirubin (mg/dL) & \multicolumn{2}{|c|}{$\begin{array}{l}>1 \mathrm{mo} \\
>3.5\end{array}$} & 6 \\
\hline Potassium $(\mathrm{mEq} / \mathrm{L})$ & & & 5 \\
\hline Calcium (mg/dL) & \multicolumn{2}{|c|}{$\begin{array}{l}\text { All ages } \\
7.0-8.0\end{array}$} & 2 \\
\hline & \multicolumn{2}{|c|}{$\begin{array}{l}<7.0 \\
>15.0\end{array}$} & 6 \\
\hline Glucose $(\mathrm{mg} / \mathrm{dL})$ & \multicolumn{2}{|c|}{$\begin{array}{l}\text { All ages } \\
40-60\end{array}$} & 4 \\
\hline & \multicolumn{2}{|c|}{$\begin{array}{l}<40 \\
>400\end{array}$} & 8 \\
\hline Bicarbonate\| $(\mathrm{mEq} / \mathrm{L})$ & \multicolumn{2}{|c|}{$\begin{array}{c}\text { All ages } \\
<16 \\
>32\end{array}$} & 3 \\
\hline
\end{tabular}

* Infants are those $\leq 12$ months.

t Cannot be assessed in patients with intracardiac shunts or chronic respiratory insufficiency; requires arterial blood sampling. $\ddagger$ May be assessed with capillary blood gases.

$\$$ Assessed only if there is known or suspected central nervous system dysfunction; cannot be assessed in patients during iatrogenic sedation, paralysis, anesthesia, etc. Scores $<8$ correspond to

coma or deep stupor.

\|Use measured values.

TABELA 25. Escore PRISM avaliado na admissão dos pacientes operados para correção da cardiopatia congênita acianogênica nos grupos aprotinina e controle.

\begin{tabular}{|c|c|c|c|}
\hline GRUPO APROTININA & ESCORE PRISM & $\begin{array}{l}\text { GRUPO } \\
\text { CONTROLE }\end{array}$ & ESCORE PRISM \\
\hline 1 & 5 & 3 & 14 \\
\hline 7 & 13 & 6 & 11 \\
\hline 13 & 2 & 10 & 3 \\
\hline 24 & 2 & 11 & 6 \\
\hline 25 & 4 & 12 & 4 \\
\hline 32 & 7 & 34 & 11 \\
\hline 35 & 2 & 36 & 2 \\
\hline 37 & 4 & 49 & 7 \\
\hline 40 & 2 & 53 & 11 \\
\hline 45 & 2 & & \\
\hline Mediana & 3 & Mediana & 7 \\
\hline Média & $4,3 \pm 3,49$ & \begin{tabular}{|l|} 
Média \\
\end{tabular} & $7,6 \pm 4,24$ \\
\hline
\end{tabular}


TABELA 26. Variáveis que compõem o Índice clínico-cirúrgico de resultados na unidade de cuidados intensivos cardiológicos pediátricos (MATTOS, 2006)

\begin{tabular}{|c|c|c|}
\hline Variáveis & Categorias & Escore $^{1}$ \\
\hline 1. Idade & $\begin{array}{l}\text { Maior } 1 \text { ano } \\
1 \text { mês a } 1 \text { ano } \\
\text { Menor que } 1 \text { ano }\end{array}$ & $\begin{array}{l}0 \\
1 \\
2\end{array}$ \\
\hline 2. Estado nutricional ${ }^{2}$ & $\begin{array}{l}\text { Adequado } \\
\text { Subnutrido } \\
\text { Desnutrido }\end{array}$ & $\begin{array}{l}0 \\
1 \\
2\end{array}$ \\
\hline 3. Fatores de risco associados ${ }^{3}$ & $\begin{array}{l}\text { Nenhum } \\
\text { Um } \\
\text { Dois ou mais }\end{array}$ & $\begin{array}{l}0 \\
1 \\
2 \\
\end{array}$ \\
\hline 4. Complexidade cirúrgica* & $\begin{array}{l}\text { Jenkins } 1 \text { e } 2 \\
\text { Jenkins } 3 \text { e } 4 \\
\text { Jenkins } 5 \text { e } 6 \\
\text { Aristótele } 1 \text { e } 2 \\
\text { Aristótele } 3 \\
\text { Aristótele } 4\end{array}$ & $\begin{array}{l}0 \\
1 \\
2 \\
0 \\
1 \\
2\end{array}$ \\
\hline 5. Tempo de circulação extracorpórea & $\begin{array}{l}\text { Nenhum } \\
\text { Até } 90 \text { minutos } \\
\text { Mais de } 90 \text { minutos }\end{array}$ & $\begin{array}{l}0 \\
1 \\
2\end{array}$ \\
\hline
\end{tabular}

TABELA 27 - Índice clínico-cirúrgico de resultados (MATTOS, 2006) no CTIP das crianças operadas por cardiopatia congênita acianogênica com CEC nos Grupos Aprotinina e Controle

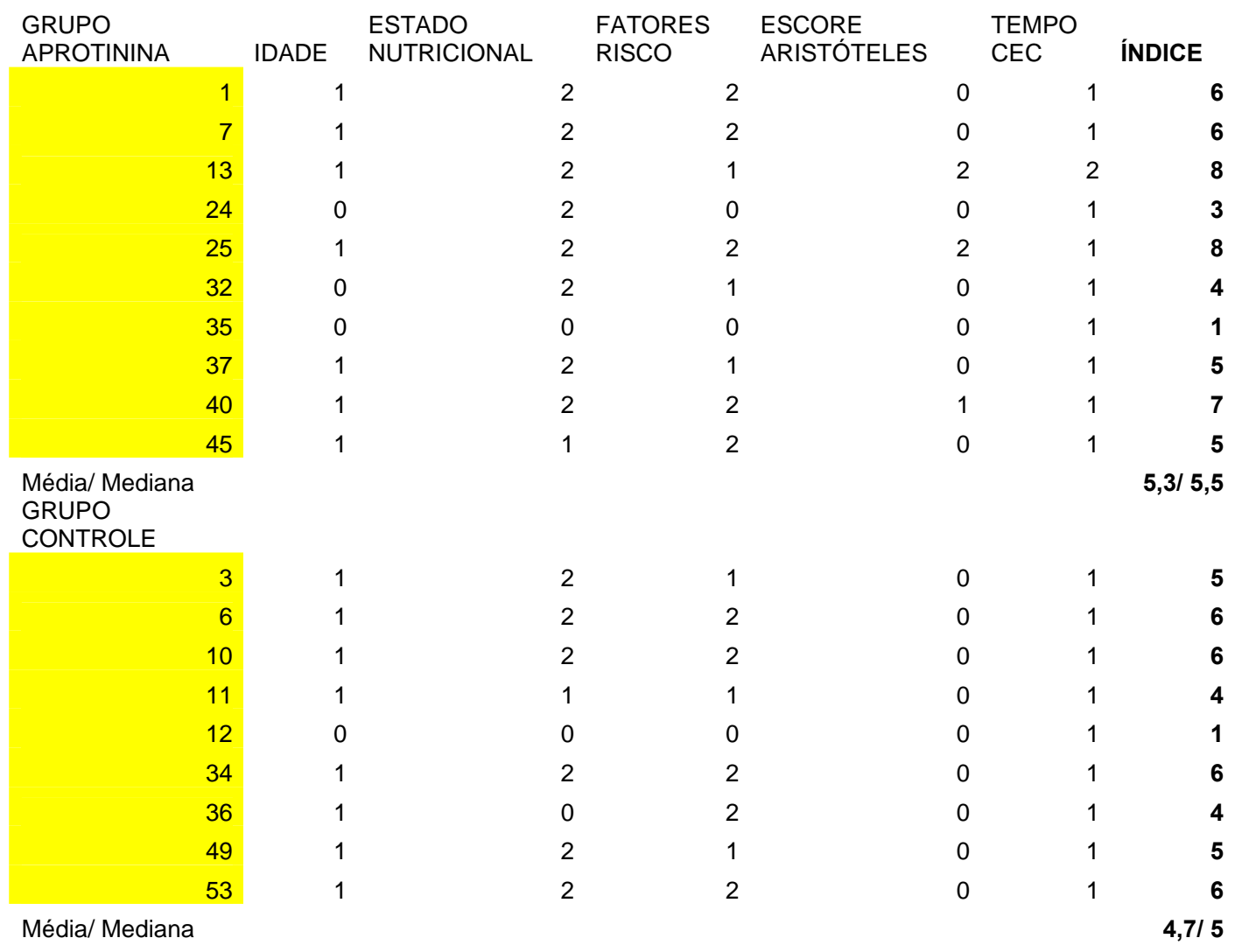


TABELA 28. Comparação das variáveis clínicas pós-operatórias entre os grupos tratamento e controle.

\begin{tabular}{cccc}
\hline Variável & Mediana $\left(1 .{ }^{\circ}\right.$ Quartil;2. ${ }^{\circ}$ Quartil) & $\begin{array}{c}\text { Tratamento } x \\
\text { Controle } \\
\text { P-valor }\end{array}$ \\
\hline PRISM Admissão UTI & Aprotinina & Controle & 0,07 \\
Balanço hídrico (ml) & $3,00(2,00 ; 4,75)$ & $7,00(4,00 ; 11,00)$ & 0,99 \\
Uso de Inotrópicos - tempo (h) & $175,00(50,00 ; 313,75)$ & $185,00(155,00 ; 225,00)$ & 0,12 \\
Tempo de Ventilação Mecânica (h) & $132,00(66,00 ; 186,00)$ & $48,00(31,75 ; 107,25)$ & 0,81 \\
Tempo de Permanência CTI (dias) & $36,00(7,50 ; 138,75)$ & $16,00(4,0072,00)$ & 0,27 \\
\hline
\end{tabular}

TABELA 29: Comparação de variáveis clínicas pós-op.entre indivíduos que apresentaram escore ROSS $>=5$ contra os que apresentaram $<5$ dentro do grupos Aprotinina e Controle

\begin{tabular}{cccc}
\hline Grupo Aprotinina & Mediana $\left(1 .^{\circ}\right.$ Quartil;3. ${ }^{\circ}$ Quartil) & $<5$ & P-valor \\
\hline VM (h) & $133,50(66,75 ; 162,00)$ & $3,00(1,50 ; 7,50)$ & $<0,01$ \\
CTIP (d) & $8,00(6,25 ; 11,25)$ & $2,00(2,00 ; 2,00)$ & 0,01 \\
Int. Hosp (d) & $11,50(8,25 ; 16,25)$ & $5,00(4,75 ; 5,25)$ & 0,01 \\
Inotrópico (h) & $144,00(126,00 ; 270,00)$ & $24,00(0,00 ; 0,48)$ & 0,01 \\
Escore Inotrópico I & $6,00(5,25 ; 9,00)$ & $1,00(0,00 ; 2,00)$ & 0,02 \\
Escore Inotrópico II & $32,50(26,25 ; 51,50)$ & $2,00(0,00 ; 4,25)$ & 0,01 \\
\hline Grupo Controle & Mediana $\left(1 .^{\circ}{ }^{\text {Quartil;3. }}{ }^{\circ}\right.$ Quartil) & 0,02 \\
VM (h) & $>=5$ & $4,00(3,00 ; 8,00)$ & 0,03 \\
CTIP (d) & $168,00(63,75 ; 276,00)$ & $1,60(1,50 ; 2,00)$ & 0,05 \\
Int. Hosp (d) & $8,50(4,50 ; 12,50)$ & $3,00(3,00 ; 5,00)$ & 0,33 \\
Inotrópico (h) & $12,00(7,75 ; 21,75)$ & $34,00(25,00 ; 48,00)$ & 0,42 \\
Escore Inotrópico I & $120,00(40,25 ; 210,00)$ & $2,00(2,00 ; 2,00)$ & 0,21 \\
Escore Inotrópico II & $4,00(1,50 ; 6,00)$ & $4,00(4,00 ; 5,00)$ & \\
\hline
\end{tabular}

TABELA 30. Definição de Suporte inotrópico

Pacientes que receberem infusão como droga única ou combinação de milrinona, dobutamina, epinefrina, norepinefrina ou dopamina $>5 \mathrm{ug} / \mathrm{kg} / \mathrm{min}$ por mais de 6 horas;

TABELA 31. Escores Inotrópicos I e II

Escore inotrópico I (GESSLER, 2006) foi calculado como segue:

Dobutamina (dopamina) $<5 \mathrm{mcg} / \mathrm{kg} / \mathrm{min}=1 ; \geq 5 \mathrm{mcg} / \mathrm{kg} / \mathrm{min}=2$ (Nor)epinefrina $<0,05 \mathrm{mcg} / \mathrm{kg} / \mathrm{min}=1 ;<0,1$ $\mathrm{mcg} / \mathrm{kg} / \mathrm{min}=2 ;<0,2 \mathrm{mcg} / \mathrm{kg} / \mathrm{min}=3 ; \geq 0,2 \mathrm{mcg} / \mathrm{kg} / \mathrm{min}=4$ Milrinone $<0,4 \mathrm{mcg} / \mathrm{kg} / \mathrm{min}=1 ;<0,7$ $\mathrm{mcg} / \mathrm{kg} / \mathrm{min}=2 ;>0,7 \mathrm{mcg} / \mathrm{kg} / \mathrm{min}=3$.

Escore inotrópico II (SARAIYA, 2005) foi calculado conforme a fórmula: dopamina em $\mu \mathrm{g} / \mathrm{kg} / \mathrm{min}+$ dobutamina em $\mu \mathrm{g} / \mathrm{kg} / \mathrm{min}+$ milrinona $10 \times \mu \mathrm{g} / \mathrm{kg} / \mathrm{min}+($ nor)epinefrina $\mu \mathrm{g} / \mathrm{kg} / \mathrm{min} \times 100$ 

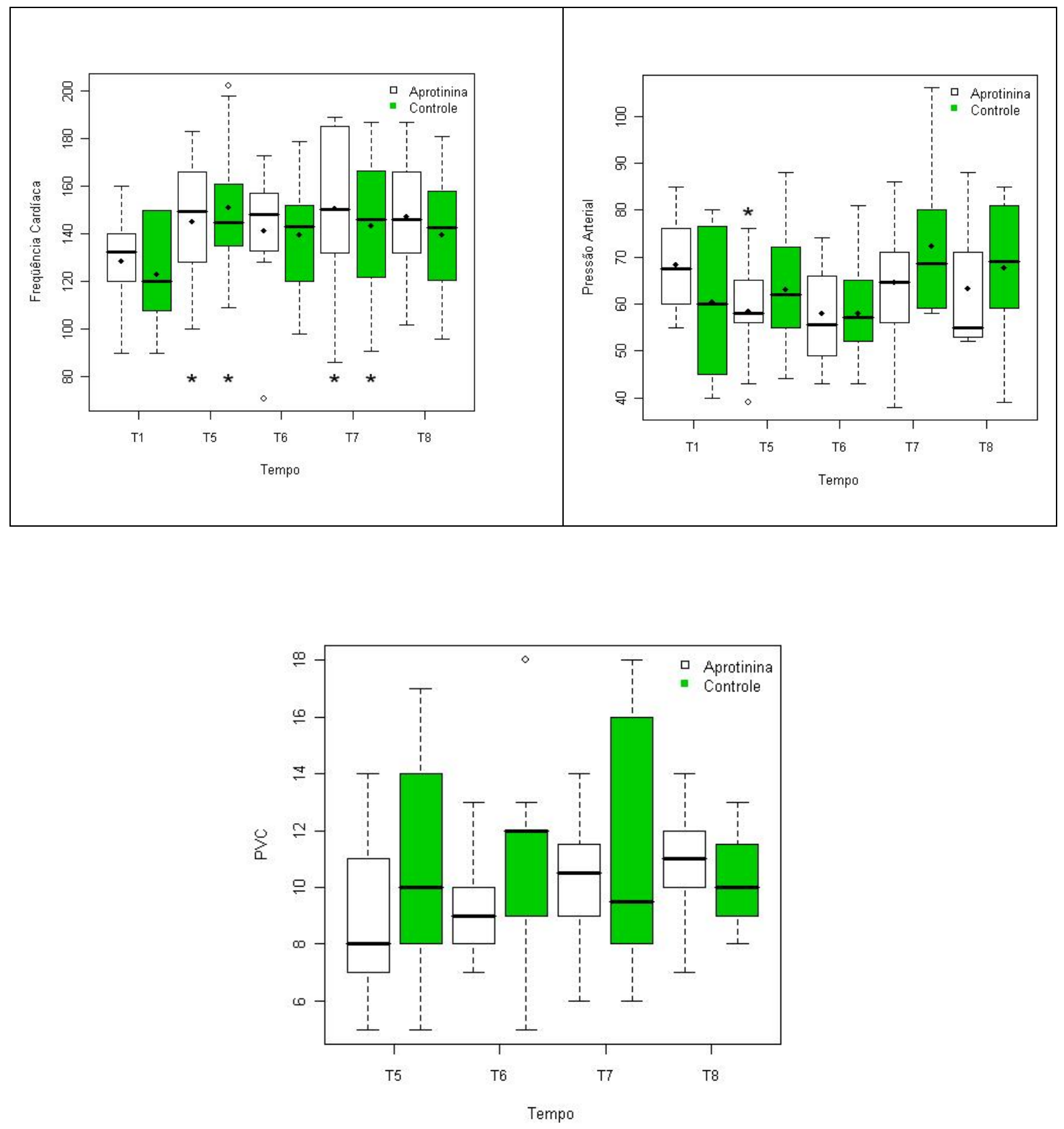

FIGURA 1: Freqüência cardíaca (bpm) pressão arterial sistêmica $(\mathrm{mmHg})$ e pressão venosa central (PVC) $(\mathrm{mmHg})$ nos pacientes dos grupos aprotinina e controle nos tempos T5 a T8. As diferenças intragrupos estão assinaladas. 
TABELA 32: Comparação entre ao grupos controle e aprotinina para cada tempo Variável FC.

\begin{tabular}{cccc}
\hline \multirow{2}{*}{ Tempo } & Controle & Média (DP) & Diferença de médias \\
& $151,33(31,56)$ & $145,40(24,57)$ & P-valor $(*)$ \\
\hline T5 & $139,89(27,36)$ & $141,60(28,95)$ & 0,57 \\
T6 & $143,38(31,01)$ & $150,60(32,02)$ & 0,90 \\
T7 & $139,88(28,50)$ & $147,22(26,08)$ & 0,79 \\
T8 &
\end{tabular}

(*) Transformação Box-Cox - Médias ponderadas por T1.

TABELA 33: Comparação entre grupos controle e aprotinina para cada tempo Variável PAM.

\begin{tabular}{cccc}
\hline \multirow{2}{*}{ Tempo } & Controle & Média (DP) & Diferença de médias \\
& Aprotinina & 0,13 \\
T5 & $63,11(14,90)$ & $58,40(11,49)$ & 0,11 \\
T6 & $58,00(11,61)$ & $57,90(11,11)$ & 0,01 \\
T7 & $72,38(16,28)$ & $64,50(14,65)$ & 0,10 \\
T8 & $67,75(15,31)$ & $63,22(13,17)$ & \\
\hline
\end{tabular}

$(*)$ Transformação Box-Cox - Médias ponderadas por T1.

TABELA 34: Comparação entre grupos controle e aprotinina para cada tempo Variável PVC.

\begin{tabular}{cccc}
\hline \multirow{2}{*}{ Tempo } & Controle & Média (DP) & $\begin{array}{c}\text { Diferença de médias } \\
\text { P-valor }(*)\end{array}$ \\
\hline T5 & $10,56(4,10)$ & Aprotinina & 0,36 \\
T6 & $11,00(3,74)$ & $9,00(2,83)$ & 0,36 \\
T7 & $11,17(4,83)$ & $9,33(2,12)$ & 0,65 \\
T8 & $10,33(2,52)$ & $10,25(2,43)$ & 0,22 \\
\hline
\end{tabular}

(*) Transformação Box-Cox. 
TABELA 35. Escore inotrópico I dos grupos Aprotinina e Controle, nos tempos T5 a T8.

\begin{tabular}{|c|c|c|c|c|c|}
\hline $\begin{array}{l}\text { Pacientes Grupo } \\
\text { Aprotinina }\end{array}$ & T5 & T6 & T7 & \multicolumn{2}{|c|}{ T8 } \\
\hline 1 & & 6 & 2 & 10 & 6 \\
\hline 7 & & 2 & 6 & 6 & 6 \\
\hline 13 & & 0 & 0 & 0 & 0 \\
\hline 24 & & 2 & 2 & 2 & 2 \\
\hline 25 & & 2 & 2 & 5 & 2 \\
\hline 32 & & 5 & 10 & 12 & 8 \\
\hline 35 & & 0 & 0 & 0 & 0 \\
\hline 37 & & 2 & 2 & 2 & 2 \\
\hline 40 & & 2 & 2 & 2 & 2 \\
\hline 45 & & 5 & 6 & 6 & 6 \\
\hline Média / Mediana & & $2,6 / 2$ & $3,2 / 2$ & $4,5 / 3,5$ & $3,4 / 2$ \\
\hline Desvio-padrão & & 2,06 & 3,15 & 4,08 & 2,83 \\
\hline Pacientes Grupo Controle & T5 & T6 & T7 & & \\
\hline 3 & & 2 & 2 & 2 & 0 \\
\hline 6 & & 0 & 2 & 0 & 0 \\
\hline 10 & & 2 & 2 & 2 & 2 \\
\hline 11 & & 0 & 0 & 0 & 0 \\
\hline 12 & & 2 & 2 & 2 & 0 \\
\hline 34 & & 5 & 5 & 6 & 6 \\
\hline 36 & & 2 & 2 & 2 & 2 \\
\hline 49 & & 2 & 2 & 2 & 2 \\
\hline 53 & & 6 & 6 & 6 & 6 \\
\hline Média / Mediana & & $2,3 / 2$ & $2,5 / 2$ & $2,4 / 2$ & $2 / 2$ \\
\hline Desvio- padrão & & 2 & 1,81 & 2,18 & 2,44 \\
\hline
\end{tabular}

TABELA 36. Comparação entre os grupos tratamento e controle - Escore Inotrópico I -Teste de Wilcoxon.

\begin{tabular}{cccc}
\hline \multirow{2}{*}{ Tempo } & Mediana $\left(1 .^{\circ}\right.$ Quartil;3. ${ }^{\circ}$ Quartil) & Tratamento $\times$ Controle & P-valor \\
\cline { 2 - 3 } Tratamento & $2,00(2,00 ; 4,25)$ & $2,00(2,00 ; 2,00)$ & 0,82 \\
T6 & $2,00(2,00 ; 5,00)$ & $2,00(2,00 ; 2,00)$ & 0,89 \\
T7 & $3,50(2,00 ; 6,00)$ & $2,00(2,00 ; 2,00)$ & 0,35 \\
T8 & $2,00(2,00 ; 6,00)$ & $2,00(0,00 ; 2,00)$ & 0,25 \\
\hline
\end{tabular}


TABELA 37. Escore inotrópico II dos grupos Aprotinina e Controle nos tempos T5 a T8

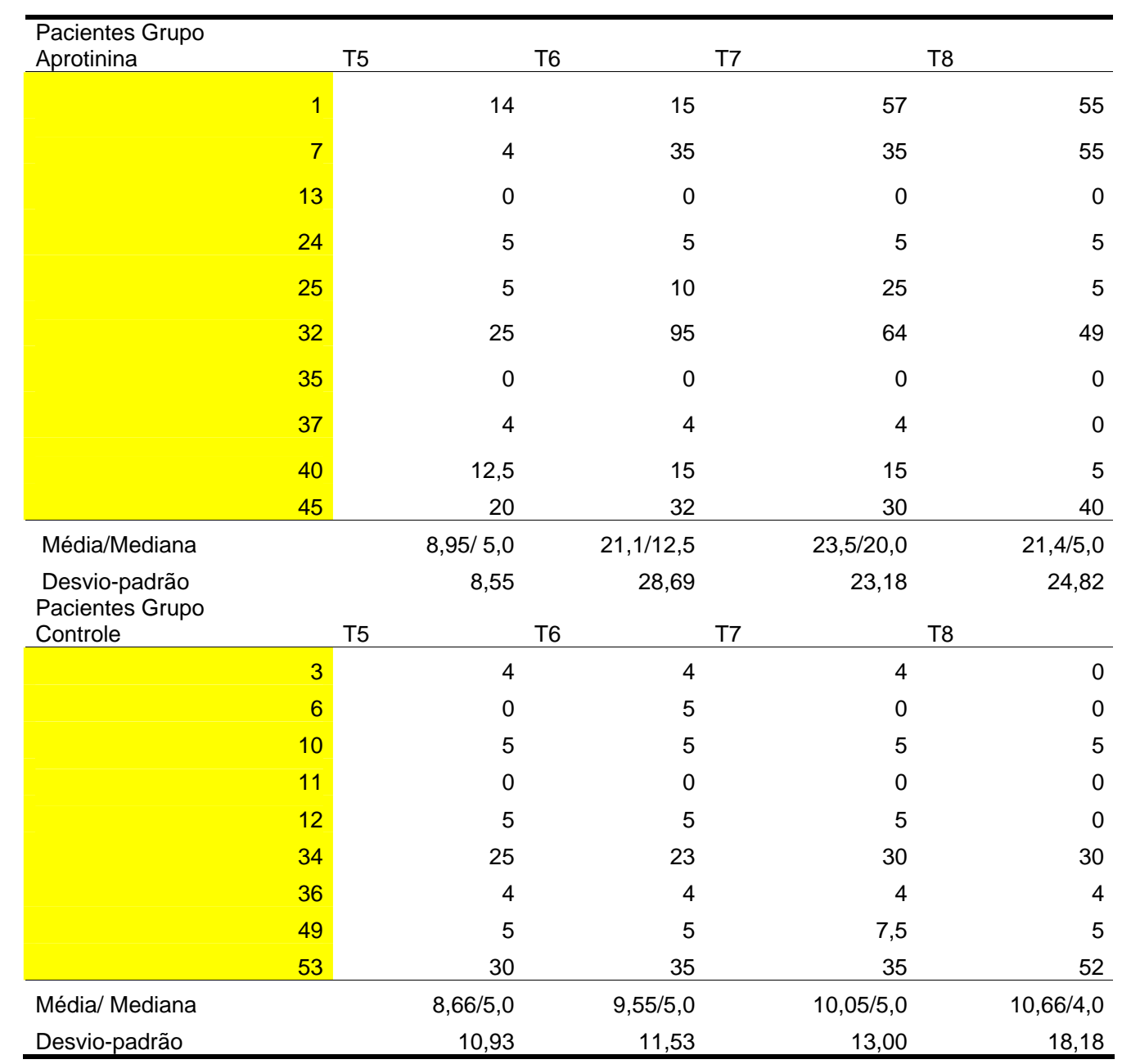

TABELA 38. Comparação entre os grupos tratamento e controle - Escore Inotrópico II -Teste de Wilcoxon.

\begin{tabular}{cccc}
\hline \multirow{2}{*}{ Tempo } & Mediana $\left(1 .{ }^{\circ}\right.$ Quartil; $3 .^{\circ}$ Quartil) & Tratamento $\times$ Controle & \\
& Tratamento $^{\text {T5 }}$ & Controle & P-valor \\
\hline T6 & $5,00(4,00 ; 13 ; 62)$ & $5,00(4,00 ; 5,00)$ & 0,87 \\
T7 & $12,50(4,25 ; 27,75)$ & $5,00(4,00 ; 5,00)$ & 0,46 \\
T8 & $20,00(4,25 ; 33,75)$ & $5,00(4,00 ; 7,50)$ & 0,30 \\
& $5,00(1,25 ; 46,75)$ & $4,00(0,00 ; 5,00)$ & 0,29 \\
\hline
\end{tabular}


TABELA 39. Distribuição individual de congestão pulmonar e asma cardíaca, choque, anasarca, ascite e derrame pleural, no pós-op. no grupo Aprotinina.

\begin{tabular}{cccc}
\hline Grupo Aprotinina & $\begin{array}{c}\text { Congestão pulmonar } \\
\text { Asma cardíaca }\end{array}$ & Choque & $\begin{array}{c}\text { Anasarca / Ascite } \\
\text { Derrame pleural }\end{array}$ \\
\hline 1 & - & + & $\begin{array}{c}\text { Anasarca / Ascite } \\
\text { Derrame pleural }\end{array}$ \\
7 & - & + & Anasarca \\
13 & - & - & - \\
24 & - & - & - \\
25 & - & + & - \\
32 & + Congestão pulmonar & + & Anasarca / Ascite \\
35 & Asma cardíaca & - & Derrame pleural \\
37 & + Congestão pulmonar & - & - \\
40 & Asma cardíaca & - & Anasarca \\
45 & + Congestão pulmonar & - & - \\
\hline
\end{tabular}

TABELA 40. Distribuição individual de congestão pulmonar e asma cardíaca, choque, anasarca, ascite e derrame pleural, no pós-op. no grupo Controle.

\begin{tabular}{cccc}
\hline Grupo Controle & $\begin{array}{c}\text { Congestão pulmonar } \\
\text { Asma cardíaca }\end{array}$ & Choque & $\begin{array}{c}\text { Anasarca / Ascite } \\
\text { Derrame pleural }\end{array}$ \\
\hline 3 & - & - & - \\
6 & - & + & - \\
10 & + Congestão pulmonar & - & - \\
11 & - & - & - \\
12 & - & - & - \\
34 & - & + & Anasarca \\
36 & + Congestão pulmonar & - & - \\
49 & Asma cardíaca & - & - \\
53 & - & + & Anasarca \\
& + Congestão pulmonar & & Derrame pleural \\
\hline
\end{tabular}




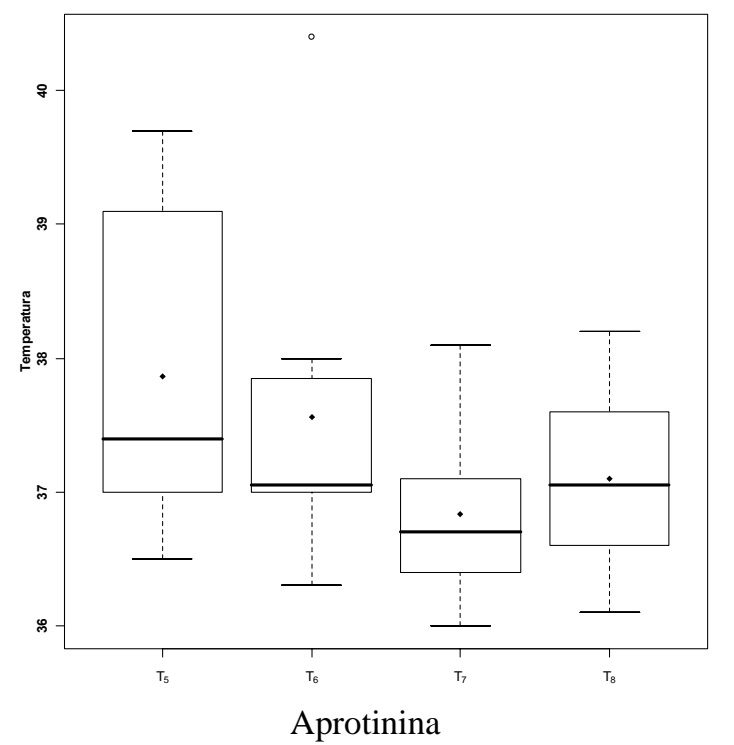

(a)

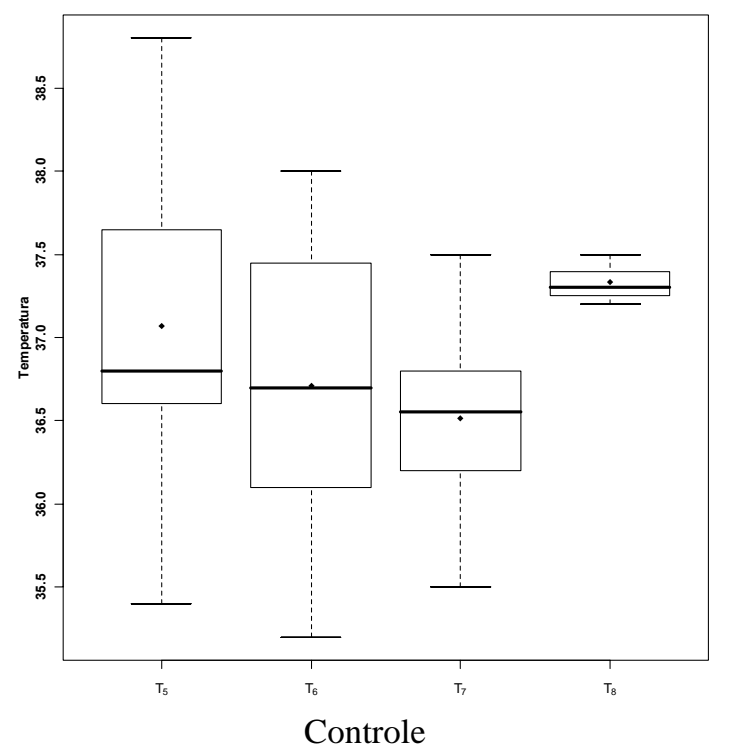

(b)

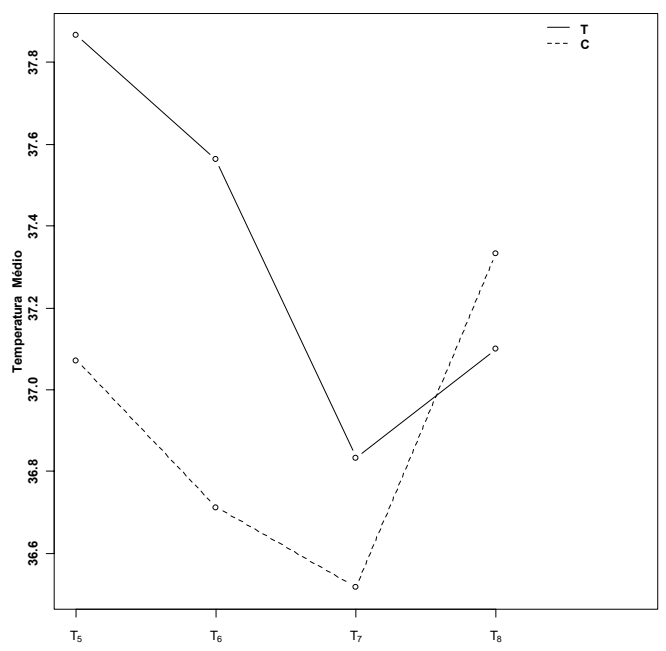

(c)

FIGURA 2: Temperatura $\left({ }^{\circ} \mathrm{C}\right)$ nas crianças operadas dos grupos aprotinina (a) e controle (b), nos tempos T5 a T8. Em (c), estão os valores médios da variável temperatura nos tempos.

TABELA 41: Comparação entre os grupos para cada tempo - Variável Temperatura.

\begin{tabular}{cccc}
\hline \multirow{2}{*}{ Tempo } & Controle & Média (DP) & Diferença de médias \\
& $37,07(1,1)$ & Tratamento & 0,09 \\
T5 & $36,71(0,93)$ & $37,87(1,2)$ & 0,05 \\
T6 & $36,52(0,67)$ & $37,56(1,25)$ & 0,54 \\
T7 & $37,33(0,15)$ & $36,83(0,7)$ & 0,67 \\
T8 & $37,1(0,74)$ & \\
\hline
\end{tabular}


TABELA 42. Drenagem mediastinal total e por peso corpóreo (entre parênteses) no pós-operatório dos grupos Aprotinina e Controle

\begin{tabular}{|c|c|c|c|c|}
\hline $\begin{array}{l}\text { Grupo Aprotinina } \\
\text { PACIENTE / peso } \\
\text { (kg) }\end{array}$ & $\begin{array}{l}\text { T5 } \\
\text { (4 horas após } \\
\text { protamina) } \\
\text { Total e } \mathrm{ml} / \mathrm{kg}\end{array}$ & $\begin{array}{l}\text { T6 } \\
\text { (12 horas após } \\
\text { protamina) } \\
\text { Total e } \mathrm{ml} / \mathrm{kg}\end{array}$ & $\begin{array}{l}\text { T7 } \\
\text { (24 horas após } \\
\text { protamina) } \\
\text { Total e } \mathrm{ml} / \mathrm{kg}\end{array}$ & $\begin{array}{l}\text { T8 } \\
\text { (48 horas após } \\
\text { protamina) } \\
\text { Total e } \mathrm{ml} / \mathrm{kg}\end{array}$ \\
\hline $\begin{array}{ll}14,30) \\
\end{array}$ & $48(11,16)$ & 0 & $18(4,18)$ & $39(9,07)$ \\
\hline $\begin{array}{ll}7 & (3,45)\end{array}$ & $38,4(11,13)$ & 0 & $20(5,79)$ & 0 \\
\hline $13(5,15)$ & 0 & 0 & $138,8(26,95)$ & $100(19,41)$ \\
\hline $24 \quad(8,17)$ & 0 & $17(2,08)$ & $17(2,08)$ & 0 \\
\hline $25 \quad(3,32)$ & $25(7,53)$ & $7(2,10)$ & 0 & $20(6,02)$ \\
\hline $32 \quad(9,00)$ & $43(4,77)$ & $32(3,55)$ & $22(2,44)$ & $45(5,00)$ \\
\hline $35 \quad(15,00)$ & $30(2,00)$ & $20(1,33)$ & 0 & 0 \\
\hline $37 \quad(5,03)$ & 0 & $20(3,97)$ & $15(2,98)$ & 0 \\
\hline $40 \quad(3,65)$ & $58(15,89)$ & 0 & $22(6,02)$ & $40(10,95)$ \\
\hline $45 \quad(3,60)$ & 0 & $25(6,94)$ & 0 & $11(3,05)$ \\
\hline Média & $\begin{array}{l}24,24 \mathrm{ml} \\
5,24 \mathrm{ml} / \mathrm{kg} / 4 \mathrm{~h}\end{array}$ & $\begin{array}{l}12,1 \mathrm{ml} \\
1,99 \mathrm{ml} / \mathrm{kg} / 8 \mathrm{~h}\end{array}$ & $\begin{array}{l}25,28 \mathrm{ml} \\
5,04 \mathrm{ml} / \mathrm{kg} / 12 \mathrm{~h}\end{array}$ & $\begin{array}{l}25,5 \mathrm{ml} \\
5,35 \mathrm{ml} / \mathrm{kg} / 24 \mathrm{~h}\end{array}$ \\
\hline $\begin{array}{l}\text { Grupo Controle } \\
\text { PACIENTE / peso } \\
\text { (kg) }\end{array}$ & $\begin{array}{l}\text { T5 } \\
\text { (4 horas após } \\
\text { protamina) } \\
\text { Total e } \mathrm{ml} / \mathrm{kg}\end{array}$ & $\begin{array}{l}\text { T6 } \\
\text { (12 horas após } \\
\text { protamina) } \\
\text { Total e } \mathrm{ml} / \mathrm{kg}\end{array}$ & $\begin{array}{l}T 7 \\
\text { (24 horas após } \\
\text { protamina) } \\
\text { Total e } \mathrm{ml} / \mathrm{kg} \\
\end{array}$ & $\begin{array}{l}\text { T8 } \\
\text { (48 horas após } \\
\text { protamina) } \\
\text { Total e } \mathrm{ml} / \mathrm{kg}\end{array}$ \\
\hline $3 \quad(6,87)$ & $66(9,60)$ & $49(7,13)$ & $102(14,84)$ & $30(4,36)$ \\
\hline $\begin{array}{ll}6 \quad(2,20) \\
\end{array}$ & $50(22,7)$ & $60(27,27)$ & 0 & 0 \\
\hline $10(4,80)$ & $24(5,00)$ & $31(6,45)$ & $31,8(6,62)$ & 0 \\
\hline $11(6,65)$ & 0 & $14(2,10)$ & $20(3,00)$ & 0 \\
\hline $12(15,8)$ & $60(3,79)$ & $90(5,69)$ & $60(3,79)$ & $40(2,53)$ \\
\hline $34(2,89)$ & 0 & 0 & $12(4,15)$ & $5(1,73)$ \\
\hline $36(7,31)$ & 0 & 0 & $73(9,98)$ & $100(13,67)$ \\
\hline $49(4,52)$ & 0 & $20(4,42)$ & 0 & 0 \\
\hline $53(4,52)$ & 0 & $20(4,42)$ & 0 & 0 \\
\hline Média & $\begin{array}{l}22,22 \mathrm{ml} \\
4,56 \mathrm{ml} / \mathrm{kg} / 4 \mathrm{~h}\end{array}$ & $\begin{array}{l}31,55 \mathrm{ml} \\
6,38 \mathrm{ml} / \mathrm{kg} / 8 \mathrm{~h}\end{array}$ & $\begin{array}{l}33,20 \mathrm{ml} \\
4,70 \mathrm{ml} / \mathrm{kg} / 12 \mathrm{~h} \\
\end{array}$ & $\begin{array}{l}18,8 \mathrm{ml} \\
2,47 \mathrm{ml} / \mathrm{kg} / 24 \mathrm{~h}\end{array}$ \\
\hline
\end{tabular}


TABELA 43. Utilização de hemoderivados total e por peso corpóreo (entre parênteses) nas primeiras $48 \mathrm{~h}$ de pós-operatório, nos grupos Aprotinina e Controle.

\begin{tabular}{|c|c|c|c|c|}
\hline $\begin{array}{l}\text { GRUPO } \\
\text { APROTININA } \\
\text { PACIENTE / peso } \\
\text { (kg) }\end{array}$ & $\begin{array}{l}\text { T5 } \\
\text { (4 horas após } \\
\text { protamina) } \\
\text { Total e } \mathrm{ml} / \mathrm{kg}\end{array}$ & $\begin{array}{l}\text { T6 } \\
\text { (12 horas após } \\
\text { protamina) } \\
\text { Total e } \mathrm{ml} / \mathrm{kg}\end{array}$ & $\begin{array}{l}\text { T7 } \\
\text { (24 horas após } \\
\text { protamina) } \\
\text { Total e } \mathrm{ml} / \mathrm{kg}\end{array}$ & $\begin{array}{l}\text { T8 } \\
\text { (48 horas após } \\
\text { protamina) } \\
\text { Total e } \mathrm{ml} / \mathrm{kg}\end{array}$ \\
\hline $\begin{array}{ll}14,30) \\
\end{array}$ & 40ml albumina $(9,30)$ & $\begin{array}{l}\text { 80ml albumina } \\
(18.60)\end{array}$ & $\begin{array}{l}\text { 120ml albumina } \\
(27,90)\end{array}$ & $\begin{array}{l}\text { 40ml albumina } \\
(9,30)\end{array}$ \\
\hline $\begin{array}{ll}7 & (3,45)\end{array}$ & $\begin{array}{l}52,5 \mathrm{ml} \text { albumina } \\
(15,21)\end{array}$ & $\begin{array}{l}\text { 36ml albumina } \\
(10,43)\end{array}$ & $\begin{array}{l}\text { 54ml albumina } \\
(15,65)\end{array}$ & - \\
\hline $13(5,15)$ & $\begin{array}{l}\text { 40ml albumina } \\
(7,76)\end{array}$ & - & - & - \\
\hline $24 \quad(8,17)$ & - & $\begin{array}{l}\text { 80ml albumina } \\
(9,79)\end{array}$ & - & - \\
\hline $25 \quad(3,32)$ & $\begin{array}{l}\text { 46ml albumina } \\
(13,85)\end{array}$ & $\begin{array}{l}\text { 48ml albumina } \\
(14,45)\end{array}$ & $\begin{array}{l}\text { 20ml albumina } \\
(6,02)\end{array}$ & - \\
\hline $32(9,00)$ & $\begin{array}{l}\text { 180ml albumina } \\
(20,00)\end{array}$ & - & $\begin{array}{l}\text { 63ml albumina } \\
(7,0)\end{array}$ & - \\
\hline $35 \quad(15,00)$ & $\begin{array}{l}\text { 150ml Conc hem } \\
(10,00)\end{array}$ & - & - & - \\
\hline $37 \quad(5,03)$ & - & - & - & - \\
\hline $40 \quad(3,65)$ & $\begin{array}{l}\text { 76ml albumina } \\
(20,82)\end{array}$ & $\begin{array}{l}\text { 19ml albumina } \\
(5,20)\end{array}$ & - & - \\
\hline $45 \quad(3,60)$ & $\begin{array}{l}72 \mathrm{ml} \text { albumina } \\
(20,00)\end{array}$ & $\begin{array}{l}\text { 36ml albumina } \\
(10,0)\end{array}$ & $\begin{array}{l}\text { 36ml albumina } \\
(10,0)\end{array}$ & $\begin{array}{l}\text { 54ml albumina } \\
\text { (15) }\end{array}$ \\
\hline Média (ml/kg) & $10,69 \pm 8,56$ & $6,84 \pm 6,81$ & $6,65 \pm 9,22$ & $3,40 \pm 5,68$ \\
\hline
\end{tabular}

\begin{tabular}{|c|c|c|c|c|}
\hline $\begin{array}{l}\text { GRUPO CONTROLE } \\
\text { PACIENTE / peso } \\
\text { (kg) }\end{array}$ & $\begin{array}{l}\text { T5 } \\
\text { (4 horas após } \\
\text { protamina) } \\
\text { Total e } \mathrm{ml} / \mathrm{kg}\end{array}$ & $\begin{array}{l}\text { T6 } \\
\text { (12 horas após } \\
\text { protamina) } \\
\text { Total e } \mathrm{ml} / \mathrm{kg}\end{array}$ & $\begin{array}{l}\text { T7 } \\
\text { (24 horas após } \\
\text { protamina) } \\
\text { Total e } \mathrm{ml} / \mathrm{kg}\end{array}$ & $\begin{array}{l}\text { T8 } \\
\text { (48 horas após } \\
\text { protamina) } \\
\text { Total e } \mathrm{ml} / \mathrm{kg}\end{array}$ \\
\hline $3 \quad(6,87)$ & - & - & - & - \\
\hline $6 \quad(2,20)$ & $\begin{array}{l}\text { 14ml albumina } \\
(6,36)\end{array}$ & $\begin{array}{l}\text { 14ml albumina }(6,36) \\
28 \mathrm{ml} \text { Conc plaq } \\
(12,72)\end{array}$ & - & - \\
\hline $10(4,80)$ & - & - & - & - \\
\hline $11(6,65)$ & 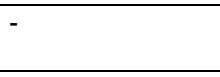 & $\begin{array}{l}\text { 33ml albumina } \\
(4,96)\end{array}$ & (2) & - \\
\hline $12(15,8)$ & $\begin{array}{l}\text { 80ml albumina } \\
(5,06)\end{array}$ & $\begin{array}{l}\text { 80ml albumina } \\
(5,06)\end{array}$ & $\begin{array}{l}180 \mathrm{ml} \text { Conc plaq } \\
(11,39)\end{array}$ & - \\
\hline $34(2,89)$ & $\begin{array}{l}\text { 10ml albumina } \\
(3,46)\end{array}$ & - & - & - \\
\hline $36(7,31)$ & $\begin{array}{l}\text { 117ml albumina } \\
(16,00)\end{array}$ & - & - & - \\
\hline $49(4,52)$ & $\begin{array}{l}\text { 66ml albumina } \\
(14,60)\end{array}$ & $\begin{array}{l}\text { 22ml albumina } \\
(4,86)\end{array}$ & - & - \\
\hline $53(4,52)$ & $\begin{array}{l}\text { 75ml albumina } \\
(16,59)\end{array}$ & $\begin{array}{l}\text { 113ml albumina } \\
(25,00)\end{array}$ & - & - \\
\hline Média (ml/kg) & $6,89 \pm 7,02$ & $4,80 \pm 7,99$ & $1,26 \pm 3,57$ & 0 \\
\hline
\end{tabular}


TABELA 44. Exposição a doadores de hemoderivados durante o tempo de internação hospitalar, nos grupos Aprotinina e Controle.

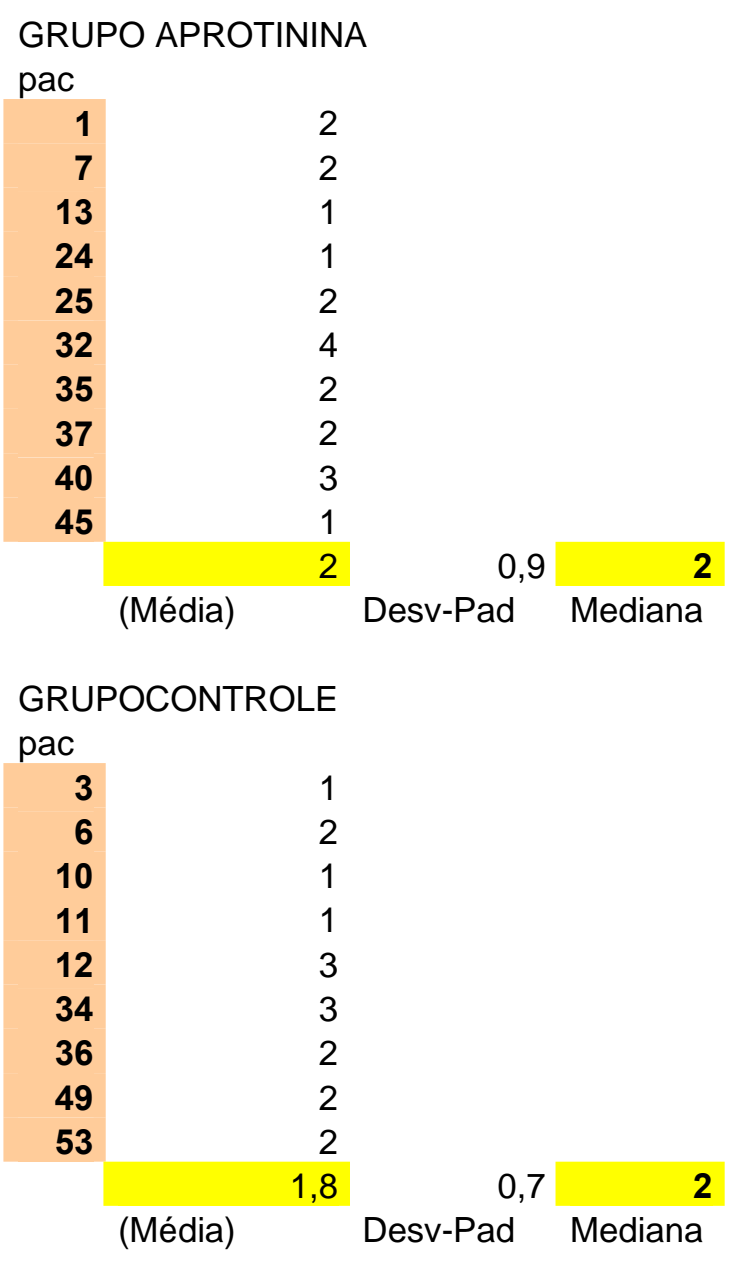


TABELA 45. Diurese total no pós-operatório das crianças operadas para correção das cardiopatias congênitas acianogênicas nos grupos aprotinina e controle.

\begin{tabular}{|l|l|l|l|l|}
\hline $\begin{array}{l}\text { PACIENTE / peso } \mathbf{( k g}) \\
\text { GRUPOAPROTININA }\end{array}$ & $\begin{array}{l}\text { T5 } \\
\mathbf{4} \text { horas após } \\
\text { protamina) } \\
\text { Total }\end{array}$ & $\begin{array}{l}\text { T6 } \\
\mathbf{( 1 2} \text { horas após } \\
\text { protamina) } \\
\text { Total }\end{array}$ & $\begin{array}{l}\text { T7 } \\
\mathbf{2} \text { horas após } \\
\text { protamina) } \\
\text { Total }\end{array}$ & $\begin{array}{l}\text { T8 } \\
\text { (48 horas após } \\
\text { protamina) } \\
\text { Total }\end{array}$ \\
\hline $\mathbf{1}(4,30)$ & $98 \mathrm{ml}$ & $39 \mathrm{ml}$ & $48 \mathrm{ml}$ & $310 \mathrm{ml}$ \\
\hline $\mathbf{7}(3,45)$ & $58 \mathrm{ml}$ & $16 \mathrm{ml}$ & $35,5 \mathrm{ml}$ & $94 \mathrm{ml}$ \\
\hline $\mathbf{1 3}(5,15)$ & $100 \mathrm{ml}$ & $105 \mathrm{ml}$ & $75 \mathrm{ml}$ & 170 \\
\hline $\mathbf{2 4}(8,17)$ & $240 \mathrm{ml}$ & $108 \mathrm{ml}$ & $125 \mathrm{ml}$ & $390 \mathrm{ml}$ \\
\hline $\mathbf{2 5}(3,32)$ & $40 \mathrm{ml}$ & $32,4 \mathrm{ml}$ & $29 \mathrm{ml}$ & $145 \mathrm{ml}$ \\
\hline $\mathbf{3 2}(9,00)$ & $175 \mathrm{ml}$ & $95 \mathrm{ml}$ & $180 \mathrm{ml}$ & 370,6 \\
\hline $\mathbf{3 5}(15,00)$ & $80 \mathrm{ml}$ & $155 \mathrm{ml}$ & $415 \mathrm{ml}$ & $415 \mathrm{ml}$ \\
\hline $\mathbf{3 7}(5,03)$ & $90 \mathrm{ml}$ & $70 \mathrm{ml}$ & $230 \mathrm{ml}$ & \\
\hline $\mathbf{4 0}(3,65)$ & $118,6 \mathrm{ml}$ & $6,8 \mathrm{ml}$ & $34,6 \mathrm{ml}$ & $157 \mathrm{ml}$ \\
\hline $\mathbf{4 5}(3,60)$ & $80 \mathrm{ml}$ & $65,6 \mathrm{ml}$ & $55,2 \mathrm{ml}$ & $187,7 \mathrm{ml}$ \\
\hline Média & 107,96 & 69,28 & 122,73 & 248,81 \\
\hline
\end{tabular}

\begin{tabular}{|l|l|l|l|l|}
\hline $\begin{array}{l}\text { PACIENTE / peso } \mathbf{( k g}) \\
\text { GRUPOCONTROLE }\end{array}$ & $\begin{array}{l}\text { T5 } \\
\text { (4 horas após } \\
\text { protamina) } \\
\text { Total }\end{array}$ & $\begin{array}{l}\text { T6 } \\
\mathbf{1 2} \text { horas após } \\
\text { protamina) } \\
\text { Total }\end{array}$ & $\begin{array}{l}\text { T7 } \\
\mathbf{2} \text { horas após } \\
\text { protamina) } \\
\text { Total }\end{array}$ & $\begin{array}{l}\text { T8 } \\
\text { (48 horas após } \\
\text { protamina) } \\
\text { Total }\end{array}$ \\
\hline $\mathbf{3}(6,87)$ & $100 \mathrm{ml}$ & $113 \mathrm{ml}$ & $80 \mathrm{ml}$ & $395 \mathrm{ml}$ \\
\hline $\mathbf{6}(2,20)$ & $50 \mathrm{ml}$ & $53 \mathrm{ml}$ & $18 \mathrm{ml}$ & $235 \mathrm{ml}$ \\
\hline $\mathbf{1 0}(4,80)$ & $27 \mathrm{ml}$ & $82 \mathrm{ml}$ & $75 \mathrm{ml}$ & $420 \mathrm{ml}$ \\
\hline $\mathbf{1 1}(6,65)$ & $45 \mathrm{ml}$ & $65 \mathrm{ml}$ & $65 \mathrm{ml}$ & \\
\hline $\mathbf{1 2}(15,8)$ & $355 \mathrm{ml}$ & $180 \mathrm{ml}$ & $270 \mathrm{ml}$ & $470 \mathrm{ml}$ \\
\hline $\mathbf{3 4}(2,89)$ & $140 \mathrm{ml}$ & $20 \mathrm{ml}$ & $48 \mathrm{ml}$ & $306 \mathrm{ml}$ \\
\hline $\mathbf{3 6}(7,31)$ & $500 \mathrm{ml}$ & $150 \mathrm{ml}$ & $126 \mathrm{ml}$ & $514 \mathrm{ml}$ \\
\hline $\mathbf{4 9}(4,52)$ & $20 \mathrm{ml}$ & $46 \mathrm{ml}$ & & 137 \\
\hline $\mathbf{5 3}(4,52)$ & $25 \mathrm{ml}$ & $75 \mathrm{ml}$ & $20 \mathrm{ml}$ & 353,86 \\
\hline Média & 140,22 & 87,11 & 87,75 & \\
\hline
\end{tabular}

TABELA 46: Diurese pós-operatória ( $\mathrm{ml} / \mathrm{kg}$ ) comparando os grupos Aprotinina e Controle para cada tempo da variável.

\begin{tabular}{|c|c|c|c|}
\hline \multirow{2}{*}{ Tempo } & \multicolumn{2}{|c|}{ Média (DP) } & \multirow{2}{*}{$\begin{array}{c}\text { Diferença de médias } \\
\text { P-valor }\left({ }^{*}\right)\end{array}$} \\
\hline & Controle & Aprotinina & \\
\hline T5 & $22,10(22,33)$ & $19,78(7,82)$ & 0,39 \\
\hline T6 & $14,77(5,60)$ & $11,19(5,61)$ & 0,16 \\
\hline T7 & $12,57(4,81)$ & $17,82(11,34)$ & 0,24 \\
\hline T8 & $69,72(32,41)$ & $43,08(13,87)$ & 0,19 \\
\hline
\end{tabular}


TABELA 47. Comparação entre os picos médios e o valor médio em T5 dentro de cada grupo - Variável Diurese pós-op ( $\mathrm{ml} / \mathrm{kg})$.

\begin{tabular}{cccccc}
\hline Grupo & Tempo & Média (DP) & Tempo & Média (DP) & $\begin{array}{c}\text { Diferença de médias } \\
\text { P-valor (**) }\end{array}$ \\
\hline Tratamento & T5 & $19,78(7,82)$ & T8 & $43,08(13,87)$ & $<0,01$ \\
Controle & T5 & $22,10(22,33)$ & T8 & $69,72(32,41)$ & $<0,01$ \\
\hline
\end{tabular}

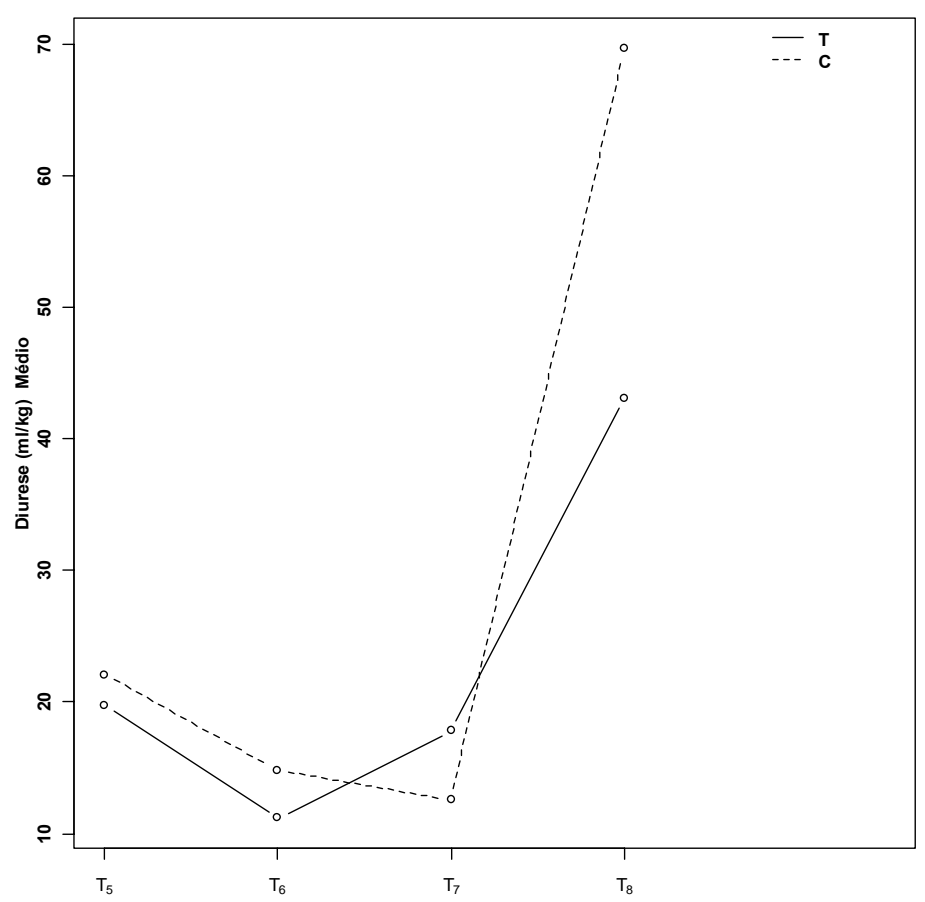

FIGURA 3. Diurese média ( $\mathrm{ml} / \mathrm{kg}$ ) dos grupos Aprotinina (T) e Controle (C), nos tempos de T5 a T8.

TABELA 48. Depuração de creatinina estimada pela fórmula de SCHWARTZ (1987)

"Clearance" de creatinina = TFG ( taxa de filtração glomerular)

$T F G=\boldsymbol{\kappa} \times$ altura $(\mathrm{cm}) /$ creatinina plasmática $(\mathrm{mg} / \mathrm{dL})$

Sendo K:

0,33 - recém-nascido pré-termo

$\mathbf{0 , 4 5}$ - recém-natos a termo $<1$ ano

$\mathbf{0 , 5 5}$ - crianças de 1 a 18 anos 
TABELA 49. Demonstração da depuração ("clearance") de creatinina calculada pela equação de Schwartz no pós-operatório imediato e $1^{\circ}$ dia de pós-operatório nos pacientes operados para correção de cardiopatia congênita acianogênica, nos grupos aprotinina e controle.

\begin{tabular}{|c|c|c|c|c|c|c|}
\hline $\begin{array}{r}\text { Grupo } \\
\text { aprotinina }\end{array}$ & Altura $(\mathrm{cm})$ & Constante $\mathbf{~}$ & Alt $\times \mathrm{k}$ & $\begin{array}{l}\text { Pré-operatório } \\
\left(\mathrm{ml} / \mathrm{min} / 1,73 \mathrm{~m}^{2}\right)\end{array}$ & $\begin{array}{l}\text { Pós-operatório } \\
\text { imediato } \\
\left(\mathrm{ml} / \mathrm{min} / 1,73 \mathrm{~m}^{2}\right)\end{array}$ & $\begin{array}{c}1^{0} \text { dia de pós- } \\
\text { operatório } \\
\left(\mathrm{ml} / \mathrm{min} / 1,73 \mathrm{~m}^{2}\right)\end{array}$ \\
\hline 1 & 58 & 0,45 & 26,1 & & 30,5 & 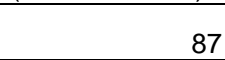 \\
\hline 7 & 51 & 0,45 & 22,95 & & 57,37 & 45,9 \\
\hline 13 & 61,5 & 0,45 & 27,675 & & 92,25 & 69,18 \\
\hline 24 & 71 & 0,55 & 39,05 & & 195,25 & 130,16 \\
\hline 25 & 54 & 0,45 & 24,3 & 60,75 & 81 & 60,75 \\
\hline 32 & 74 & 0,55 & 40,7 & 101,75 & 135,66 & 135,6 \\
\hline 35 & 104 & 0,55 & 57,2 & 114,4 & 114,4 & 143 \\
\hline 37 & 60 & 0,45 & 27 & 90 & 270 & 135 \\
\hline 40 & 54 & 0,45 & 24,3 & 60,75 & 121,5 & 40,5 \\
\hline 45 & 51 & 0,45 & 22,95 & & 28,68 & 57,37 \\
\hline Média & & & & & 112,66 & 90,44 \\
\hline $\begin{array}{l}\text { Desvio- } \\
\text { padrão }\end{array}$ & & & & & 74,88 & 41,20 \\
\hline $\begin{array}{l}\text { Grupo } \\
\text { controle }\end{array}$ & Altura $(\mathrm{cm})$ & & & & & \\
\hline 3 & 67 & 0,45 & 30,15 & 75,35 & 100,5 & 100,5 \\
\hline 6 & 49 & 0,45 & 22,05 & 55,12 & 73,5 & 73,5 \\
\hline 10 & 60 & 0,45 & 27 & 67,5 & 67,5 & 90 \\
\hline 11 & 68 & 0,45 & 30,6 & & 153 & 76,5 \\
\hline 12 & 96 & 0,55 & 52,8 & 132 & 132 & 132 \\
\hline 34 & 50 & 0,45 & 22,5 & & 112,5 & 45 \\
\hline 36 & 71 & 0,45 & 31,95 & 106,5 & 63,9 & 53,25 \\
\hline 49 & 54 & 0,45 & 24,3 & 40,5 & 60,75 & 60,75 \\
\hline 53 & 57 & 0,45 & 25,65 & 42,75 & 64,12 & 36,64 \\
\hline Média & & & & & 91,97 & 74,23 \\
\hline $\begin{array}{l}\text { Desvio- } \\
\text { padrão }\end{array}$ & & & & & 34,09 & 29,93 \\
\hline
\end{tabular}


TABELA 50. Dados laboratoriais: TNF- $\alpha$, Interleucinas, cTnl e NT-proBNP, dos grupos aprotinina e controle.

\begin{tabular}{|c|c|c|c|c|c|c|c|c|c|}
\hline \multirow[t]{2}{*}{ Variável } & \multirow[t]{2}{*}{ Grupos } & \multicolumn{8}{|l|}{ Tempos } \\
\hline & & $\mathrm{T} 1$ & $\mathrm{~T} 2$ & T3 & $\mathrm{T} 4$ & T5 & T6 & $\mathrm{T} 7$ & T8 \\
\hline \multirow[t]{2}{*}{$\begin{array}{l}\text { TNF-a } \\
(\mathrm{pg} / \mathrm{ml})\end{array}$} & Aprotinina & $\begin{array}{c}13,19 \\
(12,28)\end{array}$ & $\begin{array}{l}39,83 \\
(78,43)\end{array}$ & $\begin{array}{l}20,72 \\
(31,46)\end{array}$ & $\begin{array}{l}34,49 \\
(54,67)\end{array}$ & $\begin{array}{l}9,60 \\
(7,00)\end{array}$ & $\begin{array}{l}9,74 \\
(7,06)\end{array}$ & $\begin{array}{l}9,07 \\
(4,27)\end{array}$ & $\begin{array}{l}7,36 \\
(5,78)\end{array}$ \\
\hline & Controle & $\begin{array}{c}6,82 \\
(5,41)\end{array}$ & $\begin{array}{l}19,35 \\
(15,82)\end{array}$ & $\begin{array}{l}9,38 \\
(4,32)\end{array}$ & $\begin{array}{l}10,37 \\
(4,64)\end{array}$ & $\begin{array}{l}12,21 \\
(17,60)\end{array}$ & $\begin{array}{l}11,21 \\
(12,14)\end{array}$ & $\begin{array}{l}7,04 \\
(8,05)\end{array}$ & $\begin{array}{l}7,03 \\
(4,90)\end{array}$ \\
\hline \multirow[t]{2}{*}{ Il-6 (pg/ml) } & Aprotinina & $\begin{array}{c}160,34 \\
(217,47)\end{array}$ & $\begin{array}{l}249,83 \\
(226,74)\end{array}$ & $\begin{array}{l}148,35 \\
(91,51)\end{array}$ & $\begin{array}{l}374,00 \\
(186,79)\end{array}$ & $\begin{array}{l}376,70 \\
(250,54)\end{array}$ & $\begin{array}{l}349,27 \\
(327,10)\end{array}$ & $\begin{array}{l}322,44 \\
(286,81)\end{array}$ & $\begin{array}{l}164,45 \\
(178,43)\end{array}$ \\
\hline & Controle & $\begin{array}{c}40,54 \\
(42,94)\end{array}$ & $\begin{array}{l}80,91 \\
(76,20)\end{array}$ & $\begin{array}{l}180,76 \\
(177,86)\end{array}$ & $\begin{array}{l}315,88 \\
(313,09)\end{array}$ & $\begin{array}{l}285,15 \\
(223,46)\end{array}$ & $\begin{array}{l}329,40 \\
(236,26)\end{array}$ & $\begin{array}{l}305,02 \\
(232,48)\end{array}$ & $\begin{array}{l}189,68 \\
(170,37)\end{array}$ \\
\hline \multirow[t]{2}{*}{$\begin{array}{l}\text { IL-8 } \\
\text { (pg/ml) }\end{array}$} & Aprotinina & $\begin{array}{l}10,28 \\
(4,17)\end{array}$ & $\begin{array}{c}45,87 \\
(47,47)\end{array}$ & $\begin{array}{l}70,67 \\
(58,48)\end{array}$ & $\begin{array}{l}281,50 \\
(275,21)\end{array}$ & $\begin{array}{l}148,32 \\
(98,26)\end{array}$ & $\begin{array}{l}123,97 \\
(114,62)\end{array}$ & $\begin{array}{l}81,43 \\
(69,22)\end{array}$ & $\begin{array}{l}70,06 \\
(88,87)\end{array}$ \\
\hline & Controle & $\begin{array}{l}13,38 \\
(8,53)\end{array}$ & $\begin{array}{l}47,37 \\
(44,61)\end{array}$ & $\begin{array}{l}82,63 \\
(47,86)\end{array}$ & $\begin{array}{l}165,62 \\
(84,32)\end{array}$ & $\begin{array}{l}95,93 \\
(67,70)\end{array}$ & $\begin{array}{l}79,10 \\
(56,60)\end{array}$ & $\begin{array}{l}56,30 \\
(47,24)\end{array}$ & $\begin{array}{l}37,22 \\
(30,72)\end{array}$ \\
\hline \multirow[t]{2}{*}{$\begin{array}{l}\text { IL-10 } \\
\text { (pg/ml) }\end{array}$} & Aprotinina & $\begin{array}{c}19,42 \\
(18,17)\end{array}$ & $\begin{array}{l}66,46 \\
(82,38)\end{array}$ & $\begin{array}{l}69,04 \\
(68,14)\end{array}$ & $\begin{array}{l}266,30 \\
(250,17)\end{array}$ & $\begin{array}{l}52,83 \\
(35,31)\end{array}$ & $\begin{array}{l}57,57 \\
(41,42)\end{array}$ & $\begin{array}{l}31,62 \\
(17,57)\end{array}$ & $\begin{array}{l}22,15 \\
(14,36)\end{array}$ \\
\hline & Controle & $\begin{array}{c}10,77 \\
(10,43)\end{array}$ & $\begin{array}{l}31,41 \\
(17,32)\end{array}$ & $\begin{array}{l}156,48 \\
(262,12)^{\mathbf{a}}\end{array}$ & $\begin{array}{l}449,72 \\
(659,08)\end{array}$ & $\begin{array}{l}28,10 \\
(16,22)\end{array}$ & $\begin{array}{l}34,17 \\
(24,73)\end{array}$ & $\begin{array}{l}17,84 \\
(14,42)\end{array}$ & $\begin{array}{l}20,44 \\
(11,66)\end{array}$ \\
\hline \multirow[t]{2}{*}{ IL-6/IL 10} & Aprotinina & $\begin{array}{l}19,15 \\
(31,99)\end{array}$ & $\begin{array}{l}6,54 \\
(9,97)\end{array}$ & $\begin{array}{l}3,81 \\
(3,53)\end{array}$ & $\begin{array}{l}3,99 \\
(4,23)\end{array}$ & $\begin{array}{l}13,25 \\
(13,25)\end{array}$ & $\begin{array}{l}11,73 \\
(13,65)\end{array}$ & $\begin{array}{l}13,66 \\
(14,08)\end{array}$ & $\begin{array}{l}10,59 \\
(14,07)\end{array}$ \\
\hline & Controle & $\begin{array}{l}5,73 \\
(7,6)\end{array}$ & $\begin{array}{l}3,27 \\
(3,49)\end{array}$ & $\begin{array}{l}3,80 \\
(5,40)\end{array}$ & $\begin{array}{l}3,12 \\
(4,49)\end{array}$ & $\begin{array}{l}14,07 \\
(14,97)\end{array}$ & $\begin{array}{l}10,75 \\
(7,97)\end{array}$ & $\begin{array}{l}20,58 \\
(16,74)\end{array}$ & $\begin{array}{l}12,10 \\
(11,43)\end{array}$ \\
\hline \multirow[t]{2}{*}{$\begin{array}{l}\text { cTnI } \\
(\mathrm{ng} / \mathrm{ml})\end{array}$} & Aprotinina & $\begin{array}{l}0,20 \\
(0,00)\end{array}$ & $\begin{array}{l}1,18 \\
(0,69)\end{array}$ & $\begin{array}{l}11,22 \\
(19,08)\end{array}$ & $\begin{array}{l}19,04 \\
(27,93)\end{array}$ & $\begin{array}{l}14,35 \\
(12,17)\end{array}$ & $\begin{array}{l}18,29 \\
(17,32)\end{array}$ & $\begin{array}{l}15,67 \\
(13,86)\end{array}$ & $\begin{array}{l}9,07 \\
(8,45)\end{array}$ \\
\hline & Controle & $\begin{array}{l}0,20 \\
(0,00)\end{array}$ & $\begin{array}{l}1,36 \\
(0,91)\end{array}$ & $\begin{array}{l}4,86 \\
(2,52)\end{array}$ & $\begin{array}{l}10,76 \\
(4,72)\end{array}$ & $\begin{array}{l}18,82 \\
(8,43)\end{array}$ & $\begin{array}{l}13,08 \\
(10,23)\end{array}$ & $\begin{array}{l}9,64 \\
(6,70)\end{array}$ & $\begin{array}{l}5,06 \\
(4,40)\end{array}$ \\
\hline \multirow[t]{2}{*}{$\begin{array}{l}\text { Nt-proBNP } \\
(\mathbf{f m o l} / \mathbf{m l})\end{array}$} & $\begin{array}{l}\text { Aprotinina } \\
\text { Aprotinina }^{\mathbf{b}}\end{array}$ & $\begin{array}{l}403,64 \\
(401,1) \\
283,54 \\
(136,87)\end{array}$ & $\begin{array}{l}329,09 \\
(450,53) \\
207,04 \\
(246,59)^{a}\end{array}$ & $\begin{array}{l}437,02 \\
(648,63) \\
236,35 \\
(142,47)\end{array}$ & $\begin{array}{l}1692,96 \\
(4537,90) \\
259,31 \\
(\mathbf{2 1 0 , 2 9 )}\end{array}$ & $\begin{array}{l}773,11 \\
(692,76) \\
580,74 \\
(351,63)\end{array}$ & $\begin{array}{l}1282,23 \\
(888,01) \\
1061,00 \\
(580,11)\end{array}$ & $\begin{array}{l}1015,66 \\
(490,24) \\
868,63 \\
(164,95)\end{array}$ & $\begin{array}{l}876,42 \\
(427,43) \\
794,84 \\
(374,61)\end{array}$ \\
\hline & Controle & $\begin{array}{l}380,8 \\
(324,84)\end{array}$ & $\begin{array}{l}390,41 \\
(276,28)\end{array}$ & $\begin{array}{l}278,92 \\
(184,56)\end{array}$ & $\begin{array}{l}291,88 \\
(235,42)\end{array}$ & $\begin{array}{l}471,99 \\
(427,42)\end{array}$ & $\begin{array}{l}1245,78 \\
(1118,67)\end{array}$ & $\begin{array}{l}1015,94 \\
(795,97)\end{array}$ & $\begin{array}{l}885,88 \\
(963,82)\end{array}$ \\
\hline
\end{tabular}

Dados são média + Desvio-padrão; Aprotinina (n=10); Controle (n=9).

a $\mathbf{p}<\mathbf{0 , 0 5}$ aprotinina vs controle

b Excluindo paciente $\mathrm{n}^{\mathbf{0}} 10$ do grupo aprotinina, devido aos valores muito discrepantes em relação a todos os outros pacientes dos dois grupos (T1=1484,5; T2=1427,4; T3=2243; T4=14596; T5=2504,3; T6=3273,3; T7=2338,8; T8=1529,1fmol/.ml).

Tempos: T1: Após indução da anestesia, antes do início da administração da Aprotinina; T2 - 15 min após o início da CEC; T3 - Imediatamente antes do término da CEC; T4 - Cinco min após a administração de protamina; T5 - Quatro h após T4; T6 - Doze h após T4; T7 - Vinte e quatro h após T4; T8 - Quarenta e oito h após T4. 
TABELA 51. Definições das Disfunções Orgânicas (GOLDSTEIN, 2005)

Choque, definido no âmbito de disfunção cardiovascular, apesar da infusão de fluidos isotônicos EV > 40ml/kg em 1 hora, hipotensão (Pressão sistólica $<70 \mathrm{mmHg}$ em crianças 1 mês a 1 ano e $<70+2 \times$ a idade em anos para crianças > 1 ano - 10 anos, segundo Suporte Avançado de Vida em Pediatria - SAVP) ou necessidade de droga vasoativa para manter a pressão arterial (dopamina $>5 \mu \mathrm{g} / \mathrm{kg} / \mathrm{min}$ ou dobutamina ou epinefrina ou norepinefrina em qualquer dose)

Disfunção cardiovascular: além do referido acima, ou dois dos seguintes itens: - acidose metabólica inexplicada

- aumento do lactato arterial $>2$ vezes o limite superior

- oligúria - débito urinário $<0,5 \mathrm{ml} / \mathrm{kg} / \mathrm{hora}$

- enchimento capilar prolongado; $>5$ segundos

- diferença entre temperatura central e periférica $>3^{\circ} \mathrm{C}$

Disfunção renal - clinicamente pela presença de oligo-anúria, ou creatinina sérica $\geq 2$ vezes o valor superior de normalidade para idade ou com aumento de 2 vezes na creatinina de base

Disfunção respiratória: necessidade de ventilação mecânica ou necessidade de FiO2 $>50 \%$ para saturação $\geq$ $92 \%$ ou paCO2 $>20 \mathrm{mmHg}$ da $\mathrm{PaCO} 2$ de base ou $\mathrm{PaO} 2 / \mathrm{FiO} 2<300$ na ausência de cardiopatia cianogênica ou doença pulmonar preexistente

Disfunção hematológica: plaquetas $<80000 / \mathrm{mm}^{3}$ ou queda de $50 \%$ da contagem plaquetária a partir do valor mais alto registrado nos 3 dias prévios

Disfunção neurológica: escala de coma de Glasgow $\leq 11$ ou mudança aguda no estado mental com queda na escala de Glasgow $\geq 3$ pontos da linha de base (GGOLDSTEIN,2005).

Disfunção hepática: bilirrubina total $>4 \mathrm{mg} / \mathrm{dl}$ (não válido para recém-nascidos) e ALT com valor 2 vezes acima do limite superior para a idade (SRIS)

\section{Critérios para o diagnóstico da Síndrome da Resposta Inflamatória Sistêmica}

A primeira tentativa de sistematização bem sucedida, embora ainda não ideal e criticada até hoje por muitos autores, surgiu em agosto de 1991. Foi resultado da Conferência de Consenso sobre Sepse, ocorrida em Northbrook (Illinois, EUA), sob o patrocínio do American College of Chest Physicians (ACCP) e da Society of Critical Care Medicine (SCCM). Nesse fórum, foi proposto um novo termo - Síndrome da Resposta Inflamatória Sistêmica (SRIS) - para designar a reação inflamatória do organismo humano a uma série de agressões, infecciosas localizadas ou generalizadas, trauma, lesão térmica ou processos inflamatórios estéreis, adotando-se como ponto de corte para a caracterização do envolvimento sistêmico a presença de alterações (pelo menos duas) em valores de temperatura, freqüência cardíaca, freqüência respiratória e leucograma (BONE, 1992). O termo SRIS provém uma referência para os complexos achados que resultam de uma ativação sistêmica da resposta imune inata, independentemente da causa (LEVY, 2003).

De acordo com a Conferência de Consenso do ACCP-SCCM, a SRIS consiste na resposta inflamatória sistêmica a uma variedade de insultos clínicos graves, infecciosos ou não, sendo essa resposta manifestada por duas ou mais das seguintes condições:

- $\quad$ Temperatura $>38^{\circ} \mathrm{C}$ ou $<36^{\circ} \mathrm{C}$

- $\quad$ Freqüência cardíaca $>90$ batimentos/min

- Freqüência respiratória $>20$ movimentos $/ \mathrm{min}$ ou $\mathrm{PaCO} 2<32 \mathrm{mmHg}(<4,3 \mathrm{kPa})$ (hiperventilação)

- Contagem de leucócitos $>12.000$ células $/ \mathrm{mm} 3$, ou $<4.000$ células $/ \mathrm{mm} 3$ ou $>10 \%$ de formas jovens

Quando essa resposta está associada a uma infecção documentada, diz-se que o paciente encontra-se em sepse e, se a sepse é acompanhada de disfunção orgânica, sinais de hipoperfusão (acidose, oligúria, alteração aguda do estado mental, entre outros) ou hipotensão (PA sistólica $<90 \mathrm{mmHg}$ ou redução de $>40 \mathrm{mmHg}$ da linha de base, na ausência de outras causas) está caracterizada a sepse grave. Por outro lado, fala-se em choque séptico se a sepse grave cursa com hipotensão, a despeito de adequada reposição volumétrica, associada à presença de anormalidades da perfusão (pacientes que estão sob ação de agentes inotrópicos podem não estar hipotensos no momento em que as anormalidades da perfusão são mensuradas). Se há disfunção orgânica em que a homeostasia não pode ser mantida sem intervenção, caracteriza-se a síndrome da disfunção de múltiplos órgãos (BONE,1992).

Uma Conferência Internacional de Consenso em Sepsis Pediátrica, realizada em 2002 no Texas (EUA) (GOLDSTEIN, 2005), avaliaram as variáveis clínicas utilizadas para definir SRIS e disfunção orgânica são muito afetadas pelas alterações fisiológicas que ocorrem com a idade da criança. Propuseram seis grupos de idade fisiologicamente significativos para sinais vitais e dados laboratoriais idade- específicos para os critérios de SIRS, como específica na tabela abaixo. 
TABELA 52. Grupos de idade pediátrica para definições de sepsis severa

\begin{tabular}{|l|l|}
\hline Recém- nascido & 0 dias a 1 semana \\
Neonato & 1 semana a 1 mês \\
Lactente & 1 mês a 1 ano \\
Criança pré- escolar & 2 a 5 anos \\
Criança idade escolar & 6 a 12 anos \\
Adolescente ou adulto jovem & 13 a < 18 anos \\
\hline
\end{tabular}

Estes grupos de idade foram determinados por uma combinação de riscos idade-específicos para infecções invasivas, recomendações de tratamento antibiótico idade-específicos e alterações fisiológicas no desenvolvimento cardiorrespiratório.

Embora as recomendações básicas de BONE et al (1992) para a definição de SRIS sejam aplicáveis à população pediátrica, taquicardia e taquipnéia são sintomas comumente presentes de muitos processos de doença pediátrica. Por conseguinte, a principal diferença na definição de SIRS entre adultos e crianças é que o diagnóstico de SRIS pediátrica necessita que anormalidades de temperatura ou de leucócitos sejam presentes (ou seja, SRIS não deve ser diagnosticada se um paciente pediátrico exibe somente freqüências cardíacas e respiratórias elevadas) (GOLDSTEIN, 2005). Em adição, valores numéricos para cada critério necessitam ser modificados considerando a diferença fisiológica das crianças. Finalmente, bradicardia pode ser um sinal de SRIS no grupo etário de recém-nascido, mas não na criança mais velha (no qual é um evento próximo ao terminal).

TABELA 53. Definições de síndrome da resposta inflamatória sistêmica (SRIS) SRIS

A presença de ao menos dois dos seguintes critérios, um dos quais deve ser temperatura ou contagem leucocitária anormal:

Temperatura central de $>38,5^{\circ} \mathrm{C}$ ou $<36^{\circ} \mathrm{C}$

Taquicardia, definida como freqüência cardíaca média >2SD acima do normal para a idade na ausência de estímulo externo, drogas de uso crônico ou estímulos dolorosos; ou elevação persistente inexplicável de outra maneira acima de um período de tempo de 0,5 a 4 horas ou para crianças < 1 ano: bradicardia, definida como uma freqüência cardíaca média $<10^{\text {th }}$ percentil para a idade na ausência de estímulo vagal externo, drogas $\beta$-bloqueadoras, ou doença cardíaca congênita; ou depressão persistente inexplicável de outra forma acima de um período de tempo de meia hora.

Freqüência respiratória média $>2 \mathrm{SD}$ acima do normal para idade ou ventilação mecânica por um processo agudo não relacionado à doença neuromuscular subjacente ou sob anestesia geral.

Contagem leucocitária elevada ou deprimida para a idade (não secundária à leucopenia induzida por quimioterapia) ou $>10 \%$ neutrófilos imaturos.

TABELA 53. Sinais vitais e variáveis laboratoriais idade-específicas (valores inferiores para freqüência cardíaca, contagem leucocitária e pressão sangüínea sistólica estão no $5^{\text {th }}$ percentil e os valores superiores para freqüência cardíaca, freqüência respiratória ou contagem leucocitária no $95^{\text {th }}$ percentil)

\begin{tabular}{|l|c|c|c|c|c|}
\hline \multicolumn{1}{|c|}{ Grupo etário } & $\begin{array}{c}\text { Freqüência } \\
\text { cardíaca } \\
\text { Taquicardia } \\
\text { (batimentos/min) }\end{array}$ & $\begin{array}{c}\text { Freqüência } \\
\text { cardíaca } \\
\text { Bradicardia } \\
\text { (batimentos/min) }\end{array}$ & $\begin{array}{c}\text { Freqüência respiratória } \\
\text { (respirações/minuto) }\end{array}$ & $\begin{array}{c}\text { Contagem } \\
\text { leucocitária } \\
\text { (Leucócitos } x \\
10^{3} / \mathrm{mm}^{3}\end{array}$ & $\begin{array}{c}\text { Pressão } \\
\text { sangüínea } \\
\text { sistólica } \\
\text { (mmHg) }\end{array}$ \\
\hline 0 dias a 1 sem & $>180$ & $<100$ & $>50$ & $>34$ & $<65$ \\
1 sem a 1 mês & $>180$ & $<100$ & $>40$ & $>19,5$ ou $<5$ & $<75$ \\
1 mês a 1 ano & $>180$ & NA & $>34$ & $>17,5$ ou $<5$ & $<100$ \\
$2-5$ anos & $>140$ & NA & $>18$ & $>15,5$ ou $<6$ & $<94$ \\
$6-12$ anos & $>130$ & NA & $>14$ & $>11$ ou $<4,5$ & $<105$ \\
13 a <18anos & $>110$ & & & $>117$ \\
\hline
\end{tabular}

NA- não aplicável 


\section{Critérios para o diagnóstico da Síndrome do Extravasamento Capilar Sistêmico (SECS)}

A Síndrome do Extravasamento Capilar Sistêmico (SECS) foi definido como o desenvolvimento de edema generalizado não cardiogênico incluindo derrame pleural, ascite ou anasarca, e instabilidade da pressão sangüínea necessitando reposição volêmica, de acordo com SEGHAYE et al (1996).

Foi determinada no pós-operatório independente do diagnóstico de SRIS (de acordo com os critérios supracitados) dentro das 48 horas.

TABELA 54. Diagnóstico de Síndrome da Resposta Inflamatória Sistêmica (SRIS) e Síndrome do Extravasamento Capilar Sistêmico (SECS) no pós-operatório nos pacientes operados para correção de cardiopatia congênita nos grupos I aprotinina e II controle (BONE, 1992; GOLDSTEIN, 2005; SEGHAYE, 1996).

\begin{tabular}{|c|c|c|c|}
\hline $\begin{array}{l}\text { Grupo } \\
\text { aprotinina }\end{array}$ & $\begin{array}{l}\text { Critérios principais para SRIS e/ou SECS } \\
\text { até } 48 \text { horas (T8) }\end{array}$ & $\begin{array}{l}\text { Diagnóstico SRIS até } \\
\text { T8/ após T8 }\end{array}$ & SECS \\
\hline 1 & $\begin{array}{l}\mathrm{PS}<100, \mathrm{VM}, \mathrm{FC}>180, \mathrm{~T}>38,5^{\circ} \mathrm{C}(\mathrm{T} 5) \\
\text { Anasarca / Ascite } \\
\text { Derrame pleural }\end{array}$ & $\begin{array}{l}\text { SRIS } \\
\text { Infecção cirúrgica } 29^{\circ} \mathrm{PO} \\
\text { Pneumonia } 33^{\circ} \mathrm{PO} \\
\end{array}$ & SECS \\
\hline 7 & $\begin{array}{l}\mathrm{PS}<100, \mathrm{FC}>180 \\
\text { Anasarca }\end{array}$ & Pneumonia $6^{\circ} \mathrm{PO}$ & SECS \\
\hline 13 & Leuc > 17500 (23600 T7) & - & - \\
\hline 24 & Leuc $>17500(18000$ T7) & - & - \\
\hline 25 & $\begin{array}{l}\mathrm{PS}<100, \mathrm{VM}, \text { leuc }>17500 \text { (17700 T5), T > } \\
38,5^{\circ} \mathrm{C} \text { (após } 70 \text { h PO) }\end{array}$ & SRIS & - \\
\hline 32 & $\begin{array}{l}\mathrm{PS}<100, \mathrm{VM}, \text { Leuc }>17500 \text { (25300 T6) } \\
\text { Anasarca / Ascite / Derrame pleural }\end{array}$ & SRIS & SECS \\
\hline 35 & Leuc >17500 (20700 T5) & - & - \\
\hline 37 & - & - & - \\
\hline 40 & $\mathrm{~T}>38,5^{\circ} \mathrm{C}\left(39^{\circ} \mathrm{C} 10 \mathrm{~h} \mathrm{PO}\right)$ & - & - \\
\hline 45 & $\begin{array}{l}\mathrm{PS}<100, \mathrm{FC}>180 \\
\text { Anasarca }\end{array}$ & - & SECS \\
\hline \multicolumn{4}{|l|}{$\begin{array}{l}\text { Grupo } \\
\text { controle }\end{array}$} \\
\hline 3 & $\mathrm{~T}>38,5^{\circ} \mathrm{C}\left(38,8^{\circ} \mathrm{C} 14 \mathrm{~h} \mathrm{PO}\right)$ & - & - \\
\hline 6 & $\mathrm{PS}<100, \mathrm{VM}, \mathrm{T}<36^{\circ} \mathrm{C}(\mathrm{T} 5 \mathrm{a} \mathrm{T} 6)$ & SRIS & - \\
\hline 10 & - & - & - \\
\hline 11 & Leuc $>17500(18700 \mathrm{~T} 7), \mathrm{T}>38,5^{\circ} \mathrm{C}(\mathrm{T} 6, \mathrm{~T} 7)$ & $\begin{array}{l}\text { SRIS } \\
\text { Traqueobronquite aguda } 5^{\circ} \\
\text { PO }\end{array}$ & - \\
\hline 12 & - & - & - \\
\hline 34 & $\begin{array}{l}\mathrm{PS}<100, \mathrm{VM}, \quad \mathrm{FC}>180, \text { Leuc }>17500 \\
(23300 \mathrm{~T} 7), \mathrm{T}>38,5(\mathrm{~T} 5, \mathrm{~T} 7) \\
\text { Anasarca / derrame pleural }\end{array}$ & $\begin{array}{l}\text { SRIS } \\
\text { Pneumonia } 1^{\circ} \mathrm{PO}\end{array}$ & SECS \\
\hline 36 & $\mathrm{~T}>38,5^{\circ} \mathrm{C}$ & - & - \\
\hline 49 & Leuc $>17500(22800 \mathrm{~T} 6), \mathrm{T}<36^{\circ} \mathrm{C}(\mathrm{T} 8)$ & SRIS & - \\
\hline 53 & $\begin{array}{l}\mathrm{PS}<100, \mathrm{VM}, \mathrm{FC}>180 \\
\text { Anasarca / derrame pleural }\end{array}$ & - & SECS \\
\hline
\end{tabular}

$<=$ menor que; > = maior que; PS = pressão sistólica $(\mathrm{mmHg}) ; \mathrm{FC}=$ freqüência cardíaca (bpm); T = temperatura $\left({ }^{\circ} \mathrm{C}\right) ; \mathrm{PO}=$ pós-operatório; Leuc = leucócitos (células $\left./ \mathrm{mm}^{3}\right) ; \mathrm{VM}=$ ventilação pulmonar mecânica; T5, T6, T7, T8 tempos de coleta de sangue e de dados clínicos (vide Material e Métodos) 
TABELA 55: Comparação entre indivíduos que apresentaram SIRS e/ou SECS contra os que não apresentaram dentro do grupo tratamento.

\begin{tabular}{cccc}
\hline Variável & \multicolumn{2}{c}{ Mediana $\left(1 . .^{\circ}\right.$ Quartil;3..$^{\circ}$ Quartil) } & SIRS $\times$ Não SIRS \\
& SIRS e/ou SECS & Não SIRS e/ou SECS & P-valor \\
\hline VM (h) & $144,00(123,00 ; 168,00)$ & $11,00(3,50 ; 19,50)$ & 0,02 \\
CTIP (d) & $7,00(6,00 ; 12,00)$ & $2,00(2,00 ; 3,75)$ & 0,11 \\
Int. Hosp (d) & $9,00(8,00 ; 14,00)$ & $5,00(4,75 ; 8,00)$ & 0,18 \\
Inotrópico (h) & $144,00(144,00 ; 312,00)$ & $48,00(36,00 ; 54,00)$ & 0,02 \\
Escore Inotrópico I & $6,00(6,00 ; 10,00)$ & $2,00(1,50 ; 2,00)$ & 0,02 \\
Escore Inotrópico II & $35,00(30,00 ; 57,00)$ & $4,50(3,00 ; 7,50)$ & 0,02 \\
\hline
\end{tabular}

TABELA 56: Comparação entre indivíduos que apresentaram SIRS e/ou SECS contra os que não apresentaram dentro do grupo controle.

\begin{tabular}{|c|c|c|c|}
\hline \multirow{2}{*}{ Variável } & \multicolumn{2}{|c|}{ Mediana (1.0 Quartil;3.º Quartil) } & \multirow{2}{*}{$\begin{array}{l}\text { SIRS } \times \text { Não SIRS } \\
\text { P-valor }\end{array}$} \\
\hline & SIRS e/ou SECS & Não SIRS elou SECS & \\
\hline VM (h) & $72,00(39,00 ; 264,00)$ & $6,00(3,00 ; 10,00)$ & 0,11 \\
\hline CTIP (d) & $5,00(3,00 ; 12,00)$ & $1,80(1,58 ; 2,42)$ & 0,29 \\
\hline Int. Hosp (d) & $8,00(7,00 ; 16,00)$ & $4,00(3,00 ; 5,75)$ & 0,21 \\
\hline Inotrópico (h) & $48,00(17,00 ; 192,00)$ & $41,00(31,75 ; 55,75)$ & 0,99 \\
\hline Escore Inotrópico I & $2,00(0,00 ; 6,00)$ & $2,00(2,00 ; 2,00)$ & 0,99 \\
\hline Escore Inotrópico II & $7,50(0,00 ; 30,00)$ & $4,50(4,00 ; 5,00)$ & 0,71 \\
\hline
\end{tabular}

TABELA 57: Comparação entre indivíduos que apresentaram SIRS e/ou SECS entre os grupos tratamento e controle.

\begin{tabular}{cccc}
\hline Variável & \multicolumn{2}{c}{ Mediana $\left(1 .^{\circ}\right.$ Quartil;3. ${ }^{\circ}$ Quartil) } & SIRS x Não SIRS \\
& Tratamento & Controle & P-valor \\
\hline VM (h) & $144,00(123,00 ; 168,00)$ & $72,00(39,00 ; 264,00)$ & 0,75 \\
CTIP (d) & $7,00(6,00 ; 12,00)$ & $5,00(3,00 ; 12,00)$ & 0,40 \\
Int. Hosp (d) & $9,00(8,00 ; 14,00)$ & $8,00(7,00 ; 16,00)$ & 0,83 \\
Inotrópico (h) & $144,00(144,00 ; 312,00)$ & $48,00(17,00 ; 192,00)$ & 0,21 \\
Escore Inotrópico I & $6,00(6,00 ; 10,00)$ & $2,00(0,00 ; 6,00)$ & 0,08 \\
Escore Inotrópico II & $35,00(30,00 ; 57,00)$ & $7,50(0,00 ; 30,00)$ & 0,09 \\
\hline
\end{tabular}

TABELA 58: Comparação entre indivíduos que não apresentaram SIRS e/ou SECS entre os grupos tratamento e controle.

\begin{tabular}{cccc}
\hline Variável & \multicolumn{2}{c}{$\begin{array}{c}\text { Mediana }\left(1 .{ }^{\circ} \text { Quartil;3. }{ }^{\circ} \text { Quartil) }\right. \\
\text { Tratamento }\end{array}$} & $\begin{array}{c}\text { SIRS } \times \text { Não SIRS } \\
\text { P-valor }\end{array}$ \\
\hline VM (h) & $11,0(3,50 ; 19,50)$ & $6.00(3,00 ; 10,00)$ & 0,56 \\
CTIP (d) & $2,00(2,00 ; 3,75)$ & $1,80(1,58 ; 2,42)$ & 0,36 \\
Int. Hosp (d) & $5,00(4,75 ; 8,00)$ & $4,00(3,00 ; 5,75)$ & 0,46 \\
Inotrópico (h) & $48,00(36,00 ; 54,00)$ & $41,00(31,75 ; 55,75)$ & 0,99 \\
Escore Inotrópico I & $2,00(1,50 ; 2,00)$ & $2,00(2.00 ; 2,00)$ & 0,45 \\
Escore Inotrópico II & $4,50(3,00 ; 7,50)$ & $4,50(4,00 ; 5,00)$ & 0,99 \\
\hline
\end{tabular}


TABELA 59. Avaliação ecoDopllercardiográfica das operações realizadas nos pacientes operados no grupos aprotinina.

\begin{tabular}{|c|c|c|c|}
\hline $\begin{array}{l}\text { PACIENTES } \\
\text { GRUPO } \\
\text { APROTININA }\end{array}$ & Operação realizada & PO & Resultado ecocardiográfico pós-operatório \\
\hline 1 & $\begin{array}{l}\text { ligadura canal arterial+ } \\
\text { ventriculosseptoplastia + } \\
\text { plastia valvar tricúspide }\end{array}$ & $\begin{array}{l}2^{\circ} \mathrm{PO} / \\
7^{\circ} \mathrm{PO}\end{array}$ & $\begin{array}{l}\text { Desempenho sistólico ventrículos preservado. } \\
\text { Dissinergia septal. Mínimo fluxo residual pelo } \\
\text { "patch" SIV. Fluxo residual canal arterial. } \\
\text { PSAP=27 mmHg. FE = 63\%. }\end{array}$ \\
\hline 7 & $\begin{array}{l}\text { ligadura canal arterial + } \\
\text { ventriculoseptoplastia + } \\
\text { atriosseptorrafia }\end{array}$ & $\begin{array}{l}17^{\circ} \mathrm{PO} \\
2 \text { anos } \mathrm{PO}\end{array}$ & $\begin{array}{l}\text { Hipertrofia leve VD. Septos íntegros, sem fluxo } \\
\text { residual. Valva tricúspide competente. } \\
\text { FE } 68 \% \text {. PSAP - } 32 \mathrm{mmHg} \text {. }\end{array}$ \\
\hline 13 & $\begin{array}{l}\text { ligadura canal arterial + } \\
\text { ventriculosseptoplastia tunelizando } \\
\text { VE- Ao + plastia tricúspide }\end{array}$ & $5^{\circ} \mathrm{PO}$ & $\begin{array}{l}\text { "Patch" SIV com fluxo residual apical e } \\
\text { subtricuspídeo, com gradiente VE-VD pico de } \\
60 \mathrm{mmHg} . \mathrm{FE}=51 \% \text {. }\end{array}$ \\
\hline 24 & $\begin{array}{l}\text { ligadura do canal arterial }+ \\
\text { Comissurotomia valvar pulmonar }\end{array}$ & $5^{\circ} \mathrm{PO}$ & $\begin{array}{l}\text { Valva pulmonar com leve espessamento } \\
\text { folhetos, gradiente sistólico VD/TP } 27 \text { (pico) e } \\
13 \mathrm{mmHg} \text { (médio). Desempenho sistólico } \\
\text { normal dos ventrículos. FE = 64\%. } \\
\text { Gradiente sistólico VD-TP } 20 \mathrm{mmHg} \text {. Insuf } \\
\text { Pulm leve. }\end{array}$ \\
\hline 25 & $\begin{array}{l}\text { Ligadura PCA + } \\
\text { Ventriculosseptoplastia tunelizando } \\
\text { VE- Ao }\end{array}$ & $8^{\circ} \mathrm{PO}$ & $\begin{array}{l}\text { Desempenho ventrículos preservado. } \\
\text { Dissinergia septal. Fluxo residual pelo "patch" } \\
\text { SIV em ambas extremidades. Dilatação leve } \\
\text { câmaras direitas. FE }=75 \% \text {. }\end{array}$ \\
\hline 32 & $\begin{array}{l}\text { Ventriculosseptoplastia + } \\
\text { remoção do segmento de bandagem } \\
\text { da artéria pulmonar e anastomose } \\
\text { término-terminal + fechamento FOP }\end{array}$ & $14^{\circ} \mathrm{PO}$ & $\begin{array}{l}\text { Desempenho sistólico dos ventrículos } \\
\text { preservado. "patch" SIV sem fluxo residual. }\end{array}$ \\
\hline 35 & $\begin{array}{l}\text { ligadura PCA + } \\
\text { fechamento "cleft" mitral + } \\
\text { atriosseptoplastia para correção } \\
\text { do DSAV parcial + } \\
\text { atriosseptorrafia }\end{array}$ & $5^{\circ} \mathrm{PO}$ & $\begin{array}{l}\text { Desempenho sistólico preservado dos } \\
\text { ventrículos. Dissinergia septal. Desempenho } \\
\text { sistólico VD deprimido grau moderado. } \\
\text { Insuficiência valva AV esquerda moderada. } \\
\text { Insuficiência valva AV direita leve. PSAP = } 60 \\
\text { mmHg. HP moderada/ acentuada. SIV } \\
\text { retificado. Septos sem fluxo residual. FE =84\% } \\
\text { Desempenho sistólico ventrículos preservados. } \\
\text { Insuficiência moderada valva AV esquerda. } \\
\text { Sem HP. FE }=71 \% \text {. }\end{array}$ \\
\hline 37 & $\begin{array}{l}\text { ligadura canal arterial + } \\
\text { ventriculosseptoplastia + } \\
\text { inspeção da valva pulmonar }\end{array}$ & $29^{\circ} \mathrm{PO}$ & $\begin{array}{l}\text { Desempenho sistólico ventrículos preservado. } \\
\text { Septos íntegros, sem "shunts". Valva pulmonar } \\
\text { com estenose discreta, com gradiente VD-TP } \\
\text { pico } 14 \text { e médio de } 6 \mathrm{mmHg} \text {. FE }=67 \% \text {. }\end{array}$ \\
\hline 40 & $\begin{array}{l}\text { ligadura canal arterial + } \\
\text { ventriculosseptoplastia + } \\
\text { atriosseptorrafia }\end{array}$ & $13^{\circ} \mathrm{PO}$ & $\begin{array}{l}\text { Desempenho ventrículos preservados. Valva } \\
\text { pulmonar com estenose discreta, gradiente } \\
\text { VD-TP pico } 17 \mathrm{mmHg} \text { e médio de } 9 \mathrm{mmHg} \text {. } \\
\text { Pontos de fluxo pelo SIV, de } 1,5 \text { e } 2,0 \mathrm{~mm} \text {. }\end{array}$ \\
\hline 45 & $\begin{array}{l}\text { ligadura canal arterial + } \\
\text { ampliação transanular pulmonar } \\
\text { por } 1 \mathrm{~cm} \text { e ressecção de } \\
2 \text { dos } 3 \text { folhetos pulmonares e } \\
\text { reconstrução com selo de } \\
\text { pericárdio bovino +fechamento FOP. }\end{array}$ & $2^{\circ} \mathrm{PO}$ & $\begin{array}{l}\text { VD com hipertrofia acentuada e desempenho } \\
\text { sistólico preservado. VSVD com hipertrofia } \\
\text { infundibular, sem gradiente. Gradiente VD-TP } \\
\text { residual leve, sendo } 18 \text { de pico e } 9 \mathrm{mmHg} \\
\text { médio. Insuf Pulm leve/moderada. Câmaras } \\
\text { esquerdas normais. }\end{array}$ \\
\hline
\end{tabular}


TABELA 60. Avaliação ecoDopllercardiográfico das operações realizadas nos pacientes do Grupos Controle.

\begin{tabular}{|c|c|c|c|}
\hline $\begin{array}{l}\text { PACIENTES } \\
\text { GRUPO } \\
\text { CONTROLE }\end{array}$ & Operação realizada & PO & Resultado ecocardiográfico pós-operatório \\
\hline 3 & $\begin{array}{l}\text { ligadura do canal arterial + } \\
\text { ventriculosseptoplastia + plastia } \\
\text { valvar tricúspide }\end{array}$ & $\begin{array}{l}2^{\circ} \mathrm{PO} / \\
5^{\circ} \text { mês } \mathrm{PO}\end{array}$ & $\begin{array}{l}\text { Desempenho sistólico preservado dos } \\
\text { ventrículos. Dissinergia septal. CIV residual de } \\
2-3 \mathrm{~mm} \text {, com gradiente VE-VD de } 64 \mathrm{mmHg} \text {. } \\
\text { PSAP }=23 \mathrm{mmHg} \text {. IT discreta. FE }=72 \% \text {. }\end{array}$ \\
\hline 6 & $\begin{array}{l}\text { ligadura do canal arterial }+ \\
\text { ventriculosseptoplastia }+ \\
\text { atriosseptorrafia }\end{array}$ & $8^{\circ} \mathrm{PO}$ & $\begin{array}{l}\text { "Patch" SIV sem “shunt". Ventrículos } \\
\text { preservados. PSAP = } 45 \mathrm{mmHg} \text {. }\end{array}$ \\
\hline 10 & $\begin{array}{l}\text { clipagem do ligamento arterial + } \\
\text { ventriculosseptoplastia + plastia } \\
\text { valvar tricúspide }\end{array}$ & $5^{\circ 0} \mathrm{PO}$ & $\begin{array}{l}\text { Desempenho sistólico preservado dos } \\
\text { ventrículos. Dilatação leve global das câmaras } \\
\text { cardíacas. Hipertrofia concêntrica VE. "Shunt" } \\
\text { residual pelo SIV de } 1,8 \mathrm{~mm} \text { com fluxo VE-VD. } \\
\text { FE }=59 \% \text {. }\end{array}$ \\
\hline 11 & atriosseptorrafia & $3^{\circ} \mathrm{PO}$ & $\begin{array}{l}\text { Dilatação moderada das câmaras direitas. } \\
\text { Septo interatrial íntegro. IT leve. PSAP }=18 \\
\mathrm{mmHg} . \mathrm{FE}=36 \% \text {. }\end{array}$ \\
\hline 12 & $\begin{array}{l}\text { ligadura do canal arterial + } \\
\text { ventriculosseptoplastia }+ \\
\text { ressecção membrana subaórtica + } \\
\text { plastia tricúspide }\end{array}$ & $\begin{array}{l}3^{\circ} \mathrm{PO} \\
2^{\circ} \text { mês PO }\end{array}$ & $\begin{array}{l}\text { Desempenho sistólico do VE no limite inferior } \\
\text { da normalidade. Sem fluxos pelos septos. FE= } \\
51 \% \\
\text { Desempenho sistólico VE no limite inferior da } \\
\text { normalidade. IAo leve, com jato excêntrico. FE } \\
=51 \% \text {. }\end{array}$ \\
\hline 34 & $\begin{array}{l}\text { ligadura do canal arterial + } \\
\text { ventriculosseptoplastia + plastia } \\
\text { valvar tricúspide }\end{array}$ & $6^{\circ} \mathrm{PO}$ & $\begin{array}{l}\text { Septos íntegros, sem "shunts". IT leve. PSAP } \\
=24 \mathrm{mmHg} . \mathrm{FE}=70 \% .\end{array}$ \\
\hline 36 & $\begin{array}{l}\text { ligadura do canal arterial + } \\
\text { ventriculosseptoplastia + plastia } \\
\text { valvar tricúspide }\end{array}$ & $4^{\circ} \mathrm{PO}$ & $\begin{array}{l}\text { Desempenho sistólico VE no limite inferior da } \\
\text { normalidade. "Patch" porção alta do SIV com } \\
\text { fluxo residual de } 2 \mathrm{~mm} \text {. }\end{array}$ \\
\hline 49 & $\begin{array}{l}\text { ligadura do canal arterial + } \\
\text { ventriculosseptoplastia + plastia } \\
\text { valvar tricúspide }\end{array}$ & $7^{\circ} \mathrm{PO}$ & $\begin{array}{l}\text { Desempenho sistólico ventricular preservado. } \\
\text { "Patch" porção alta do SIV com fluxo residual } \\
\text { de } 1 \mathrm{~mm} \text {. FE = 79\%. }\end{array}$ \\
\hline 53 & ventriculosseptoplastia & $16^{\circ} \mathrm{PO}$ & $\begin{array}{l}\text { Ventrículos preservados. CIV mínima residual } \\
\text { de } 2,2 \mathrm{~mm} \text {. IT leve. HP acentuada (PSAP = } 69 \\
\mathrm{mmHg} \text { ). FE }=88 \% \text {. }\end{array}$ \\
\hline
\end{tabular}


TABELA 61. Quadro descritivo das complicações respiratórias dos pacientes do Grupo aprotinina

\begin{tabular}{|c|}
\hline $\begin{array}{l}\text { Derrame pleural (DP): } \\
\text { Criança de } 137 \text { dias com síndrome de Down (caso } 1 \text { ), operada para correção de CIV e PCA, que desenvolveu } \\
\text { P direito no } 2^{\circ} \text { dia PO; } \\
\text { Criança de } 408 \text { dias (caso } 32 \text { ), com dois procedimentos prévios por toracotomia esquerda para correção de } \\
\text { parctação de aorta, operada para correção de CIV e remoção da bandagem pulmonar, que desenvolveu DP direito no } \\
\text { dia PO; em ambos os casos o derrame pleural resolveu espontaneamente em poucos dias, sem colocar dreno } \\
\text { rácico. }\end{array}$ \\
\hline $\begin{array}{l}\text { Atelectasia pulmonar: } \\
\text { Atelectasia pulmonar esquerda no POI da criança de } 137 \text { dias com síndrome de Down (caso 1), operada } \\
\text { para correção de CIV e PCA, resolvido com reposicionamento da cânula endotraqueal e fisioterapia; } \\
\text { Atelectasia base pulmonar esquerda e hiperinsuflação pulmonar direita, no } 8^{\circ} \text { dia de PO da criança de } 408 \\
\text { dias (caso 32), supramencionado, que resolveu com fisioterapia; } \\
\text { Atelectasia da base e ápice pulmonar direito no } 5^{\circ} \text { dia de PO em criança de } 109 \text { dias (caso 40), operada para } \\
\text { correção de CIVs múltiplas, CIA e PCA, resolvido com fisioterapia; } \\
\text { Atelectasia ápice pulmonar direito no } 1^{\circ} \text { PO de criança de } 33 \text { dias (caso 45), operada para correção de EPV e } \\
\text { PCA, que resolveu com fisioterapia. } \\
\text { Atelectasia de terço inferior de pulmão esquerdo no } 17^{\circ} \text { PO da criança de } 110 \text { dias (caso } 37 \text { ) operada para } \\
\text { correção de CIV e PCA, decorrente de eventração diafragmática por paresia nervo frênico esquerdo, avaliada por } \\
\text { fluoroscopia (movimentação paradoxal cúpula diafragmática esquerda). }\end{array}$ \\
\hline $\begin{array}{l}\text { Edema de glote levando ao estridor alto e sibilos no } 1^{\circ} \text { e } 2^{\circ} \text { dia de pós-operatório, na criança de } 189 \text { dias (caso } \\
\text { 3) operada para correção de DVSVD e PCA, que resolveu com tratamento clínico (inalação com adrenalina). }\end{array}$ \\
\hline $\begin{array}{l}\text { Pneumonia: } \\
\text { Pneumonia em base pulmonar e lobo médio do pulmão direito no } 33^{\circ} \text { PO, na criança de } 137 \text { dias com } \\
\text { síndrome de Down (caso 1), operada para correção de CIV e PCA com boa evolução após tratamento antibiótico por } \\
14 \text { (quatorze) dias; } \\
\text { Pneumonia com aspecto radiográfico de velamento pulmonar direito, no } 6^{\circ} \text { PO da criança de } 47 \text { dias (caso } 7 \text { ) } \\
\text { operada para correção de CIV e CIA, com boa evolução com tratamento antibiótico por } 8 \text { (oito) dias; } \\
\text { Pneumonia de ápice pulmonar esquerdo no } 3^{\circ} \text { PO de criança de } 408 \text { dias (caso 32), com dois procedimentos } \\
\text { prévios por toracotomia esquerda para correção de coarctação de aorta, operada para correção de CIV e remoção da } \\
\text { bandagem pulmonar, com boa evolução com tratamento antibiótico por } 8 \text { (oito) dias; }\end{array}$ \\
\hline $\begin{array}{l}\text { Hipertensão pulmonar (HP) importante no } 1^{\circ} \mathrm{PO} \text {, na criança de } 47 \text { dias (caso } 7 \text { ), operada para correção de } \\
\text { IV e CIA, com medida direta de PAP média de } 36-40 \mathrm{mmHg} \text { e ecocardiográfica de } 50-60 \mathrm{mmHg} \text {, sendo iniciado } \\
\text { xido nítrico inalatório (NO), com redução da PAP para } 27 \mathrm{mmHg} \text {. No } 5^{\circ} \mathrm{PO} \text {, ocorreu efeito rebote após interrupção do } \\
\mathrm{JO} \text {, com aumento da PAP média para } 50 \mathrm{mmHg} \text {. Resolução da HP com suspensão do NO no } 9^{\circ} \mathrm{PO} \text {. }\end{array}$ \\
\hline $\begin{array}{l}\text { Hipoxemia aguda por distúrbio ventilatório: } \\
\text { Episódio de hipoxemia, dificuldade ventilatória e instabilidade hemodinâmica, no } 1^{\circ} \text { PO de criança de } 86 \text { dias } \\
\text { índrome de Pierre-Robin, operada para correção de DVSVD e PCA (caso 25), com troca de tubo endotraqueal e } \\
\text { oação com auxílio de fibroscópio, com melhora do quadro respiratório e hemodinâmico; } \\
\text { Episódio de hipoxemia, choque e FC de } 80 \text {, atividade elétrica sem pulso e parada cardíaca, no } 4^{\circ} \text { PO de criança } \\
8 \text { dias (caso 32) (com dois procedimentos prévios por toracotomia esquerda para correção de coarctação de } \\
\text { operada para correção de CIV e remoção da bandagem pulmonar, procedido massagem cardíaca externa, com } \\
\text { ão imediata. Observou-se secreção pulmonar obstrutiva da cânula endotraqueal. }\end{array}$ \\
\hline
\end{tabular}

\section{TABELA 62. Quadro descritivo das complicações respiratórias dos pacientes do} Grupo Controle:

Derrame pleural bilateral discreto no PO imediato em criança de 132 dias (caso 53) operada para correção de $\mathrm{CIV}$, que evoluiu com derrame pleural importante no $1^{\circ} \mathrm{PO}$, que regrediu progressivamente com tratamento clínico.

Atelectasia pulmonar direita no $10^{\circ} \mathrm{PO}$, em criança de 132 dias (caso 53) operada para correção de CIV, com boa evolução com fisioterapia.

Pneumonia:

Pneumonia no $1^{\circ} \mathrm{PO}$, em criança de 63 dias (caso 34) operada para correção de CIV e CIA, caracterizada por velamento pulmonar direito à radiografia de tórax, sendo iniciado antibioticoterapia; no $4^{\circ}$ PO evoluiu com velamento pulmonar esquerdo e apagamento do seio costofrênico direito à radiografia de tórax, sendo mantido tratamento até $15^{\circ} \mathrm{PO}$. No $20^{\circ} \mathrm{PO}$, evolução com taquidispnéia e necessidade de cateter de oxigênio suplementar por nova pneumonia hospitalar, sendo que na tomografia de tórax foram demonstradas bronquiectasias e padrão de vidro fosco. No $3^{\circ}$ mês de PO, confirmou-se bronquiolite obliterante.

Pneumonia com velamento de ápice pulmonar direito à radiografia de tórax, no $4^{\circ} \mathrm{PO}$ de criança de 132 dias (caso 53) operada para correção de CIV, com boa evolução com tratamento antibiótico por 10 dias.

Traqueobronquite aguda bacteriana no $5^{\circ} \mathrm{PO}$ da criança de 242 dias (caso 11) operada para correção de CIA, com boa evolução após tratamento com antibiótico.

\section{Hipertensão pulmonar (HP):}

Hipertensão pulmonar no $1^{\circ} \mathrm{PO}$ da criança de 63 dias (caso 34) operada para correção de CIV e CIA, sendo iniciado óxido nítrico (NO), com boa evolução e resolução no $6^{\circ} \mathrm{PO}$.

Hipertensão pulmonar no PO imediato, na criança de 132 dias (caso 53) operada para correção de CIV, com medida de PAP média de $40 \mathrm{mmHg}$, sendo iniciado $\mathrm{NO}$, com resolução no $9^{\circ} \mathrm{PO}$ 
TABELA 63. Quadro descritivo das complicações neurológicas que ocorreram apenas nos pacientes do Grupo Controle:

Agitação psicomotora e sonolência no PO imediato, na criança de 256 dias (caso 3), operada para correção de CIV, que apresentou boa evolução e regressão no $1^{\circ} \mathrm{PO}$.

Crise convulsiva parcial complexa no PO imediato, na criança de 77 dias (caso 49) operada para correção de CIV e PCA, com tremores, movimentos repetitivos de face, lábio inferior e língua, sendo iniciado e mantido com anticonvulsivante após a alta hospitalar.

Crise convulsiva generalizada tônico-clônica de membros superiores, 2 episódios, no $12^{\circ} \mathrm{PO}$, em criança de 132 dias operada para correção de CIV, sendo investigada com eletroencefalograma, demonstrando desorganização difusa de base sem paroxismos secundária à anóxia perioperatória, com ultrassonografia de crânio normal, sendo tratada com anticonvulsivante, não tendo mais episódios.

TABELA 64. Quadro descritivo das complicações cardíacas que ocorreram nos pacientes dos Grupos Aprotinina e Controle

Grupo Aprotinina

Bloqueio AV total no $5^{\circ} \mathrm{PO}$, em criança de 408 dias (caso 32) com dois procedimentos prévios por toracotomia esquerda para correção de coarctação de aorta, operada para correção de CIV e remoção da bandagem pulmonar, sendo necessário marcapasso provisório, com reversão espontânea no $8^{\circ}$ PO.

Episódios de bradicardia no $4^{\circ} \mathrm{PO}$, em criança de 86 dias (caso 25) operada por DVSVD e PCA, provavelmente associada à hipotermia, com boa evolução.

Grupo Controle

Taquicardia supraventricular paroxística (TSVP) no PO imediato, com Fc de 240 bpm e hipotensão, com reversão espontânea, na criança de 37 dias (caso 6) operada para correção de CIV, CIA e PCA. No $1^{\circ}$ PO apresentou novo episódio de TSVP com Fc de 250, revertido com adenosina.

TABELA 65. Quadro descritivo das complicações hemorrágicas que ocorreram apenas nos pacientes do Grupo Controle:

Sangramento pelo dreno mediastinal no PO imediato, na criança de 37 dias (caso 6) operada para correção de CIV, CIA e PCA, necessitando transfusão de concentrado de plaquetas, com boa evolução.

Sangramento pelo cateter de veia jugular e orifícios de punção no PO imediato, em criança de 1468 dias (caso 12), operada para correção de CIV e membrana subaórtica, necessitando transfusão de concentrado de plaquetas.

TABELA 66. Quadro descritivo das complicações da ferida cirúrgica (esternotomia) que ocorreram nos pacientes dos Grupos Aprotinina e Controle Grupo Aprotinina

Infecção superficial de pele e tecido celular subcutâneo da ferida cirúrgica da esternotomia, com saída de secreção amarelada no $29^{\circ}$ PO, em criança de 137 dias com síndrome de Down (caso 1), operada para correção de CIV e PCA, com cultura de secreção positiva para estafilococo "aureus", sensível à vancomicina.

Saída de secreção serosanguinolenta pelo terço distal da ferida cirúrgica da esternotomia no $3^{\circ} \mathrm{PO}$, em criança de 109 dias (caso 40), operada para correção de CIVs múltiplas, CIA e PCA, evoluindo no $5^{\circ}$ PO com deiscência de pele de cerca de $2 \mathrm{~cm}$, sem sinais de infecção, crepitação da esternotomia. No $7^{\circ} \mathrm{PO}$, apresentou deiscência da ferida cirúrgica, de pele, subcutâneo e deiscência parcial da esternotomia, com presença de fibrina, sem secreção purulenta, sendo reoperado para limpeza e fechamento do tórax. Boa evolução, sendo que no $40^{\circ} \mathrm{PO}$ apresentou granuloma de cicatriz cirúrgica com secreção serosanguinolenta.

Grupo Controle

Infecção superficial de ferida cirúrgica no $6^{\circ} \mathrm{PO}$, em criança de 63 dias (caso 34) operada para correção de CIV e CIA, sendo tratada com antibioticoterapia e tratamento local, com boa evolução.

Pseudoartrose de esterno detectado no $3^{\circ}$ Mês de PO, em criança de 185 dias (caso 36), operada para correção de CIV e PCA.

TABELA 66. Quadro descritivo de outras complicações que ocorreram apenas nos pacientes do Grupo Aprotinina

Monilíase oral diagnosticada no $17^{\circ} \mathrm{PO}$ em criança de 47 dias (caso 7) operada para correção de CIV e CIA.

Lesões fúngicas de pele, candidíase oral e perineal, com hemocultura negativa para fungos, em criança de 408 dias (caso 32) (com dois procedimentos prévios por toracotomia esquerda para correção de coarctação de aorta), operada para correção de CIV e remoção da bandagem pulmonar, tratada com anfotericina B, com boa evolução. 
TABELA 67. Quadro descritivo dos pacientes dos grupos Aprotinina e Controle que evoluíram com queda da depuração de creatinina abaixo de $50 \mathrm{ml} / \mathrm{min} / 1,73 \mathrm{~m}^{2}$ após $2^{\circ}$ dia pós-operatório.

\begin{abstract}
Grupo Aprotinina
Caso 7, criança de 47 dias e $3450 \mathrm{~g}$ de peso, operada para correção de CIV e CIA, que evoluiu no pósoperatório com choque e anasarca, necessidade de ventilação mecânica prolongada por 264 horas, óxido nítrico por 216 horas devido hipertensão pulmonar, e de inotrópicos por 312 horas, com escore inotrópico I de 6 e escore inotrópico II de 55, nas 48 horas após administração de protamina (T8) (adrenalina e dopamina). No $2^{\circ}$ PO apresentou depuração de creatinina estimada de $45,9 \mathrm{ml} / \mathrm{min} / 1,73 \mathrm{~m}^{2}$, que evoluiu do $3^{\circ}$ ao $5^{\circ} \mathrm{PO}$ com depuração de $32,78 \mathrm{ml} /$ $\mathrm{min} / 1,73 \mathrm{~m}^{2}$. No $6^{\circ} \mathrm{PO}$ apresentou pneumonia à direita, sendo iniciado antibioticoterapia. A depuração creatinina recuperou-se no $8^{\circ} \mathrm{PO}$ quando atingiu $57,37 \mathrm{ml} / \mathrm{min} / 1,73 \mathrm{~m}^{2}$.
\end{abstract}

Caso 40, criança de 109 dias e 3650 g de peso, operada para correção de CIVs múltiplas, que evoluiu no pós-operatório com necessidade de ventilação mecânica por 24 horas e de uso de inotrópicos por 72 horas,com escore inotrópico I e II de 2 e 5, respectivamente, após 48 horas da administração da protamina (T8) (dopamina). No $1^{\circ} \mathrm{PO}$ apresentou depuração de creatinina de $40,5 \mathrm{ml} / \mathrm{min} / 1,73 \mathrm{~m}^{2}$, que normalizou no $3^{\circ} \mathrm{PO}$ atingindo valor estimado de 81 $\mathrm{ml} / \mathrm{min} / 1,73 \mathrm{~m}^{2}$, acima do registrado no pré-operatório $\left(60,75 \mathrm{ml} / \mathrm{min} / 1,73 \mathrm{~m}^{2}\right)$.

Caso 45, criança de 33 dias e peso de $3600 \mathrm{~g}$, operada para correção de EPV e PCA, que evoluiu no pósoperatório com anasarca, choque e necessidade de ventilação mecânica por 48 horas e de uso de inotrópicos por 120 horas, com escore inotrópico I e II de 6 e 40, respectivamente, após 48 horas da administração de protamina (adrenalina, dopamina). No $2^{\circ} \mathrm{PO}$ e $3^{\circ} \mathrm{PO}$ apresentou depuração de creatinina de 38,25 e $32,78 \mathrm{ml} / \mathrm{min} / 1,73 \mathrm{~m} 2$, recuperando no $5^{\circ} \mathrm{PO}$, atingindo $45,9 \mathrm{ml} / \mathrm{min} / 1,73 \mathrm{~m}^{2}$. No $7^{\circ} \mathrm{PO}$ apresentava ainda depuração de creatinina estimada de $32,78 \mathrm{ml} / \mathrm{min} / 1,73 \mathrm{~m}^{2}$.

\title{
Grupo Controle
}

Caso 34, criança de 63 dias e peso de $2890 \mathrm{~g}$, operada para correção de CIV, CIA e PCA, que evoluiu no pós-operatório com anasarca, choque e necessidade de ventilação mecânica por 312 horas, óxido nítrico por 144 horas para tratamento de hipertensão pulmonar e de uso de inotrópicos por 192 horas, com escore inotrópico I e II de 6 e 30, respectivamente, após 48 horas da administração da protamina (T8) (dopamina, adrenalina). No $1^{\circ}$ Pó apresentou pneumonia direita, no $4^{\circ} \mathrm{PO}$ velamento pulmonar esquerdo e no $6^{\circ} \mathrm{PO}$ infecção ferida cirúrgica. Do $1^{\circ}$ ao $3^{\circ} \mathrm{PO}$ apresentou depuração de creatinina de $45 \mathrm{ml} / \mathrm{min} / 1,73 \mathrm{~m}^{2}$, que recuperou no $4^{\circ}$ dia de $\mathrm{PO}$, com valor estimado de $56,25 \mathrm{ml} / \mathrm{min} / 1,73 \mathrm{~m}^{2}$, atingindo valores plenamente normais no $7^{\circ}$ e $8^{\circ} \mathrm{PO}$, com valores de 75 e $112,5 \mathrm{ml} / \mathrm{min} / 1,73 \mathrm{~m}^{2}$, respectivamente,

Caso 53, criança de 132 dias e peso de 4520g, operada para correção de CIV, que evoluiu no pós-operatório com choque, anasarca, derrame pleural importante bilateral e congestão pulmonar. Necessitou ventilação mecânica por 264 dias, óxido nítrico por 192 horas para tratamento de hipertensão pulmonar, uso de inotrópicos por 264 horas, com escore inotrópico I e II de 6 e 52, respectivamente, após 48 horas da administração da protamina (adrenalina, dopamina). No $4^{\circ} \mathrm{PO}$ apresentou pneumonia direita. No $1^{\circ}$ e $2^{\circ} \mathrm{PO}$, o paciente apresentou depuração de creatinina estimada de 36,64 e $32,06 \mathrm{ml} / \mathrm{min} / 1,73 \mathrm{~m}^{2}$, sendo que foi esta criança que apresentou oligo-anúria importante. A partir do $4^{\circ} \mathrm{PO}$ apresentou valor estimado de $42,75 \mathrm{ml} / \mathrm{min} / 1,73 \mathrm{~m}^{2}$, sendo observado no $8^{\circ} \mathrm{PO}$ depuração de creatinina ainda de $36,64 \mathrm{ml} / \mathrm{min} / 1,73 \mathrm{~m}^{2}$. 


\section{ANEXO IV}

\section{TERMO DE CONSENTIMENTO LIVRE E ESCLARECIDO}

\section{Introdução}

Prezado(a) senhor(a), sou o pesquisador responsável pelo trabalho científico "Influência do uso da aprotinina na resposta inflamatória sistêmica à circulação extracorpórea (CEC) em crianças operadas por cardiopatia congênita", para obtenção do título de Doutor pela FMRP-USP.

Seu filho(a) foi internado e será operado do coração, para corrigir o defeito cardíaco com que ele(a) nasceu. Como toda operação, apresenta risco de complicações. Essas complicações podem ser devidas ao defeito do coração da criança, à cirurgia, à anestesia ou às alterações tipo inflamação após a cirurgia, por causa da máquina coração- pulmão que usamos em todos as operações, para corrigir este tipo de defeito cardíaco do seu filho(a). Esta inflamação pode afetar os pulmões ("encharcar" de água), o coração ("bate" mais fraco), os rins ("parar de urinar") e todo o corpo (fica "inchado").

Já utilizamos várias maneiras de modificar esta inflamação como deixar o sangue diluído, controlar mais a coagulação do sangue, o uso de tubos menores e de máquinas coração-pulmão muito pequenas e, ainda, utilizando ou não medicações como a aprotinina (Trasylol) e o corticóide nestas crianças operadas, para reduzir a inflamação.

Por esse motivo estamos procurando detectar e tratar melhor esta inflamação nestas crianças operadas. Para isso, estamos fazendo esta pesquisa científica e gostaríamos de contar com a participação de seu filho(a).

\section{Como será feito o estudo?}

O trabalho será feito coletando-se informações sobre as condições da criança antes e depois da cirurgia, os medicamentos utilizados, as complicações que surgiram, o tipo e a duração da cirurgia, dados que constam na ficha de descrição da operação pelo cirurgião, da ficha de anestesia e do CTI pediátrico, dos resultados dos exames da criança e também das amostras de sangue colhidas para dosagem de substâncias.

O uso da medicação aprotinina (Trasylol), cuja ação é diminuir o sangramento e a inflamação causada pela operação e pelo uso da máquina coraçãopulmão, além de outras medidas, como o uso de corticóide, depende da decisão do cirurgião e do anestesista, de acordo com a necessidade de cada paciente, sendo já procedimentos de rotina.

O estudo também observará a evolução do seu filho durante o tratamento no hospital, e usará uma série de informações sobre sua condição de saúde durante o tratamento. Nenhum outro procedimento diferente da rotina daqueles normalmente necessários para o tratamento de sua doença ou das complicações relacionados à doença ou à cirurgia é feito por causa do estudo. 


\section{Existem riscos para os participantes do estudo?}

Não há diferença entre os participantes do estudo e aqueles não-participantes. A utilização ou não da medicação chamada aprotinina (Trasylol) será de acordo com a decisão do cirurgião em conjunto com o anestesista. Tudo isto não trará prejuízo ou riscos à criança operada. Os riscos de reações tipo alergia, se foi utilizada a aprotinina, são baixos, sendo uma medicação segura.

\section{Quais os benefícios do estudo?}

O tratamento de seu filho não será em nada alterado e o conhecimento adquirido poderá ajudar e beneficiar outras crianças operadas no futuro, com o mesmo problema do seu (sua) filho(a). Não haverá benefícios diretos para a criança com os resultados desta pesquisa mas apenas os benefícios do tratamento com a operação, o que já foi o programado.

\section{Sou obrigado a participar do estudo?}

$\mathrm{O}$ (a) senhor(a) tem a liberdade e o direito de autorizar ou não a participação de seu filho(a) nesta pesquisa e, mesmo após concordar, retirar o consentimento em qualquer momento ou fase da pesquisa, com a garantia de que não vai haver paralização e nenhum prejuízo ao tratamento e seus cuidados no Hospital das Clínicas de Ribeirão Preto. O tratamento será exatamente o mesmo daqueles pacientes que participam ou não do estudo.

\section{A identidade de meu filho será preservada?}

Os resultados da pesquisa serão tornadas públicas, com publicação inclusive em revistas científicas, sejam elas favoráveis ou não. Assumo o compromisso de que não vai haver divulgação pública dos dados pessoais (nome da criança, dos pais, registro, endereço) que possa identificar a criança ou os pais. Está garantido o sigilo que assegura a privacidade das crianças quanto aos dados confidenciais envolvidos na pesquisa.

Em nenhum momento durante a realização do estudo, ou durante a divulgação dos resultados do estudo, o seu filho terá a identidade revelada.

\section{Quem é o responsável pelo estudo?}

O responsável é o médico Cesar Augusto Ferreira, pós- graduando do departamento de Cirurgia e Anatomia, em conjunto com o médico Fábio Carmona, pós- graduando do Departamento de Puericultura e Pediatria, do Hospital das Clínicas da FMRP-USP. Será orientado pelo Prof. Dr. Walter Villela de Andrade Vicente, docente da Disciplina de Cirurgia Torácica e Cardiovascular do Departamento de Cirurgia e Anatomia.

\section{Indenizações}

$\mathrm{O}$ (a) senhor(a) tem o direito de solicitar indenização nos termos da lei Brasileira vigente caso ache que a participação neste estudo o tenha prejudicado ou a seu filho de alguma maneira.

Não está prevista nenhuma forma de compensação ou remuneração pela participação no estudo. 


\section{Informações adicionais}

A qualquer momento o(a) senhor(a) poderá solicitar esclarecimentos adicionais sobre a participação no estudo ou sobre o tratamento utilizado. Em caso de dúvidas, durante ou após a participação no estudo, você ou qualquer membro de sua família poderá contatar o responsável pelo estudo ou a equipe da Disciplina de Cirurgia Torácica e Cardiovascular ou o Centro de Terapia Intensiva Pediátrico do Hospital das Clínicas da FMRP-USP, pessoalmente ou pelos telefones (16) 6022497 e (16) 6022577.

\section{Autorização para inclusão no estudo}

$\mathrm{Eu}$,

RG $n^{0}$ : após ler este documento pessoalmente, e receber todas as informações necessárias e ter minhas dúvidas esclarecidas, e tendo conhecimento de todos os meus direitos abaixo relacionados, concordo e autorizo voluntariamente a participação de meu filho

no estudo "Influência do uso da aprotinina na resposta inflamatória sistêmica à circulação extracorpórea (CEC) em crianças operadas por cardiopatia congênita acianótica".

1) A garantia de receber a resposta a qualquer pergunta ou esclarecimento a qualquer dúvida acerca dos procedimentos, riscos, benefícios e outros relacionados com a pesquisa e o tratamento a que serei submetido;

2) A liberdade de retirar meu consentimento a qualquer momento e deixar de participar no estudo sem que isso traga prejuízo à continuação dos cuidados e tratamento da criança;

3) A segurança de que meu filho(a) não será identificado(a) e que será mantido o caráter confidencial da informação relacionada com a privacidade da criança e a minha;

4) O compromisso de me proporcionar informação atualizada durante o estudo, ainda que esta possa afetar minha vontade de continuar concordando com a participação;

5) A disponibilidade de tratamento médico e indenização que legalmente teria direito, por parte da Instituição à Saúde, em caso de danos que a justifiquem, diretamente causados pela pesquisa.

Tenho ciência do exposto acima e das questões esclarecidas pelo médico que subscreve este documento.

Ribeirão Preto, de de

Responsável pela criança

RG.:

Assinatura

Cesar Augusto Ferreira

Investigador

Assinatura

Testemunha

Assinatura 